\title{
INTEGRATION OF HYDROGEOPHYSICS AND REMOTE SENSING WITH COUPLED HYDROLOGICAL MODELS
}

\author{
Alain Pascal Francés
}




\section{PhD dissertation committee}

Chair

Prof. dr. ir. T. Veldkamp University of Twente Promotor

Prof. dr. Z. Su University of Twente

Co-promotor

Dr. ir. M.W. Lubczynski University of Twente

Members

Prof. dr. ing. W. Verhoef University of Twente

Dr. M. van der Meijde

University of Twente

Prof. dr. ir. M.F.P. Bierkens

University of Utrecht

Prof. dr. F.J. Samper Calvete

University of A Coruña

Dr. G. Favreau

University of Montpellier

Dr. F.A. Monteiro Santos

University of Lisbon

\section{FCT Fundação para a Ciência e a Tecnologia} MINISTÉRIO DA EDUCAÇÃO E CIÊNCIA

ITC dissertation number 275

ITC, P.O. Box 217, 7500 AE Enschede, The Netherlands

ISBN: $\quad 978-90-365-3916-6$

DOI: $\quad$ http://dx.doi.org/10.3990//1.9789036539166

Printed by: ITC Printing Department

(c) Alain Pascal Francés, Enschede, The Netherlands All rights reserved. No part of this publication may be reproduced without the prior written permission of the author.

TU FACULTy OF GEO-INFORMATION SCIENCE AND EARTH OBSERVATION 


\title{
INTEGRATION OF HYDROGEOPHYSICS AND REMOTE SENSING WITH COUPLED HYDROLOGICAL MODELS
}

\author{
DISSERTATION
}

\author{
to obtain \\ the degree of doctor at the University of Twente, \\ on the authority of the rector magnificus, \\ prof. dr. H. Brinksma, \\ on account of the decision of the graduation committee, \\ to be publicly defended \\ on Friday, July 17, 2015 at 14:45
}

by

\author{
Alain Pascal Francés \\ born on February 02, 1971 \\ in Narbonne, France
}


This dissertation is approved by:

Prof. dr. Z. Su (promotor)

Dr. ir. M.W. Lubczynski (co-promotor) 
Enquanto não alcançares a verdade, não poderás corrigi-la.

Porém, se não a corrigires, não a alcançarás.

Entretanto, não te resignes.

As long as you don't reach the truth, you will not be able to correct it.

However, as long as you don't correct it, you will not be able to reach it.

Meanwhile, never give up.

from O Livro dos Conselhos,

in José Saramago, O Evangelho segundo Jesus Cristo

It never rains in Jahilia; there are no fountains in the silicon gardens. A few palms stand in enclosed courtyards, their roots travelling far and wide below the earth in search of moisture.

in Salman Rushdie, The Satanic Verses 



\section{Acknowledgments}

I would like to express my gratitude to the institutions that funded this study, namely the Fundação para a Ciência e a Tecnologia (FCT) through the Programa Operacional Potencial Humano of the QREN Portugal 20072013 (Ph.D. scholarship SFRH/BD/27425/2006) and ITC Faculty (University of Twente). I would also thank the Laboratório Nacional de Energia e Geologia (LNEG) to grant me with a scholarship in the framework of the FREEZE project (PTDC/MAR/102030/2008), as well as for the logistic support during field work in Pisões and Salamanca and during the writing of the thesis.

This thesis is the result of a close and strong cooperation with my supervisor Maciek Lubczynski. I'm fully indebted with his genuine interest and commitment to this work. Maciek had always shown a high working capacity and a full availability to participate at all levels of this research, including drilling during field work. His open mind, high level of exigence and strong hydrological knowledge was crucial to guide me towards the conclusion of this work and to teach me to do science and to structure my work using the scientific method.

I am grateful to Bob Su to support my work, for his strategical advices and to believe in my capacity to conclude this thesis.

I thank all the co-authors of the papers presented in this thesis. In particular, I'm very grateful to Jean Roy for sharing his expertise in MRS and geophysics in general, for his instruction during field work and for the rigor of his advices, guidance and detailed revisions.

This study required the use of quite a lot of geophysical equipments and would not be possible without the collaboration of the following persons: Michel Groen (VU), ABEM Terrameter SAS-4000 (Sardón, Albufeira); Fernando Santos (IDL/FCUL), IRIS Syscal pro and AEMR TEM-FAST 48 (Albufeira); Anatoly Legchenko (LTHE), IRIS Numis ${ }^{L I T E}$ (Sardón); Elsa Ramalho (LNEG), Geonics EM-34 (Pisões) and Scintrex TSQ-3 (Albufeira); Pedro Sousa (LNEG), Geometrics G856 and G816 magnetometers (Sardón and Carrizal); Mark van Meijde (ITC), Geonics EM-31 and AEMR TEM-FAST 48 (Sardón); Sébastien Lambot (UCL), GSSI SIR-20 GPR; and Arno Mulder and Alber Hemstede (TUDelft), AGI Supersting R8 (Sardón). Many thanks to all of them for sharing their equipment, field experience as well as data processing and inversion routines.

I am very grateful to Augusto Costa (LNEG), with whom I started to 
work in hydrogeology, for his collaboration with the Pisões and Salamanca field work. I acknowledge Eduardo Paralta to share his dataset of the Pisões catchment and to visit me at the far Enschede. I thank the Beja pole of the LNEG, as well as the Centro Operativo e de Tecnologia de Regadio (COTR), for their support during the field campaign at Pisões. The field work campaigns at Sardón were possible thanks to the cooperation of José Martínez Fernández and Nilda Sánchez Martín (CIALE). I also thank the land owners of the Sardón area, in particular Lucidio Calvo Herrero and Ana Maria Garcia Herrero, for their kind permit to carry our research on their property. The work in Albufeira benefited from the cooperation of Eng. Rui Santos (Câmara Municipal de Albufeira), who facilitated the access to the municipality boreholes, Eng. Edite Reis (ARHA), who provided borehole data, Dr. Teresa Cunha (LNEG), who made available the digital geological cartography and Manuel Silva (LNEG), who collaborated in carrying out the Scintrex geoelectrical survey. Many thanks also to the FREEZE team and in particular to Gabriela Carrara and Judite Fernandes for their notable support.

The experience at ITC was impressive and constitutes a milestone in my professional and private life. The life with the international community of ITC, which joins simultaneously people from several tenths of nationalities that collaborate peacefully and harmoniously, is a precious example that conflicts and barbarity can be overpassed when investing in knowledge. I would thank the ITC staff for their availability and precious advices during these years of research. I also thank Anke de Koning, Tina Butt-Castro and Loes Colenbrander for the attention and preoccupation they always shown to the students life.

My focus on this work would not be possible with some escape and good time proportioned by the colleagues and friends I met during these years. A special attention goes to the "Sardón's hell crew" and to my ITC and field work mates, with whom I shared rewarding and memorable moments: Enrico Balugani, Leonardo Reyes-Acosta, Guido Baroncini Turrichia, Yijian Zeng, Chandra Prasad Ghimire, Laura Dente, Juan Francisco Sánchez Moreno, Tanvir Hassan, Mariela Yevenes and Rafael Bermudez, Claudia Pittiglio and Henry van Burgsteden, Fouad Alkhaier, Mustafa Gökmen, Mireia Romaguera, Xin Tian, Christiaan van der Tol, Gabriel Parodi, Ruwan Rajapakse, Abubeker Ali Mohammed, Ermias Tseggai Berhe and many other ITC students. A special attention is due to Diana Chavarro and to Jamshid Farifteh, who shared our family life. And to the Diekman tennis club and the BiZZdesign team for the exciting competitions and after match Dutch classes.

Finally, I am of course very grateful to my whole family for their support and encouragement. Many thanks to my mother Rose Marie, to Jacques and to all the Bize Minervois tribe, to my father Jean-Paul and to Josette, to amazing "vóvó" Odete and to the Padrinhos. Huge tender abraços and beijinhos go to Catarina, Alice and Vincent who daily followed with amusement and, sometimes, worries, the long elaboration time of this thesis. 


\section{Contents}

Acknowledgments iii

Contents v v

List of Figures vii

List of Tables $\quad$ ix

List of symbols and abbreviations $\quad$ xi

1 General introduction 1

1.1 Background and problem statement . . . . . . . . . . . . 1

1.2 Research objectives . . . . . . . . . . . . . . . . . . . . . 3

1.3 Proposed methodology . . . . . . . . . . . . . . . . . . . 4

1.4 Thesis outline ................. 5

2 Topsoil thickness prediction at the catchment scale 11

2.1 Introduction . . . . . . . . . . . . . . . . . 11

2.2 Material and methods . . . . . . . . . . . . . . . 14

2.3 Results . . . . . . . . . . . . . . . . . . . . . . . . . . . . . 42

2.4 Discussion and conclusion . . . . . . . . . . 46

3 Hydrogeological conceptual model of a coastal aquifer 51

3.1 Introduction . . . . . . . . . . . . . . 51

3.2 Study area . . . . . . . . . . . . . . . . . 53

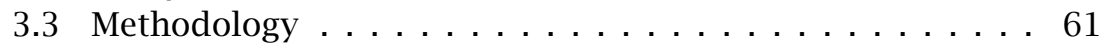

3.4 Results . . . . . . . . . . . . . . . . . . . . . . . . . . . . . . . . . . . . . . .

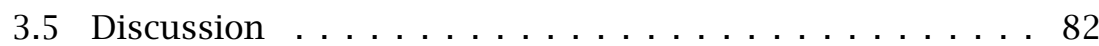

3.6 Conclusion . . . . . . . . . . . . . . . . 89

4 Design of hydrogeological conceptual models in hard rocks 93

4.1 Introduction . . . . . . . . . . . . . . . . . . 93

4.2 Study area . . . . . . . . . . . . . . . . . . . . . . . . . . . . . . . . . . . . . . . . .

4.3 Methodology . . . . . . . . . . . . . . . . . 101

4.4 Results and discussion . . . . . . . . . . . . . . . . . . . . . . . . . . . . . . . . . . . . . . . .

4.5 Conclusion . . . . . . . . . . . . . . 133 
5 Coupled MARMITES-MODFLOW model 137

5.1 Introduction . . . . . . . . . . . . . . . . . . . 137

5.2 Material and Methods . . . . . . . . . . . . . . 141

5.3 Results and discussion . . . . . . . . . . . . . . 162

5.4 Conclusions . . . . . . . . . . . . . . . . . . 179

6 Integrating MRS data with hydrologic model 183

6.1 Introduction . . . . . . . . . . . . . . . 183

6.2 Material and methods . . . . . . . . . . . . . 185

6.3 Results and discussion . . . . . . . . . . . . . . . . 193

6.4 Conclusions . . . . . . . . . . . . . . . . . . . . . 203

7 Conclusions 205

A Appendix - Using GPR to investigate the groundwater table depth 209

A.1 Introduction . . . . . . . . . . . . . . . . . 209

A.2 Materials and Methods . . . . . . . . . . . . . 211

A.3 Results and interpretations . . . . . . . . . . . . 219

A.4 Conclusions . . . . . . . . . . . . . . . . . . . . . . 229

$\begin{array}{ll}\text { Bibliography } & 231\end{array}$

$\begin{array}{ll}\text { Summary } & 257\end{array}$

$\begin{array}{ll}\text { Samenvatting } & 263\end{array}$ 


\section{List of Figures}

1.1 Catchment and hydrological fluxes $\ldots \ldots \ldots \ldots \ldots$

2.1 Flowchart of the methodology . . . . . . . . . . 16

2.2 Soil map and location of invasive measurements . . . . . . 18

2.3 QuickBird image and EM-31 transects . . . . . . . . . . 25

2.4 RS-based soil classification . . . . . . . . . . . . . 34

2.5 CTT and $E C_{a}$ relationship models . . . . . . . . . . 36

2.6 Boxplots of CTT-REF, CTT-CAL, fitted values and residuals . . 37

2.7 Boxplots of CTT-EC and CTT-ECpred . . . . . . . . 37

2.8 Boxplot of the lower and upper values obtained for the dataset

CTT-EC and CTT-ECpred raster . . . . . . . . . . . . 38

2.9 CTT maps obtained with predREF $\ldots \ldots \ldots \ldots \ldots . \ldots . \ldots 4$

2.10 CTT maps obtained with pred $4 \ldots \ldots \ldots \ldots$. . . . . 45

3.1 Geology of the study area $\ldots \ldots \ldots \ldots \ldots \ldots \ldots$

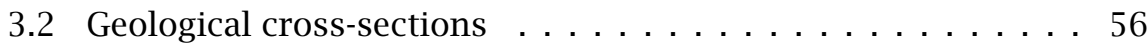

3.3 Location of the hydrogeophysical surveys . . . . . . . . 65

3.4 Regional static piezometric map . . . . . . . . . . . 70

3.5 ERT cross-sections A1 to A5 of longitudinal transect A . . . . 72

3.6 FDEM cross-sections . . . . . . . . . . . . . . 75

3.7 ERT cross-sections B1 to B6 of transversal transect B . . . . 78

3.8 Transects C, D and E composed by TDEM 1D soundings . . . . 81

3.9 Sea bottom map and location of the offshore seismic profile . 85

3.10 Interpreted seismic profile $\ldots \ldots \ldots$. . . . . . . 85

3.11 Schematic cross-sections representing the hydrogeological conceptual model . . . . . . . . . . . . . . . . . . . 87

4.1 Sardón catchment: geological map . . . . . . . . . . 98

4.2 Lineament detection and interpretation . . . . . . . . 100

4.3 Mapping of granite outcrops with remote sensing image pro-

cessing . . . . . . . . . . . . . . . . 102

4.4 Inverted electrical resistivity cross-sections of ERT data . . . 112

4.5 Inverted electrical resistivity cross-sections of FDEM data . . 115

4.6 MRS data and inversion results . . . . . . . . . . . 117

4.7 Hydrogeological conceptual model maps . . . . . . . . . . 128 
4.8 Schematic cross-section of the Sardón hydrogeological conceptual model . . . . . . . . . . . . . . . . . . . . . . . . . 129

5.1 Conceptual schema of the coupled MARMITES-MODFLOW models143

5.2 Linear relationships between actual soil moisture and water fluxes . . . . . . . . . . . . . . . . . . . 150

5.3 Sequential coupling of MARMITES and MODFLOW models . . 154

5.4 Groundwater evaporation curves . . . . . . . . . . . . . . 155

5.5 La Mata sub-catchment . . . . . . . . . . . . . . . . . 158

5.6 Sourcing transpiration function and sensitivity analysis . . . 165

5.7 Time series of observed and simulated soil moisture and groundwater table depth at observation points . . . . . . . 168

5.8 Evapotranspiration observed at the ECT and simulated by model168

5.9 Time series of surface and subsurface water fluxes averaged at the catchment scale . . . . . . . . . . . . . 170

5.10 Sankey diagrams representing the yearly water balance at the catchment scale . . . . . . . . . . . . . . . . . 172

5.11 Two-year average of soil evaporation and groundwater evaporation . . . . . . . . . . . . . . . . . 173

5.12 Two-year average of soil transpiration and groundwater transpiration . . . . . . . . . . . . . . . . . . . . . 174

5.13 Two-year average groundwater net recharge and groundwater exfiltration . . . . . . . . . . . . . . . . . 175

6.1 Geology of the Carrizal study area . . . . . . . . . . . 186

6.2 Monitoring network of the Carrizal catchment . . . . . . 188

6.3 Magnetic field in MRS experiments . . . . . . . . . . . . 195

6.4 MRS inversion results . . . . . . . . . . . . . . . . . . 196

6.5 Calibration analysis . . . . . . . . . . . . . . 200

6.6 Spatial distribution of the calibrated specific yield . . . . . . . 201

6.7 Spatial distribution of the calibrated hydraulic conductivity . . 202

A.1 Location of the study area . . . . . . . . . . . . . . . . 212

A.2 Schematic of E-W cross-section . . . . . . . . . . . . . . 213

A.3 GPR data acquisition . . . . . . . . . . . . . 214

A.4 Example of hydrostratigraphy $\ldots \ldots \ldots \ldots \ldots \ldots 216$

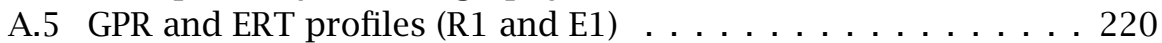

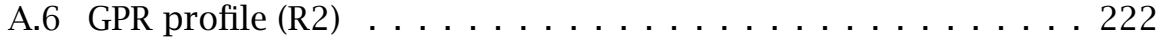

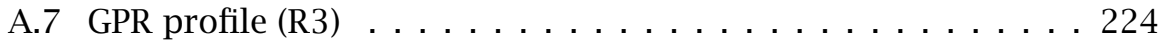

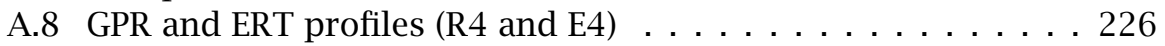

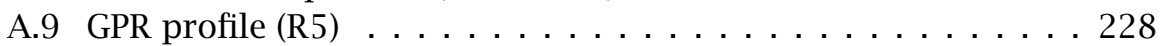




\section{List of Tables}

2.1 Soil characteristics . . . . . . . . . . . . . . . . 19

2.2 Reference dataset of invasive CTT measurements . . . . . . . 21

2.3 Characteristics of the QuickBird image . . . . . . . . . . . . . 23

2.4 Description of the statistical and geostatistical models derived from MLM. . . . . . . . . . . . . . . . . . . . . . 29

2.5 Summary statistics of the terrain parameters. . . . . . . . . 33

2.6 Calibration models based on CTT-CAL dataset and diagnostic results. . . . . . . . . . . . . . . . . . . . 39

2.7 Prediction models based on CTT-EC (pred1 to pred5) and CTTREF (predREF) datasets, and diagnostic results. . . . . . . . . . . 42

3.1 Lithostratigraphy and hydrostratigraphy of the study area . . 57

3.2 Characteristics of the hydrogeophysical methods . . . . . . . 66

3.3 Geoelectrical range of the hydrostratigraphical units. . . . . . . 83

4.1 Sardón geology . . . . . . . . . . . . . . . . . . . . . . . 99

4.2 Summary of the three MRS campaigns . . . . . . . . . . . . 106

4.3 Characterization of the saprolite layer based on MRS results . 118

4.4 Hydrogeophysical results and comparison with other studies . 121

4.5 Slug test results . . . . . . . . . . . . . . . . . . . . . . . 123

4.6 Parameters of the hydrogeological conceptual model . . . . . 130

5.1 MM-MF input parametric maps . . . . . . . . . . . . . . . . . 145

5.2 MMsurf input parameters and variables . . . . . . . . . . . . 147

5.3 Parameters of groundwater evaporation equation . . . . . . . . 156

5.4 Calibrated soil hydraulic properties of the 2 soil types of $\mathrm{La}$ Mata catchment . . . . . . . . . . . . . . . . . . 160

5.5 MODFLOW parameters of La Mata catchment . . . . . . . . . . . 161

5.6 Vegetation parameters of the groundwater transpiration equation defined for the La Mata catchment . . . . . . . . . . . . . . . 164

5.7 Calibration criteria results on soil moisture and hydraulic heads167

5.8 Comparison between evaporation and transpiration computing by several approaches . . . . . . . . . . . . . . . . . 177

6.1 Description of the MRS surveys . . . . . . . . . . . . . . . . 194

6.2 MRS survey results . . . . . . . . . . . . . . . . 197 
A.1 GWTD in wells and ponds . . . . . . . . . . . . . . . 215

A.2 Measured hydrolayer parameters . . . . . . . . . . 218 


\section{List of symbols and abbreviations}

\begin{tabular}{ll}
$\alpha$ & aquifer compressibility \\
$\beta_{0}$ & intercept LR model \\
$\beta_{1}$ & slope LR model \\
$\beta$ & water compressibility \\
$\Delta B_{0}$ & ambient magnetic field inhomogeneity \\
$\Delta B$ & Earth magnetic field inhomogeneity \\
$\Delta f_{l}$ & variation of Larmor frequency \\
$\Delta S_{g}$ & groundwater storage change \\
$\Delta z$ & thickness of layer \\
$\Delta Z_{M R S}$ & MRS thickness \\
$\gamma$ & gyromagnetic ratio \\
$\hat{Y}$ & estimation on natural logarithm scale \\
$\hat{z}\left(s_{i}\right)$ & predicted value at location $s_{i}$ \\
$\hat{Z}$ & estimation in original unit \\
$\lambda$ & GPR effective wavelength \\
$\phi$ & initial soil moisture \\
$\rho_{w}$ & soil moisture at field capacity \\
$\rho$ & horosity \\
$\sigma_{f}$ & water density \\
$\mathrm{K}_{x x}$ & electrical resistivity \\
$\mathrm{K}_{y y}$ & hydraug variance \\
$\mathrm{K}_{z z}$ & hree water content \\
$\theta_{f}$ & hydraulic conductivity along the y coordinate axis \\
\hline &
\end{tabular}




\begin{tabular}{|c|c|}
\hline$\theta_{w p}$ & soil moisture at wilting point \\
\hline$\theta_{M R S}$ & MRS free water content \\
\hline$\theta$ & actual volumetric soil moisture \\
\hline$\varepsilon^{\prime}(s)+\varepsilon^{\prime \prime}$ & $\begin{array}{l}\text { stochastic component composed by the spatially } \\
\text { correlated random component and pure noise/nugget } \\
\text { respectively }\end{array}$ \\
\hline$\varepsilon_{0}$ & free space permittivity \\
\hline$\varepsilon_{i}$ & $\begin{array}{l}\text { imaginary component of relative soil complex dielec- } \\
\text { tric permittivity }\end{array}$ \\
\hline$\varepsilon_{r}$ & $\begin{array}{l}\text { real component of relative soil complex dielectric } \\
\text { permittivity }\end{array}$ \\
\hline$\varepsilon_{r}$ & soil dielectric constant \\
\hline$B(x, t)$ & raw GPR B-scan \\
\hline$B_{\text {avg }}$ & $\begin{array}{l}\text { Earth magnetic field averaged at MRS survey loca- } \\
\text { tion }\end{array}$ \\
\hline$B$ & Earth magnetic field \\
\hline$b$ & decay coefficient \\
\hline$C_{e}$ & MRS storage multiplier of $S_{e}$ \\
\hline$C_{T}$ & MRS transmissivity multiplier \\
\hline$C_{y}$ & MRS storage multiplier of $S_{y}$ \\
\hline$C_{T 0}$ & default MRS transmissivity multiplier \\
\hline$c$ & speed of the light in free space \\
\hline$d^{\prime \prime}$ & decoupling depth \\
\hline$D_{T}$ & $T_{1} / T_{2}^{*}$ ratio \\
\hline$d_{t}$ & $\begin{array}{l}\text { depth derived from the 2-way travel time of the } \\
\text { GPR signal }\end{array}$ \\
\hline$D_{a q}$ & thickness of the aquifer \\
\hline$D$ & extinction depth \\
\hline$d$ & groundwater table depth \\
\hline$E_{0}$ & free induction decay initial signal amplitude \\
\hline$E_{g}$ & groundwater evaporation \\
\hline$E_{p}$ & percolation zone evaporation \\
\hline$E_{u}$ & unsaturated zone evaporation \\
\hline$E_{\text {soil }}$ & soil evaporation \\
\hline
\end{tabular}




\begin{tabular}{|c|c|}
\hline$E_{\text {surf }}$ & surface water evaporation \\
\hline$E C_{a}$ & $\begin{array}{l}\text { soil apparent electrical conductivity (measured in- } \\
\text { ductively with EM-31/EM-38 [kHz range]) }\end{array}$ \\
\hline$E C_{s}$ & $\begin{array}{l}\text { soil apparent electrical conductivity (measured gal- } \\
\text { vanically with Hydra Probe [MHz range] }\end{array}$ \\
\hline eps & Brooks-Corey function exponent \\
\hline$E T_{g}$ & groundwater evapotranspiration \\
\hline$E T_{p}$ & evapotranspiration from the percolation zone \\
\hline$E T_{u}$ & unsaturated zone evapotranspiration \\
\hline$E T$ & evapotranspiration \\
\hline$E x f_{g}$ & groundwater exfiltration \\
\hline Exf & saturated soil exfiltration \\
\hline$E$ & evaporation \\
\hline$f_{l}$ & Larmor frequency \\
\hline$f$ & frequency \\
\hline$g$ & gravitational acceleration \\
\hline$h_{T}$ & transition zone thickness \\
\hline$h k$ & horizontal hydraulic conductivity \\
\hline$h$ & hydraulic head \\
\hline $\operatorname{Inf}$ & soil infiltration \\
\hline$I$ & interception \\
\hline$k_{\operatorname{Tmax}}$ & $\begin{array}{l}\text { maximum quantitative control parameter of the } \\
\text { vegetation-dependent groundwater transpiration } \\
\text { sourcing function }\end{array}$ \\
\hline$k_{T \min }$ & $\begin{array}{l}\text { minimum quantitative control parameter of the } \\
\text { vegetation-dependent groundwater transpiration } \\
\text { sourcing function }\end{array}$ \\
\hline$K_{M R S}$ & MRS estimate of hydraulic conductivity \\
\hline Ksat & soil saturated hydraulic conductivity \\
\hline$K$ & hydraulic conductivity \\
\hline$k$ & number of stress periods \\
\hline$L_{E R T}$ & total ERT length \\
\hline Ls & loop shape and size \\
\hline$m(s)$ & deterministic component at location $s$ \\
\hline
\end{tabular}


$m$

N

$n$

$P E_{g}$

PET

$P E$

$P T_{g}$

PT

Q.i.

Q.p.

$Q_{R}$

$Q_{W}$

$Q i$

Qo

Q

$R_{p}$

$R_{\text {soil }}$

res

RFe

$R F$

$R g$

$R n$

Ro

$R$

$r$

$S_{e}$

$S_{g}$

$S_{p}$

$S_{r}$

$S_{S}$

Sy

$S_{\text {soil }}$
MRS storage multiplier

total number of scans in the B-scan

shape controlling parameter of the vegetation-dependent groundwater transpiration sourcing function

groundwater potential evaporation

potential evapotranspiration

potential evaporation

groundwater potential transpiration

potential transpiration

Quercus ilex

Quercus pyrenaica

flow produced by the UZF1 package

flow produced by the WEL package

groundwater inflow

groundwater outflow

MRS excitation moment

percolation from the soil zone

soil percolation

residuals

rainfall excess

rainfall

gross groundwater recharge

net recharge

surface runoff

Annan's ratio

Pearson's correlation coefficient

elastic storativity

groundwater storage

percolation zone storage

specific retention / field capacity

specific storage

specific yield

soil storage 


\begin{tabular}{|c|c|}
\hline$S_{\text {surf }}$ & surface storage \\
\hline$S_{y, M R S}$ & MRS estimate of specific yield \\
\hline$S$ & storativity \\
\hline$s$ & coordinates vector $\left(s_{x}, s_{y}\right)$ \\
\hline$T_{1}$ & longitudinal decay time constant \\
\hline$T_{2}^{*}$ & free induction decay time constant \\
\hline$T_{2}$ & transversal decay time constant \\
\hline$T_{g}$ & groundwater transpiration \\
\hline$T_{p}$ & percolation zone transpiration \\
\hline$T_{u}$ & unsaturated zone transpiration \\
\hline$T_{M R S}$ & MRS estimate of transmissivity \\
\hline$T_{\text {soil }}$ & soil transpiration \\
\hline$T_{S T}$ & transmissivity from slug test \\
\hline thti & initial water content \\
\hline thts & saturated water content \\
\hline$T$ & transpiration \\
\hline$t$ & 2-way travel time \\
\hline$t$ & time \\
\hline$v k s$ & saturated vertical hydraulic conductivity \\
\hline$W$ & water sources or sinks \\
\hline$y_{0}$ & correction factor \\
\hline$z\left(s_{i}\right)$ & observed value at location $s_{i}$ \\
\hline$Z(s)$ & geostatistically predicted value at location $s$ \\
\hline$z_{\text {tot }}$ & total thickness of the aquifer \\
\hline$Z r$ & root depth \\
\hline$z$ & depth \\
\hline -pred & predicted (suffix) \\
\hline $1 \mathrm{D}$ & 1-dimensional \\
\hline $2 \mathrm{D}$ & 2-dimensional \\
\hline $3 \mathrm{D}$ & 3-dimensional \\
\hline a.s.l. & above sea level \\
\hline $\mathrm{AB}$ & $\mathrm{AB}$ soil horizon \\
\hline
\end{tabular}




\begin{tabular}{|c|c|}
\hline ADAS & automatic data acquisition system \\
\hline AEMR & Applied Electromagnetic Research \\
\hline AGI & Advanced Geosciences Inc. \\
\hline AIC & Akaike information criterion \\
\hline ANOCOVA & covariance analysis \\
\hline ANOVA & variance analysis \\
\hline $\mathrm{AO}$ & aerial orthophoto \\
\hline APA & $\begin{array}{l}\text { Agência Portuguesa do Ambiente (Portuguese En- } \\
\text { vironment Agency) }\end{array}$ \\
\hline ARHA & Administraçã da Região Hidrográfica do Algarve \\
\hline ARQ & Albufeira-Ribeira de Quarteira coastal aquifer \\
\hline ASCII & american standard code for information interchange \\
\hline ASTER & $\begin{array}{l}\text { Advanced Spaceborne Thermal Emission and Re- } \\
\text { flection Radiometer }\end{array}$ \\
\hline ASTER-GDEM & global digital elevation map \\
\hline $\mathrm{BF}$ & bright field \\
\hline $\mathrm{BH}$ & borehole drilling \\
\hline BIC & Bayesian information criterion \\
\hline $\mathrm{Bp}$ & soil 'barros pretos', black clay, not calcareous \\
\hline Врс & soil 'barros pretos', black clay, calcareous \\
\hline BW & brackish water \\
\hline $\mathrm{C}$ & C soil horizon \\
\hline $\mathrm{CA}$ & coastal aquifer \\
\hline CALCR & calcrete soil \\
\hline CEC & cation exchange capacity \\
\hline CLAY & clayey soil \\
\hline CMA & $\begin{array}{l}\text { Câmara Municipal de Albufeira / Albufeira Muni- } \\
\text { cipality }\end{array}$ \\
\hline CNIG & Spanish Centro Nacional de Informacíon Geográfica \\
\hline Conf. & confined \\
\hline $\mathrm{Cp}$ & soil 'barros pretos', black clay, calcareous \\
\hline CRET & Cretaceous \\
\hline CTD & electrical conductivity, temperature and depth \\
\hline
\end{tabular}




\begin{tabular}{|c|c|}
\hline CTT & clayey topsoil thickness \\
\hline CTT-CAL & clayey topsoil thickness calibration data set \\
\hline CTT-EC & $\begin{array}{l}\text { clayey topsoil thickness from soil apparent elec- } \\
\text { trical conductivity dataset }\end{array}$ \\
\hline CTT-REF & clayey topsoil thickness reference dataset \\
\hline CVES & $\begin{array}{l}\text { continuous vertical electrical sounding (equivalent } \\
\text { to ERT or 2D resistivity profiling) }\end{array}$ \\
\hline DEM & digital elevation model \\
\hline DF & dark field \\
\hline $\mathrm{DN}$ & digital number value \\
\hline DRN & MF Drain package \\
\hline DRN cond. & DRN conductivity \\
\hline DTM & digital terrain model \\
\hline EC & electrical conductivity \\
\hline ECT & eddy covariance tower \\
\hline EM & electromagnetic \\
\hline ER & electrical resistivity \\
\hline ERT & electric resistivity tomography \\
\hline $\mathrm{F} 1$ & main NNE-SSW fault zone, Sardón area \\
\hline $\mathrm{F} 2$ & set of faults with NE-SW direction, Sardón area \\
\hline FBF & groundwater fluxes from back face of the MF cells \\
\hline FDEM & frequency domain electromagnetic \\
\hline FFF & groundwater fluxes from front face of the MF cells \\
\hline FID & MRS signal free induction decay \\
\hline FLF & groundwater fluxes from lower face of the MF cells \\
\hline FLfF & groundwater fluxes from left face of the MF cells \\
\hline FRF & groundwater fluxes from right face of the MF cells \\
\hline FSWI & freshwater-saltwater interface \\
\hline FUF & groundwater fluxes from upper face of the MF cells \\
\hline FW & freshwater \\
\hline GF1 & Sagres-Algoz-Vila Real de Santo António flexure \\
\hline GF2 & Quarteira fault \\
\hline GF3 & Albufeira fault \\
\hline
\end{tabular}




\begin{tabular}{|c|c|}
\hline GF4 & Oura fault \\
\hline GF5 & Mosqueira fault \\
\hline GF6 & Olhos de Água fault \\
\hline GIS & geographic information system \\
\hline GMT & Greenwich mean time \\
\hline GPR & ground penetrating radar \\
\hline GPS & global positioning system \\
\hline GWT & groundwater table \\
\hline GWTD & groundwater table depth \\
\hline $\mathrm{H} 1$ & $\begin{array}{l}\text { seismic-derived contact between MIO and PQ form- } \\
\text { ations }\end{array}$ \\
\hline HA & hand augering \\
\hline HDF5 & hierarchical data format \\
\hline I- & irrigation (prefix) \\
\hline ID & identification code \\
\hline IDW1 & inverse distance weighted method with power 1 \\
\hline IGME & $\begin{array}{l}\text { Spanish Geological Survey (Instituto Geológico y } \\
\text { Minero de España) }\end{array}$ \\
\hline IGP & Instituto Geográfico Português \\
\hline IN & sum of fluxes entering the system \\
\hline INI & initialization files for MM-MF components \\
\hline ITC & $\begin{array}{l}\text { Faculty of Geo-Information Science and Earth Ob- } \\
\text { servation, University of Twente }\end{array}$ \\
\hline JUR & Jurassic \\
\hline KED & kriging with external drift \\
\hline $\mathrm{L}$ & number of aquifer layers \\
\hline 1 & number of soil layers \\
\hline $1 . s^{-1}$ & liter per second \\
\hline LCI & laterally constrained inversion \\
\hline $\ln$ & natural logarithm \\
\hline LNEG & Laboratório Nacional de Energia e Geologia \\
\hline LR & simple linear regression \\
\hline m b.g.s. & meters below ground surface \\
\hline
\end{tabular}

xviii 


\begin{tabular}{|c|c|}
\hline $\mathrm{m}^{2} \cdot \mathrm{d}^{-1}$ & square meter per day \\
\hline$m^{3} \cdot y^{-1}$ & cubic meter per year \\
\hline m.a.s.l. & meters above sea level \\
\hline M4 & Ferragudo-Albufeira aquifer \\
\hline M5 & Querença-Silves aquifer \\
\hline M6 & Albufeira-Ribeira de Quarteira aquifer \\
\hline M7 & Quarteira aquifer \\
\hline MAE & mean absolute error \\
\hline MB & mass balance discrepancy \\
\hline ME & mean error \\
\hline MEANC & mean curvature morphometric terrain parameter \\
\hline MF & MODFLOW (USGS groundwater model) \\
\hline MIO & Miocene \\
\hline MLM & geostatistical mixed linear model \\
\hline MLR & multiple linear regression \\
\hline MM & $\begin{array}{l}\text { MARMITES transient distributed model of the land } \\
\text { surface and the soil zone }\end{array}$ \\
\hline MM-MF & MARMITES-MODFLOW coupled model \\
\hline $\mathrm{mm} \cdot \mathrm{d}^{-1}$ & millimeters per day \\
\hline mm.month ${ }^{-1}$ & millimeters per month \\
\hline$m m \cdot y^{-1}$ & millimeters per year \\
\hline MMsoil & soil component of MARMITES \\
\hline MMsurf & surface component of MARMITES \\
\hline MODFLOW-NWT & $\begin{array}{l}\text { MODFLOW model incorporating Newton formula- } \\
\text { tion }\end{array}$ \\
\hline MRS & magnetic resonance sounding \\
\hline $\mathrm{n}$ & number of observations \\
\hline N.A. & not applicable \\
\hline n.a. & not available \\
\hline $\mathrm{NCV}$ & nonconstant error variance \\
\hline NIR & near infra red \\
\hline $\mathrm{NN}$ & nearest neighbor \\
\hline O- & catchment outlet (prefix) \\
\hline
\end{tabular}




$\begin{array}{ll}\text { OK } & \text { ordinary kriging } \\ \text { OUT } & \text { sum of fluxes leaving the system } \\ \text { P- } & \text { pond (prefix) } \\ \text { Pc } & \text { soil 'calcários pardos' calcareous } \\ \text { PD } & \text { shallow percussion drilling/digging } \\ \text { PF } & \text { profiles analysis in pitches } \\ \text { PLANC } & \text { plan curvature morphometric terrain parameter } \\ \text { PQ } & \text { Plio-Quaternary } \\ \text { PROFC } & \text { vertical or profile curvature morphometric terrain } \\ \text { Qa } & \text { parameter } \\ \text { QB } & \text { Carrizal - Alluvium } \\ \text { Qc } & \text { QuickBird Image } \\ \text { QQ-plot } & \text { Carrizal - Coluvium } \\ \text { REMEDHUS } & \text { quantile comparison plot of studentized residuals } \\ \text { RGB } & \text { soil moisture network of Salamanca University } \\ \text { RMSE } & \text { red - green - blue } \\ \text { RS } & \text { root mean square error } \\ \text { RSR } & \text { remote sensing } \\ \text { sat. } & \text { ratio of the root mean square error to the standard } \\ \text { SD } & \text { deviation } \\ \text { SGD } & \text { saturated } \\ \text { SLOP } & \text { standard deviation } \\ \text { SM- } & \text { submarine groundwater discharge } \\ \text { SP } & \text { slope morphometric terrain parameter } \\ \text { SPI } & \text { soil moisture station (prefix) } \\ \text { STI } & \text { stress periods } \\ \text { STIG } & \text { stream power index hydrological terrain parameter } \\ \text { SW } & \text { sediment transport index hydrological terrain para- } \\ \text { meter } & \\ & \text { semater University) } \\ \text { T1 } & \text { Cabrerizos Sandstones } \\ & \end{array}$


$\mathrm{T} 2$

T3

$\mathrm{T} 4$

TDEM

TEM

Thick

TPI

TWI

TWT

$\mathrm{Ua}, \mathrm{Ub}, \mathrm{Uc}$

UK

unsat.

USGS

UZF1

VES

W-

WEL
Carrizal - Low Palaeogene Group

Carrizal - High Palaeogene Group

Carrizal - Red Series

time-domain electromagnetic

transient electromagnetic (equivalent to TDEM)

thickness

topographic position index - hydrological terrain parameter

topographic wetness index - hydrological terrain parameter

two-way time

seismic-derived lithological units within PQ formation

universal kriging

unsaturated

United States Geological Surveys

MODFLOW unsaturated zone package

vertical electrical sounding

shallow well (prefix)

MF Well package 



\section{General introduction}

\subsection{Background and problem statement}

Groundwater resources constitute a major source of water in many places of the world. Due to the general increase of water scarcity (UNEP, 2008; Steduto et al., 2012), the access to this precious resources leads to conflicts between public, industrial, agricultural and ecological users. This situation can be moderated by effective exploitation practices and long term management plans that generally rely on groundwater models. Such models allow to predict dynamic responses of aquifers in reaction to groundwater abstraction scenarios and to climatic or land use changes. They are based on well-established mathematical equations integrated into algorithms and computer codes (de Marsily, 1986; Bear and Verruijt, 1987; Anderson and Woessner, 1992; Domenico and Schwartz, 1998; Fetter, 2001; Rushton, 2004; Hiscock and Bense, 2014). However, there is a gap between these sophisticated tools and the availability of hydrogeological data. Some specific aspects of the groundwater models, such as the methods of reliable data acquisition, data integration into models and handling of subsurface evapotranspiration are still underdeveloped. This knowledge gap created a scientific niche for this study.

The modeling of groundwater flow and groundwater balance of a catchment (Figure. 1.1 left) requires the definition of the following input data: (i) aquifer geometry and associated boundary conditions; (ii) aquifer parameters, e.g. hydraulic conductivity and storativity; (iii) driving forces such as rainfall and evapotranspiration fluxes; and (iv) state variables, e.g. hydraulic heads. However such data are generally scarce because: (i) the geological medium is naturally complex, being characterized by heterogeneity and anisotropy; and (ii) subsurface measurements involve costly methods such as drilling and pumping tests. Besides the spatial variability of aquifer geometry and parameters, hydrological fluxes such as precipitation, evaporation, transpiration, infiltration, runoff, percolation and groundwater flow (Figure. 1.1 right) are variable in both space and time. The exchange of such fluxes between reservoirs (i.e. surface, vegetation, unsaturated and saturated zones, see Figure. 1.1 right) defines the water balance of a catchment. The reliable closure of a subsurface water balance is challenging because subsurface water fluxes cannot be directly measured and show a small order of magnitude and high spatio-temporal 
variability. This is particularly evident in water limited environments (Newman et al., 2005; Parsons and Abrahams, 2009), i.e. areas where potential evapotranspiration $(P E T)$ is much larger than rainfall $(R F)$. In such environments, groundwater fluxes are generally small and gross recharge $(R g)$ cannot be reliably determined by subtracting $E T$ from $R F$, since unavoidable small errors in the two lead to high inaccuracy of $R g$ (Hendricks et al., 2003; Lubczynski, 2011). Due to the difficulties in assessing the groundwater recharge, a common groundwater modeling practice is to apply estimates of $R g$ a-posteriori during model calibration, which often lead to bias in parameter estimation and erroneous groundwater balances.
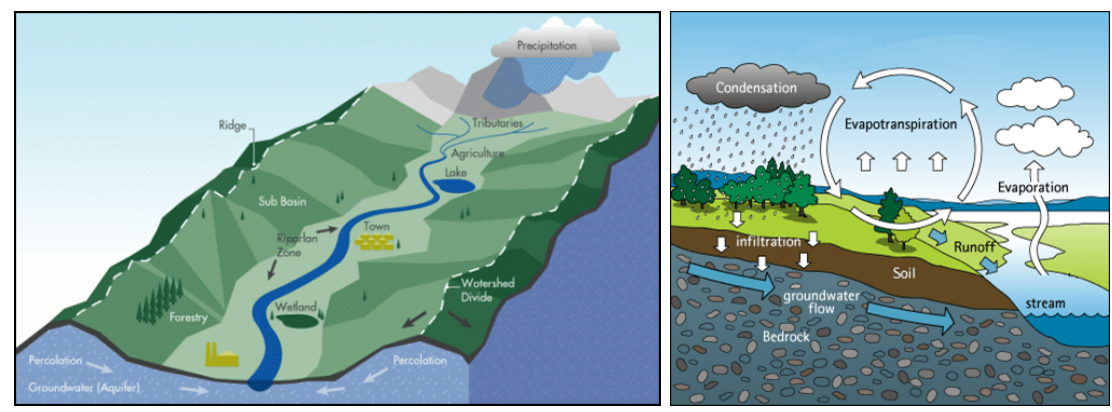

Figure 1.1: Left: definition of a catchment, showing boundaries, hydrological fluxes and land use (modified after www. ogwa-hydrog.ca). Right: main surface and subsurface water fluxes (modified after www. sperchemical.com/water.htm1)

Sustainability of groundwater resources is controlled by the net groundwater recharge (Sophocleous, 2005; Scanlon et al., 2006), defined by $R n=R g-E x f_{g}-E T_{g}$ in which $E x f_{g}$ is groundwater exfiltration and $E T_{g}$ is groundwater evapotranspiration. A source of bias in the assessment of $R n$ is not only uncertainty of evaluation of $R g$ but also typical underestimation, or even disregarding, of $E x f_{g}$ and $E T_{g}$ (Lubczynski, 2000, 2009, 2011; Hassan et al., 2014), which leads to the overestimation of $R n . E x f_{g}$ is the process of groundwater discharge in drainage areas, such as valleys, where the groundwater table intersects the topography, resulting in an interconnection between surface water and groundwater. Due to the complexity of exchange of water in such areas, $E x f_{g}$ is typically simplified or disregarded in models despite its importance (Batelaan et al., 2003; Batelaan and De Smedt, 2004; Brunner et al., 2010). $E T_{g}$ is the $E T$ component that refers to the process of groundwater uptake by plant roots and by direct evaporation from water table or its capillary fringe (Lubczynski, 2009), representing an important component of water balances particularly in water limited environments (Nichols, 1994; Banta, 2000; Lubczynski, 2000; DeMeo et al., 2003; Loheide et al., 2005; Lubczynski and Gurwin, 2005a; Naumburg et al., 2005; Shah et al., 2007; Sanderson and Cooper, 2008; Scott et al., 2008; Miller et al., 2010; Newman et al., 2010; Lubczynski, 2011; Orellana et al., 2012). The separa- 
tion of subsurface $E T$ into saturated and unsaturated zones components is referred as sourcing. As ET represents two physically different processes, evaporation $(E)$ and transpiration $(T)$, each with different spatial and temporal characteristics, hydrological models need to account these two processes separately (Guan and Wilson, 2009; Yang, 2015). Therefore, not only the sourcing but also the partitioning of $E T$ into $T$ and $E$ should be implemented into hydrological models, by considering the following subsurface $E T$ components: unsaturated zone evaporation $\left(E_{u}\right)$, groundwater evaporation $\left(E_{g}\right)$, unsaturated zone transpiration $\left(T_{u}\right)$ and groundwater transpiration $\left(T_{g}\right)$ (Lubczynski, 2011). As recent studies focused on the assessment of these components individually (e.g. Shah et al., 2007; Balugani et al., 2014; Reyes-Acosta, 2015), such research created an opportunity to generate tools to integrate these fluxes separately in coupled hydrological models, allowing this way to retrieve a detailed and complete water balance at the catchment scale.

\subsection{Research objectives}

Groundwater model uncertainties are typically related to unknown spatial distribution of aquifer parameters and unknown spatio-temporal distribution of driving forces, which lead to inaccurate or incorrect conceptual models. Moreover, the multiplicity of combinations between parameters and input fluxes results in non-uniqueness of groundwater model solutions. As a result, groundwater models are often unreliable and present limited forecasting capability.

To contribute to the constraining of groundwater models and reduction of their uncertainties, the following two main objectives and related specific objectives are proposed:

I. Spatial acquisition of subsurface parameters to contribute to the design of hydrological conceptual models:

1. Spatial subsurface parameterization of the hydrogeological medium using non-invasive techniques such as hydrogeophysics and remote sensing;

2. Design of conceptual models integrating hydrogeophysical and remote sensing data by using tools such as statistical modeling.

II. Spatio-temporal modeling of subsurface water fluxes and computing of detailed water balances at the catchment scale:

1. Development of a distributed lumped-parameter surface and soil zone model (MARMITES) and its coupling with the numerical groundwater flow model MODFLOW to assess spatio-temporally the subsurface water fluxes;

2. Computing of high-resolution, spatio-temporal water balance at the catchment scale that incorporates the novel option of partitioning and sourcing of subsurface evapotranspiration. 
The proposed approach imposes additional constraints on groundwater model calibration by providing a better spatial and temporal coverage of input data (subsurface parameters and fluxes) and by making possible the implementation of multi-criteria calibration on independent state variables (e.g. surface runoff, soil moisture, hydraulic heads) belonging to the components of the coupled models (i.e. surface, unsaturated and saturated zones). Non-uniqueness of model solution is expected to be reduced by computing more realistic boundary conditions, in particular net groundwater recharge, through the implementation of a new modeling option of partitioning and sourcing of subsurface evapotranspiration in the coupled MARMITES-MODFLOW model. Uncertainties in modeling, typically quantified using mathematical techniques during model calibration and automatic parameter optimization (Hill and Tiedeman, 2006; Doherty, 2015), are not presented hereafter because of a different focus of this study.

\subsection{Proposed methodology}

\subsubsection{Spatial acquisition of aquifer parameters}

Invasive measurements can be efficiently complemented by non-invasive hydrogeophysical and remote sensing methods which are time and cost effective. They succeed in covering large areas of land in a cheaper and quicker way than the invasive field sampling techniques. Hydrogeophysics provides methods of subsurface data acquisition to identify rock properties and heterogeneities related with the presence of groundwater (Rubin and Hubbard, 2005; Kirsch, 2009; Binley et al., 2015). Each hydrogeophysical method has its own characteristics and capability with respect to aquifer characterization, so the selection of the appropriate one must be done as a function of the objectives of a survey and geological settings. Geoelectrical and electromagnetic methods have been widely used to retrieve hydrogeological structures and aquifer parameters using empirical, area-specific relationships. The magnetic resonance soundings (MRS) method has definite advantage for quantitative groundwater assessment in comparison to other hydrogeophysical methods because of its most direct relation to in-situ subsurface water. The complementarity and joint use of hydrogeophysical methods constitutes the most powerful tool to characterize aquifers. However these methods are generally restricted to local scale, either in 1D or 2D. Therefore techniques of interpolation and/or extrapolation of data at the catchment scale are required to integrate hydrogeophysical information into hydrogeological models. Remote sensing, together with statistical and geostatistical interpolation methods, are particularly adequate for that purpose. Hydrological information can be extracted from remote sensing images and correlated to hydrogeological and hydrogeophysical data, allowing to extend the data to the image coverage. Although some remote sensing methods can also retrieve quantification of water fluxes, 
this component was not included in this thesis.

\subsubsection{Spatio-temporal modeling and assessment of subsurface water fluxes}

The transient calibration of hydrological models requires time series of driving forces and state variables. Such data can be acquired through monitoring networks. Nowadays, automatic data acquisition systems are routinely used to acquire such data, thanks to the low cost and advancement of electronic devices, i.e. sensors and loggers. Such monitoring networks allow to register at high temporal frequency and high spatial resolution the meteorological forces (e.g. precipitation, wind speed, air temperature, solar radiation) that control the hydrological dynamic of a catchment, as well as the related state variables (e.g. soil moisture, hydraulic heads, stream flow). The data acquisition can be designed using several monitoring stations located at key points of the catchment, e.g. recharge/discharge areas, allowing to register the spatio-temporal variability of the driving forces and the responses of the hydrological system. Such data are critical to provide reliable and realistic input to hydrological models (Holländer et al., 2015).

In this study, the conversion of meteorological data into boundary fluxes is proposed to be implemented through the newly developed MARMITES model. This model integrates the surface and soil zones and computes spatio-temporally the partitioning of rainfall into evaporation, transpiration, infiltration, runoff, percolation and groundwater recharge. The MARMITES model is two-way coupled with the groundwater MODFLOW-NWT model, i.e. the two models can exchange boundary conditions among themselves. Such coupling allows to integrate the interaction between surface and subsurface fluxes, particularly dynamic in drainage areas where groundwater and surface water are interconnected.

Although many models are available, it was opted in this study to develop the new surface and soil zones MARMITES model to implement the novel options of partitioning and sourcing of the evapotranspiration fluxes. Partitioning refers to the separation of the evapotranspiration $(E T)$ into the evaporation and transpiration components while the sourcing corresponds to the separation of ET into unsaturated zone and groundwater evapotranspiration. The partitioning and sourcing of evapotranspiration fluxes is relevant not only to improve the reliability of models and water balances but also to understand the role of vegetation and soil processes in the water cycle and to make reliable prediction scenarios of climate and land use changes.

\subsection{Thesis outline}

Chapters 2, 3 and 4 present methodologies based on hydrogeophysics, remote sensing and geostatistics to contribute to the design of hydrogeological conceptual model. Chapter 5 presents the development of 
the coupled MARMITES-MODFLOW model of surface, unsaturated and saturated zones that computes spatio-temporally the water fluxes at the catchment scale and integrates the sourcing and partitioning of the evapotranspiration. The coupled model capabilities are demonstrated through a case study. Finally, Chapter 6 presents the integration of MRS-based hydrogeophysics into the coupled model.

To implement and test the proposed methodologies, we selected 4 study areas located in the Iberian peninsula, all of them in semi-arid climate. Two study areas, the Pisões catchment (Alentejo, Portugal, Chapter 2) and Sardón catchment (Salamanca, Spain, Chapters 4 and 5 and Appendix A) are located in hard rock aquifer regions. Hard rocks cover large geographical areas and often constitute the only source of water supply for population, livestock and agriculture. As hard rocks are characterized by large spatial heterogeneity and low storage, the modeling of aquifer in such environment is a challenge. The third study area corresponds to a coastal aquifer located in Algarve (South Portugal, Chapter 3), in a complex hydrogeological settings. Finally the last study area, the Carrizal catchment (Salamanca, Spain, Chapter 6), is characterized by Cenozoic, fluvial deposits that support a multilayer, porous aquifer.

In Appendix A an article entitled "Using Ground Penetrating Radar to investigate the water table depth in weathered granites - Sardón case study, Spain" by Mahmoudzadeh et al. (2012) is presented. This article is co-authored by the author of this thesis. It presents a GPR application to retrieve the groundwater table depth in weathered granites in the Sardón study area, referred in Chapters 4 and 5 . This article was not included as a chapter of the thesis because the main GPR technique applied in this study is not the primary expertise of the author of this thesis.

\subsubsection{Chapter 2}

This chapter introduces a method based on invasive sampling, surface geophysics, remote sensing and geostatistics to predict the clayey topsoil thickness of a small catchment in Portugal. The approach is based on continuous, non-invasive electromagnetic (frequency domain) measurements along transects in order to capture the geomorphological dependence of the topsoil thickness. Based on statistical correlation and calibration with the invasive measurements, geophysical results are extrapolated using geostatistical methods and remote sensing images as auxiliary data.

\subsubsection{Chapter 3}

The objective of this chapter was to retrieve the structure and geometry of a coastal aquifer and to upgrade the current hydrogeological conceptual model. The methodology was based on hydrogeophysical methods such as 2D electric resistivity tomography (ERT), 2D frequency domain electromagnetic (FDEM) and 1D time-domain electromagnetic (TDEM) 
applied along transects transversal and longitudinal with respect to the aquifer. The hydrogeophysical interpretation was supported with auxiliary information such as regional piezometric map and borehole lithological logs, as well as offshore data. The hydrogeophysical methods were effective in detecting the position of the freshwater-saltwater interface and allowed redefining the boundaries and 3D structure of the coastal aquifer. The new redefined hydrogeological conceptual model supports the explanation of the location of the inter- and subtidal fresh groundwater discharge and constitute the basis of variable-density groundwater flow numerical model.

\subsubsection{Chapter 4}

In this chapter, a methodology of data acquisition for hydrogeological conceptual models, particularly suitable for data scarce areas, is presented. It involves remote sensing and non-invasive hydrogeophysical methods supported by hydrogeological field data acquisition to derive the hydrogeological conceptual model of a hard rock aquifer. Instead of interpolation or extrapolation methods of the acquired data, a downward approach is applied. This approach consists of analyzing patterns in data observed at the catchment scale to retrieve the hydrological characteristics of the catchment. The remote sensing analysis allowed to define the main hydrogeological features that were locally characterized and parameterized using several hydrogeophysical methods such as 2D ground penetrating radar (GPR), 2D electric resistivity tomography (ERT), 2D frequency domain electromagnetic and 1D magnetic resonance soundings (MRS). After verification and calibration using drilling and slug tests, hydrogeophysical results of each hydrogeological features were compiled and integrated into a hydrogeological conceptual model.

\subsubsection{Chapter 5}

A coupled model composed of the new land surface and soil zone MARMITES model and of the USGS groundwater MODFLOW-NWT model is presented to demonstrate model-based partitioning and sourcing of evapotranspiration $(E T)$ as part of spatio-temporal water balancing at the catchment scale. The partitioning of ET involves its separation into evaporation and transpiration while the sourcing of evaporation and transpiration involves separation of each of the two fluxes into soil and saturated zone components. The capability of the MARMITESMODFLOW coupled model to simulate complex hydrological systems is demonstrated by its application to a small catchment characterized by a semi-arid climate with rainfall $\sim 500 \mathrm{~mm} . \mathrm{y}^{-1}$, granitic bedrock, shallow groundwater and sparse oak woodland. 


\subsubsection{Chapter 6}

This chapter presents the integration of hydrogeophysical, magnetic resonance soundings (MRS) method of data acquisition into the MARMITESMODFLOW model. The MRS method provides quantitative hydrogeological information on hydrostratigraphy and hydraulic parameters of subsurface, e.g. flow and storage property of aquifers. The original integration method is based on the optimization of the MRS estimates of aquifer hydraulic parameters through hydrologic model calibration. The MRS integration with hydrologic model was carried out by introducing multipliers of specific yield and transmissivity/hydraulic conductivity that were optimized during transient model calibration using time-series piezometric observation points. 


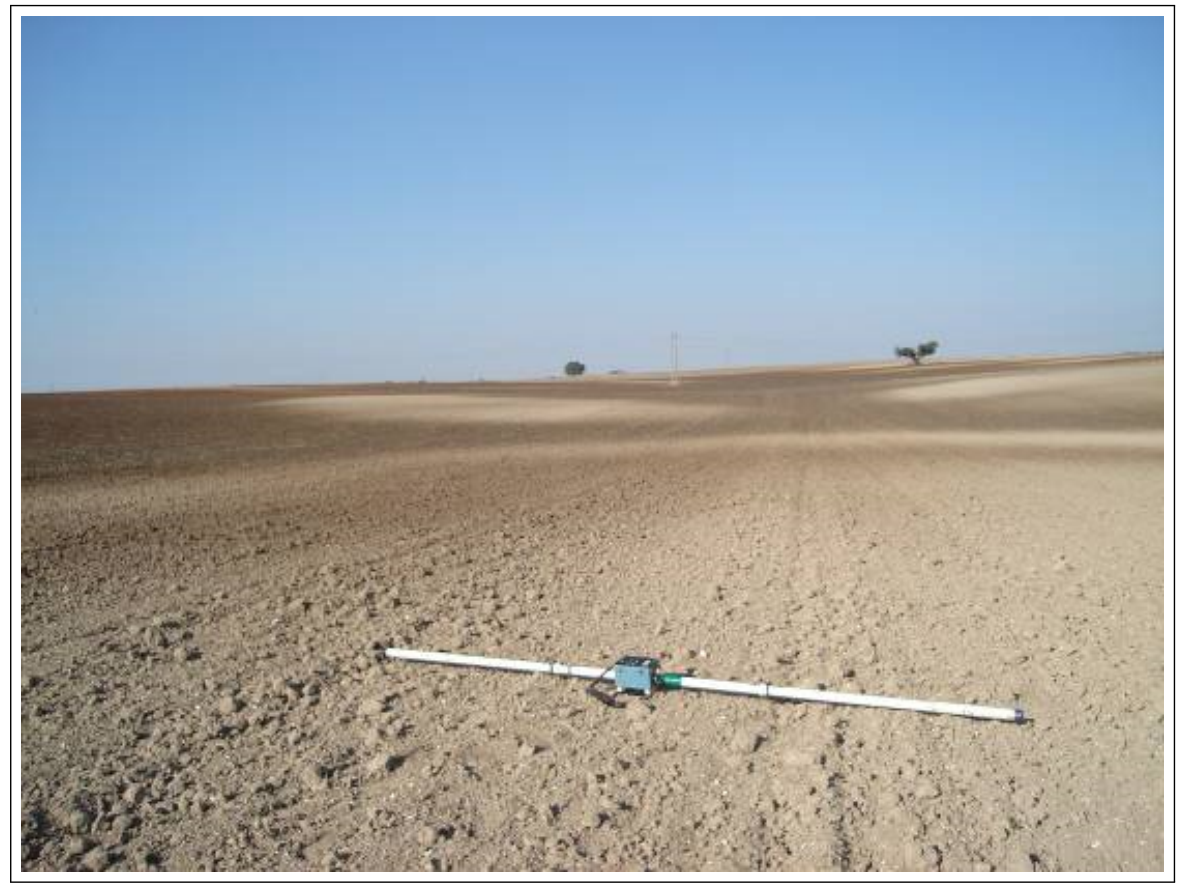

Geonics ${ }^{\mathrm{TM}}$ EM-31 instrument on plowed fields of the Pisões catchment (Beja, Alentejo, Portugal). 



\section{Topsoil thickness prediction at the catchment scale by integration of invasive sampling, surface geophysics, remote sensing and statistical modeling}

\subsection{Introduction}

Distributed hydrological models have a wide range of applications in agronomy, hydrology and hydrogeology, e.g. in crop management, runoff and flood studies, land-use and climate change impacts, and assessment of groundwater resources renewability (Finch, 1998; Lubczynski and Gurwin, 2005a; Rushton et al., 2006; Batelaan and de Smedt, 2007). Such models typically partition rainfall into: evapotranspiration, soil moisture storage, groundwater recharge and surface runoff. This partitioning largely depends not only on the hydrological conditions, but also on the pedo-geological conditions. Topsoil thickness, in conjunction with soil hydraulic properties, controls the water holding capacity and is therefore a critical parameter in the assessment of groundwater recharge. The spatial assessment of topsoil thickness is difficult due to its high spatial heterogeneity, which is controlled by several factors such as climate, geomorphology and parent material. Invasive data acquisition techniques such as drilling or trench excavations are labor-intensive, costly and involve extensive fieldwork sampling and laboratory analysis. They can be efficiently complemented by non-invasive geophysical and remote sensing (RS) methods which are time and cost effective, i.e. they succeed in covering large areas of land cheaper and quicker than the soil sampling techniques.

This chapter is based on: Topsoil thickness prediction at the catchment scale by integration of invasive sampling, surface geophysics, remote sensing and statistical modeling. Francés, A. P., and M. W. Lubczynski (2011), Journal of Hydrology, 405, 31-47 
Geophysics, as an indirect method, measures one physical property of the subsurface that has to be converted into a parameter or variable of interest. For instance, electrical conductivity per se is of little information in a hydrological sense if it is not related to soil moisture or soil salinity, i.e. a physical property that affects the soil. Its conversion can be deterministic or statistical (Corwin and Lesch, 2003). The deterministic approach assumes an a-priori knowledge of the mechanism from the studied processes, and its mathematical formulation through theoretical or empirical models. However, it often requires several parameters that are not available and/or expensive to acquire. The statistical approach, although site-specific, is more flexible. The statistical models are built by measuring target soil variables at a limited number of sampling points. Several authors (Knotters et al., 1995; Odeh et al., 1995; Bourennane et al., 2000; Bishop and McBratney, 2001; Triantafilis et al., 2001a,b; Bourennane and King, 2003; Kuriakose et al., 2009) have applied the statistical approach to predict the spatial distribution of soil variables by use of auxiliary variables such as geophysical measurements and RS information. They have used and sometimes compared several statistical methods such as simple linear regression (LR), multiple linear regression (MLR), variance analysis (ANOVA), covariance analysis (ANOCOVA) and kriging techniques, such as ordinary kriging (OK), cokriging, universal kriging (UK) and kriging with external drift (KED). These statistical and geostatistical techniques are derived from the general universal model of spatial variation as defined by Matheron (as cited in Hengl, 2009), which is also called the geostatistical mixed linear model (MLM) by Lesch and Corwin (2008). For any given dataset, the selection of an adequate prediction model derived from the MLM approach cannot be exclusively based on the model performance and goodness of fit. The selection must be primarily made by the verification of the model assumptions. In this study we applied the guidelines of Lesch and Corwin (2008), which explained the connection between the LR model and the MLM, reviewed the underlying assumptions and presented statistical diagnostic tools. We also followed the methodology of Hengl (2009) who developed a decision chart, based on the sequential verification of the model assumptions, to guide in selecting an appropriate prediction model.

The soil apparent electrical conductivity $\left(E C_{a}\right)$ retrieved by geophysical techniques, such as electrical resistivity (ER) or electromagnetic (EM) methods, has been used in environmental sciences to efficiently characterize the subsurface (Corwin and Lesch, 2005b). $E C_{a}$ depends on the combination of several properties of the subsurface such as electrical conductivity of the soil aqueous solution, volumetric water content, soil texture, mineralogy and temperature (Corwin and Lesch, 2003; Friedman, 2005). Depending on the site-specific properties and the land management in agricultural areas, generally one or two of these properties (e.g. salinity, clay content, soil moisture, etc.) contribute more than the others in the measured $E C_{a}$ value. This may even lead to different $E C_{a}$ values in two adjacent plots of the same soil type which have different agricultural practices. This non-uniqueness in the relationship between the $E C_{a}$ and 
the soil properties makes the interpretation of $E C_{a}$ data difficult and generally limits its usability at the plot scale where subsurface conditions are relatively homogeneous.

The RS proved to be an efficient complement to the invasive methods and the geophysical surveys. RS allows integration within the spatial heterogeneity into the modeling of the relationship between the $E C_{a}$ and soil properties. Bishop and McBratney (2001) compared several prediction methods to map the soil cation exchange capacity (CEC) at the plot scale based on a combination of $E C_{a}$ measured by ER method, bare soil color obtained by RS information (LANDSAT TM imagery and aerial photographs), terrain parameters and crop yield data. They found that the CEC was better estimated with the statistical models that integrated either the bare soil information, which was obtained from color aerial photographs, or the $E C_{a}$. Triantafilis et al. (2001a) predicted the clay content at the field scale by testing several spatial prediction models. The spatial prediction models that integrated auxiliary variables such as $E C_{a}$ from Geonics ${ }^{\mathrm{TM}} \mathrm{EM}-31$ and EM-38 survey and RS color bands of aerial photographs proved to be more accurate.

The approach of combining geophysical $E C_{a}$ with RS data and statistical modeling was tested at a larger scale by several authors. For mapping clay content at a landscape scale, Weller et al. (2007) applied a nearest neighbor correction to the $E C_{a}$ data measured with EM-38 in agricultural fields. This method reduced the variance of the $E C_{a}$ data by more than $50 \%$ and improved the coefficient of determination $\left(R^{2}\right)$ from 0.66 (no correction) to 0.85 . Triantafilis and Lesch (2005) mapped the average clay content for a 0-7 m depth range at the catchment scale $\left(\sim 60 \mathrm{~km}^{2}\right)$ using the $E C_{a}$ data measured with EM-34 and EM-38 instruments. They used a fuzzy k-means method to classify the $E C_{a}$ data into physiographic and hydrological units. In each unit, a relationship between the $E C_{a}$ signal measured by the EM-34 and the EM-38 and the first-order trend surface component was applied to predict the averaged clay content. They concluded that although the method was useful to determine a soil sampling scheme, it did not result in an improvement in the relationship between $E C_{a}$ and the averaged clay content. They recommended the incorporation of remotely sensed information (e.g. gamma radiometric, LANDSAT, RADARSAT, etc.) into the classification process.

The focus of this study, i.e. the spatial variability of topsoil thickness, has already been investigated by several authors at the plot scale in relatively homogeneous areas characterized by low relief and low slopes. In all prior cases, a high contrast of $E C_{a}$ was observed between overlaying soil horizons due to texture differences. Doolittle et al. (1994) found a high correlation between the depth to claypan $(d)$ and the $E C_{a}$ measured by EM-38 using an exponential regression model $d=n e^{\left(m E C_{a}\right)}$, where $m$ and $n$ were the model constants. Sudduth et al. (2003) obtained good results in claypan soils using a linear regression between the topsoil thickness and the inverse of the $E C_{a}$. Brus et al. (1992) predicted the boulder clay depth beneath a sand cover using $E C_{a}$ values measured by EM-38 and EM-31. They used regression analysis to fit an empirical 
exponential model and a physical spherical model, concluding that the use of $E C_{a}$ to predict topsoil thickness was not very appropriate due to the fact that the $E C_{a}$ was affected by spatial variation in the soil moisture. They improved the relationship by integrating land-use information that accounted for soil moisture variation. In addition, they recommended the integration of RS with $E C_{a}$ data into the modeling process in order to better account for the spatial variation of soil variables and parameters. These suggestions were followed by Bourennane and King (2003) who predicted satisfactorily the topsoil thickness at the plot scale by using $E C_{a}$ and the slope gradient. Kuriakose et al. (2009) implemented the previous methodologies on a larger scale, i.e. to a small catchment $\left(\sim 9 \mathrm{~km}^{2}\right)$, and predicted the soil depth using an extensive dataset of invasive measurements (276 values). They applied several statistical and geostatistical methods that integrated topographic variables derived from a digital elevation model (DEM) and land use map information.

The objective of this study was to predict the topsoil thickness at the catchment scale and to use this prediction as input in a hydrological distributed model in further studies. We developed a novel data acquisition and data-integration method applicable at the catchment scale that limited the number of invasive field observations. The proposed method involved: (i) invasive sampling (augering and drilling); (ii) surface geophysics using EM-31; (iii) RS imagery (high resolution QuickBird image, aerial orthophotos and ASTER GDEM) processing; and (iv) MLM approach and model diagnostic.

We applied the proposed method in the Pisões catchment $\left(19 \mathrm{~km}^{2}\right)$ of the Alentejo province in Portugal, to predict the spatial distribution of the clayey topsoil thickness (CTT). The CTT was recognized as a major controlling factor in the hydrological processes. It was therefore critical for an adequate parameterization of the distributed unsaturated model that was developed in order to improve the groundwater resource assessment (Chapter 5, Francés and Lubczynski, 2015).

\subsection{Material and methods}

The general methodology of the CTT spatial prediction combines invasive sampling, surface geophysics, RS and the MLM approach and is presented in the flowchart in Figure 2.1. In step 1, we compiled a preliminary dataset of invasive CTT measurements based on previous studies. In steps 2 and 3, we analyzed and processed the RS imagery to obtain the soil classification and terrain parameters. In step 4, following the information acquired in steps 1-3, we designed the sampling scheme of the surface-geophysics (EM-31 $E C_{a}$ measurements) and complementary CTT invasive measurements that, together with the compiled CTT data of step 1, constituted the CTT reference dataset (CTT-REF). We established a calibration dataset (CTT-CAL) composed of co-located pair-points of invasive CTT measurements and corresponding $E C_{a}$ data. In step 5, we applied several calibration models, based on the MLM approach and the 
integration of auxiliary spatial information (soil classification of step 2 and terrain parameters of step 3), to convert the $E C_{a}$ data into CTT to obtain the CTT-EC dataset. In step $6 \mathrm{a}$, we predicted the CTT at the catchment scale by using the MLM approach and the CTT-EC dataset (CTT-ECpred raster). In step 6b, we performed a similar procedure to obtain the CTT-REFpred raster but by using exclusively the invasive CTT measurements (i.e. CTT-REF). The objective for performing these two predictions was to assess the effectiveness of the geophysical data as a substitute for invasive observations. Finally, in step 7, we assessed the quality of the prediction models by computing the mean error (ME), the mean absolute error (MAE) and the root mean square error (RMSE) between the predicted (CTT-ECpred and CTT-REFpred rasters) and the observed (CTT-REF) dataset.

All the spatial data acquired from the field and from RS imagery (steps 1 to 4) were converted into the same projected coordinate system (ED50-UTM zone 29N). To retrieve the positions of the invasive CTT measurements, the geophysical data points and several geodetic benchmarks, we used a standard GPS receiver (GARMIN GPSMAP 60C). To convert the coordinates we utilized the seven transformation parameters of the Bursa-Wolf method. We obtained a horizontal positional accuracy of $\sim 2.5 \mathrm{~m}$, which was satisfactory considering the scale of the CTT spatial variation. 


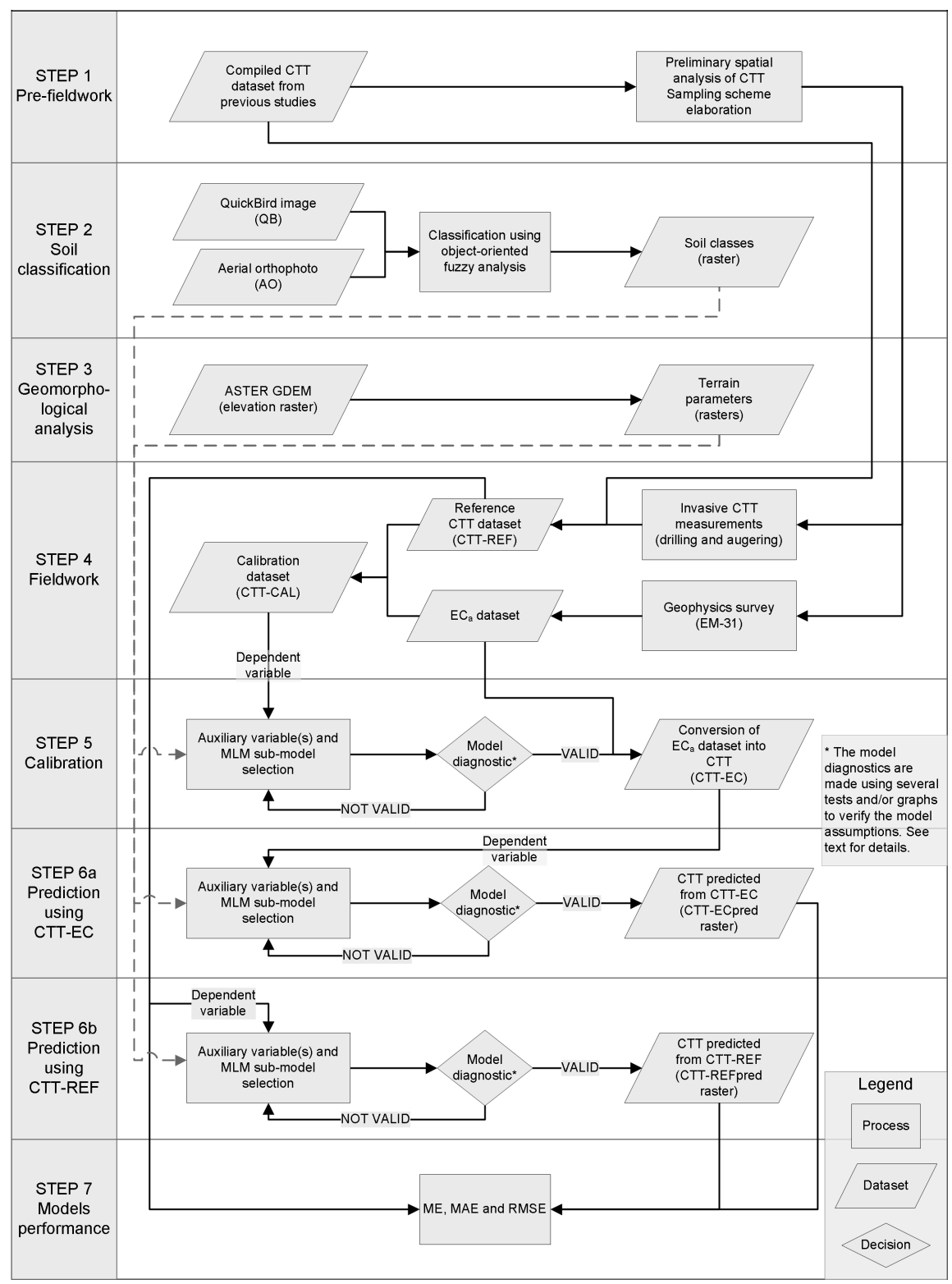

Figure 2.1: Flowchart of the methodology used to predict the CTT at the catchment scale. 


\subsubsection{Study area}

The Pisões catchment $\left(\sim 19 \mathrm{~km}^{2}\right)$ is located in the Alentejo region (Portugal), west of Beja city (Figure 2.2). The topography is smooth, with gentle slopes and flat surfaces. The catchment boundaries correspond to the basin water divides. The perennial Ribeira da Chamine stream drains a phreatic aquifer, flowing to the south-west towards the catchment outlet. The catchment water table follows the topography, becoming deeper in the hill tops and more shallow within the drainage areas. The land use is mainly characterized by rainfed agriculture (wheat and olive groves), although in the last decade the practice of irrigating crops (drip irrigation for olive groves and sprinkler pivot for corn and beetroot crops) has become more common. These practices, combined with the high evapotranspiration rate, have provoked an increase in soil salinity.

The geology of the study area is composed of gabbros and diorites (Oliveira, 1992). The chemical weathering of the gabbro-dioritic rocks has resulted in the formation of clay minerals, mainly montmorillonite (Vieira e Silva, 1991). The main soil classes (Cp, Bp and Bpc, see Figure 2.2 and Table 2.1) belong to the so-called Barros Pretos unit (Cardoso, 1965). The high concentration of swelling clay in the topsoil provokes the development of wide and deep cracking systems during dry seasons. The soil profiles consist of a clayey topsoil (horizons $\mathrm{AB}$ ) overlying a weathered parent rock material (horizon $C$ ) that can be carbonaterich (Table 2.1). The $\mathrm{AB}$ horizon is thicker along the drainage area of the catchment ( $\mathrm{Cp}$ class) than in the $\mathrm{Bp}$ and Bpc classes. Along the steep slopes, carbonate soils (Pc class, so-called calcrete) outcrop predominantly (Figure 2.2). They are characterized by a thinner $A B$ horizon and a lighter color than the other soil classes (Cp, Bpc and Bp). 


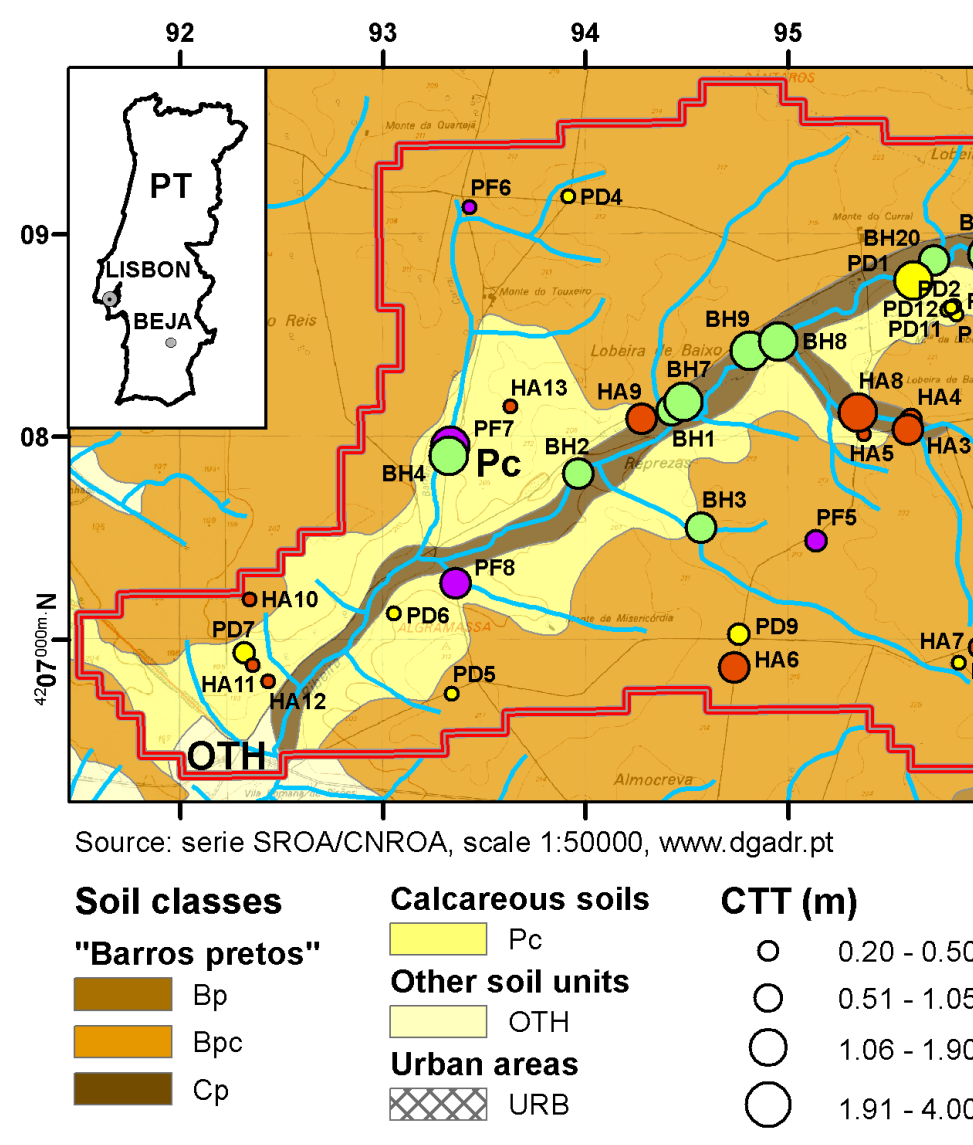

Figure 2.2: Soil map (see Table 2.1 for more details) and location of invasive CTT measurements (CTT-REF dataset, 61 values classified in quartiles; BH: boreholes; HA: hand augering; PD: percussion drilling and digging; PF: profiles; see Table 2.2 for more details). 
Table 2.1: Soil characteristics (source: www.dgadr.pt). Bp (Barros Pretos): black clay, not calcareous, from diorites or gabbros or others crystalline basic rocks. Bpc (Barros Pretos): black clay, calcareous, from diorites or gabbros or others crystalline basic rocks, associated with friable calcareous material. Cp (Barros Pretos): black clay, calcareous, from eruptive or crystalline basic rocks, associated with friable calcareous material. Pc (Solos Calcários Pardos): calcareous soil, greyish dun from climate with xeric regime, from non-compact limestones, friable or not, mixed with material from diorites or gabbros or eruptive or crystalline rocks.

\begin{tabular}{|c|c|c|c|c|c|c|}
\hline Soil type & Horizon & \multicolumn{2}{|c|}{ Thickness (cm) } & Colour & Texture & СaCO3 \\
\hline \multirow[t]{4}{*}{$\mathrm{Bp}$} & Ap & \multirow[t]{4}{*}{$40-120$} & $20-40$ & $\begin{array}{l}\text { dun-greyish very dark } \\
\text { or brown }\end{array}$ & \multicolumn{2}{|l|}{ clayey or loam-clayey } \\
\hline & B & & $10-60$ & $\begin{array}{l}\text { dun-greyish very dark } \\
\text { or brown }\end{array}$ & \multicolumn{2}{|l|}{ clayey } \\
\hline & $\mathrm{BC}$ & & $10-20$ & & \multicolumn{2}{|l|}{$\begin{array}{l}\text { clayey more or less cal- } \\
\text { careous }\end{array}$} \\
\hline & $\mathrm{C}$ & & \multicolumn{4}{|c|}{$\begin{array}{l}\text { material from weathered diorite or gabbros or other eruptive or basic crystalline } \\
\text { rocks }\end{array}$} \\
\hline \multirow[t]{4}{*}{ Врс } & Ap & \multirow[t]{4}{*}{$40-115$} & $20-40$ & $\begin{array}{l}\text { dun-greyish very dark } \\
\text { or brown }\end{array}$ & clayey & no effervescence to $\mathrm{HCl}$ \\
\hline & B & & $10-60$ & $\begin{array}{l}\text { dun-greyish very dark } \\
\text { or brown }\end{array}$ & clayey & no effervescence to $\mathrm{HCl}$ \\
\hline & B Cса & & $10-15$ & & $\begin{array}{l}\text { clayey more or less cal- } \\
\text { careous }\end{array}$ & $\begin{array}{l}\text { calcareous concretions } \\
\text { increasing with depth }\end{array}$ \\
\hline & Cca and C & & \multicolumn{4}{|c|}{$\begin{array}{l}\text { material from weathered diorite or gabbros or other eruptive or basic crystalline } \\
\text { rocks generally associated with friable calcareous material }\end{array}$} \\
\hline
\end{tabular}

Continued on next page 


\subsubsection{Invasive sampling}

We compiled a reference dataset of 61 invasive CTT measurements (CTTREF) derived from several data sources (Figure 2.2 and Table 2.2). We also collected soil samples to characterize the soil horizons properties (see below). The CTT-REF was composed of: (i) 39 data points compiled from previous work (data obtained from borehole drilling reports, hand augering and profile analysis in pitches); and (ii) 22 new invasive CTT measurements made during fieldwork in September 2007 and September 2009. The locations of the new CTT measurements were selected using purposive sampling in order to obtain an equal coverage of the geomorphologic features of the catchment and be positioned along the geophysical transects. The soil sampling was difficult due to the hardness of the clayey topsoil during dry season and softness in wet season. In zones where the topsoil was thin $(\sim 0.5 \mathrm{~m})$, we made observations and sampling using hand augering or digging with appropriate tools (shovels, digging hoes and pick axes). In thicker clayey soils, we used a gasoline powered COBRA percussion hammer. Although this technique was timeconsuming ( $\sim 2 \mathrm{~h}$ per core of $2 \mathrm{~m}$ depth), it allowed us to collect soil samples at different depths (up to $2.5 \mathrm{~m}$ ) and to measure the CTT. Only one drilling profile was performed in the drainage area ( $\mathrm{Cp}$ soil class), at location PD1 (Figure 2.2). This profile did not reach the $\mathrm{C}$ horizon due to the drilling equipment's limited depth of penetration. No samples were taken from the Bp class since it was very similar to the Bpc class and only present on a small area of the NE of the catchment (Figure 2.2).

Table 2.2: Reference dataset of invasive CTT measurements (CTT-REF dataset, 61 values).

\begin{tabular}{llrll}
\hline $\begin{array}{l}\text { Data } \\
\text { source }\end{array}$ & Description & $\begin{array}{r}\text { Number } \\
\text { of data }\end{array}$ & Collector & Period \\
\hline BH & $\begin{array}{l}\text { borehole drilling } \\
\text { reports }\end{array}$ & 22 & $\begin{array}{l}\text { Several } \\
\text { companies }\end{array}$ & $1960-2000$ \\
HA & hand augering & 9 & Cortez (2004) & $09 / 2003$ \\
& & 4 & This study & $09 / 2009$ \\
PD & $\begin{array}{l}\text { shallow percussion } \\
\text { drilling/digging }\end{array}$ & 18 & This study & $09 / 2007$ \\
PF & $\begin{array}{l}\text { profiles analysis in } \\
\text { pitches }\end{array}$ & 8 & Paralta (2009) & $05-07 / 2005$ \\
& & & & \\
\hline
\end{tabular}




\subsubsection{Soil analysis}

We characterized the $\mathrm{AB}$ and $\mathrm{C}$ soil horizons based on soil texture determination, laboratory mineral spectra analysis and dielectric property measurements. Such characterization was necessary to interpret the surface geophysical measurements. The soil texture was determined by Paralta (2009) for each sub-horizon of the 8 soil profiles of the PF category (Table 2.2 and Figure 2.2). In total, 25 samples were collected and analyzed (23 from horizon $\mathrm{AB}$ and 2 from horizon $\mathrm{C}$ ). For each profile, we computed the average clay content in the horizon $A B$ (the average was weighted by the thickness of the 23 sub-horizons). We performed mineral recognition of the soil horizons by means of mineral spectra analysis of 32 samples in the PD dataset (Table 2.2) taken at 11 locations (PD1 to PD10 and PD13, Figure 2.2). 15 samples were from the $A B$ horizon and 17 from the $C$ horizon. Finally, we measured the apparent soil electrical conductivity of discrete, homogeneous soil horizons $\left(E C_{s}\right)$ to check the consistency with the surface geophysics $E C_{a}$, since the latter corresponds to a bulk measurement of the soil horizons $E C_{s}$ above the depth of penetration of the geophysical instrument. We measured the real $\left(\epsilon_{r}^{\prime}\right)$ and imaginary $\left(\varepsilon_{r}^{\prime \prime}\right)$ dimensionless components of the soil complex dielectric permittivity with a portable Stevens Hydra Probe (Seyfried and Murdock, 2004; Seyfried and Grant, 2007) on the $\mathrm{AB}$ and $\mathrm{C}$ horizons at 10 vertical soil profiles (locations PD1 to PD10, Figure 2.2). $E C_{s}(\mathrm{~S} / \mathrm{m})$ is related to $\varepsilon_{r}^{\prime \prime}$ as following:

$$
E C_{s}=\varepsilon_{0} \varepsilon_{r}^{\prime \prime} f 2 \pi
$$

where $\varepsilon_{0}$ is the free space permittivity $\left(8.854 \times 10^{-12} \mathrm{~F}^{-1}\right)$ and $f$ is the measurement frequency (50 MHz). A correction for temperature effect was considered as suggested by Seyfried and Grant (2007) in order to obtain standardized values of $E C_{S}$ at $25^{\circ} \mathrm{C}$. The areas with a ratio of $\varepsilon_{r}^{\prime \prime} / \varepsilon_{r}^{\prime}>2$ were identified as affected by soil salinity (Seyfried et al., 2005).

\subsubsection{Remote Sensing}

\subsubsection{Soil classification}

The general purpose of any soil classification is to identify groups with one or several homogeneous properties. This advantageously reduces the variability in relation to the whole population, while increasing the precision of any prediction made. Each soil type class in Figure 2.2 indicates a range of CTT, as shown in Table 2.1. The introduction of these classes in statistical modeling improves the relationship between the CTT and the explanatory variables (geophysical data and terrain parameters). However, in this study the only soil map available (Figure 2.2) was not applicable because its scale (1:50 000) was too coarse for the required level of details. In addition, our field observations were in disagreement with that map. We thus decided to perform our own soil classification based on field observation and on RS interpretation. At the end of 
the dry season, the agricultural fields are bare and the color of the surface is indicative of the dominant soil type. Although the whitish calcrete outcrops can be visually identified among the darker clayey soils (Figure 2.3), the RS recognition of the soil types and its classification is additionally complicated by the occurrence of dark and bright fields due to the presence or the absence of dry crops and plowing. For example, a calcrete soil area in a dark field has a spectral signature similar to a clayey soil area in a bright field resulting in classification non-uniqueness. However, as the color intensity of the dark and bright fields varies throughout the year and seasons due to crop rotation, the confusing effect of dark and bright fields can be minimized by analyzing images acquired at different periods. In this study, we fused a multispectral QuickBird (QB) high resolution image from the $20^{\text {th }}$ of September 2006 at 11:40 (GMT) (Figure 2.3 and Table 2.3) and a 3 bands (RGB) aerial orthophoto (AO) of $0.5 \mathrm{~m}$ resolution, acquired in November 2004 by the Instituto Geográfico Português (IGP). The fusion of the QB with AO images was done according to the following procedure: (i) pre-processing using a smoothing filter ( $9 \times 9$ pixels for $\mathrm{QB} ; 11 \times 11$ for $\mathrm{AO}$ ) to attenuate the linear structures due to plowing; (ii) conversion of the wave length into DN values; (iii) coordinates conversion and rectification; and (iv) the fusion of the two images at the $\mathrm{QB}$ resolution (QBAO image).

Table 2.3: Main characteristics of the QuickBird image, cloud-free, acquired the $20^{\text {th }}$ of September 2006 at 11:40 (GMT). Acquisition time, close to sun zenith, was convenient to minimize the shadows and influence of sunray obliquity on the images color and brightness.

\begin{tabular}{llllll}
\hline \multirow{2}{*}{$\begin{array}{l}\text { Sensor } \\
\text { resolution }\end{array}$} & $\begin{array}{l}\text { Dynamic } \\
\text { range }\end{array}$ & \multicolumn{4}{l}{ Spectral bandwidth (nm) } \\
\cline { 3 - 6 } & $\begin{array}{l}\text { Band 1 } \\
\text { (blue) }\end{array}$ & $\begin{array}{l}\text { Band 2 } \\
\text { (green) }\end{array}$ & $\begin{array}{l}\text { Band 3 } \\
\text { (red) }\end{array}$ & $\begin{array}{l}\text { Band 4 } \\
\text { (NIR) }\end{array}$ \\
\hline $\begin{array}{l}2.4 \mathrm{~m} \\
\text { multispectral } \\
\text { at nadir }\end{array}$ & $\begin{array}{l}\text { 11 bits per } \\
\text { pixel }\end{array}$ & $\begin{array}{l}450 \text { to } \\
520\end{array}$ & $\begin{array}{l}520 \text { to } \\
600\end{array}$ & 630 to & 760 to \\
\hline
\end{tabular}

Since the pixel-based approach was not suitable to classify the study area into calcrete (CALCR) and clayey (CLAY) soils due to the nonuniqueness of the spectral signature, we applied an object-oriented fuzzy-logic analysis (Benz et al., 2004) using the Definiens Developer 7 software. This approach produces very good results for the cases in which the spectral based classification approach is causing confusion between classes due to their similar spectral characteristics. Some examples are burned areas mapping Mitri and Gitas (2002) and land use map production in complex mosaics of urban, forest and agricultural areas (Al Fugara et al., 2009). The object-oriented fuzzy-logic analysis incorporates two main steps: segmentation and classification. The image is first segmented into object primitives (groups of pixels that share similar spectral signature) based on region-merging techniques. The 
merging, which starts with a one-pixel object, is iteratively processed while the heterogeneity between adjacent object primitives, which refers to gray tones and shapes, is less than a certain threshold. In the next step, the nearest neighbor (NN) classification and fuzzy logic are used to classify the object primitives into real-word objects. To define the feature space, the user first selects the spectral properties of the real-word objects. Second, the user collects training samples representative of the real-word objects. The distance between the object primitives and the nearest real-word objects in the feature space is computed. Then, by using fuzzy logic, this distance is converted into a membership value that varies between 1 (belong to the class) and 0 (does not belong to the class). Each object primitives is then classified into the real-word objects to which the membership score is higher. We applied this methodology to obtain the soil classification using the fused QBAO image as following: (i) multi-resolution segmentation based on the 7 bands (4 from $\mathrm{QB}$ and 3 from $\mathrm{AO}$ ); (ii) classification of the study area into dark fields (DF), bright fields (BF) and other land covers (vegetation, urban areas and water bodies) using training samples and standard NN method; and (iii) reclassification of DF and BF in CLAY and CALCR soil types: DFclay (dark), DFcalcr (intermediate), BFclay (intermediate) and BFcalcr (bright) using fuzzy logic and NN. Our target was to reach an overall accuracy (computed between the training samples and the final classification) higher than $95 \%$. 


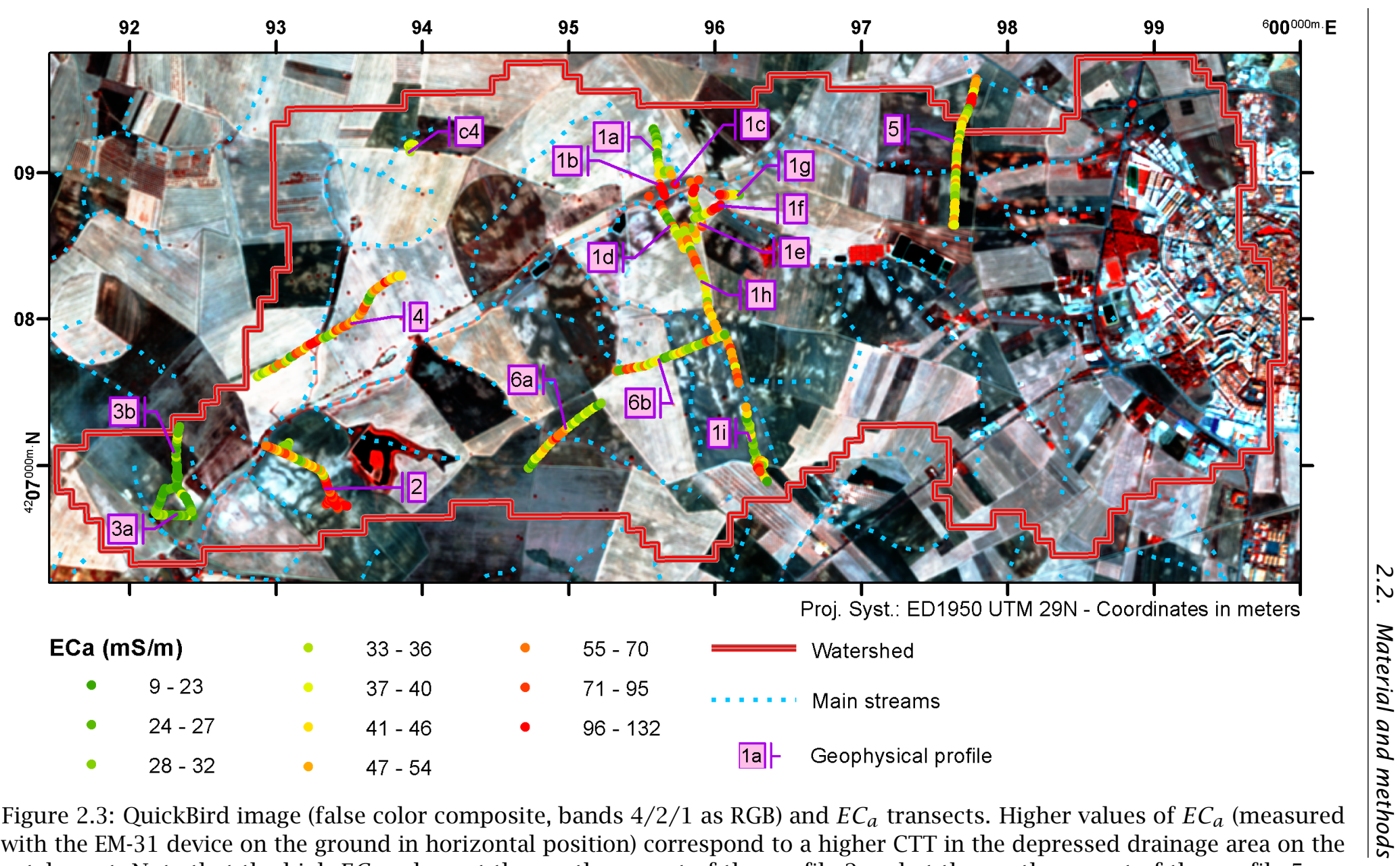
with the EM-31 device on the ground in horizontal position) correspond to a higher (TT in the depressed drainage area on the catchment. Note that the high $E C_{a}$ values at the southern part of the profile 2 and at the northern part of the profile 5 are respectively due to soil salinity (sprinkler pivot irrigated field) and an electric power line. 


\subsubsection{Terrain parameters}

The terrain geomorphology controls the intensity of erosion and deposition processes and influences soil formation and evolution. To study the relationship between the CTT and the geomorphology, we computed several terrain parameters that summarize the terrain capacity to accumulate or to transport sediments. We utilized the methodology and algorithms presented in Hengl et al. (2003a) to derive the morphometric and hydrological terrain parameters. The morphometric terrain parameter groups describe the morphology of the surface that controls the water flow. They are computed by using elevation gradients between the actual cell and its 8 surrounding cells. We computed: (i) slope (SLOP); (ii) mean curvature (MEANC); (iii) vertical or profile curvature (PROFC); and (iv) plan curvature (PLANC). The hydrological (or flow accumulationbased) terrain parameter groups quantify flow intensity, accumulation potential and erosion potential. They are computed using the upslope contributing area per unit contour length draining through the cell and the local slope angle. The parameters used in this study are: (i) topographic wetness index (TWI); (ii) stream power index (SPI); and (iii) sediment transport index (STI). We also computed the topographic position index (TPI) defined by Weiss (2001) using the algorithm of Jenness (2006). TPI is a quantitative representation of the elevation of the actual cell in relation to the elevation of the surrounding cells (selected by a user-input buffer), which represents the erosion/accumulation capacity of the terrain. We derived the terrain parameters from the Global Digital Elevation Model (GDEM) of the Advanced Spaceborne Thermal Emission and Reflection Radiometer (ASTER) satellite (www.gdem. aster. ersdac.or. jp). The ASTER stereoscopic capability using the near infrared spectral band permits the derivation of a DEM which has a spatial resolution of $15 \mathrm{~m}$ in the horizontal plane, and a horizontal accuracy of $30 \mathrm{~m}$ at $95 \%$ confidence and vertical accuracy of $20 \mathrm{~m}$ at $95 \%$ confidence. We verified the horizontal accuracy and confirmed the GDEM compatibility with the previous dataset (RS imagery and geophysics). The absolute vertical accuracy was considered not relevant in this study if the image did not show distortion, i.e. if the relative error was spatially uniform. We compared the GDEM with a digital terrain model (DTM) computed from a digital vectorial topographic map (Portuguese cartographic institute IGeoE, sheet 521, SÃl'rie M888 Continente at scale 1:25 000, www. igeoe.pt) obtained by stereophotogrammetry on aerial images. The IGeoE-DTM was created as triangulated irregular network format using ArcGis - 3D Analyst (contour lines as softlines, hydrography as hardlines and points as mass points). The correlation (computed by the Spearman method) between the GDEM and the IGeoE-DTM proved to be very good (0.98). However, the correlation of the slopes was poor (0.15). This was expected because the GDEM, due to its inherent continuous raster format and its relatively high resolution, leads to smoother and more realistic slope values than the broad and large triangles obtained with the IGeoE-DTM. The GDEM processing was carried out in ILWIS (Unit Geo Software Development, 
2001). We used the DEM hydro-processing tool (Maathuis and Wang, 2006) to remove artificial depressions (sinks) and to include the existing drainage pattern (Figure 2.2) obtained from the digital topographic IGeoE map, updated using the QB image (Figure 2.3).

\subsubsection{Surface geophysics}

The geophysical survey was designed taking into consideration the scientific objectives of this study, the geomorphologic characteristics of the study area and the time and financial constraints inherent in the envisaged field campaign. The method to be applied had to: (i) cover the spatial variability of the CTT over the investigated catchment; (ii) be efficient, i.e. to provide data in a limited amount of time and with crew of 2 people; and (iii) allow for measurements to be taken on plowed fields. A pre-field work analysis based on the CTT dataset compiled from previous studies revealed the dependence of the CTT on the geomorphological features, i.e. the clayey topsoil was thinner on hilltops and slopes and thicker in valleys, with a thickness variation from 0.2 to $4.0 \mathrm{~m}$. We thus designed the geophysical survey in transects transversal to the streams so as to optimally capture the spatial variability of the CTT (Figure 2.3). We selected the Frequency Domain Electromagnetic (FDEM) induction method because it is particularly efficient in shallow $E C_{a}$ data acquisition. As ground contact is not necessary, the FDEM method has the advantage, when compared to electrical resistivity tomography (ERT) or resistivity profiling, to be less man-power demanding and to provide faster data acquisition for equivalent information. A discussion about the advantages and disadvantages of the FDEM and the ERT methods can be found in Corwin and Lesch $(2003,2005 a)$. For this geophysical survey, we selected the EM-31 ground conductivity meter (FDEM commercial implementation from Geonics ${ }^{\mathrm{TM}}$ ) because its penetration depth up to $5.5 \mathrm{~m}$ was in the depth range of the CTT in the investigated catchment. We performed several transects transversal to the streams. In total there were 473 survey locations separated by a median distance of $21 \mathrm{~m}$ (Figure 2.3). We acquired 10 measurements for each survey location with the EM-31 device in vertical and horizontal positions at 5 different heights $(0,30$, 60,90 and $120 \mathrm{~cm}$ above the ground). The measurements at each survey point took only a few minutes, making it possible to cover a transect of $1 \mathrm{~km}$ length in $\sim 2$ hours. The EM-31 instrument was calibrated every $\sim 10$ points during the survey progress. At some survey locations, we confirmed the absence of magnetic rocks that could disturb the measurements by verifying the consistency between the in-phase and the quadrature phase. Although the $E C_{a}$ readings were not corrected for temperature effect, we assumed that the temperature influence was similar for all the measurements since the survey was done during a short period ( $\sim 10$ days in September 2007) within the same temperature range. We minimized the influence of the soil moisture content by carrying out the survey at the end of the dry season. The low water content was confirmed by Francés (2008) on 40 soil samples, taken at different depths 
at 10 locations (PD1 to PD10, Figure 2.2), by verifying that the actual water content (determined by the gravimetric method) was in the same range as the water content at the wilting point (the latter determined using a Decagon WP4-T Dewpoint Meter). In the early stages of this study, the objective of this design was to optimally constrain inversion models in order to obtain $E C_{a}$ vertical soil profiles. In this line, Francés (2008) obtained 2D $E C_{a}$ profiles that depicted the depth-wise variation along the catchment features. Later however, it was found that this way of data acquisition was not optimal to retrieve the CTT. We thus decided to apply statistical techniques to convert the geophysical data into CTT.

\subsubsection{Statistical modeling}

We applied statistical modeling to convert the geophysical data into CTT (step 5, Figure 2.1) and to predict the CTT at the catchment scale (steps $6 \mathrm{a}$ and $6 \mathrm{~b}$, Figure 2.1). The selection of the model was based on the MLM approach. The statistical and geostatistical models listed in Table 2.4 are special cases derived from the MLM following a set of assumptions (Lesch and Corwin, 2008). The MLM formulation is (Hengl, 2009):

$$
Z(s)=m(s)+\varepsilon^{\prime}(s)+\varepsilon^{\prime \prime}
$$

where $s$ is a vector of coordinates $\left(s_{x}, s_{y}\right)$ associated with quantitative and/or qualitative attributes, $Z(s)$ is the predicted value, $m(s)$ is the deterministic component (i.e. the relationship between the predicted variable and quantitative and/or qualitative attributes) and $\varepsilon^{\prime}(s)+\varepsilon^{\prime \prime}$ is the stochastic component (the first term is the spatially correlated random component and the second is the pure noise or nugget in geostatistical vocabulary). 
Table 2.4: Description of the statistical and geostatistical models derived from MLM.

\begin{tabular}{|c|c|c|c|c|c|c|}
\hline Model & Name & Formulation & $\begin{array}{l}\text { Quantitative } \\
\text { explanatory } \\
\text { variable }\end{array}$ & $\begin{array}{l}\text { Qualitative } \\
\text { explanatory } \\
\text { variable }\end{array}$ & $\begin{array}{l}\text { Spatial } \\
\text { auto- } \\
\text { correlation }\end{array}$ & Comment \\
\hline \multirow{4}{*}{$\begin{array}{l}\text { Statistical }^{a} \\
\text { (Faraway, } \\
\text { 2002; } \\
\text { Cornillon } \\
\text { et al., 2008) }\end{array}$} & $\begin{array}{l}\text { Simple } \\
\text { linear re- } \\
\text { gression, } \\
\text { LR }\end{array}$ & $\begin{array}{l}y_{i}=\beta_{0}+\beta 1 x_{i}+\epsilon_{i} \\
i=1, \ldots, n\end{array}$ & $\begin{array}{l}\text { One, } 1 \text { variable } X \\
\text { with } n \\
\text { observations }\end{array}$ & None & No & $\begin{array}{l}\beta_{0}: \text { intercept; } \beta_{1}: \text { slope; } \varepsilon_{i} \text { : } \\
\text { residual }\end{array}$ \\
\hline & $\begin{array}{l}\text { Multiple } \\
\text { linear re- } \\
\text { gression, } \\
\text { MLR }\end{array}$ & $\begin{array}{l}y_{i}=\beta_{0}+\beta_{1} x_{i 1}+ \\
\beta_{2} x_{i 2}+\ldots+\beta_{p} x_{i p}+\epsilon_{i} \\
i=1, \ldots, n\end{array}$ & $\begin{array}{l}\text { Several, } p \\
\text { variables } X \text { with } \\
n \text { observations }\end{array}$ & None & & $\begin{array}{l}\beta_{0}: \text { intercept; } \beta_{1}, \beta_{2}, \ldots, \beta_{p}: \\
\text { slope; } \varepsilon_{i}: \text { residual }\end{array}$ \\
\hline & $\begin{array}{l}\text { Analysis } \\
\text { of } \\
\text { variance, } \\
\text { ANOVA }^{b}\end{array}$ & $\begin{array}{l}y_{i j}=\mu+\alpha_{i}+\epsilon_{i j} \\
i=1, \ldots, I, j=1, \ldots, n_{i}\end{array}$ & None & $\begin{array}{l}\text { One or several, } 1 \\
\text { factor } A \text { with } I \\
\text { levels and } n_{i} \\
\text { observations per } \\
\text { level }\end{array}$ & & $\begin{array}{l}\mu: \text { average effect; } \alpha_{i} \text { : effect } \\
\text { of the level } A_{i} ; \epsilon_{i j}: \text { residual }\end{array}$ \\
\hline & $\begin{array}{l}\text { Analysis } \\
\text { of covari- } \\
\text { ance, } \\
\text { ANOCOVA }^{c}\end{array}$ & $\begin{array}{l}y_{i, j}=\alpha_{i}+\gamma_{i} x_{i, j}+\epsilon_{i, j} \\
i=A 1, \ldots A I \\
j=1, \ldots, n_{i}\end{array}$ & $\begin{array}{l}\text { One or several, } 1 \\
\text { variable } X \text { with } \\
n \text { observations }\end{array}$ & $\begin{array}{l}\text { One or several, } 1 \\
\text { factor } A \text { with } I \\
\text { levels and } n_{i} \\
\text { observations per } \\
\text { level }\end{array}$ & & $\begin{array}{l}\alpha_{i}: \text { intercept of the level } i \\
\gamma_{i}: \text { slope of the level } i ; \epsilon_{i, j} \text { : } \\
\text { residual }\end{array}$ \\
\hline & & & & & & Continued on next page \\
\hline
\end{tabular}


- continued from previous page

\begin{tabular}{|c|c|c|c|c|c|c|}
\hline Model & Name & Formulation & $\begin{array}{l}\text { Quantitative } \\
\text { explanatory } \\
\text { variable }\end{array}$ & $\begin{array}{l}\text { Qualitative } \\
\text { explanatory } \\
\text { variable }\end{array}$ & $\begin{array}{l}\text { Spatial } \\
\text { auto- } \\
\text { correlation }\end{array}$ & Comment \\
\hline \multirow{3}{*}{$\begin{array}{l}\text { Geostatistical }^{d} \\
\text { (Webster and } \\
\text { Oliver, 2008; } \\
\text { Hengl, 2009) }\end{array}$} & $\begin{array}{l}\text { Ordinary } \\
\text { kriging, } \\
\text { OK }\end{array}$ & $Z(s)=\mu+\epsilon^{\prime}(s)$ & None & None & Yes & $\begin{array}{l}\mu \text { : global mean (cte); } \epsilon^{\prime}(s) \text { : } \\
\text { random variable with mean } \\
\text { zero and variogram } \gamma(h)\end{array}$ \\
\hline & $\begin{array}{l}\text { Universal } \\
\text { kriging, } \\
\text { UK }\end{array}$ & $\begin{array}{l}Z(s)= \\
m(s)+\epsilon^{\prime}(s), m(s)= \\
f(x, y)+\epsilon\end{array}$ & $\begin{array}{l}\text { Geographical } \\
\text { coordinates of } s \\
\text { (trend model) }\end{array}$ & None & & $\begin{array}{l}f(x, y) \text { : function of the } \\
\text { geographical coordinates } \\
(x, y) ; \epsilon^{\prime}(s) \text { : random } \\
\text { variable with mean zero } \\
\text { and variogram } \gamma(h), \text { i.e. } \\
\text { OK of } \epsilon \text { (residuals of } m(s))\end{array}$ \\
\hline & $\begin{array}{l}\text { Kriging } \\
\text { with } \\
\text { external } \\
\text { drift, KED }\end{array}$ & $\begin{array}{l}Z(s)= \\
m(s)+\epsilon^{\prime}(s), m(s)= \\
\left\{q_{k}(s)\right\}+\epsilon\end{array}$ & One or several & One or several & & $\begin{array}{l}q_{k}(s) \text { : statistical function } \\
\text { (LR, MLR, ANOVA, } \\
\text { ANOCOVA); } \epsilon^{\prime}(s) \text { : random } \\
\text { variable with mean zero } \\
\text { and variogram } \gamma(h) \text {, i.e. } \\
\text { OK of } \epsilon \text { (residuals of } m(s) \text { ) }\end{array}$ \\
\hline
\end{tabular}

In all formulas, $\mathrm{Z}$ is the target variable with $\mathrm{n}$ observations $Z\left(s_{1}\right), Z\left(s_{2}\right), \ldots, Z\left(s_{n}\right)$ where $s_{i}=\left(x_{i}, y_{i}\right)$ is a location and $x_{i}$ and $y_{i}$ are the geographical coordinates. ${ }^{a}$ In all formulas, $Y$ is the dependent variable. ${ }^{b}$ Formula for one qualitative explanatory variables (one-way ANOVA). ${ }^{c}$ Formula for one qualitative explanatory variable and one explanatory quantitative variable. ${ }^{d}$ We present only the formulation of the mathematical models, for their implementation refer to the bibliography. 
The general methodology in the calibration and prediction processes was to first develop the deterministic component $m(s)$ of the MLM by building the LR, MLR and ANOCOVA models between the dependent variable and quantitative and/or qualitative explanatory variable(s). These models are supported by 3 assumptions related to the residuals (difference between predicted and observed values): normal distribution, homoscedacity (i.e. homogeneity of variance) and no spatial correlation. Normality and homoscedacity are inherent to the mathematical formulation used to compute the parameters of these models (slope and intercept). We verified these two assumptions using diagnostics tools such as statistical tests and graphs (Faraway, 2002; Fox, 2002; Quinn and Keough, 2002; Reimann et al., 2008): normality of the residuals was tested using the Shapiro-Wilk test and the quantile comparison plot of studentized residuals (QQ-plot) while homoscedascity of the residuals was tested using the score test for non-constant error variance (NCV) and the spread-level plot (plot of the logarithm of the absolute studentized residuals against the logarithm of the fitted value). The models that did not respect these assumptions were rejected. To avoid a collinearity effect in the models, the auxiliary quantitative predictors were selected using the principal component analysis and the variance inflation factor. We assessed the goodness of fit between predicted and observed values using: (i) the coefficient of determination adjusted with the number of parameters considered in the model $\left(R_{a d j}^{2}\right)$, which varies between 0 and 1 , the latter corresponding to a perfect fit; (ii) Akaike information criterion (AIC); and (iii) Bayesian information criterion (BIC). The latter two penalize over-fitting due to over-parameterization, a smaller value indicating a better trade-off between goodness of fit and number of parameters. The final selection of the predictors was based on the principle of parsimony, i.e. we selected the model with the smaller number of predictors for equivalent goodness of fit between observed and predicted data. We next tested the assumption of no spatial correlation of the residuals using the Moran's I and variogram analysis. When Moran's I indicated spatial auto-correlation, we computed the stochastic component of Equation (2.2). The resultant KED model combines the regression model with OK of the regression residuals. The error propagation of the models was taken into account by computing the prediction intervals of the statistical models and the kriging variance of the geostatistical models. The final assessment of the prediction was made by computing the mean error (ME, Equation (2.3)), mean absolute error (MAE, Equation (2.4)) and the root mean square error (RMSE, Equation (2.5)) between the predicted and the observed values.

$$
\begin{aligned}
& M E=1 / n \sum_{i=1}^{n}\left[\hat{z}\left(s_{i}\right)-z\left(s_{i}\right)\right] \\
& M A E=1 / n \sum_{i=1}^{n}\left|\hat{z}\left(s_{i}\right)-z\left(s_{i}\right)\right|
\end{aligned}
$$




$$
R M S E=\sqrt{1 / n \sum_{i=1}^{n}\left[\hat{z}\left(s_{i}\right)-z\left(s_{i}\right)\right]^{2}}
$$

where $\hat{z}\left(s_{i}\right)$ is the predicted value at location $s_{i}, z\left(s_{i}\right)$ is the observed value at location $s_{i}$ and $n$ is the number of observations. The statistical data processing was implemented in the R environment (R Development Core Team, 2009) using the packages car (Fox and Weisberg, 2011), gstat (Pebesma, 2004), faraway (Faraway, 2009) and ape (Paradis et al., 2004).

\subsubsection{Variable transformation}

Several variable transformations, namely natural logarithm (ln), power and root square, were tested to improve the relationship between explanatory and dependent variables and to verify the model assumptions. Although the back-transformation of the inferred variable is straightforward for the LR, MLR and ANOCOVA models, the back-transformation of residuals and regression parameters requires a proper mathematical formulation. For example, the left side of Equation (2.6) formulates the LR model between $\ln C T T$ and $\ln E C_{a}$, where $\beta_{0}$ and $\beta_{1}$ are the intercept and the slope respectively. The left side of Equation (2.8) presents the residuals expressed in the ln scale ( $\left.r e s_{l n}\right)$ that are produced by the left side of Equation (2.6) (CTT $T_{\text {obs }}$ are observations and $C T T_{\text {pred }}$ predicted values). On Equations (2.6) and (2.7), the right sides , derived from the left sides, provide the relationship between $C T T$ and $E C_{a}$ and the residuals (res) in their original unit.

$$
\begin{aligned}
\ln C T T=\beta_{0}+\beta_{1} \ln E C_{a} & \Leftrightarrow C T T=\exp ^{\beta_{0}}\left(E C_{a}\right)^{\beta_{1}} \\
\text { res }_{l n}=\ln C T T_{\text {obs }}-\ln C T T_{\text {pred }} & \Leftrightarrow \text { res }=C T T_{\text {pred }}\left(\exp ^{\text {resln }}-1(2.7)\right.
\end{aligned}
$$

For the geostatistical models, we obtained the back-transformed values using the approach suggested by Pebesma and de Kwaadsteniet (1997): if $\hat{Y}$ is the estimation on the $\ln$ scale, $\hat{Z}$ the estimation in the original unit and $\sigma_{k}$ the kriging variance, $\exp ^{\hat{Y}}$ is an estimate of the median of $\hat{Z}$ and the interval $\left[\exp ^{\left(\hat{Y}-2 \sigma_{k}\right)}, \exp ^{\left(\hat{Y}+2 \sigma_{k}\right)}\right]$ is an approximate of the $95 \%$ confidence interval of the median of $\hat{Z}$.

\subsection{Results}

\subsubsection{Soil characterization}

The median of the 61 CTT-REF observations is $1.1 \mathrm{~m}$, with an interquartile range of $1.3 \mathrm{~m} \mathrm{(} 1^{\text {st }}$ quartile is $0.5 \mathrm{~m}$ and $3^{\text {rd }}$ quartile is $\left.1.9 \mathrm{~m}\right)$. The minimum and maximum values are respectively 0.2 and $4.0 \mathrm{~m}$. The texture analysis of the 8 profiles in the PF category (Table 2.2 and Figure 2.2) revealed that the mean value of the clay content in horizon $\mathrm{AB}$ was $42 \%$ (maximum was $50 \%$ and minimum was $34 \%$ ), while the two samples of 
horizon C showed the same clay content at 35\%. Montmorillonite was recognized by spectra analysis as the dominant mineral in all the 32 samples of the PD category (Table 2.2 and Figure 2.2). 10 samples (9 from $\mathrm{C}$ horizon and 1 from $\mathrm{AB}$ horizon) also showed carbonated minerals (calcite, dolomite and nontronite) as the second-dominant mineral (Francés, 2008). The median of the soil electrical conductivity $\left(E C_{s}\right)$ retrieved with the Steven Hydraprobe was $87.0 \mathrm{mS} / \mathrm{m}\left(1^{\text {st }}\right.$ and $3^{\text {rd }}$ quartiles respectively 41.5 and $141.0 \mathrm{mS} / \mathrm{m})$ in the $\mathrm{AB}$ horizon $(15$ samples $)$ and $35.0 \mathrm{mS} / \mathrm{m}\left(1^{\text {st }}\right.$ and $3^{\text {rd }}$ quartiles respectively 19.5 and $\left.67.0 \mathrm{mS} / \mathrm{m}\right)$ in the $C$ horizon $(15$ samples). This contrast was expected due to the higher content of clay in the $\mathrm{AB}$ horizon. Based on these results, we assumed that the spatial variation of $E C_{a}$ measured by a FDEM instrument was mainly controlled by the clay content and the thickness of the $\mathrm{AB}$ soil horizon.

\subsubsection{Remote sensing: soil classification and terrain parameters}

The final soil classification derived in this study is presented in Figure 2.4. To reach an overall accuracy $>95 \%$, we collected training samples over the QBAO image on $\sim 25 \%$ of the study area. The CLAY class in Figure 2.4 corresponds to the soil type Bp, Bpc and Cp (Table 2.1 and Figure 2.2) and the CALCR class corresponds to the Pc class.

The summary statistics of the terrain parameters computed from the ASTER GDEM are presented in Table 2.5. Note that some terrain attributes produced outliers, which is inherent to this type of processing and can also be due to the GDEM quality. TPI was computed using a buffer of $500 \mathrm{~m}$.

Table 2.5: Summary statistics of the terrain parameters. SLOP: slope gradient; MEANC: mean curvature; PROFC: vertical or profile curvature; PLANC: plan curvature; TWI: topographic wetness index; SPI: stream power index; STI: sediment transport index; TPI: topographic position index.

\begin{tabular}{lrrrrrrrr}
\hline $\begin{array}{l}\text { Terrain } \\
\text { parameter }\end{array}$ & $\begin{array}{r}\text { SLOP } \\
(\%)\end{array}$ & $\begin{array}{r}\text { MEANC } \\
(1 / \mathrm{m})\end{array}$ & $\begin{array}{r}\text { PLANC } \\
(1 / \mathrm{m})\end{array}$ & $\begin{array}{r}\text { PROFC } \\
(1 / \mathrm{m})\end{array}$ & $\begin{array}{r}\text { SPI } \\
(-)\end{array}$ & $\begin{array}{r}\text { STI } \\
(-)\end{array}$ & $\begin{array}{r}\text { TWI } \\
(-)\end{array}$ & $\begin{array}{r}\text { TPI } \\
(-)\end{array}$ \\
\hline Min. & 0.0 & -0.2700 & -50.00 & -0.2800 & 0.0 & 0.00 & 4.3 & -10.1 \\
$1^{\text {st }}$ quart. & 1.8 & -0.0224 & -0.45 & -0.0231 & 3.8 & 0.18 & 7.1 & -1.8 \\
Median & 3.1 & 0.0001 & 0.34 & 0.0033 & 6.9 & 0.46 & 7.7 & 0.0 \\
Mean & 3.4 & 0.0016 & 0.20 & 0.0024 & 7.6 & 0.60 & 7.7 & 0.3 \\
$3^{\text {rd }}$ quart. & 4.9 & 0.0258 & 1.12 & 0.0296 & 10.7 & 0.88 & 8.2 & 2.1 \\
Max. & 41.4 & 0.5500 & 49.50 & 0.5600 & 97.7 & 11.78 & 13.0 & 20.6 \\
\hline
\end{tabular}


Figure 2.4: RS-based soil classification obtained by object-oriented fuzzy analysis of the QBAO image (see Figure 2.3) 


\subsubsection{Conversion of $E C_{a}$ data into CTT (calibration)}

Out of the 473 geophysical measurements of $E C_{a}$, we filtered out the data affected by soil salinization and the proximity of power lines (Figure 2.3) to obtain 436 EM-31 valid $E C_{a}$ measurements. Soil salinization was identified using Equation 2.1 in the surrounding of the PD3 and PD5 profiles (Figure 2.2) located within irrigated fields. We next converted the $E C_{a}$ dataset into CTT using MLM based statistical modeling (step 5, Figure 2.1). The $10 E C_{a}$ measurements carried out at each survey location showed to be highly correlated (Spearman correlation $>0.96$ ) and would thus introduce an undesirable collinearity effect in the regression models. We therefore selected the $E C_{a}$ measurement carried out with the EM31 on the ground in horizontal mode because its depth of penetration $(\sim 2.75 \mathrm{~m})$ was representative of the observed CTT range. Next, we established the calibration dataset (CTT-CAL) with 25 co-located pairpoints of CTT and $E C_{a}$ measurements to define statistical relationships between them (Figure 2.5). The boxplot of the CTT-CAL dataset evidences smaller value than the boxplot of the CTT-REF dataset (Figure 2.6). We built the LR model cal0 (Table 2.6) between $E C_{a}$ and CTT using the In transformation for both variables to integrate the outliers and to obtain homoscedasticity and normal distribution of the residuals. This LR model showed a good relationship ( $R_{a d j}^{2}$ equal to 0.68 ). Next, we built two MLR (cal1 and cal2) and three ANOCOVA (cal3, cal4 and cal5) models (Table 2.6) that integrated categorical and/or qualitative auxiliary predictors (RS derived soil classes and terrain parameters). Figure 2.5 presents graphically the cal 0 and cal 3 models (note that variables and regression parameters were back-transformed). All the models presented in Table 2.6 respected the assumptions of homoscedasticity, normality and no spatial auto-correlation. The MLR and ANOCOVA models showed lower BIC and AIC and higher $R_{a d j}^{2}$ (between 0.72 and 0.92) than the cal0 LR model. The boxplots of the Figure 2.6 indicated similar distribution of the fitted values and relatively low residuals (median of $\sim 0.20 \mathrm{~m}$ ). We thus used them to convert the $436 E C_{a}$ values into CTT in order to obtain the CTT-EC dataset (Figure 2.7, left). The distributions are similar to the CTT-CAL dataset. Note that the models cal2 and cal5, which incorporate the terrain parameters MEANC and PLANC, produced outliers with high CTT values $>4.0 \mathrm{~m}$ (not shown in the figure). The prediction interval was computed at a 95\% confidence interval and the upper and lower values are presented in Figure 2.8 (left) in the cal4 model. 


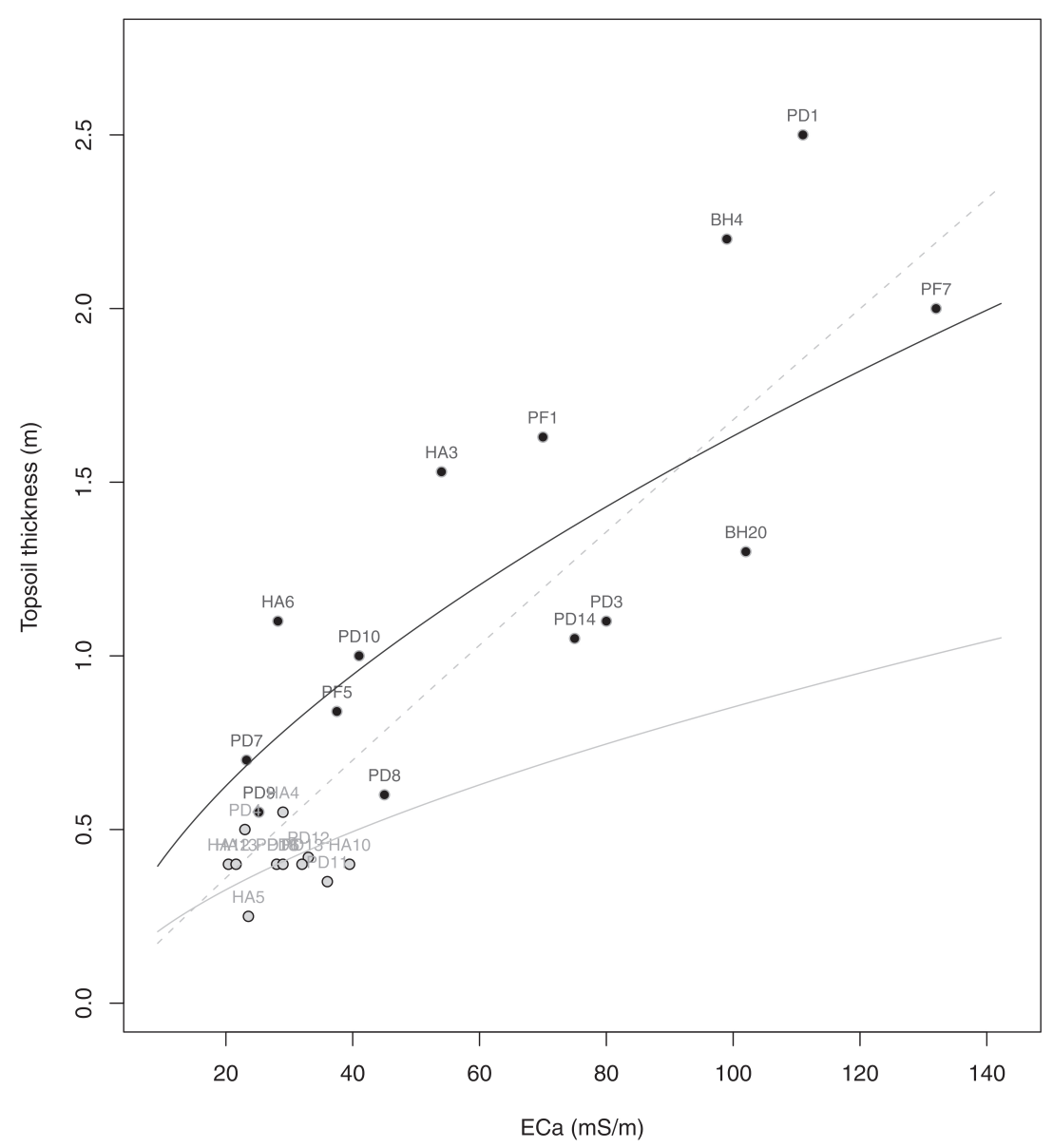

Figure 2.5: CTT and $E C_{a}$ relationship models (Table 2.6). Gray dash line: model cal0. Gray solid line: model cal3, calcrete soil class (CALCR). Black solid line: model cal3, clayey soil class (CLAY). Back-transformation of the regression curves was done following Equation (2.6). $E C_{a}$ was measured with the EM-31 device on the ground and in the horizontal position (depth of penetration $\sim 2.75 \mathrm{~m}$ ). 

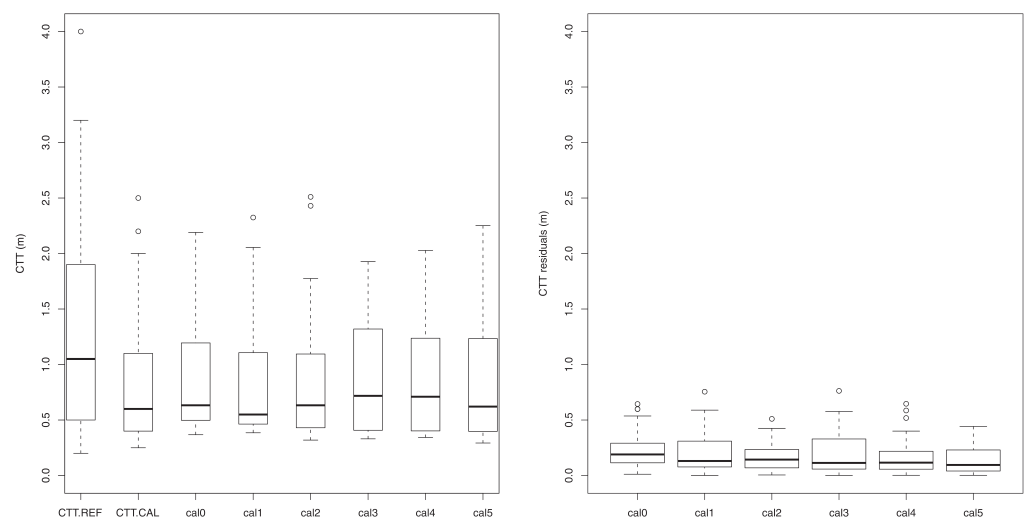

Figure 2.6: Left: boxplots of CTT-REF (61 data), CTT-CAL (25 data) and fitted values of the calibration models as per Table 2.6. Right: boxplots of the residuals in the calibration models
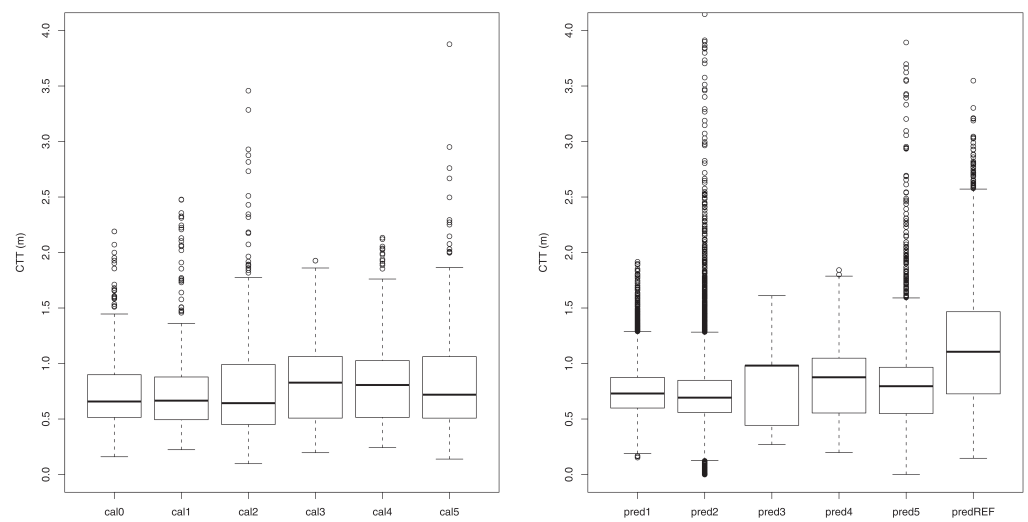

Figure 2.7: Left: boxplots of CTT-EC (436 data) obtained with the calibration models as per Table 2.6. Right: boxplots of CTT-ECpred raster (9615 data) obtained with the prediction models as per Table 2.7 

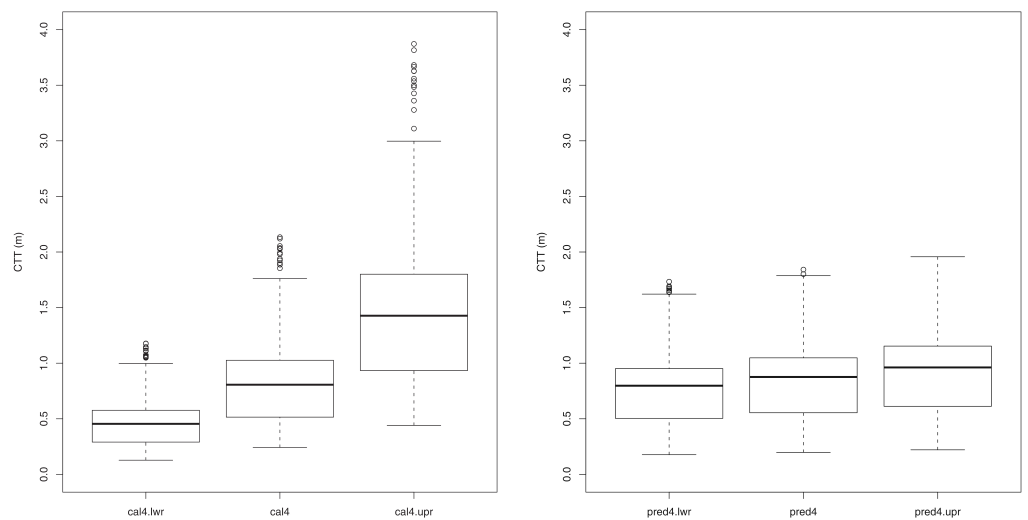

Figure 2.8: Boxplot of the lower and upper values obtained for the dataset CTT-EC (436 data) and CTT-ECpred raster (9615 data) respectively predicted with the models cal4 (Table 2.6) and pred4 (Table 2.7). 
Table 2.6: Calibration models based on CTT-CAL dataset and diagnostic results.

\begin{tabular}{|c|c|c|c|c|c|c|c|c|c|c|c|c|c|c|}
\hline \multirow[t]{3}{*}{ Model } & \multirow[t]{3}{*}{ Predictor } & \multirow{3}{*}{$\begin{array}{l}\text { Sig. } \\
\text { code }^{(a)} \\
\text { (slope/inter.) }\end{array}$} & \multirow[t]{3}{*}{ Slope } & \multirow[t]{3}{*}{ Inter. } & \multirow[t]{3}{*}{$R_{a d j}^{2}$} & \multirow[t]{3}{*}{ AIC } & \multirow[t]{3}{*}{ BIC } & \multicolumn{6}{|c|}{ Residuals diagnostic } & \multirow{3}{*}{$\begin{array}{l}\text { Selected } \\
\text { sub- } \\
\text { geostat. } \\
\text { MLM }\end{array}$} \\
\hline & & & & & & & & \multicolumn{2}{|c|}{$\begin{array}{l}\text { Homo- } \\
\text { scedasti- } \\
\text { city }^{(b)}\end{array}$} & \multicolumn{2}{|c|}{ Normality ${ }^{(c)}$} & \multicolumn{2}{|c|}{$\begin{array}{l}\text { No spatial } \\
\text { correlation }^{(d)}\end{array}$} & \\
\hline & & & & & & & & $\begin{array}{l}\text { Chi- } \\
\text { square }\end{array}$ & $\begin{array}{l}\text { p- } \\
\text { value }^{+}\end{array}$ & W & $\begin{array}{l}\mathrm{p}- \\
\text { value }^{+}\end{array}$ & $\begin{array}{l}\text { Moran's } \\
I\end{array}$ & $\begin{array}{l}\mathrm{p}- \\
\text { value }^{+}\end{array}$ & \\
\hline cal0 & $\ln \left(E C_{a}\right)$ & $+++/+++$ & 0.96 & -3.88 & 0.68 & 25.2 & 28.9 & 0.57 & 0.45 & 0.97 & 0.55 & 0.03 & 0.67 & LR \\
\hline \multirow{2}{*}{ cal1 } & $\ln \left(E C_{a}\right)$ & $+++/+++$ & 0.82 & \multirow{2}{*}{-3.36} & \multirow{2}{*}{0.72} & \multirow{2}{*}{23.0} & \multirow{2}{*}{27.8} & \multirow{2}{*}{0.53} & \multirow{2}{*}{0.47} & \multirow{2}{*}{0.98} & \multirow{2}{*}{0.81} & \multirow{2}{*}{-0.10} & \multirow{2}{*}{0.73} & \multirow{2}{*}{ MLR } \\
\hline & TPI & $-/+++$ & -0.06 & & & & & & & & & & & \\
\hline \multirow{3}{*}{ cal2 } & $\ln \left(E C_{a}\right)$ & $+++/+++$ & 0.92 & \multirow{3}{*}{-3.77} & \multirow{3}{*}{0.86} & \multirow{3}{*}{5.74} & \multirow{3}{*}{11.8} & \multirow{3}{*}{0.42} & \multirow{3}{*}{0.52} & \multirow{3}{*}{0.97} & \multirow{3}{*}{0.54} & & & \\
\hline & MEANC & $+++/+++$ & -9.11 & & & & & & & & & -0.11 & 0.72 & MLR \\
\hline & PLANC & $+++/+++$ & 0.22 & & & & & & & & & & & \\
\hline cal3 & $\ln \left(\left[E C_{a}\right]_{C A L C R}\right)$ & $+++/+++$ & 0.65 & -2.90 & 0.83 & 9.8 & 14.7 & 0.37 & 0.54 & 0.94 & 0.20 & -0.14 & 0.58 & ANOCOVA \\
\hline & $\ln \left(\left[E C_{a}\right]_{C L A Y}\right)$ & $+++/+++$ & & -2.31 & & & & & & & & & & \\
\hline & $\ln \left(\left[E C_{a}\right]_{C A L C R}\right)$ & $+++/+++$ & 0.52 & -2.60 & & & & & & & & & & \\
\hline cal4 & {$[\mathrm{TPI}]_{C A L C R}$} & $-/+++$ & -0.04 & & 0.85 & 7.7 & 13.8 & 0.58 & 0.44 & 0.96 & 0.38 & -0.29 & 0.17 & ANOCOVA \\
\hline & $\ln \left(\left[E C_{a}\right]_{C L A Y}\right)$ & $+++/+++$ & 0.52 & -2.00 & & & & & & & & & & \\
\hline & {$[\mathrm{TPI}]_{C L A Y}$} & $-/+++$ & -0.04 & & & & & & & & & & & \\
\hline & & & & & & & & & & & & Conti & nued on & next page \\
\hline
\end{tabular}


- continued from previous page

\begin{tabular}{|c|c|c|c|c|c|c|c|c|c|c|c|c|c|c|}
\hline \multirow[t]{3}{*}{ Model } & \multirow[t]{3}{*}{ Predictor } & \multirow{3}{*}{$\begin{array}{l}\text { Sig. } \\
\text { code }^{(a)} \\
\text { (slope/inter.) }\end{array}$} & \multirow[t]{3}{*}{ Slope } & \multirow[t]{3}{*}{ Inter. } & \multirow[t]{3}{*}{$R_{a d j}^{2}$} & \multirow[t]{3}{*}{ AIC } & \multirow[t]{3}{*}{ BIC } & \multicolumn{6}{|c|}{ Residuals diagnostic } & \multirow{3}{*}{$\begin{array}{l}\text { Selected } \\
\text { sub- } \\
\text { geostat. } \\
\text { MLM }\end{array}$} \\
\hline & & & & & & & & \multicolumn{2}{|c|}{$\begin{array}{l}\text { Homo- } \\
\text { scedasti- } \\
\text { city }^{(b)}\end{array}$} & \multicolumn{2}{|c|}{ Normality $^{(c)}$} & \multicolumn{2}{|c|}{$\begin{array}{l}\text { No spatial } \\
\text { correlation }^{(d)}\end{array}$} & \\
\hline & & & & & & & & $\begin{array}{l}\text { Chi- } \\
\text { square }\end{array}$ & $\begin{array}{l}\mathrm{p}- \\
\text { value }^{+}\end{array}$ & $\mathrm{W}$ & $\begin{array}{l}\mathrm{p}- \\
\text { value }^{+}\end{array}$ & $\begin{array}{l}\text { Moran' } \\
I\end{array}$ & value ${ }^{+}$ & \\
\hline \multirow{6}{*}{ cal5 } & $\ln \left(\left[E C_{a}\right]_{C A L C R}\right)$ & $+++/+++$ & 0.70 & & \multirow{6}{*}{0.92} & \multirow{6}{*}{-7.4} & \multirow{6}{*}{0.1} & \multirow{6}{*}{0.33} & \multirow{6}{*}{0.56} & \multirow{6}{*}{0.94} & \multirow{6}{*}{0.1} & \multirow{6}{*}{\multicolumn{2}{|c|}{-0.21}} & \multirow{6}{*}{ ANOCOVA } \\
\hline & {$[\mathrm{MEANC}]_{C A L C R}$} & ++/+++ & -6.11 & -3.18 & & & & & & & & & & \\
\hline & {$[\text { PLANC }]_{C A L C R}$} & $+++/+++$ & 0.17 & & & & & & & & & & & \\
\hline & $\ln \left(\left[E C_{a}\right]_{C L A Y}\right)$ & $+++/+++$ & 0.70 & & & & & & & & & & & \\
\hline & {$[\mathrm{MEANC}]_{C L A Y}$} & $++/+++$ & -6.11 & -2.74 & & & & & & & & & & \\
\hline & {$[\mathrm{PLANC}]_{C L A Y}$} & $+++/+++$ & 0.17 & & & & & & & & & & & \\
\hline
\end{tabular}

+ p-value indicates the probability that the null hypothesis (in this case the model assumption) arose purely by chance. A value of 0.05 indicates $95 \%$ of chance that the assumption is respected. (a) - Significance codes: 0 '+++' 0.001 '++' 0.01 '+' 0.05 '-' 0.1 'x' 1. . (b) - ncv.test in car (Fox and Weisberg, 2011). ${ }^{(c)}$ - Shapiro-Wilk test. ${ }^{(d)}$ - Moran's I (weight matrix computed following Lesch and Corwin, 2008). 


\subsubsection{CTT prediction at the catchment scale}

We predicted the CTT at the catchment scale on a grid of $25 \mathrm{~m}$ resolution using: (i) the CTT-EC datasets (Figure 2.7, left) computed in step 5 (Figure 2.1) to obtain the CTT-ECpred rasters (step 6a, Figure 2.1); and (ii) the CTT-REF dataset to obtain the CTT-REFpred raster (step 6b, Figure 2.1). For each CTT-EC dataset obtained with the respective calibration model (Table 2.6), we computed the prediction models listed in Table 2.7 using the same auxiliary variables as in the calibration model (excluding the $E C_{a}$ variable that was only available at the geophysical survey points and exclusively used for calibration). The model pred1 violated the assumption of homoscedasticity and was therefore not used in the prediction. In all the other models (pred2 to pred5), spatial-autocorrelation of the residuals was significant. We thus elaborated the variogram of the residuals and applied KED to predict CTT over the catchment. All the variograms of the residuals showed a relatively high nugget $(\sim 50 \%$ of the total sill, which was between 0.05 and $\left.0.15[\ln (m)]^{2}\right)$, that can be explained by the error associated with the $E C_{a}$ conversion into CTT. The ranges of the variograms of the models pred2 to pred 5 were between 403 and $850 \mathrm{~m}$. CTT-REFpred raster was built with the model predREF (ANOCOVA) that incorporated the same predictors as the model pred4 (Table 2.7). We next computed the ME, MAE and RMSE for all the CTTECpred rasters (i.e. pred2 to pred5) and for the CTT-REFpred raster using the same CTT-REF dataset. The summary statistics of the 5 CTT-ECpred and CTT-REFpred rasters, listed in Table 2.7, are shown in the boxplots in Figure 2.7 (right). Models pred2 and pred5 showed long positive tails with some CTT values $>4.0 \mathrm{~m}$ (not shown in the figure) and the highest RMSE (i.e. lowest accuracy). The model pred4 showed the lowest ME, MAE and RMSE, with values comparable to predREF. Note that ME of predREF (ANOCOVA model) is much lower $(0.1 \mathrm{~m})$ than the one of the models pred2 to pred5 (KED models) since it corresponds to the mean of the residuals of the ANOCOVA model (that assumes normal distribution of the residuals with 0 mean). The prediction intervals computed at the 95\% confidence interval are presented in Figure 2.8 (right) for the pred 4 model. Figures 2.9 and 2.10 show the CTT maps obtained with the models predREF and pred 4 respectively. The two patterns are nearly identical, due to the inclusion of the same auxiliary variables (TPI and RS-derived soil classes) in the prediction models. The CTT values of the pred4 model estimated using the geophysical data are lower than the values of the predREF model, because its calibration dataset (CTT-CAL) has lower CTT values than the CTT-REF dataset. 
Table 2.7: Prediction models based on CTT-EC (pred1 to pred5) and CTT-REF (predREF) datasets, and diagnostic results.

\begin{tabular}{|c|c|c|c|c|c|c|c|c|c|c|c|c|c|c|}
\hline \multirow[t]{3}{*}{ Model } & \multirow{3}{*}{$\begin{array}{l}\text { Cal. } \\
\text { model } \\
\text { Table } 2.6\end{array}$} & \multirow{3}{*}{ Predictor } & \multirow{3}{*}{$\begin{array}{l}\text { Sig. } \\
\text { code }^{(a)} \\
\text { (slope/inter.) }\end{array}$} & \multirow[t]{3}{*}{ Slope } & \multirow[t]{3}{*}{ Inter. } & \multirow[t]{3}{*}{$R_{a d j}^{2}$} & \multirow[t]{3}{*}{ AIC } & \multirow[t]{3}{*}{ BIC } & \multicolumn{6}{|c|}{ Residuals diagnostic } \\
\hline & & & & & & & & & \multicolumn{2}{|c|}{$\begin{array}{l}\text { Homo- } \\
\text { scedasti- } \\
\text { city }(b)\end{array}$} & \multicolumn{2}{|c|}{ Normality $^{(c)}$} & \multicolumn{2}{|c|}{$\begin{array}{l}\text { No spatial } \\
\text { correlation }^{(d)}\end{array}$} \\
\hline & & & & & & & & & $\begin{array}{l}\text { Chi- } \\
\text { square }\end{array}$ & $\begin{array}{l}\text { p- } \\
\text { value }^{+}\end{array}$ & $\mathrm{W}$ & $\begin{array}{l}\mathrm{p}- \\
\text { value }^{+}\end{array}$ & $\begin{array}{l}\text { Moran' } \\
I\end{array}$ & $\begin{array}{l}\text { s p- } \\
\text { value }\end{array}$ \\
\hline pred1 & cal1 & TPI & $+++/+++$ & -0.34 & -0.08 & 0.34 & 376.5 & 388.7 & 27.4 & $1 \mathrm{E}-7$ & 0.99 & 0.04 & 0.59 & 0.00 \\
\hline \multirow[t]{2}{*}{ pred2 } & \multirow[t]{2}{*}{ cal2 } & MEANC & $+++/+++$ & -12.42 & \multirow{2}{*}{-0.41} & \multirow{2}{*}{0.58} & \multirow{2}{*}{464.8} & \multirow{2}{*}{481.1} & \multirow{2}{*}{0.11} & \multirow{2}{*}{0.74} & \multirow{2}{*}{1.00} & \multirow{2}{*}{0.15} & \multirow{2}{*}{0.57} & \multirow{2}{*}{0.00} \\
\hline & & PLANC & $+++/+++$ & 0.22 & & & & & & & & & & \\
\hline \multirow[t]{2}{*}{ pred3 } & \multirow[t]{2}{*}{ cal3 } & CALCR & N.A./+++ & N.A. & -0.83 & \multirow{2}{*}{0.67} & \multirow{2}{*}{87.5} & \multirow{2}{*}{99.8} & \multirow{2}{*}{0.81} & \multirow{2}{*}{0.37} & \multirow{2}{*}{1.00} & \multirow{2}{*}{0.19} & 0.59 & 0.00 \\
\hline & & CLAY & N.A./+++ & N.A. & -0.02 & & & & & & & & & \\
\hline pred4 & cal4 & {$[\mathrm{TPI}]_{C A L C R}$} & $+++/+++$ & -0.05 & -076 & 0.76 & -404 & -241 & 6.54 & 0.01 & 100 & 0.66 & 0.60 & 000 \\
\hline & & {$[\mathrm{TPI}]_{C L A Y}$} & $+++/+++$ & -0.02 & & & & & & & & & & \\
\hline pred5 & cal5 & {$[\mathrm{MEANC}]_{C A L C R}$} & $+++/+++$ & -8.20 & -0 & & & & & & & & & \\
\hline & & {$[\text { PLANC }]_{C A L C R}$} & $+++/+++$ & 0.17 & & 0.70 & 204.0 & 224.4 & 0.35 & 0.56 & 1.00 & 0.67 & 0.58 & 0.00 \\
\hline & & {$[\text { MEANC] }]_{C L A Y}$} & $+++/+++$ & -8.20 & -014 & & & & & & & & & \\
\hline & & {$[\text { PLANC }]_{C L A Y}$} & $+++/+++$ & 0.17 & -0.14 & & & & & & & & & \\
\hline predRE & *N.A. & {$[\mathrm{TPI}]_{C A L C R}$} & $+++/+++$ & -0.11 & $-0,49$ & 0.56 & 1059 & 1149 & 101 & 032 & 098 & 017 & 012 & 015 \\
\hline & & {$[\mathrm{TPI}]_{C L A Y}$} & +++/+++ & 0.27 & & & & & & & & & & \\
\hline
\end{tabular}


- continued from previous page

\begin{tabular}{llllrr}
\hline Model & $\begin{array}{l}\text { Cal. } \\
\text { model } \\
\text { Table 2.6 }\end{array}$ & $\begin{array}{l}\text { Selected } \\
\text { sub-geostat. } \\
\text { MLM }\end{array}$ & $\begin{array}{r}\text { ME } \\
(\mathrm{m})\end{array}$ & $\begin{array}{r}\text { MAE } \\
(\mathrm{m})\end{array}$ & $\begin{array}{r}\text { RMSE } \\
(\mathrm{m})\end{array}$ \\
\hline pred1 & cal1 & LR & $\begin{array}{l}\text { mod. not valid: } \\
\text { heteroscedast. }\end{array}$ \\
\hline pred2 & cal2 & $\begin{array}{l}\text { KED (det. } \\
\text { model: MLR) }\end{array}$ & 0.47 & 0.84 & 1.09 \\
\hline pred3 & cal3 & $\begin{array}{l}\text { KED (det. } \\
\text { model: } \\
\text { ANOVA) }\end{array}$ & 0.48 & 0.68 & 0.97 \\
\hline pred4 & cal4 & $\begin{array}{l}\text { KED (det. } \\
\text { model: } \\
\text { ANOCOVA) }\end{array}$ & 0.41 & 0.61 & 0.88 \\
\hline pred5 & cal5 & $\begin{array}{l}\text { KED (det. } \\
\text { model: }\end{array}$ & 0.49 & 0.75 & 1.00 \\
\hline ANOCOVA) & & & \\
\hline
\end{tabular}

N.A.: not applicable. ${ }^{+}$p-value indicates the probability that the null hypothesis (in this case the model assumption) arose purely by chance. A value of 0.05 indicates $95 \%$ of chance that the assumption is respected. ${ }^{*}$ the dependent variable in this model is CTT-REF dataset, while in the previous models it is CTT-EC. (a) - Significance codes: 0 '+++' 0.001 '++' 0.01 '+' 0.05 '-' 0.1 'x' 1. (b) - ncv.test in car (Fox and Weisberg, 2011). ${ }^{(c)}$ - Shapiro-Wilk test. ${ }^{(d)}$ - Moran's I (weight matrix computed following Lesch and Corwin (2008)). 


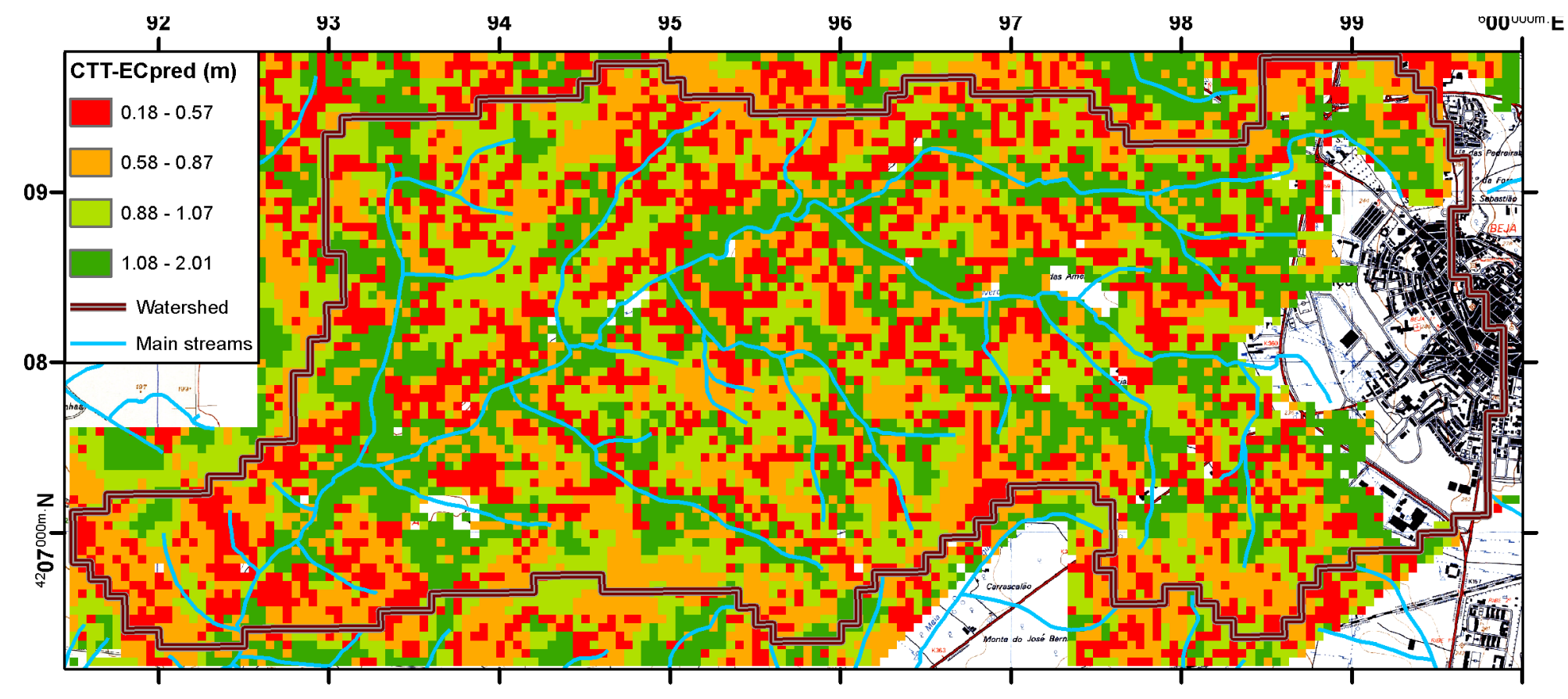

Figure 2.10: CTT map obtained with pred4 (CTT-ECpred raster) model (Table 2.7). CTT classes are shown using quartiles 


\subsection{Discussion and conclusion}

We presented a data-integration method to predict the CTT at the catchment scale based on: (i) invasive sampling; (ii) surface geophysics; (iii) RS imagery; and (iv) MLM. The invasive sampling was used as a reference dataset, the geophysics was applied to reduce the number of costly and time-consuming invasive field measurements and the MLM was combined with the RS imagery and geophysical data to integrate the CTT variability at the catchment scale. We predicted CTT at the catchment scale using 436 EM-31 $E C_{a}$ measurement points calibrated with 25 invasive CTT measurements. The calibration and prediction processes were done using MLM and respective model diagnostics that allowed the integration of the RS-derived soil classes and terrain attributes in the statistical modeling. We also predicted CTT using the 61 invasive CTT measurements of the CTT-REF dataset and the RS-derived auxiliary variables. We compared this prediction with the CTT prediction based on geophysical data.

We applied expedite, spatially- and cost-efficient RS methods based on the interpretation of high resolution satellite and airborne imagery to derive soil classes and terrain parameters. Instead of using the available but unreliable soil map presented in Figure 2.2, we utilized a more representative soil classification obtained from the interpretation of two fused high resolution images ( $\mathrm{QB}$ and $\mathrm{AO}$ ) acquired in different seasons. The soil classification method was based on a multi-resolution segmentation of image objects and fuzzy logic (Benz et al., 2004). This supervised classification corresponds to a semi-manual extraction of the image features, as it was necessary to digitize the training samples of $25 \%$ of the QBAO image area to reach the target classification accuracy (95\%). This method has the advantage of being repeatable and quantitatively assessed. However, it does require technical knowledge and it can be time consuming. The terrain parameters were computed from the ASTER GDEM. Although the geomorphological classification of the area into landforms can be done by combining terrain parameters, it is subjective since the classes of the parameters to be related to landforms are arbitrary. To avoid the introduction of artificial correlation, we preferred to directly use the parameters in the statistical modeling. However, the morphometric terrain parameters MEANC, PLANC and PROFC, showed that outliers had a strong influence upon the statistical modeling. This is because the computing of the morphometric and the hydrological parameters integrate the elevation gradients between the actual cell and its 8 surrounding cells. They are thus very sensitive to artifacts in the ASTER GDEM, despite the filtering of such errors is included in the terrain attribute algorithm. In contrast to the morphometric and hydrological parameters, the TPI computing is based on a large number of cells obtained by a user-defined buffer range (in this study $500 \mathrm{~m}$ ). TPI is thus less sensitive to the GDEM artifacts and better depicts the terrain geomorphology.

The geophysical data acquisition with the EM-31 device was quite efficient and adequate for the high electrical conductivity of the CTT. 
However, in more resistive conditions the geophysical survey would need to be adapted by substituting the FDEM method for another one, for instance the ER, which however would imply a reduction of efficiency. In our study case, we performed 436 EM-31 survey locations along geophysical transects transversal to the drainage features of the catchment (Figure 2.3) to capture the CTT spatial variability. In our first attempt to extract the CTT from the $E C_{a}$ data (Francés, 2008), we used $10 E C_{a}$ measurements at each survey location to constrain the geophysical data inversion, which in turn allowed us to retrieve the depth-wise $E C_{a}$ soil profiles. However, the extraction of the CTT based on the interpretation of the $E C_{a}$ inverted profiles, guided by the CTT field observations, proved to be highly subjective, not repeatable, and time-consuming. In addition, the uncertainties were not quantifiable. As that method was not suitable for the objective of this study, instead we implemented a new approach based on the statistical modeling of the relationship between CTT and $E C_{a}$. The $10 E C_{a}$ measurements were highly inter-correlated and had similar correlation with the CTT. To avoid collinearity effect in the statistical models, we selected only one representative $E C_{a}$ measurement made with the EM-31 on the ground with horizontal coil, corresponding to the penetration depth of $\sim 2.75 \mathrm{~m}$. As the LR between CTT and $E C_{a}$ showed a good relationship ( $R_{a d j}^{2}$ of 0.68 ), the statistical modeling was suitable to convert the $E C_{a}$ data into CTT. In further studies we recommend the acquisition of two $E C_{a}$ measurements at each survey location instead of 10. Two measurements permit to verify the consistency of the field measurements and to increase the number of survey locations, which is highly valuable for studies at catchment scales that require large data coverage.

For the calibration of the $E C_{a}$ data and the CTT prediction, we tested several statistical models derived from the MLM approach (Table 2.6 and Table 2.7) using several combinations of the geophysical data and the RS-derived auxiliary variables. We selected the most appropriate calibration and prediction models by verifying the assumptions with diagnostic tools and by assessing the goodness of fit. The validation of the statistical models, in particular the assumptions of homoscedasticity and normality of the residuals, allowed us to take into account the error propagation throughout the modeling process. The calibration of the $E C_{a}$ data with the 25 CTT and $E C_{a}$ pair-points (CTT-CAL) provided good results, with $R_{a d j}^{2}$ equal to 0.85 for the model cal4 (Table 2.6). The best CTT-ECpred prediction model (RMSE of $0.88 \mathrm{~m}$ ) was obtained with KED and ANOCOVA model (pred4) that integrated the RS-derived soil classes and TPI as auxiliary variables (Table 2.7). We also computed the CTT prediction model predREF, exclusively using the 61 invasive CTT measurements of the CTT-REF dataset (i.e. without geophysics data and calibration process). This was done using ANOCOVA model that integrated the RS-derived soil classes and TPI as auxiliary variables (Table 2.7). For this reason, the two maps (Figures 2.9 and 2.10), i.e. CTT-ECpred derived from cal 4 and CTT-REFpred derived from predREF, have a similar pattern that successfully depict the spatial variability of the CTT along 
the geomorphologic catchment features. They show similar RMSE $(0.88 \mathrm{~m}$ for pred 4 and $0.76 \mathrm{~m}$ for predREF). However, CTT-ECpred derived from pred4 showed lower CTT values than CTT-REFpred. This is because the calibration dataset (CTT-CAL) used to convert the geophysical data into CTT also showed lower values than the reference observation dataset (CTT-REF) and because the $\ln$ transformation of the estimated variables had an attenuation effect on higher values. The sampling scheme of $E C_{a}$ and invasive CTT measurements were based on purposive sampling. This option was imposed because most of the invasive CTT measurements were inherited from a previous study (39 data points). We complemented this dataset by arbitrarily selecting 22 other points along the geophysical transects in order to cover the geomorphologic catchment features. A more elaborated sampling scheme presented by Hengl et al. (2003b) based on the analysis of the feature and geographical spaces of auxiliary variables could be attempted in future studies. However, as the relationship between the target variable and the predictor is unknown a-priori, the sampling can be biased by an incorrect selection of uncorrelated predictors.

In this study, the objective was to derive efficiently a map that depicts the CTT spatial variability at the catchment scale. The CTT was recognized as a major controlling factor in the hydrological processes and was used as input for a hydrological distributed model (Chapter 5, Francés and Lubczynski, 2015) that computes groundwater recharge. This model follows a lumped-parametric approach, in which the reservoir parameters lose their physical meaning and the model calibration corresponds to parameter fitting. As the CTT, in conjunction with the soil hydraulic parameters, are optimized during the calibration process, the eventual underestimation of the CTT obtained with the best statistical prediction model (pred4) is not critically relevant for the performance of the hydrological model. This implies that CTT-ECpred using pred4 model can be considered as good as the CTT-REFpred and that the presented methodology is suitable for hydrological and environmental studies. In hydrology, where catchments often need to be investigated over large areas, the proposed method could be particularly useful, because it minimizes the labor-intensive field data acquisition and provides useful and acceptable results. 


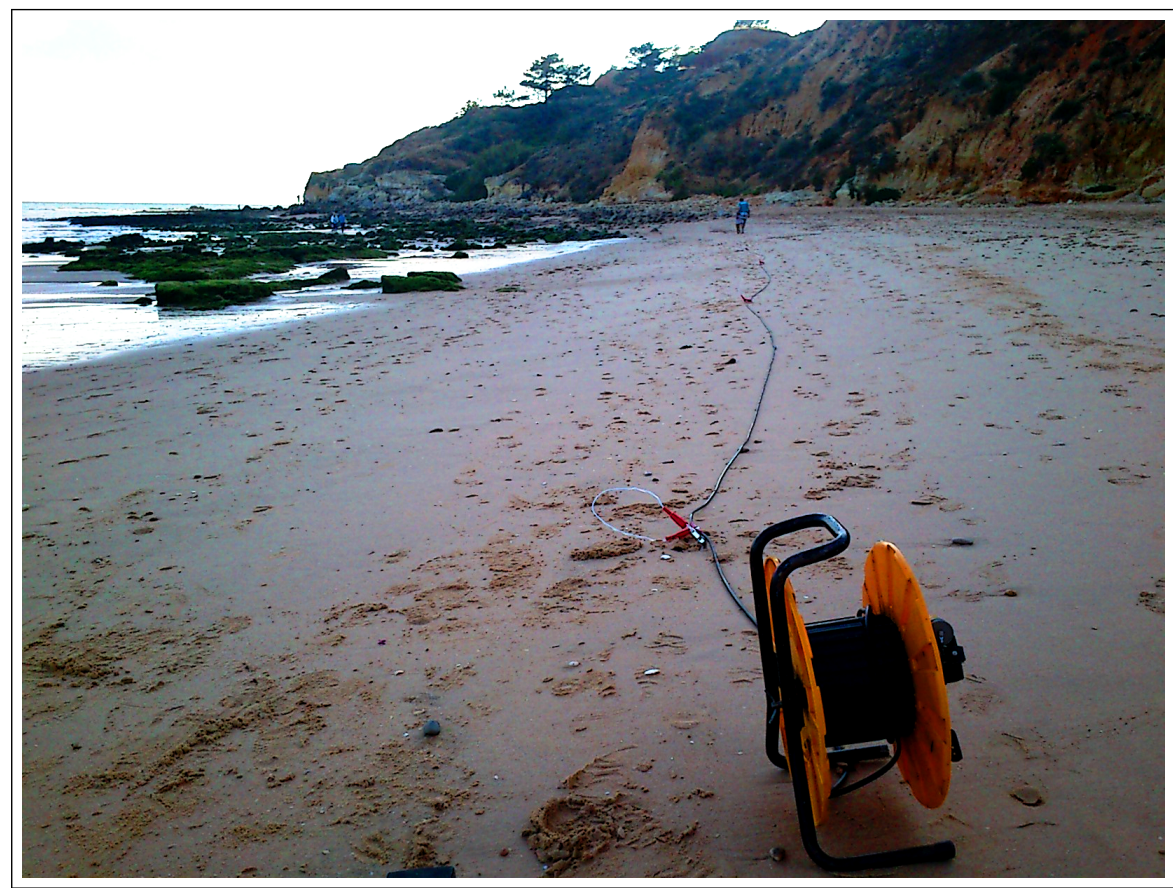

Electrical resistivity tomography survey on the beach of Olhos de Água (Albufeira, Algarve, Portugal). 



\section{Contributions of hydrogeophysics to the hydrogeological conceptual model of the Albufeira-Ribeira de Quarteira coastal aquifer in Algarve, Portugal}

\subsection{Introduction}

Coastal areas aggregate $\sim 50 \%$ and $\sim 75 \%$ of the world's and Portugal population respectively (Creel, 2003; Presidência do Conselho de Ministros, 2009). They concentrate economic activities related to harbors and maritime transport, being also often propitious to the development of beach tourism. In these areas, water supply to domestic, agricultural, industrial and tourism sectors is generally provided by coastal aquifers (CA). The increase of permanent population and tourists during dry season constitutes a tremendous pressure on the CA groundwater resources. Besides threats common to any aquifer, such as overexploitation, pollution by waste water or leaching of contaminates, decrease of groundwater recharge due to climate change and soil impermeabilization in urban areas, CA are also vulnerable to seawater intrusion and upconing that cause freshwater salinization (Post, 2005; Dörfliger, 2013).

The protection of groundwater resources in coastal areas and their sustainable management, in conjunctive use with other water resources (e.g. surface water, desalinized seawater), require the understanding of the CA hydrogeology. Since the late XIX century with the work of Baden Ghijben (1888-1889), complemented by Herzberg (1901), hydrogeologists developed tools to study CA, such as analytical models (see

This chapter is based on: Contributions of hydrogeophysics to the hydrogeological conceptual model of the Albufeira-Ribeira de Quarteira coastal aquifer in Algarve, Portugal. Francés, A. P., E. Ramalho, J. Fernandes, M. Groen, R. Hugman, M. A. Khalil, J. De Plaen, and F. A. Monteiro Santos (2015), Hydrogeology Journal, accepted (April 2015) 
examples in Fetter, 2001; Oude Essink, 2001; Dingman, 2002), numerical models of variable-density flow and solute transport (Bakker and Schaars, 2005; Langevin et al., 2007), field data acquisition methods including airborne and ground-based geophysics (Auken et al., 2010; Henderson et al., 2010; Kok et al., 2010; Faneca Sanchez et al., 2012) and automatic data acquisition systems that allow high-resolution monitoring of groundwater level, temperature and salinity (Poulsen et al., 2010; Dörfliger, 2013). These tools allowed to identify and map CA occurrences (Fleury et al., 2007; Custodio, 2010, and other papers of the "Saltwater and freshwater interactions in coastal aquifers" issue of Hydrogeology Journal), as well as to a better understanding of their dynamics (Aunay et al., 2007; de Montety et al., 2008; Oude Essink et al., 2010; Post and Abarca, 2010; Dörfliger, 2013; Werner et al., 2013) and to improve their management (Aunay et al., 2006; Barazzuoli et al., 2008). However, there are still scientific challenges to be solved in order to support the resolution of critical situations. Following Post (2005), these challenges are grouped in: (i) conceptual issues; (ii) mathematical models; and (iii) subsurface characterization. Indeed, the theoretical conceptual model of the steady-state freshwater-saltwater interface (FSWI) is more an exception than a rule. The position of the FSWI is ruled by highly dynamic processes, superimposed on the regional and local geology, and varies spatio-temporally. In some cases, it results in deep submarine groundwater discharge (SGD) and in other cases in continental brackish springs with elevation above seawater level. It was shown that the interface position and fresh and saline groundwater distribution is also a result of sea transgression and regression at long time scale, i.e. hundreds of thousands of years (Post, 2005; Fleury et al., 2007; Post et al., 2013). Multilayered aquifers separated by aquitard and aquiclude, as well as geological settings such as karstification, complicate the theoretical framework. Mathematical models of variable-density groundwater flow may help in understanding the aquifer dynamics and support management decisions. Such models require parametric and geometry knowledge of the aquifer obtained by subsurface characterization methods. These subsurface data are generally scarce because invasive methods such as borehole drilling and associated aquifer tests are expensive and time-consuming. Moreover, the hydrogeological information is often missing from the existing commercial boreholes. Non-invasive hydrogeophysical methods of subsurface data acquisition provide an alternative or a complement to direct observations, although the measured geophysical parameter has to be hydrogeologically interpreted. As each hydrogeophysical method has its own characteristics and capability, their complementary use covers a wide range of hydrogeological problems, including those specific to CA.

In this study, hydrogeophysical methods were applied to contribute to the development of the hydrogeological conceptual model of the Albufeira-Ribeira de Quarteira (ARQ) CA (Algarve, southern Portugal). In particular, the specific objectives were: (i) to identify the water-bearing layers and aquitards and relate them with the geological formations; and (ii) to detect the FSWI position along the coast line. The hydrogeophysical 
results were interpreted using a regional piezometric map and borehole lithological logs as auxiliary information. Finally, the current data were integrated with offshore data from other studies to extend the hydrogeological conceptual model to the offshore proximal shelf and explain the spatial distribution of the inter- and subtidal groundwater discharge.

\subsection{Study area}

The study area is located in the Algarve region, the southernmost province of Portugal (Figure 3.1), characterized by a warm Mediterranean, semi-arid climate. The Algarve mean annual temperature and precipitation are around $17^{\circ} \mathrm{C}$ and $600 \mathrm{~mm}$, respectively. The precipitation regime is irregular, having intermittent periods with heavy rains in the winter and a long dry period in the summer.

The southern coast of Portugal is characterized by an important development of the tourism sector, particularly demanding in water supply due to the irrigation of numerous hotels, resorts and golf courses flanking the coast. Furthermore, water abstraction for agricultural purpose is also significant. Vegetation is mainly composed by citrus trees used for cultivation and other commercially attractive trees such as olive, almond and cork oak trees.

The geomorphology of the Algarve littoral is characterized in the east by a shoreline of sandy deposits and in the west by a limestonedominated platform forming a cliff. Inland, the area can be described as a coastal plain with low relief, limited at north by Jurassic limestones with a more pronounced relief. Characteristic karstic features such as dolines and dry valleys can be observed.

\subsubsection{Regional geology and hydrogeology}

The onshore Meso-Cenozoic Algarve basin is an east-west trending sedimentary basin filled with $\sim 4000$ m thick sediments lying on Carboniferous schists and greywackes. Discordantly on the paleozoic substratum, sandstones and conglomerates of the "Arenitos de Silves" deposited during the middle to upper Triassic, followed by the "Complexo Pelítico Carbonatado-Evaporítico". This sedimentary cycle ends with a volcanicsedimentary complex related to the first rifting phase (Manuppella, 1992). These formations, together with the Carboniferous formations, constitute an impermeable substratum.

During the Lias, limestones and dolomites (600 m thick) deposited in central Algarve, extending from Lagoa to Tavira. The transition to the Dogger is marked by an erosional phase followed by deposition of oolitic limestones and marls (350 to $500 \mathrm{~m}$ of thickness). Lias and Dogger formations are the most important aquifers of the region, being characterized by favorable hydraulic properties, large thickness and large outcrops (e.g. M5 aquifer in Figure 3.1). Moreover, these formations were 
affected by an intense secondary dolomitization process that produced secondary porosity and permeability (Almeida et al., 2000).

During the Malm, mainly in the upper Oxfordian-lower and middle Kimmeridgian, the variation between sedimentary environments increased due to a second phase of rifting. From the upper Kimmeridgian on, an inner platform environment developed, promoting thick regressive carbonate sequences with maximum expression in the Tithonian-Cretaceous. These formations have favorable hydrogeological properties and support important aquifer systems, namely the Albufeira-Ribeira de Quarteira (ARQ) aquifer system (M6 in Figure 3.1, see also Table 3.1).

The transition to the Cretaceous is marked by a marine and fluvial sedimentation, while in the lower Aptian the subsidence increases and begins a transgressive episode due to the North Atlantic expansion. The lower Cretaceous sediments are composed by marls, limestones, dolostones and a few sandy and conglomeratic levels (Rey, 2006, see Table 3.1). Hydrogeologically, they are less favorable than the Jurassic formations, but can in some cases support aquifers when sufficiently thick and extensive.

The Lagos-Portimão Formation (Table 3.1) corresponds to deposits of carbonate platform, developed during a long time span (lower Burdigalian to upper Serravallian). It overlies the Carboniferous, Jurassic, Cretaceous and possible Paleogene units with angular unconformity, stratigraphical hiatuses or paraconformaties (Pais et al., 2000). Hydrogeologically, this highly karstified formation is very productive and constitutes an important source for freshwater supply and irrigation (Almeida et al., 2000). Next to this formation, the sedimentation conditions passed from carbonate to siliciclastic environments during the lower Tortonian with the deposition of the Olhos de Água Sands (Pais et al., 2000).

The Faro-Quarteira Sands (Table 3.1) corresponds to quaternary continental sedimentation of siliciclastic deposits with reddish colors $(50 \mathrm{~m}$ maximum thickness). This formation covers most of the Algarve region, being largely exploited for irrigation purposes through traditional large wells called "noras". 


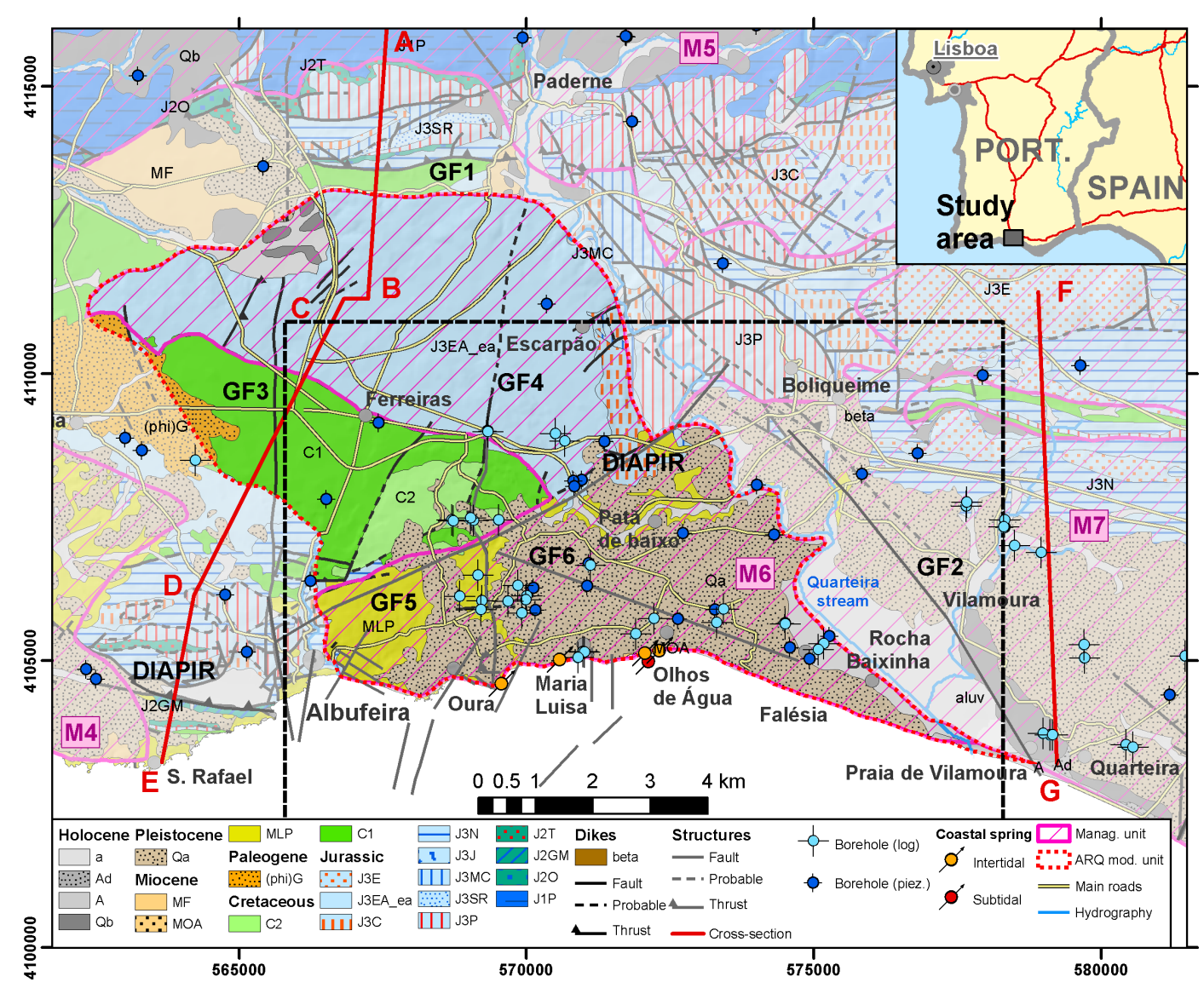

Figure 3.1: Geological map of the study area adapted from Manuppella (1992). The dark grey structural map is from Terrinha et al. (2014). The black, dashed rectangle indicates the location of Figure 3.3. Aquifer management units (Almeida et al., 2000): M4 - Ferragudo - Albufeira; M5 - Querenća - Silves; M6 - Albufeira - Ribeira de Quarteira; M7 - Quarteira. Geological faults: GF1 Sagres-Algoz-Vila Real de Santo António flexure; GF2 - Quarteira fault; GF3 Albufeira fault; GF4 - Oura fault; GF5 - Mosqueira fault; GF6 - Olhos de Água fault. Coordinates system (also in next figures): UTM N29, WGS 84. 


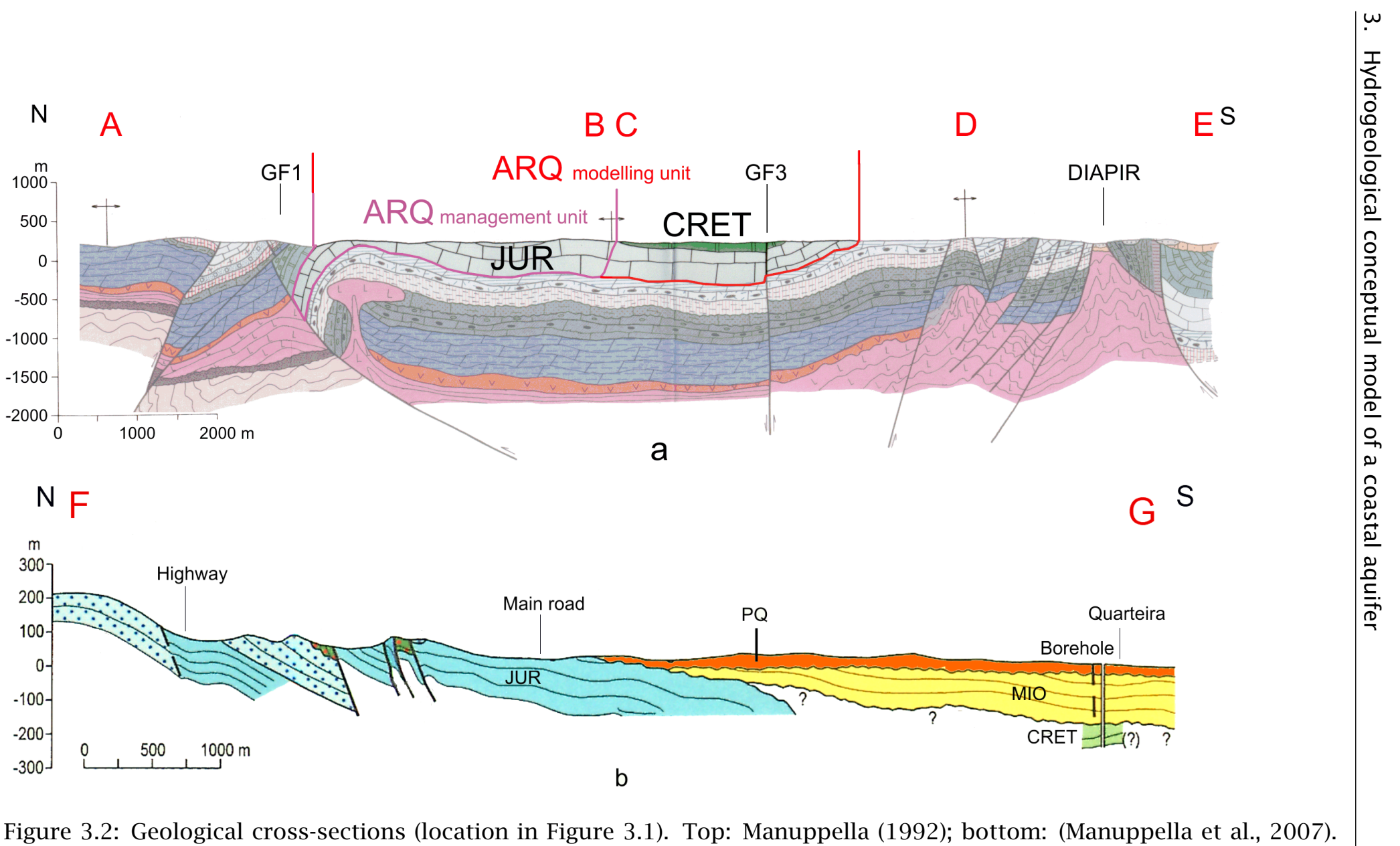

Figure 3.2: Geological cross-sections (location in Figure 3.1). Top: Manuppella (1992); bottom: (Manuppella et al., 2007). Abbreviations explained in Table 3.1 . 
Table 3.1: Lithostratigraphy and hydrostratigraphy of the study area adapted from Almeida and Lourenço da Silva (1990); Manuppella (1992); Almeida et al. (2000); Pais et al. (2000); Rey (2006).

\begin{tabular}{|c|c|c|c|c|c|c|c|}
\hline Epoch & Age & Symb. & Formation & Lithology & Thick. & $\begin{array}{l}\text { Main } \\
\text { lithology }\end{array}$ & $\begin{array}{l}\text { Hydrostrati- } \\
\text { graphy }\end{array}$ \\
\hline Pleistocene? & $?$ & Qa & Faro-Quarteira sands & $\begin{array}{l}\text { Clayey sandstones with } \\
\text { pebbles intercalations }\end{array}$ & \multirow[t]{2}{*}{$10-30 \mathrm{~m}$} & \multirow[t]{2}{*}{ Detrital } & \multirow[t]{2}{*}{ Aquitard PQ } \\
\hline Pliocene & Piazencian & MOA & Olhos de Água sands & Feldspathic sands, pebbles & & & \\
\hline Miocene & $\begin{array}{l}\text { Burdigalian- } \\
\text { Serravian }\end{array}$ & MLP & $\begin{array}{l}\text { Lagos- } \\
\text { Portimão } \\
\text { Forma- } \\
\text { tion }\end{array}$ & $\begin{array}{l}\text { Biocalcarenites, yellow or } \\
\text { pink, sandy limestones and } \\
\text { sandstones }\end{array}$ & $30-85 \mathrm{~m}$ & Limestone & Aquifer MIO \\
\hline \multirow[t]{3}{*}{$\begin{array}{l}\text { Lower } \\
\text { Cretaceous }\end{array}$} & Aptian & $\mathrm{C} 2$ & $\begin{array}{l}\text { Porto de Mós marls and } \\
\text { limestones; Luz marls; } \\
\text { Limestones and marls } \\
\text { with Palorbitolina len- } \\
\text { ticularis }\end{array}$ & $\begin{array}{l}\text { Marls and limestones; } \\
\text { Green and purple marls; } \\
\text { Massive limestones and } \\
\text { marls, brownish }\end{array}$ & $100 \mathrm{~m}$ & \multirow[t]{2}{*}{$\begin{array}{l}\text { Marl and } \\
\text { limestone }\end{array}$} & \multirow[t]{3}{*}{$\begin{array}{l}\text { Aquitard } \\
\text { CRET }\end{array}$} \\
\hline & Barremian & $\mathrm{C} 2$ & $\begin{array}{l}\text { Marls with Choffatella } \\
\text { decipiens }\end{array}$ & $\begin{array}{l}\text { Marls, sandstones, marly } \\
\text { limestones and dolomites }\end{array}$ & $50 \mathrm{~m}$ & & \\
\hline & Berriasian & $\mathrm{C} 1$ & $\begin{array}{l}\text { Limestones with Choffa- } \\
\text { tella pyrenaica; Sobral } \\
\text { sandstones; Limestones } \\
\text { with Trocholina; Pur- } \\
\text { beck facies marls and } \\
\text { limestones }\end{array}$ & $\begin{array}{l}\text { Limestones and marls, } \\
\text { yellow to purple; } \\
\text { Sandstones with quartz } \\
\text { gravels, pebbles and } \\
\text { pelites, reddish to purple; } \\
\text { Oolithic limestones; } \\
\text { Limestones, conglomerates, } \\
\text { marls and dolomites }\end{array}$ & $100 \mathrm{~m}$ & Detrital & \\
\hline
\end{tabular}




\begin{tabular}{|c|c|c|c|c|c|c|c|c|}
\hline Epoch & Age & Symb. & \multicolumn{2}{|l|}{ Formation } & Lithology & Thick. & $\begin{array}{l}\text { Main } \\
\text { lithology }\end{array}$ & $\begin{array}{l}\text { Hydrostrati- } \\
\text { graphy }\end{array}$ \\
\hline \multirow[t]{7}{*}{$\begin{array}{l}\text { Upper } \\
\text { Jurassic }\end{array}$} & Titonian & J3A & \multicolumn{2}{|c|}{$\begin{array}{l}\text { Limestones with } A \text {. lusit- } \\
\text { anica }\end{array}$} & $\begin{array}{l}\text { Massive limestones whitish } \\
\text { with calciclastic } \\
\text { intercalations }\end{array}$ & $650 \mathrm{~m}$ & $\begin{array}{l}\text { Limestone } \\
\text { and } \\
\text { dolomite }\end{array}$ & Aquifer JUR \\
\hline & \multirow[t]{5}{*}{ Kimmeridgia } & $\begin{array}{l}\text { J3- } \\
\text { EA }\end{array}$ & \multirow[t]{3}{*}{$\begin{array}{l}\text { Escarpão } \\
\text { limestones }\end{array}$} & $\begin{array}{l}\text { Transition } \\
\text { limestones }\end{array}$ & $\begin{array}{l}\text { Massive limestones whitish } \\
\text { with clayey intercalations }\end{array}$ & & & \\
\hline & & J3E & & $\begin{array}{l}\text { Limestones } \\
\text { with } V \text {. } \\
\text { striata and } \\
\text { C. jurassica }\end{array}$ & $\begin{array}{l}\text { Massive limestones, } \\
\text { whitish to grey }\end{array}$ & & & \\
\hline & & $\begin{array}{l}\text { J3- } \\
\text { EA }\end{array}$ & & $\begin{array}{l}\text { Limestones } \\
\text { with } A \text {. } \\
\text { jaccardi }\end{array}$ & $\begin{array}{l}\text { Massive limestones, } \\
\text { whitish, with Nerineas and } \\
\text { oncolithes }\end{array}$ & & & \\
\hline & & J3N & \multicolumn{2}{|c|}{$\begin{array}{l}\text { Sta Bárbara de Nexe } \\
\text { dolomitic limestones } \\
\text { and dolomites }\end{array}$} & $\begin{array}{l}\text { Dolomitic limestones and } \\
\text { dolomites, pinkish or } \\
\text { yellowish }\end{array}$ & & & \\
\hline & & $\mathrm{J} 3 \mathrm{C}$ & \multicolumn{2}{|c|}{$\begin{array}{l}\text { Cerro da Cabeća bio- } \\
\text { limestones }\end{array}$} & $\begin{array}{l}\text { Massive limestones with } \\
\text { recifal fossils }\end{array}$ & & & \\
\hline & $\begin{array}{l}\text { Oxfordian- } \\
\text { Lower } \\
\text { Kim- } \\
\text { meridgian }\end{array}$ & J3P & \multicolumn{2}{|c|}{$\begin{array}{l}\text { Peral marls and lime- } \\
\text { stones }\end{array}$} & $\begin{array}{l}\text { Alternance of sandy and or } \\
\text { marly limestones, massive, } \\
\text { yellow and grey, with } \\
\text { blue/grey marls }\end{array}$ & $\begin{array}{l}80-100 \\
\mathrm{~m}\end{array}$ & $\begin{array}{l}\text { Marl and } \\
\text { marly } \\
\text { limestone }\end{array}$ & Aquiclude \\
\hline
\end{tabular}




\subsubsection{Hydrogeology of the Albufeira-Ribeira de Quarteira (ARQ) aquifer system}

The Albufeira-Ribeira de Quarteira (ARO) aquifer system (M6 in Figure 3.1, $54.6 \mathrm{~km}^{2}$ ) was characterized by Almeida and Lourenço da Silva (1990) and Almeida et al. (2000). The latter defined the limit of the ARQ (Figure 3.1, shown as Manag. unit) and other regional aquifers, with the aim of defining inventory and management units for the national and local water authorities. The water-bearing formations are composed by detritalcarbonate rocks dating from Miocene and Upper Jurassic (Table 3.1 and Figure 3.1). Both aquifers, henceforth MIO and JUR respectively, are generally separated by the Cretaceous aquitard (CRET), as shown in Figure 3.2 (bottom). However, in some sectors, depositional and structural conditions allow the contact between the two water-bearing formations, making hydraulic connection possible (Almeida et al., 2000). Between Albufeira and the Quarteira stream, the sub-tabular Miocene tilts slightly towards south-southeast (Figure 3.2 bottom). Miocene formations sedimented with a strong angular unconformity over the Cretaceous and Jurassic formations (Figure 3.2 bottom). They are partly recovered by the Plio-quaternary formations that act as an aquitard, confining unit (PQ aquitard).

The diapir west of Albufeira (Figures 3.1 and 3.2 top) caused a strong local angular unconformity (near $90^{\circ}$ ) between the Miocene and Cretaceous formations. Another not outcropping salt diapir, but whose presence is revealed by the groundwater hydrogeochemical characteristics, is located east of Escarpão, extending southwards to the vicinity of Patã de Baixo, i.e. along the east border of the ARQ (Figure 3.1) and Quarteira stream (Almeida et al., 2000; Bronzini, 2011).

The aquifer system boundaries are defined by three tectonic major accidents (Figure 3.1):

- East: the northwest-southeast Quarteira fault (GF2), which conditioned the Miocene sedimentation as evidenced by a thicker eastern compartment (180 m, M7 aquifer) as compared to the western compartment (80 m, ARQ-M6 aquifer). The boundary is located along the Quarteira stream that constitutes a discharge area, although it may also be influent in its northern section (Almeida et al., 2000; Reis et al., 2007);

- North: west-east Sagres-Algoz-Vila Real de Santo António flexure zone (GF1, Figure 3.2 top);

- West: north-south Albufeira fault and Albufeira diapir (GF3 and DIAPIR, Figure 3.2 top).

The southern boundary is formed by the seacoast. The ARQ discharges into the sea through inter- and subtidal springs of fresh/brackish water mainly located at Olhos de Água. The subtidal springs create at the surface of the sea rounded shapes that are well detectable from the top of the cliffs, giving their name to the village (Olhos de Água means "Water Eyes"). The electrical conductivity (EC) and temperature (T) of 
subtidal springs located at $\sim 120 \mathrm{~m}$ from the base of the coastal cliffs of Olhos de Água (Figure 3.1) were measured by scuba diving survey (Encarnação et al., 2013). On July 2013, the subtidal springs EC was $\sim 9000 \mu \mathrm{S} . \mathrm{cm}^{-1}$, i.e. $1.1 \Omega . \mathrm{m}$, and the temperature was $19.8^{\circ} \mathrm{C}$, while the sea water had a EC and temperature of $\sim 56000 \mu \mathrm{S} . \mathrm{cm}^{-1}(0.2 \Omega . \mathrm{m})$ and $21.5^{\circ} \mathrm{C}$ respectively. For comparison, EC from the MIO aquifer ranges between $\sim 800$ and $1200 \mu$ S.cm ${ }^{-1}$, i.e. $8.3 \Omega . \mathrm{m}$ and $12.5 \Omega$.m respectively, with a groundwater temperature $\sim 19^{\circ} \mathrm{C}$. The intertidal springs are also observable on the beach at low tide. Their temperature is similar to the MIO groundwater and their EC is generally lower $\left(\sim 3000 \mu\right.$ S. $\mathrm{cm}^{-1}$, i.e. $3.3 \Omega . \mathrm{m})$ than the subtidal springs.

Transmissivity, estimated in 30 boreholes exploiting the MIO layer, ranges between 84 and $3080 \mathrm{~m}^{2} \cdot \mathrm{d}^{-1}$, with an average of $540 \mathrm{~m}^{2} \cdot \mathrm{d}^{-1}$ and median of $235 \mathrm{~m}^{2} \cdot \mathrm{d}^{-1}$ (Almeida and Lourenço da Silva, 1990). The MIO aquifer is strongly affected by karstification, observable on the outcrops cliffs along the coastline. Consequently, it shows a heterogeneous distribution of hydraulic conductivity and secondary porosity, which is indirectly confirmed by low hydraulic gradients between 0.005 and 0.0005 , and by seasonal fluctuations of the water level varying between few meters to several tenths of meters.

Recharge of the ARQ aquifer system was originally estimated as $8.7 \times 10^{6} \mathrm{~m}^{3} \cdot \mathrm{y}^{-1}$ (Almeida et al., 2000), based on an average yearly rainfall of $550 \mathrm{~mm}$ and considering recharge rates of $50 \%$ and $15 \%$ for the JUR and MIO aquifers respectively. Based on water balance modeling using soil type and vegetation covers and considering an average yearly rainfall of $593 \mathrm{~mm}$, Monteiro et al. (2007b) computed a deep percolation of $11.0 \times 10^{6} \mathrm{~m}^{3} \cdot \mathrm{y}^{-1}$ (36\% of the rainfall), being the JUR recharge rate more than twice the MIO recharge rate.

Groundwater abstraction for public supply were $3.3 \times 10^{6} \mathrm{~m}^{3} \cdot \mathrm{y}^{-1}$ during year 1993 (Almeida et al., 2000). During year 1999 and for both aquifers ARQ and Quarteira (M7 in Figure 3.1), this value was $8.43 \times 10^{6} \mathrm{~m}^{3} . \mathrm{y}^{-1}$, which corresponds to $30 \%$ of estimated average annual recharge of these two aquifers (Hugman et al., 2014b). After 1999, public water supply was mainly ensured by surface water, although groundwater was also episodically pumped in summer season to compensate dam surface water shortage. Almeida et al. (2000) assessed as $3.5 \times 10^{6} \mathrm{~m}^{3} \cdot \mathrm{y}^{-1}(\sim 12 \%$ of the estimated average annual recharge) the water extractions for irrigation in 1979. However the volume of groundwater extracted by private wells is unknown and was not considered in these studies.

Recently, numerical flow models were applied to quantify the interand subtidal groundwater discharge and the impact of changes in groundwater use (Monteiro et al., 2007b; Hugman et al., 2014b). These authors used the ARQ management unit boundary shown in Figure 3.1 that was defined by Almeida et al. (2000). 


\subsection{Methodology}

The general methodology was composed by the following main steps: (i) review of geological and hydrogeological information (maps, reports, thesis and articles) to identify uncertainties related with the 3D aquifer structure, hydraulic relationships between geological formations and position of the FSWI; (ii) selection of the hydrogeophysical parameter and equipment; (iii) selection of key-sites where hydrogeophysical methods were carried out; (iv) interpretation of the results and integration in the hydrogeological conceptual model.

Although the previously mentioned hydrogeological studies allowed the acquisition of important information about the ARQ aquifer system, questions related to its current boundaries and structure still remain unanswered:

- Is the CRET aquitard present between the MIO and JUR aquifers?

- Does the CRET stripe outcropping between the JUR and the MIO in the central west part of the aquifer, i.e. between Ferreiras and Albufeira, extend towards south below the MIO, and does it act as a hydraulic barrier or as an aquitard semi-confining the JUR aquifer?

- What is the shape and position of the FSWI, and its spatial variation along the coast and inland?

- What is the explanation for the concentration of inter- and subtidal groundwater discharge at Olhos de Água?

In order to review and update the ARQ hydrogeological conceptual model, a set of geophysical methods was selected, applied and interpreted in a complementary way, taking into account the information provided by a regional piezometric surface and borehole lithological logs.

\subsubsection{Onshore hydrogeophysics}

To retrieve the hydrostratigraphy (i.e. geometry, boundary and structure of the ARQ), hydraulic relationships, depth of the water table and position of the FSWI, we selected geoelectrical (electrical resistivity tomography, ERT) and electromagnetic (time domain, TDEM, and frequency domain, FDEM) methods were selected. Such methods retrieve the subsurface electrical resistivity that is of special interest for hydrogeological purposes since it allows, e.g., to discriminate between fresh water and salt water, between soft-rock sandy aquifers and clayey material, between hard rock porous/fractured aquifers and low-permeable claystones and marlstones, and between water-bearing fractured rock and its solid host rock (Ernstson et al., 2009). The applicability of the methods used in this study to the characterization of coastal aquifers is well documented and described in detail in articles, as for instance: Goldman et al. (1991) and Yechieli et al. (2001) for TDEM, Davies et al. (2014) for FDEM and Nguyen et al. (2009) and Wilson et al. (2006) for ERT. However, the interpretation 
of electrical resistivity survey is subject to the equivalence problem. The measured apparent resistivity is related with many physically equivalent models that may differ considerably. In other words, a given resistivity may be the results of many combinations of resistivity and thickness of overlaid layers, and thus different resistivity models may fit the measured data (Ernstson et al., 2009). Moreover, the measured resistivity value depends on the combination between the lithology and the water quality of the geological medium. For instance, a clay layer saturated with fresh water may have the same electrical resistivity as a sandy layer saturated with salt water. It is thus important to interpret hydrogeophysical results together with auxiliary information, such as borehole lithological logs. Another possibility to reduce the equivalence problem is to apply methods that measure another property of the medium. However, due to logistic and financial limitations, only geoelectrical and electromagnetic methods were applied.

The geoelectrical and electromagnetic hydrogeophysical surveys were conducted between January and December 2013, comprising: (i) 17 TDEM (1D); (ii) 3 FDEM (2D); (iii) 11 ERT (2D). The surveys were organized in 5 transects transversal and longitudinal to the main groundwater flow direction (A, B, C, D and E in Figure 3.3). Note that the high urban development in the study area prevented the use of hydrogeophysics in zones considered as important (e.g. lack of extension to deploy ERT cables or electromagnetic noise limiting the use of TDEM and FDEM). Specifically, the selected methods were used to detect: (i) position and slope of the FSWI using FDEM cross-sections perpendicular to the coast, TDEM on the coastal cliffs and ERT along the beach; (ii) water-bearing formations with TDEM and ERT; and (iii) the CRET aquitard below the MIO aquifer with TDEM and ERT. The ERT method was preferentially used on the beach to detect shallow karstic structures and freshwater springs due to its relatively high-resolution and cross-sectional characteristics. The delineation of the hydrostratigraphical units was based on electrical resistivity contrasts observed in the 2D FDEM and ERT cross-sections, as well as on the 1D resistive layers obtained from the 1D TDEM inversion.

Table 3.2 resumes the main characteristics of the geophysical methods that were used in this study, namely the devices, configurations and ranges of investigation depths. Next the configurations that were applied from each of the hydrogeophysical methods are presented.

\subsubsection{Time domain electromagnetics method}

A TEM-FAST 48 from Applied Electromagnetic Research (AEMR) company was used with a square loop of 25 or $50 \mathrm{~m}$ side ( 1 turn) in coincident loop configuration with an input current of $24 \mathrm{~V}$ and $4 \mathrm{~A}$, allowing a penetration depth of 50 to $100 \mathrm{~m}$, depending on the local geoelectrical profile. A minimum of 3 curves at each site was acquired to confirm the repeatability of the measurement and the absence of EM noise induced by galvanic and/or capacitive coupling (Danielsen et al., 2003). The data were inverted using the software TEM-RES v7 from AEMR. When 
necessary, noisy data were firstly removed. Afterwards, using automatic inversion and trial and error method, a theoretical curve was fitted on observed data. The criterion of selection of the final solution was based on the minimum number of layers for the same quality of fitting, as well as hydrogeological knowledge of the area completed by local observation or borehole lithological logs and coherency with the other geophysical methods.

\subsubsection{Frequency domain electromagnetics method}

An EM-34 device from Geonics Instruments was used to perform 1D soundings every $20 \mathrm{~m}$ along profiles, allowing to retrieve 2D crosssections. At each measurement point, the $1 \mathrm{D}$ vertical soundings were carried out with 6 configurations, i.e. horizontal and vertical dipoles with coil spacing of 10,20 and $40 \mathrm{~m}$ (frequencies of $6.4,1.6$ and $0.4 \mathrm{kHz}$, respectively), which corresponds to theoretical investigation depths ranging between 7.5 and $60.0 \mathrm{~m}$ (Table 3.2). Based on these 1D soundings along profiles, the 2D geoelectrical modeling was conducted using the algorithm EM34-2D, which applies a 1D laterally constrained method (Monteiro Santos, 2004). The inverse problem is solved using a smooth inversion, where each 1D conductivity model, obtained beneath each measurement site, is constrained by its neighbors. The obtained 2D cross-sections allow visualizing a model of the vertical distribution of electrical conductivities.

\subsubsection{Geoelectrical method}

ERT were acquired using an IRIS Syscal pro, an ABEM Terrameter SAS4000 and a Scintrex TSQ-3 transmissor with a Elliot R-20A receiver. The first one was configured with four $90 \mathrm{~m}$ long cables and a total of 72 electrodes, the second with four $100 \mathrm{~m}$ long cables and a total of 64 electrodes. Schlumberger and Wenner arrays were selected. During data acquisition, the stacking option was activated to obtain at each electrode an electrical resistivity measurement with a standard deviation lower than 5\%. The Scintrex TSQ-3 device was applied with 18 electrodes in dipole-dipole array with $1350 \mathrm{~m}$ length to detect large and deep geological structures.

Inversions were carried out using RES2DINV v3.53 (Geotomo software, 2010), using model refinement. Bad datum points and points with root mean square error (RMSE) higher than 60 or $80 \%$ were removed from the final inversion.

The vertical accuracy of this method is relevant since the depth and thickness of the hydrostratigraphical units, as well as the depth of the groundwater table, was mostly derived from this method. In theory, accuracy of the depth of the interface is obtained using sensitivity studies (Geotomo software, 2010), which was not performed in this case. Applying to the distance inter-electrode the rule of thumb that defines the depth of investigation as $L_{E R T} / 5$, where $L_{E R T}$ is the total ERT length 
(Ernstson et al., 2009), one can obtain the resolution of the method. Therefore, the resolution for an inter-electrode distance of $5 \mathrm{~m}$ and $75 \mathrm{~m}$ is $\sim 1 \mathrm{~m}$ and $\sim 15 \mathrm{~m}$ respectively. Note that due to the specificity of the method, this resolution degrades laterally and in depth. 


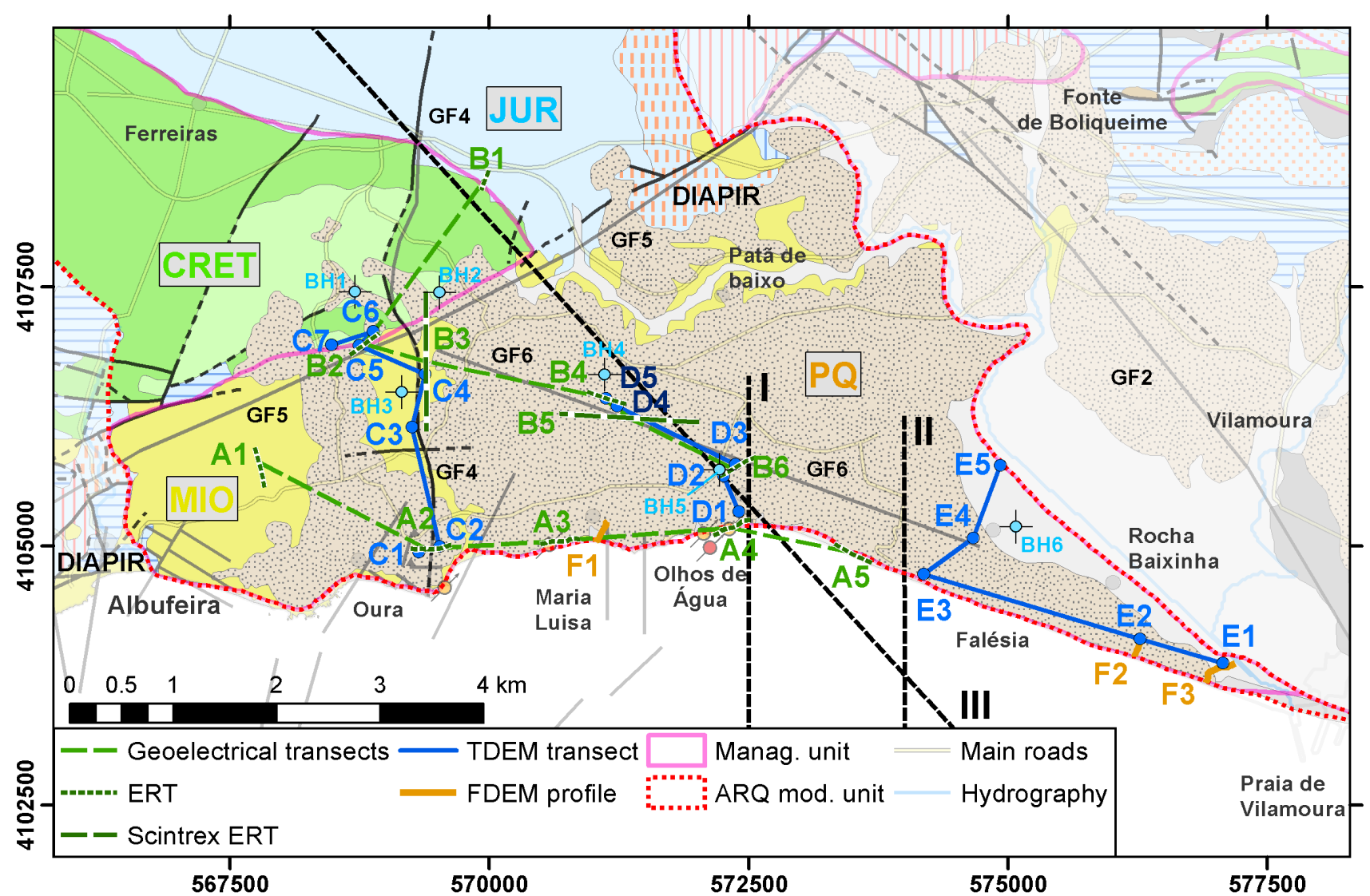

Figure 3.3: Location of the hydrogeophysical surveys. Hydrogeological cross-sections I, II and III are shown on Figure 3.11. See geological legend in Figure 3.1. PQ, MIO, CRET and JUR indicate the main hydrogeological formations. Labels BH1 to BH6 indicate the boreholes with lithological log that were used to support the hydrogeophysical interpretation and that are shown on Figures 3.5, 3.7 and 3.8. 
Table 3.2: Characteristics of the hydrogeophysical methods. All methods acquired the electrical resistivity (or its inverse, the electrical conductivity).

\begin{tabular}{|c|c|c|c|c|}
\hline Geophysical Method & Device & Configuration & $\begin{array}{l}\text { Investigation } \\
\text { depth Range }\end{array}$ & Dimension \\
\hline \multirow[t]{2}{*}{$\begin{array}{l}\text { Electrical Resistivity } \\
\text { Tomography (ERT) }\end{array}$} & $\begin{array}{l}\text { IRIS - Syscal pro; } \\
\text { ABEM - } \\
\text { Terrameter }\end{array}$ & $\begin{array}{l}\text { Schlumberger array; } \\
\text { Wenner array }\end{array}$ & $65-70 \mathrm{~m}$ & $2 \mathrm{D}$ \\
\hline & Scintrex - TSQ-3 & Dipole-dipole array & $150 \mathrm{~m}$ & $2 \mathrm{D}$ \\
\hline $\begin{array}{l}\text { Frequency Domain } \\
\text { Electromagnetics } \\
\text { (FDEM) }\end{array}$ & Geonics - EM-34 & $\begin{array}{l}2 \mathrm{D} \text { profiles based on } 1 \mathrm{D} \\
\text { soundings every } 20 \mathrm{~m} \\
\text { using horizontal and } \\
\text { vertical dipoles at coil } \\
\text { distance } 10,20 \text { and } 40 \mathrm{~m}\end{array}$ & 7.5 to $60.0 \mathrm{~m}$ & $2 \mathrm{D}$ \\
\hline $\begin{array}{l}\text { Time Domain } \\
\text { Electromagnetics } \\
\text { (TDEM) }\end{array}$ & $\begin{array}{l}\text { AEMR - } \\
\text { TEM-FAST } 48\end{array}$ & 25 to $50 \mathrm{~m}$ square loop & $50-100 \mathrm{~m}$ & $1 \mathrm{D}$ \\
\hline
\end{tabular}




\subsubsection{Auxiliary information}

\subsubsection{Hydraulic heads and regional static piezometric surface}

The objective of the piezometric analysis was not to obtain a regional piezometric surface per se but to highlight high and low hydraulic gradient areas and to detect hydraulic barriers, preferential groundwater flow zones and other relevant hydrogeological features.

The retrieval of a reliable static piezometric surface requires the availability of a dense and uniform spatial distribution of boreholes and measurements made during a short period within the same hydrological conditions, which was not available in this study. Although a high borehole density was available in the ARQ costal aquifer, most of the boreholes were in activity and equipped with pumps, which did not allow us to use a dipper (high risk of blocking the dipper's tape with the pump's cables). Hydraulic heads measurements were only possible in 22 boreholes of Albufeira Municipality (Câmara Municipal de Albufeira, CMA) that were equipped with dip tube. Hydraulic heads were also available from 69 boreholes belonging to the monitoring program of the Portuguese Environment Agency (Agência Portuguesa do Ambiente - APA, water resources information system available at http://sni rh.pt). The historical data from APA and CMA archives were thus compiled to obtain the final hydraulic heads dataset of 91 boreholes composed with records from March 1978 to December 2013 (some of the boreholes are located outside the area shown in Figure 3.1). The piezometric measurements in the CMA boreholes were made after being deactivated, i.e. after 2001. They should correspond to the static piezometric level. However, due to summer, episodic extractions, the quality of the measurements is uncertain, as some of them were carried out before the full recovery of the borehole.

The maximum number of concomitant hydraulic heads was only 29, with only 8 of them inside the ARQ area. As this dataset was insufficient to obtain a reliable interpolated surface, static piezometric surfaces were elaborated using the minimum, median and maximum hydraulic head at each of the 91 boreholes. Simple kriging was applied to the dataset to retrieve the regional piezometric surface. In theory, the minimum hydraulic head is the most reliable value in absence of pumping, because the recession part of the well hydrograph follows an asymptotic exponential decay towards the local base level (Dingman, 2002). However in practice, as some measurements were made few hours after long-term pumping, the minimum level may be biased, as it does not represent the static water level. To avoid misinterpretation and eliminate extreme values, the regional piezometric map was elaborated using the median hydraulic head at the 91 boreholes points. To avoid artifact in the south border of the study area, the interpolation was constrained by defining the groundwater table depth at sea level along the sea coast. 


\subsubsection{Borehole lithological logs}

The lithological information of 45 borehole logs (location in Figure 3.1) obtained from drilling company reports was collected from the archives of several institutions, namely Laboratório Nacional de Energia e Geologia (LNEG, data available in alphanumerical and GIS format) and Administração da Região Hidrográfica do Algarve (ARHA). The borehole logs were interpreted to associate the described lithologies to the hydrostratigraphic units referred in Table 3.1 (i.e. PQ, MIO, CRET and JUR). This information was used to support the interpretation of the hydrogeophysical results. The 1D representations of the borehole hydrostratigraphy, the 1D TDEMs and 2D ERTs were imported into ESRI ArcScene to obtain a 3D visualization of the data that eased the interpretation of the results.

\subsection{Results}

\subsubsection{Regional static piezometric surface}

The regional static piezometric surface obtained by interpolation of the hydraulic head median of 91 boreholes is shown in Figure 3.4. Most of these boreholes have unknown depth and unknown screen depth, thus the aquifer layer from which groundwater is extracted is also unknown. However, from the analysis of the boreholes with lithological logs, it was observed that the boreholes generally screen the shallowest aquifer. The interpolation between the boreholes was done without barriers, thus the interpretation should be done carefully and taking into account the geological boundaries previously described in section 3.2.2. From the regional static piezometric map (Figure 3.4), it is possible to observe the following in relation to the ARQ aquifer:

- The general trend of the groundwater flow is from the northern, elevated zone of the JUR outcrops (Escarpão plateau) towards south and southeast;

- Part of the groundwater flow is from the Escarpão plateau towards east and northeast, i.e. the Quarteira stream, which was confirmed using tracer tests (Almeida and Crispim, 1987);

- The flow from the Escarpão plateau towards north and northwest is likely an interpolation artifact because the vertical marly CRET (Figure 3.2 top) is most probably constituting there an hydraulic barrier;

- It may have hydraulic continuity between the Escarpão plateau towards west, implying a connection between the ARQ (M6) and M4 aquifers (Figure 3.1). However more data and studies are required to confirm this hypothesis;

- At north of the Oura-Albufeira sector (southwest of the ARQ aquifer), the hydraulic heads in the CRET outcrops are in continuity with those of the JUR formations. This fact is supported by the hydraulic 
heads of 3 boreholes identified by $\mathrm{BHa}, \mathrm{BHb}$ and BHc labels. Two of these boreholes are most probably implemented in the JUR aquifer: BHa was drilled inside a nora with $14.5 \mathrm{~m}$ depth, close to the contact CRET-JUR, where the CRET is very thin; BHc is $\sim 100 \mathrm{~m}$ deep, implemented in outcropping JUR formations. In agreement with the geological cross-section of Figure 3.2 (top), these data indicates that the JUR aquifer extends in continuity from the northern outcropping area towards the sea, below the CRET and the MIO formations, and that the GF3 is not a hydraulic barrier. For groundwater modeling purpose, the west border of the aquifer limit should thus be extended toward west, as shown in Figures 3.1, 3.3 and 3.4 (ARQ modeling unit);

- Groundwater flow is convergent towards a sink located between Maria Luisa and Olhos de Água, indicating preferential discharge area and/or groundwater abstraction;

- The hydraulic gradient is higher in the JUR zone of the ARQ aquifer than in the MIO aquifer, indicating higher hydraulic conductivity in MIO than in JUR. 
Figure 3.4: Regional static piezometric map retrieved using the median hydraulic head of 91 boreholes (black label next to the borehole symbol indicates the number of values). GWT stands for groundwater table depth. The GWT elevation color bar is show using 10 quantiles, meaning that each class corresponds to $10 \%$ of the values. The equidistance between equipotential lines is $5 \mathrm{~m}$. 


\subsubsection{Hydrogeophysical interpretation}

\subsubsection{ERT transect A}

The ERT cross-section A1 was performed on MIO outcrop (Figure 3.5, see location on Figure 3.3). It shows the water table at $\sim 10 \mathrm{~m}$ above sea level (m.a.s.l.). From top to bottom, it corresponds to the unsaturated MIO aquifer with a resistivity between 75 and $200 \Omega . \mathrm{m}$. The saturated zone shows a $\sim 15 \mathrm{~m}$ thick layer of resistivity $\sim 50 \Omega$.m and a deeper layer with low resistivity $(10 \Omega . \mathrm{m})$. As there is no clayey layer in the LagosPortimão formation, this configuration was interpreted as freshwater above brackish water. The brackish water is very shallow, i.e. -10 m.a.s.l., at $\sim 1300 \mathrm{~m}$ from the coast. It can be explained either by upconing of seawater or diapirism processes. Independently of the saltwater source, the salinization is probably caused by large groundwater volumes pumped from private boreholes belonging to the many Albufeira touristic installations (hotels and resorts). The high pumping would be responsible for the upward movement of deep saline water from sea or diapir and its mixing with the shallow fresh water, resulting in an increase of salinity and decrease in electrical resistivity. This hypothesis is supported by the monitoring of the groundwater electrical conductivity in private boreholes between Oura and Albufeira, which showed seasonal variations of factor 10 of the EC (data gently provided by Albufeira Municipality CMA).

As ERT at site A2 was located $\sim 400 \mathrm{~m}$ away from the coast, its interpretation was supported by direct field observation of the geological formations outcropping on the cliffs. The most resistive layer (100$600 \Omega$.m) corresponds to PQ formations. Below, the $\sim 50 \Omega$.m layer corresponds to saturated MIO formations. The contact between the PQ and the MIO formations shows an uplift on the east section of the ERT, i.e between abscissas 30 and $180 \mathrm{~m}$. This uplift corresponds to the expression of the GF4 north-south Oura fault (Figures 3.1 and 3.3). The same pattern is observed on the cliffs. The elevation of the contact between the PQ and the MIO observed in the cliffs was measured using a differential GPS. It was at $\sim 1$ and $\sim 7$ m.a.s.l. at east and at west of the GF4 fault respectively. This is in agreement with the elevation of the PQ-MIO contact retrieved by the interpretation of the ERT A2, confirming the good accuracy of the ERT method. The fact that the top of the saturated MIO layer follows the uplift indicates that the MIO aquifer is confined by the PQ formations. The deepest layer, characterized by low resistivity values $(<10 \Omega$.m) below a flat surface at -10 m.a.s.l, is most probably due to the presence of saltwater in the MIO formations, since these formations are clay-free. West of the fault, the freshwater layer is very thin $(\sim 10 \mathrm{~m})$, which constitutes a high risk of upconing. Indeed, the groundwater electrical conductivity measured from a private borehole (total depth $\sim 40 \mathrm{~m}$, screening the MIO) located at the west edge of the ERT as indicated by a gray cylinder in the figure, was $3760 \mu \mathrm{S} . \mathrm{cm}^{-1}$ (i.e.

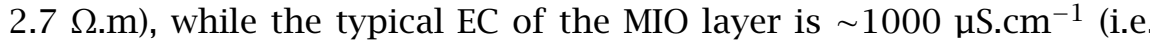



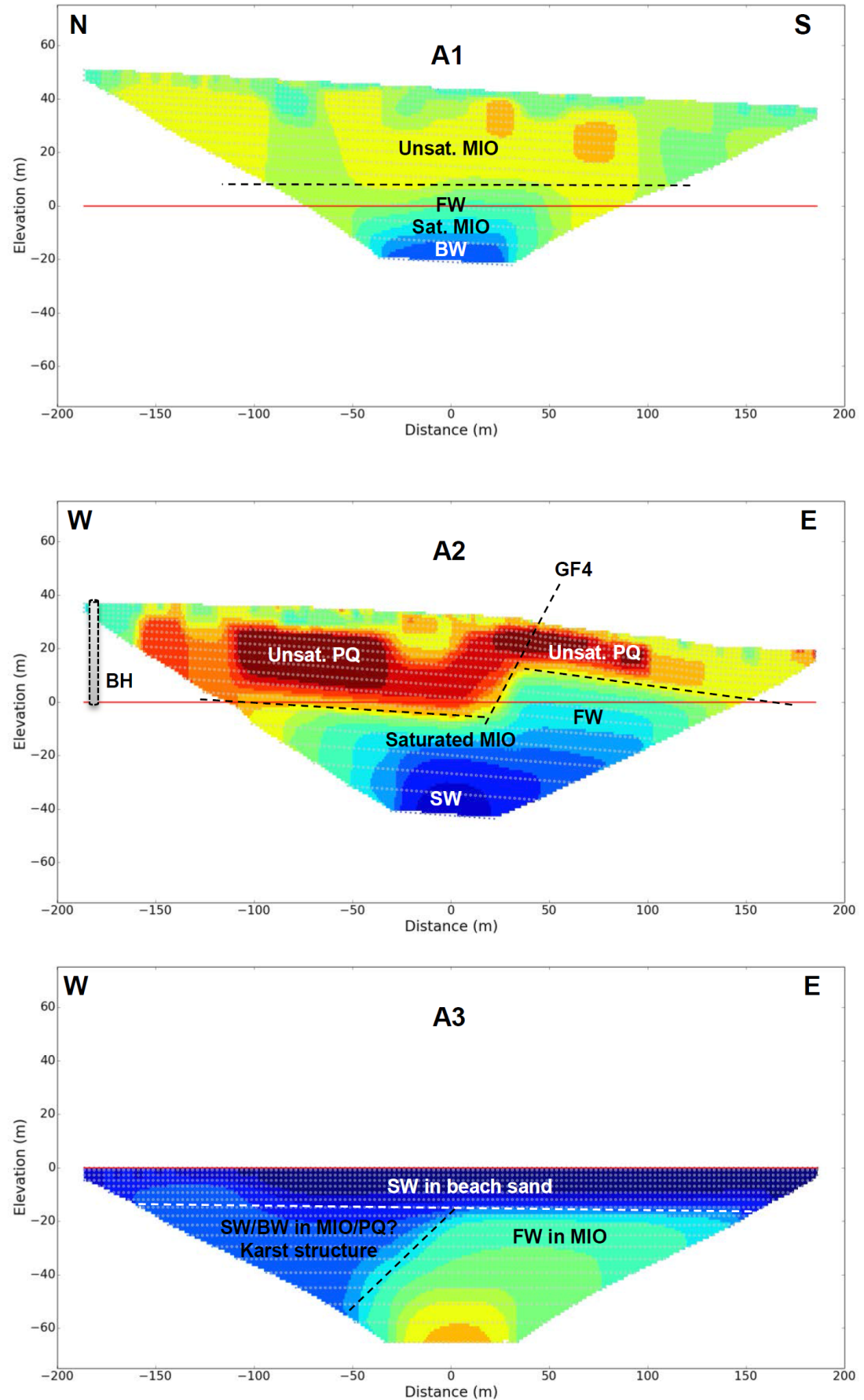

Figure 3.5: ERT cross-sections A1 to A5 of longitudinal transect A (see location in Figure 3.3). Continued on next page. 

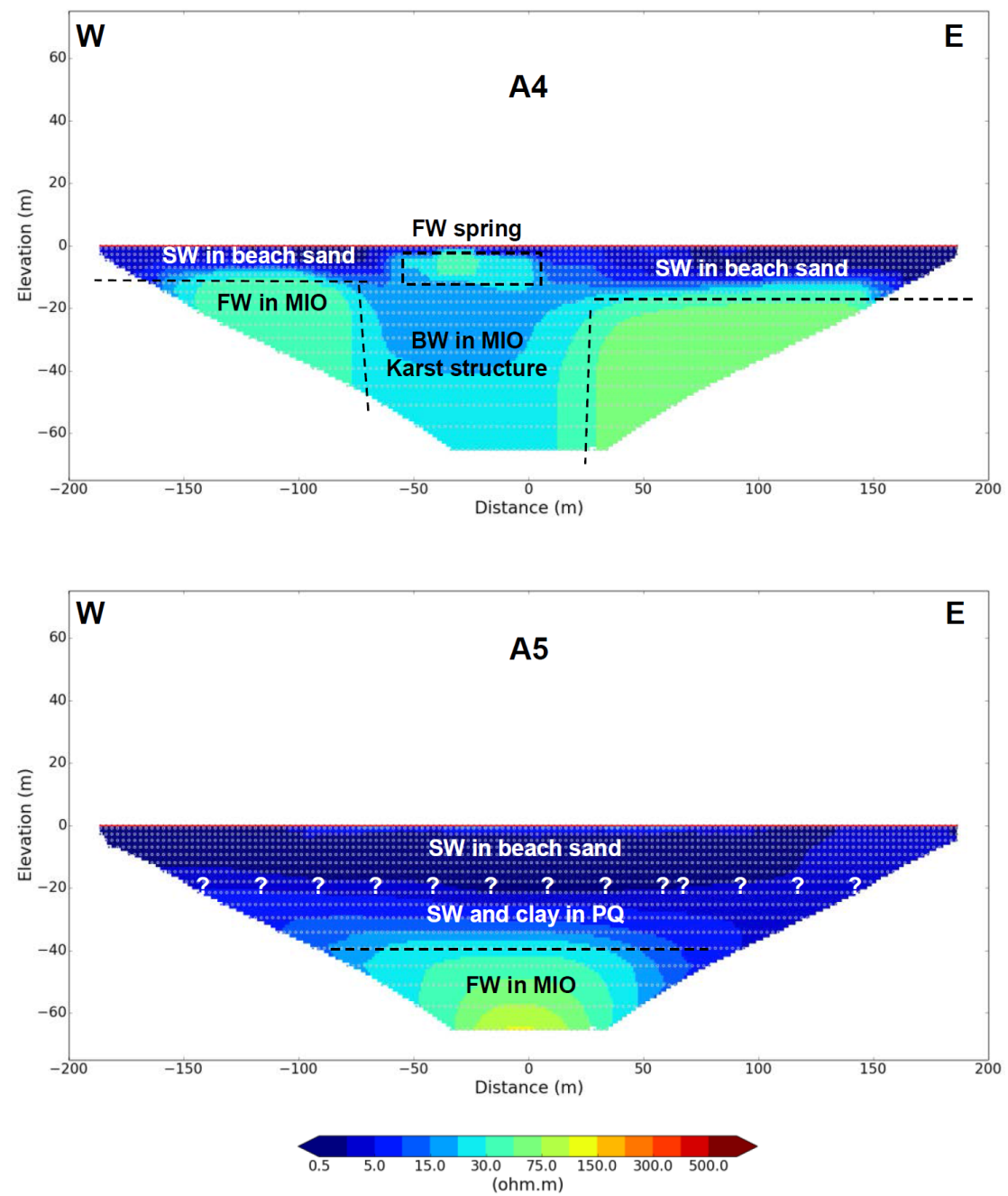

- continued from previous page. BH stands for borehole (no log available), FW for freshwater, BW for brackish water, SW for saltwater, Unsat for unsaturated and Sat. for saturated. Other abbreviations are explained in the text. Inversions of cross-sections A3 to A5 were performed without topography (flat beach). The elevation and distance scales are the same for all cross-sections. The red horizontal line indicates the mean sea level. Inversion root mean square errors (\%): A1 1.0, A2 2.6, A3 1.5, A4 1.8, A5 1.5. 
$10.0 \Omega . \mathrm{m})$.

ERTs A3 to A5, conducted on the beach, present similar settings between them: a low resistivity layer $(<10 \Omega . \mathrm{m})$ above a layer with resistivity ranging from $\sim 20-100 \Omega$.m. The first layer corresponds to seawater in beach sands while the second to fresh groundwater in MIO formations. This configuration is explained by coastal fringe processes, such as tidal dynamics and upper seawater recirculation zone (Werner et al., 2013). Karstic structures, expressed by blocks of different resistivity, are also visible on ERT A3 and A4. An intertidal freshwater spring, clearly identified in the field, is visible on ERT A4 between abscissa -60 and 0. Finally, the deepening of the top of the MIO/base of the PQ towards east is clearly visible from A4 to A5. However, PQ was expected between the sand beach and MIO, but either it is not present or its resistive signature is similar to the sand beach saturated with saltwater, probably due to the presence of saturated clayey lithology in PQ.

\subsubsection{FDEM cross-sections}

The FDEM cross-sections of Figure 3.6, all of them starting on the beach, show at south formations saturated with seawater, characterized by low resistivity $(<20 \Omega . \mathrm{m})$ and, at north, freshwater saturated formations with resistivity of $\sim 20-50 \Omega . \mathrm{m}$. At F1, the freshwater formations correspond to the MIO aquifer, while at F2 and F3 they correspond to alluvium, dune and beach sands. The slope of the FSWI is clearly imaged, showing a steep inclination at F1, while at F2 and F3, located in the eastern part of the AQR, the inclination is smooth. This geometry was expected since the hydraulic gradients are the lowest in the east sector (Figure 3.4). The relation between the hydraulic gradient and inclination of the FSWI can be confirmed using analytical models (Baden Ghijben, 1888-1889; Herzberg, 1901; Glover, 1959). Below the Quarteira stream, at North-East of the F3 cross-section, the $\sim 20-50 \Omega$.m resistivity layer seems to indicate fresh groundwater. Above, the low resistivity layer indicates saltwater intrusion from the Quarteira stream inside the alluvionar formations. This cross-section exemplifies the complex relationships between the MIO aquifer, the surficial alluvionar formations and the Quarteira stream that is at this location strongly influenced by sea and tides. 

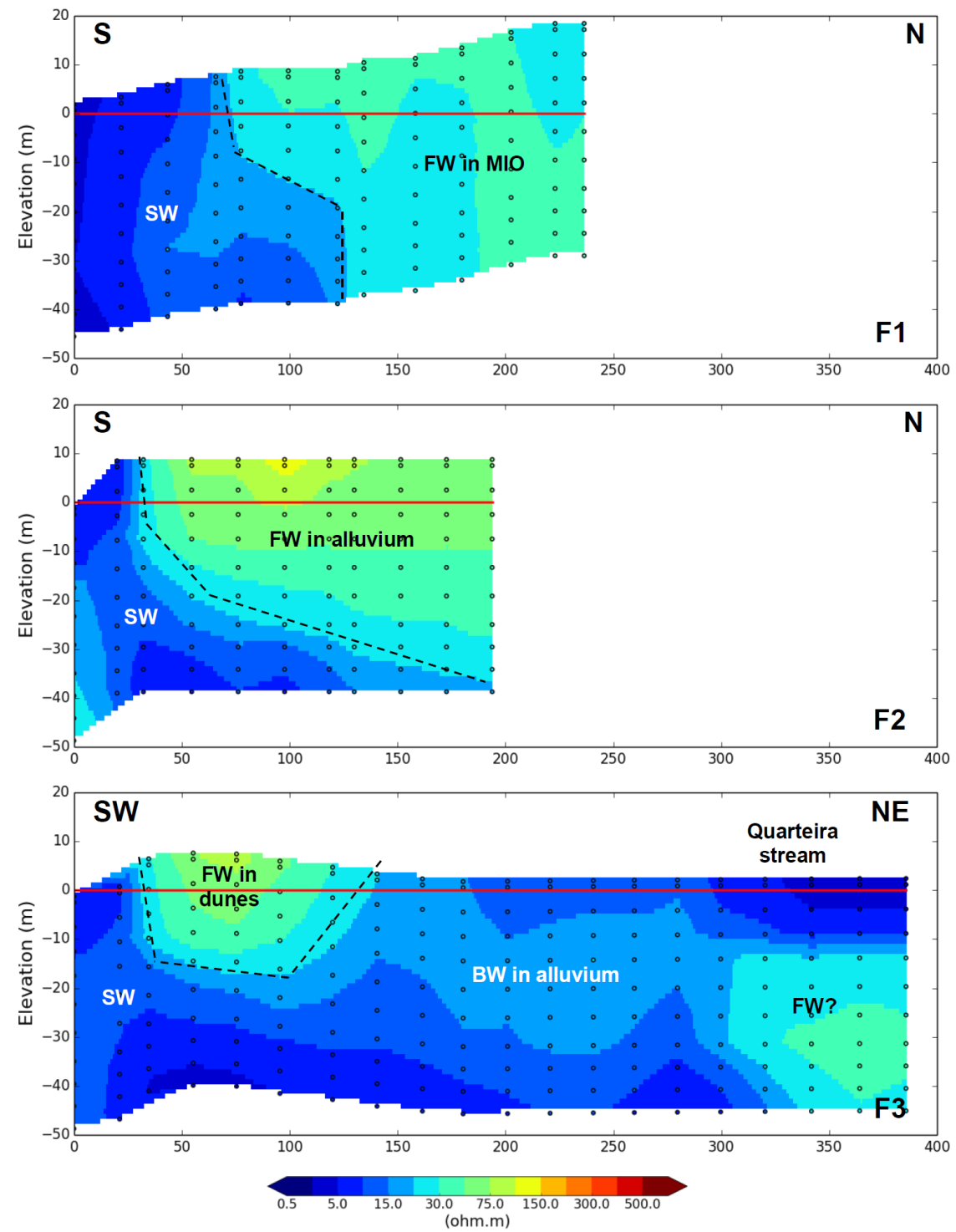

Figure 3.6: FDEM cross-sections (see location in Figure 3.3). FW stands for freshwater, BW for brackish water and SW for saltwater. Other abbreviations are explained in the text. The black dash line represents approximately the location of the freshwater-saltwater interface (FSWI). These cross-sections show steep (F1) and smooth (F2 and F3) inclined FSWI. All cross-sections started on the beach, located at south. The red horizontal line indicates the mean sea level. 


\subsubsection{ERT transect B}

On transect B (Figure 3.7), the contact diving towards south between JUR and CRET formations (respectively resistivities of $\sim 100-200 \Omega$.m and $\sim 10-75 \Omega . \mathrm{m}$ ) is visible on ERT B1. The CRET formations have a similar resistivity signature than the saturated MIO observed previously, although they show a larger range due to the presence of low resistivity marly layers (i.e. between 5 and $75 \Omega$.m). The shallow groundwater table (GWT) could also be identified in the cross-section, which was confirmed by measuring it at $\sim 8 \mathrm{~m}$ depth in a shallow, large diameter well located at $30 \mathrm{~m}$ west from the ERT cross-section. Electrical conductivity at this well was $1165 \mu \mathrm{S} . \mathrm{cm}^{-1}$ (i.e. $8.6 \Omega$ (.m). At B2, exclusively carried out in CRET formations, as confirmed with the lithological log of BH1, the GF5 Mosqueira fault, diving towards North-East, could be identified at $-100 \mathrm{~m}$ abscissa. However, it was not possible to identify the layering in the CRET formations. The long ERT B3, east of B2, clearly identified a vertical anisotropy between abscissa -250 and $-150 \mathrm{~m}$ with resistivity $\sim 150-200$ S.m. Following the structural map (Figure 3.1), it should correspond to the GF6 Olhos de Água fault. Although the lithological logs of $\mathrm{BH} 2$ and $\mathrm{BH} 3$ indicate that north of the GF6 fault the CRET is present, while the south compartment is constituted by MIO formations, the hydrostratigraphical interpretation is difficult, since MIO and CRET have similar resistivity signature and PQ is covering the underlain geological formations, impeding field direct observation. The GWT was measured at $44.8 \mathrm{~m}$ depth (i.e. $\sim 5$ m.a.s.l) in an abandoned borehole (total depth > $50 \mathrm{~m}$ ) located $100 \mathrm{~m}$ east of ERT B3 (groundwater electrical conductivity in this borehole was $1206 \mu$ S.cm ${ }^{-1}$, i.e. $8.3 \Omega$.m). However, due to coarse resolution of ERT B3, it is uncertain to recognize the GWT. The ERTs B4 and B5 interpretation was supported by the lithological log of BH4 (depth of $187 \mathrm{~m}$ ) located $220 \mathrm{~m}$ north of ERT B4. The long dipole-dipole ERT B5 is located $170 \mathrm{~m}$ south of ERT B4 (Figure 3.3). The BH4 lithological log shows, below a PQ layer $26 \mathrm{~m}$ thick, typical MIO lithology ranging from 16 to -54 m.a.s.l. These formations are identified at B4, where the outcropping $\sim 15 \mathrm{~m}$ thick, resistive layer $(\sim 100-200 \Omega$.m) corresponds to unsaturated PQ formations. Below, the MIO formations show resistivity between 30 and $100 \Omega$.m. The GWT measured at BH4 was -5 m.a.s.l., but is not visible in the ERT cross-section due to the decrease of resolution at depth. The B5 horizontal stripe between 0 and $-80 \mathrm{~m}$ elevation (resistivity between 30 and $100 \Omega . m$ ) also corresponds to MIO aquifer, although the GWT is not clearly identified. The BH4 log shows CRET marly limestones between -54 and -97 m.a.s.l. that were related with the low resistivity $(<15 \Omega . \mathrm{m})$ below $-80 \mathrm{~m}$ identified at B5. Low resistivity of outcropping marl CRET was confirmed at ERT B1. Between 97 and $146 \mathrm{~m}$ (bottom of the borehole), the BH4 log described gray and reddish hard limestone that may correspond to the JUR formations. The differences in elevation between the borehole and the inverted resistivity cross-sections are due to the coarse resolution of the geoelectrical acquisition array $(75 \mathrm{~m}$ inter-electrode distance). The vertical structure with electrical resistivity 
ranging from 100-200 $\Omega . m$ visible in the middle of B5 likely corresponds to the GF6 Olhos de Água fault. This GF6 fault is also identified in ERT $\mathrm{B} 6$ at abscissa $10 \mathrm{~m}$. The same ERT B6, located $\sim 600 \mathrm{~m}$ north from the coast, shows $\sim 20 \mathrm{~m}$ of PQ (resistivity of $150-700 \Omega . \mathrm{m}$ ) on top of MIO formations (resistivity of 50-100 $\Omega . \mathrm{m}$ ), as confirmed by BH5. As in A2, the MIO aquifer is probably confined, although the water level indicated in the drilling report was just below the interface MIO/PQ. 

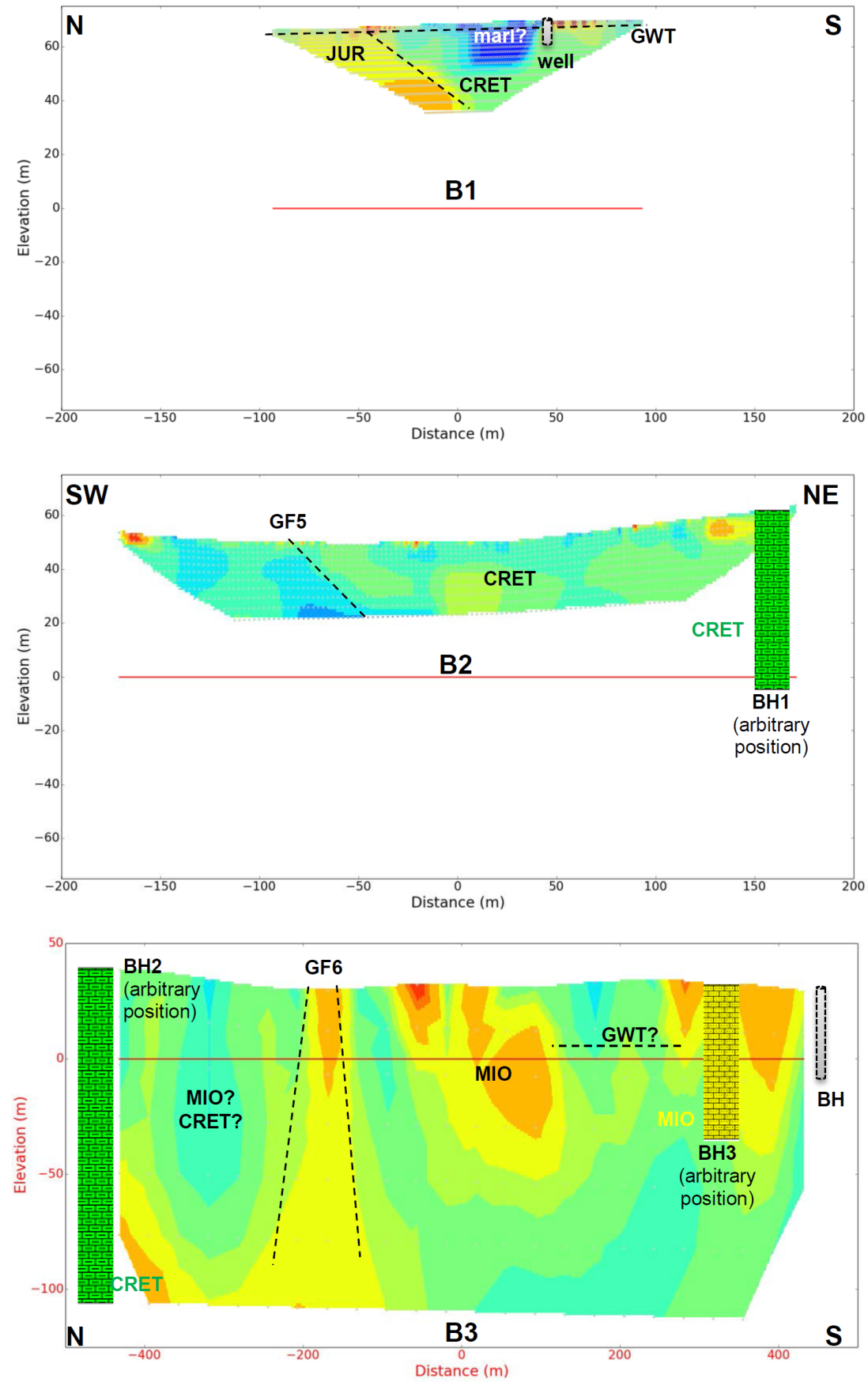

Figure 3.7: ERT cross-sections B1 to B6 of transversal transect B (see location in Figure 3.3). BH stands for borehole, Unsat. for unsaturated, FW for fresh water, GWT for groundwater table depth. Other abbreviations are explained in the text. The elevation and distance scales are the same for all cross-sections, as well as in Figure 3.5, expect for B3 and B5 (indicated with red labels). Continued on next page. 

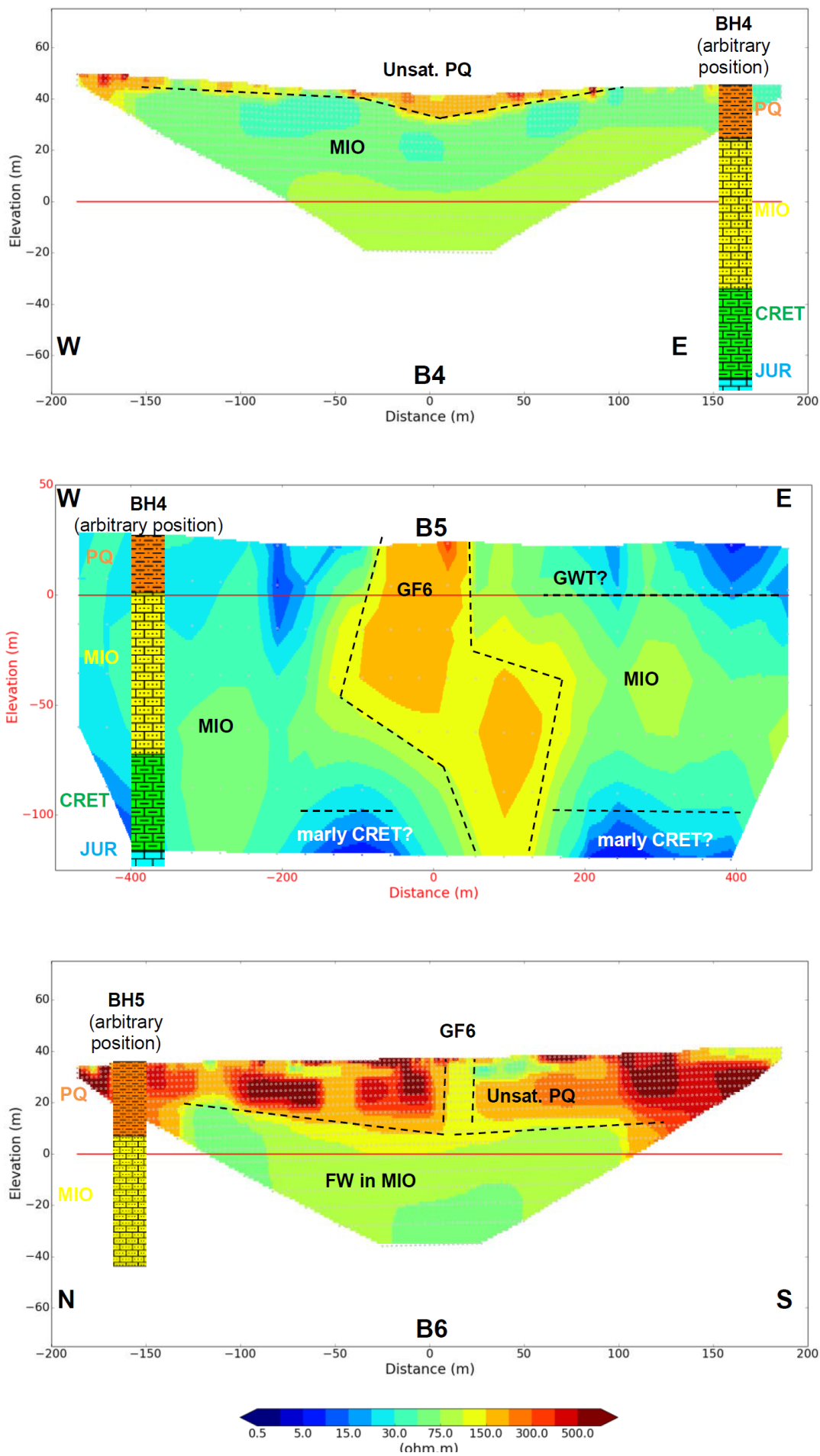

- continued from previous page. The red horizontal line indicates the mean sea level. The location of the boreholes in the cross-sections is arbitrary, see exact location in Figure 3.3. Inversion root mean square errors (\%): B1 1.3, B2 1.1, B3 9.2, B4 1.0, B5 6.9, B6 1.7. 


\subsubsection{TDEM transects $C, D$ and $E$}

In general, TDEM was less certain than ERT, particularly in the depth and thickness assessment of the hydrostratigraphical layers. This is certainly due to ambient EM noise in urban area and limited power of the instrument used. Nevertheless, several outcomes can be extracted from the TDEM transects C, D and E (Figure 3.8). TDEM C2, D1, D2 and D3, near the coast line, show low electrical resistivity in their deepest layer, that may corresponds to seawater saturated formations. Above, the layer with resistivity between 20 and $75 \Omega$.m indicates the MIO aquifer, which is similar to the values obtained with the ERTs. The boundary between MIO aquifer and saturated seawater formations corresponds to the FSWI. The upper resistive layer (> $150 \Omega . \mathrm{m})$ indicates the PQ unit. More inland, the deepest, low resistivity layer can be identified at C3, C4 and D5 (distance of $\sim 2000 \mathrm{~m}$ from the coast) as well as in C7 (> $3000 \mathrm{~m}$ from the coast). This low resistivity at a far distance from the coast, as also observed with ERT A1, may correspond to groundwater salinization due to upconing and/or diapirism. Finally, the E transect indicates similar information as ERT A3 to A5 and FDEM F3. The low resistivity observed at E1 and E5 ( 15-20 $\Omega$.m) seems to corroborate the influence of the sea influence through the Quarteira stream, causing saltwater intrusion into the alluvium formations. E4 identifies the MIO aquifer (electrical resistivity between 30 and $50 \Omega . \mathrm{m}$ ) below thin PQ layer with high resistivity (> $500 \Omega . \mathrm{m}$ ). E2 and E3, carried out on the top of the cliffs, give relevant information that helps to interpret ERT A5, performed on the beach: below a high resistive layer (> 500 $\Omega . \mathrm{m})$ corresponding to unsaturated PQ detrital formations observed on the cliff, a thin layer appears with very low resistivity, above a layer with resistivity of $\sim 30-75 \Omega$.m. This deepest layer likely corresponds to fresh groundwater in the buried, confined MIO aquifer, while the intermediate layer corresponds to saturated PQ that, due to its high clay content, shows very low resistivity similar to the resistivity of seawater saturated beach sand observed on ERT A5. 

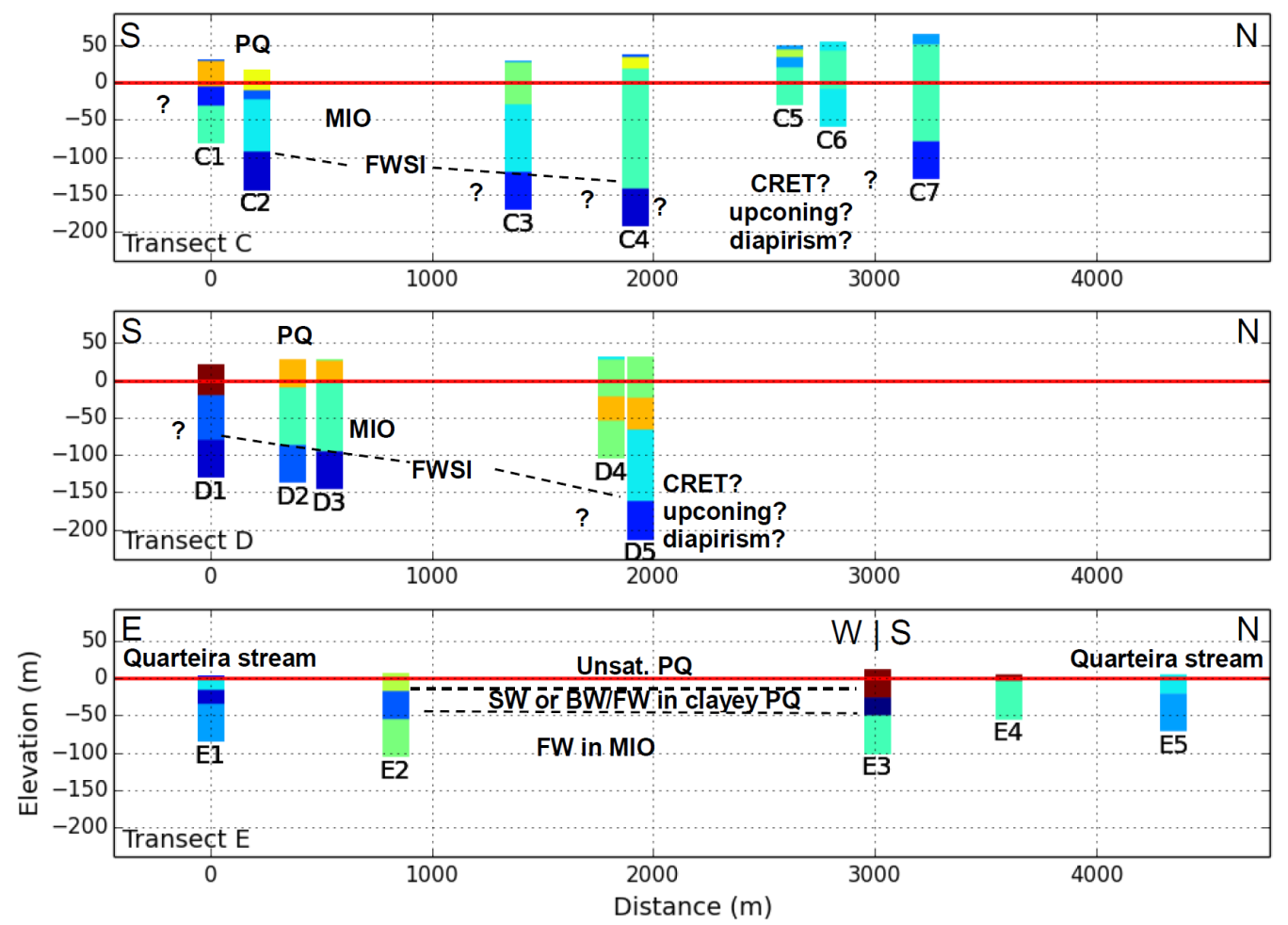

\begin{tabular}{llllllll}
\hline 0.5 & 5.0 & 15.0 & 30.0 & 75.0 & 150.0 & 300.0 & 500.0
\end{tabular}

Figure 3.8: Transects C, D and E composed by TDEM 1D soundings (see location in Figure 3.3). FW stands for freshwater, SW

for saltwater, FSWI for fresh-saltwater interface and Unsat. for unsaturated. Other abbreviations are explained in the text. Deepest layer arbitrarily set to $50 \mathrm{~m}$ thick. 


\subsection{Discussion}

\subsubsection{Geoelectrical model}

The resistivity range of the hydrogeological formations of the study area is presented in Table 3.3. A good agreement was observed among the 3 geophysical techniques. TDEM and FDEM are more expedite than ERT to carry out in the field, although more sensitive to EM noise. However, ERT gives a detailed overview of the spatial relationship among the hydrogeological formations at good resolution for the $5 \mathrm{~m}$ inter-electrode spacing. As referred earlier, TDEM is less certain than ERT in the depth and thickness assessment of the hydrostratigraphical layers. Moreover, layers detected at depth higher than $\sim 100 \mathrm{~m}$ should be carefully interpreted taking into account the high uncertainty of the measured signal at this depth, particularly in presence of ambient EM noise of urban areas.

The results presented in this study are in agreement with previous geoelectrical surveys. Elsendoorn et al. (1982) presented a north-south geoelectrical cross-section comprising 5 vertical electrical soundings (VES), located north of Olhos de Água and with $\sim 4 \mathrm{~km}$ long. In this cross-section, PQ had resistivity $\sim 270 \Omega$.m, saturated MIO $\sim 110 \Omega . m$,

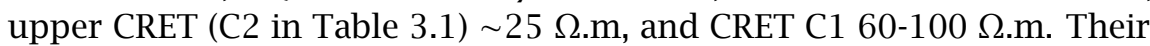
cross-section presents a sub-tabular PQ above MIO and CRET formations, diving towards south. The marly CRET was also identified by other authors in the Quarteira region, below the MIO (Geirnaert et al., 1982; Carvalho et al., 2006, 2012).

At some sites, the hydrogeophysical interpretation is still ambiguous due to three main reasons: (i) insufficient depth of investigation limited by the geophysical instruments and configurations used in this study; (ii) overlap of electrical resistivity signatures of geological formations, mainly MIO and CRET; and (iii) Archie's law (Archie, 1942; Winsauer et al., 1952) is only valid for clean sand formations, which means that karstification and clay presence preclude its direct application. The use of more powerful TDEM than the one used in this study and complementary methods, such as reflection seismics (Carvalho et al., 2012) or magnetic resonance soundings (MRS) (Legchenko et al., 2009; Vouillamoz et al., 2012a), which target other rock properties (seismic wave propagation and presence of hydrogen ion, respectively), may be extremely useful to overcome the enunciated limitations.

\subsubsection{Contributions to the hydrogeological conceptual model of the ARQ aquifer system}

The presence of the CRET between the MIO and the JUR formations seems to be confirmed by the hydrogeophysics' results of this study and the studies previously cited. It is probable that the JUR aquifer recharges the MIO aquifer from below, due to higher hydraulic heads in the JUR than in the MIO. This upward recharge may occur through the CRET aquitard, through fault zones or through direct contacts between JUR and MIO, 
Table 3.3: Geoelectrical range of the hydrostratigraphical units. PQ: Plio-quaternary; MIO: Miocene; CRET: Cretaceous; JUR: Jurassic; FW: freshwater; SW: saltwater; BW: brackish water.

\begin{tabular}{llll}
\hline Layer & $\begin{array}{l}\text { Resistivity range } \\
(\text { ohm.m) }\end{array}$ & Location & $\begin{array}{l}\text { Resistivity } \\
\text { (ohm.m) }\end{array}$ \\
\hline Sand beach (SW) & $<10$ & A3-5 & \\
\hline PQ unsat. & $100-700$ & $\begin{array}{l}\text { A1-2, B4, B6, } \\
\text { C1-2, D1-5, }\end{array}$ & \\
& & E2-4 & \\
\hline PQ sat. & $10-15$ & A3-5, E2-3 & \\
\hline MIO unsat. & $75-200$ & A1 & \\
\hline MIO sat. (FW) & $20-100$ & A1-5, B4-6, & 110 \\
& & C2-4, D1-3, & \\
& E2-4, F1 & \\
\hline MIO sat. (BW) & $10-50$ & A1-5 & \\
\hline MIO sat. (SW) & $<10-20$ & A2-3, C2-4, & \\
& & C7(?), D1-3, & \\
& & D5(?) & \\
\hline CRET & $10-100$ & B1-2, B3(?), & 25 (C2) and \\
& & B5, C5-7 & $60-100$ (C1) \\
\hline JUR unsat. & $100-200$ & B1 & \\
\hline (a) from Elsendoorn et al. (1982) & & \\
& &
\end{tabular}

although this last configuration was not identified using hydrogeophysics. As there is an apparent geological and hydraulic continuity of the JUR layer below the CRET outcrop, it is proposed that, for groundwater flow modeling, the west boundary of the ARQ management unit should be extended towards the Albufeira north-south fault (GF3), excluding the Albufeira diapir (Figure 3.1, ARQ mod. unit).

Structural accidents affecting the MIO and CRET formations were detected with the ERTs. The GF4, GF5 and GF6 faults do not constitute a hydraulic barrier, since the piezometric surface (Figure 3.4) is not affected. Some faults may have a strong influence in the hydrochemistry of the groundwater by acting as preferential flow channel of diapir ascension or seawater intrusion. Groundwater salinization may be caused by simultaneous sources of diapirism and seawater intrusion, as it has been observed in other coastal aquifers in the Mediterranean basin (Trabelsi et al., 2012; Mongelli et al., 2013). As seawater intrusion can be observed very far from the coast inland, sometimes at $8 \mathrm{~km}$ (de Montety et al., 2008), it is challenging to distinguish diapiric and sea origins. Hydrogeochemical and isotopic surveys are generally required to recognize the sources of the salinization, including rock-water interactions, sea intru- 
sion and anthropic activities (Vengosh et al., 1999; Alcalá and Custodio, 2008; Bronzini, 2011; Mongelli et al., 2013).

The FSWI interface shape was expeditiously detected using the FDEM method, showing that on the west sector it is steepest than in the east sector because of lower hydraulic gradient in this area.

Offshore data were also compiled from other studies to complement the onshore observations. The map of the sea bottom of the Algarve internal shelf (Braz Teixeira and Macedo, 2001, Figure 3.9) shows an outcropping rocky sea bottom extending from Albufeira to Olhos de Água, with its south border in the southwest direction. Correlation with the outcrops of the beach cliffs indicates that this rocky bottom is composed by MIO formations. At east, these MIO formations are covered by offshore sands that overlay the PQ formations. This description is corroborated by a seismic profile (Fig. 3.10) that evidenced the offshore MIO outcropping at the proximal shelf, while at east the offshore MIO formations are confined by $\mathrm{PQ}$. 


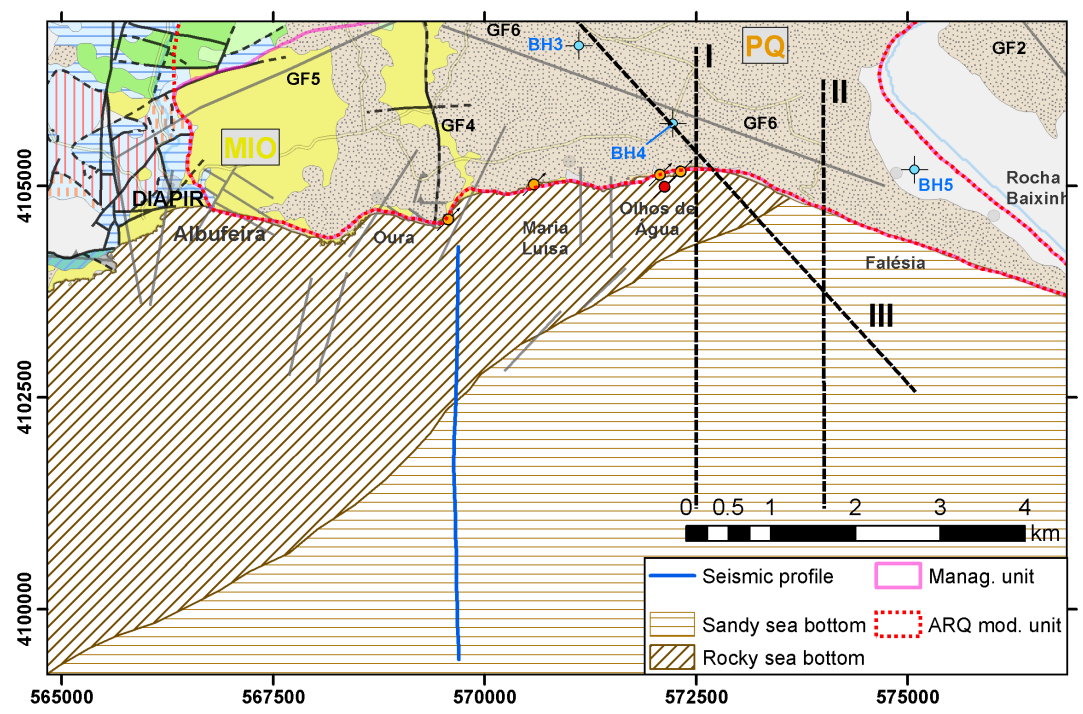

Figure 3.9: Sea bottom map (Braz Teixeira and Macedo, 2001) and location of the offshore seismic profile. See Figures 3.1 and 3.3 for description of other items.

Distance (m)

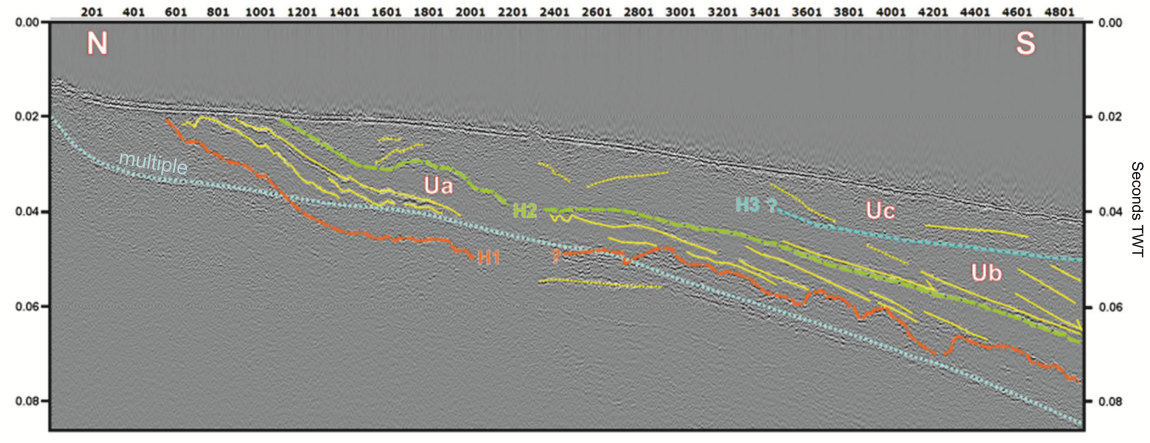

Figure 3.10: Interpreted seismic profile (see location on Figure 3.9) from unpublished FREEZE project report (available at geoportal.lneg.pt/Freeze/FCT-REPORT/Freezefinalreport.pdf). The sedimentary succession overlying the multiple reflection (light blue line with "multiple" tag) is about $32 \mathrm{~m}$ thick and composed of three seismic units (Ua to Uc) correlated with PQ formations. H1 corresponds to the contact between MIO and PQ. Vertical scale is in seconds TWT. Horizontal distance is in meters. 
Joining the geological and hydrogeological information described in section 3.2.2, the deductions made by the interpretation of the piezometric map and the hydrogeophysics, as well as offshore data previously described and other (Lopes et al., 2006; Roque, 2007; Terrinha et al., 2013), it was possible to conceive a 3D hydrogeological conceptual model. To illustrate it, 3 representative hydrogeological cross-sections are presented (Figure 3.11):

- cross-section I shows the case west of Olhos de Água, where the MIO is outcropping offshore, allowing the development of an outflow face characterized by inter- and subtidal groundwater springs. It is probable that submarine groundwater spring extends to the west of Olhos de Água between the coast and the boundary of the outcropping offshore MIO. However, as these springs should be deeper than the one at Olhos de Água, they should not be detectable at the sea surface;

- cross-section II shows the case at east of Olhos de Água, where the offshore PQ confines the offshore MIO and where no submarine groundwater springs are expected (only diffuse groundwater discharge, as represented by light blue arrows);

- cross-section III, oriented northeast-southwest, explains the concentration of the inter- and subtidal springs at Olhos de Água. Considering that groundwater flow is towards south to southeast and the groundwater is trapped in the offshore confined MIO formations, the discharge must occur at Olhos de Água where the MIO aquifer still outcrops before disappearing below the PQ confining unit.

This conceptual model was partially corroborated by an offshore survey of seawater electrical conductivity, temperature and depth (CTD) (Sousa et al., 2014). This CTD survey indicated that fresh submarine groundwater discharges (SGD) occur in the proximal shelf between Albufeira and Olhos de Água, mainly between -12 and $-20 \mathrm{~m}$, corroborating the case represented in cross-section I. East of Olhos de Água, i.e. where the MIO aquifer is confined by the PQ (cross-section II), no SGD were detected by the CTD survey. The position of the FSWI will partially depend on hydraulic heads in the MIO and JUR aquifers, although still to be solved are the hydraulic relationships between the JUR and the MIO. It is probable that as in onshore, the offshore JUR recharges the MIO, namely through fault zones. However the offshore geological settings is very complex, being also characterized by diapiric structures (Lopes et al., 2006; Roque, 2007; Terrinha et al., 2013) and there is a lack of data in the offshore proximal shelf. Deep multichannel seismic reflection surveys would be very valuable to clarify the relationships between offshore MIO, CRET and JUR.

The presented hydrogeological conceptual model indicates that the offshore, confined MIO and JUR aquifers may store large groundwater resources. Fresh groundwater resources trapped in offshore, confined aquifer, have been identified in several coastal aquifers around the world 
$\mathbf{N}$

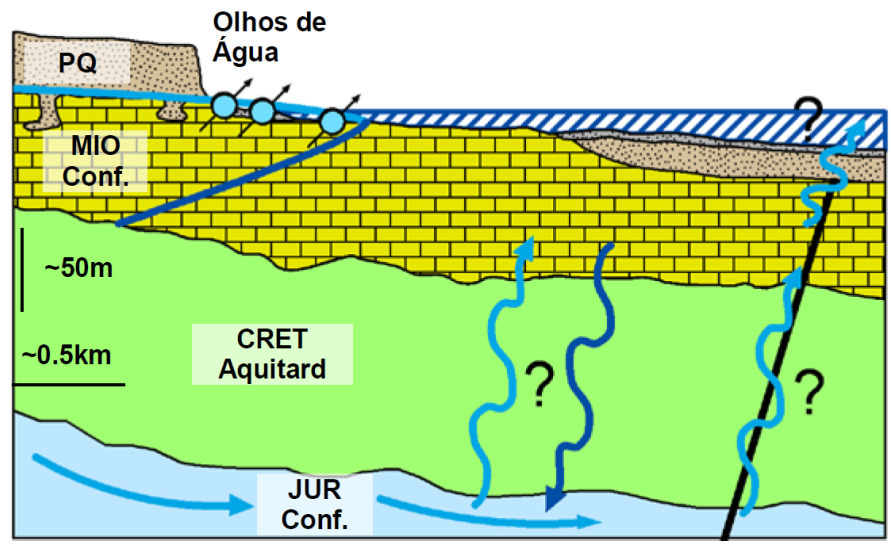

Cross-section I

$\mathbf{N}$

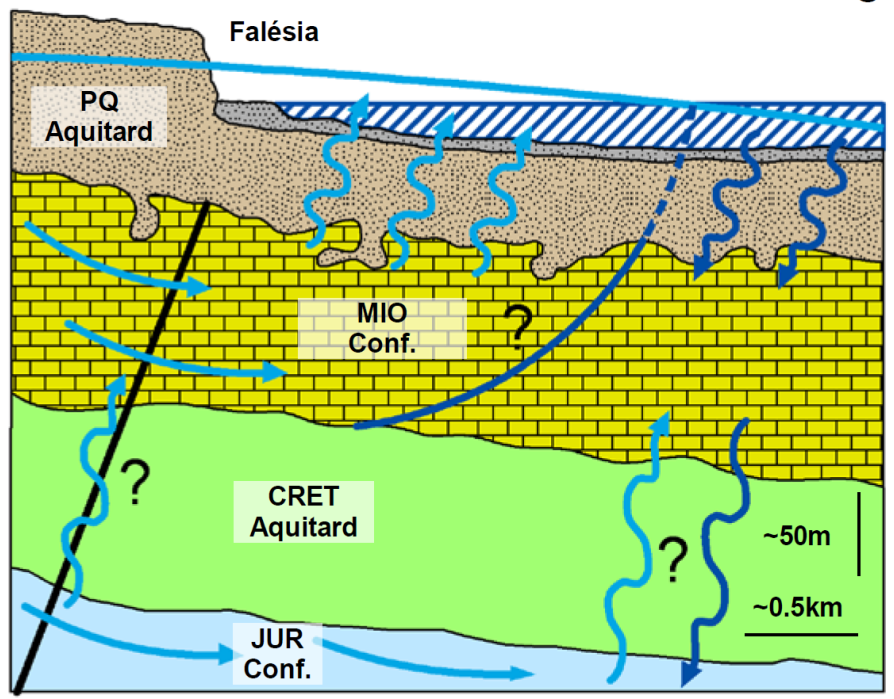

Cross-section II

NW

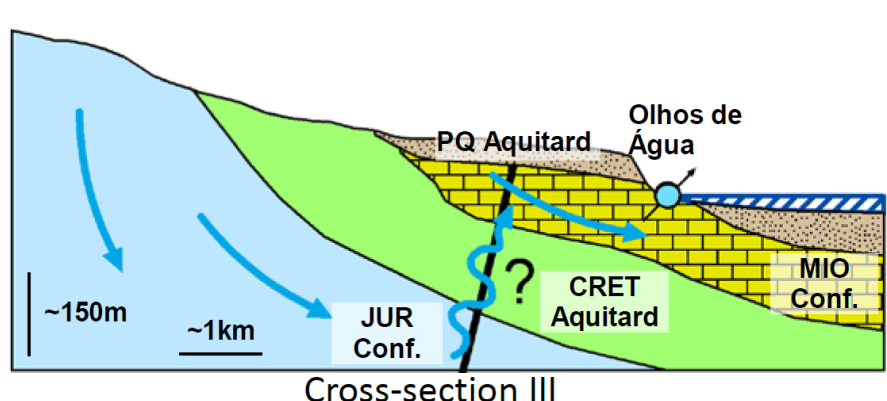

SE

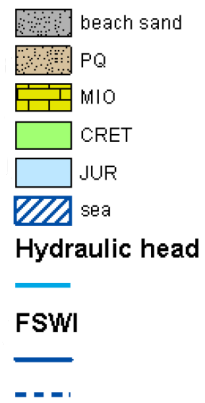

Figure 3.11: Schematic cross-sections I to III (see location on Figure 3.3) representing the hydrogeological conceptual model. Vertical and horizontal scales are approximative. 
(Post, 2005; Post et al., 2013). These authors proposed a paleoevolution model of coastal aquifers to explain the occurrence of such hydrogeological configuration. This model is in agreement with the recent coastal shoreline paleoevolution in Algarve: the shoreline moved gradually from bathymetric $-60 \mathrm{~m}$ up to its actual position during the transgressive regime succeeding the Younger Dryas, in Upper Pleistocene (Dias et al., 2000). Several authors (Dias et al., 2000; Braz Teixeira and Macedo, 2001) detected submerged morphologies (abrasion platforms, cliffs and isthmus) that were interpreted as paleoshorelines. The hydrography and hydrogeology of this period was similar to the actual ones, i.e. surface and groundwater were flowing towards south, with preferential pathways of groundwater circulation until depths of about $-40 \mathrm{~m}$, and more recently $-20 \mathrm{~m}$, where the beach springs would probably be located.

The 3D hydrogeological conceptual model of the ARQ aquifer, extending $\sim 15 \mathrm{~km}$ offshore, was converted into 2D cross-sectional and $3 \mathrm{D}$ variable-density groundwater flow numerical models (Hugman et al., 2014a). The objective of such numerical models was to test the hydraulic relationships between JUR, CRET, MIO aquifers and seawater. Results confirmed that SGD mostly occur at the offshore boundary between the MIO and the overlying low permeability PQ aquitard. Coastal freshwater discharges reached their maximum value in the area near Olhos de Água, being located up to $40 \mathrm{~m}$ away from the shoreline, which corresponds to field observations. The saltwater wedge in the MIO reached approximately $300 \mathrm{~m}$ inland. Depth and extent of the saltwater toe in the MIO were similar to results from the FDEM cross-sections (Figure 3.6).

To reduce uncertainties in the groundwater numerical model, it would be important to optimize the monitoring network, with at least one piezometer in each sector of the aquifer (unconfined JUR, unconfined MIO, confined JUR below CRET, confined JUR below MIO and CRET, confined MIO below PQ). Groundwater level, electrical conductivity and temperature measurements could be automatically recorded at high temporal resolution (hourly or daily) with probes equipped with electronic sensors and loggers at a relative low costs $(\sim 1500 €$ /sensor), only requiring downloading of the data once or twice a year, depending on the memory capacity of the logger. Such probes could be installed at low cost in the deactivated municipality boreholes for which lithological logs and screen depths are know. The spatio-temporal assessment of groundwater recharge using existing hydrometeorological network of APA and a distributed recharge model coupled with a groundwater model (Monteiro et al., 2007b,a; Francés and Lubczynski, 2015) would also be relevant to constrain the groundwater model. Such tools and data would largely benefit the groundwater management of the ARQ coastal aquifer, aiming to preserve the quality and quantity of the available groundwater resources that frequently complement the water supply based on surface water. 


\subsection{Conclusion}

A combination of geoelectrical and electromagnetic hydrogeophysical methods comprising TDEM, FDEM and ERT surveys were conducted onshore to clarify open questions related with the hydrogeological conceptual model of the ARQ coastal aquifer. Apart from useful results that were obtained, limitations of the applied hydrogeophysical methods were identified, which lead to proposals for further studies.

Two main modifications are proposed, leading to the definition of a new ARQ modeling unit to be used in future efforts of groundwater flow modeling. First, as the CRET was detected below the MIO layer in the southern area of the ARQ, this aquitard should be included in the hydrogeological conceptual model as it controls the hydraulic connection between the MIO and JUR. The multilayered nature of the system is of particular interest in a coastal aquifer due to the potential for an offshore extent of fresh groundwater. Second, the western limit of the ARQ management unit should be extended towards the Albufeira northsouth fault (GF3), as there is geological and hydrogeological evidence that the JUR layer extends south below the CRET, and that the GF5 fault does not constitute a hydraulic barrier. These two modifications are highly relevant in the implementation of a groundwater flow model since the boundaries and defined hydrostratigraphical units have a strong impact on the modeled water balance components and modeled aquifer hydrodynamics.

The shape of the FSWI was detected using the FDEM method, showing a steeper inclination in the western sector than in the eastern sector. This is explained by the higher hydraulic gradient in the west than in the east. FDEM surveys perpendicular to the Quarteira stream, carried out during different seasons, would help to clarify the hydraulic relationship between this stream and the ARQ, in particular in the north sector. These two data, i.e. the shape of the FSWI and the influent/effluent characteristics of the Quarteira stream, are of use to constrain and control the output of the groundwater flow model and would contribute to reducing uncertainty in simulated results.

The concentration of inter- and subtidal groundwater springs at Olhos de Água was explained taking into consideration the hydrostratigraphical relationships deduced by the hydrogeophysics and extending them to the offshore proximal shelf taking into account other, complementary offshore studies. This conceptual model indicates probable groundwater resources trapped offshore in the MIO layer confined by the PQ layer.

In a follow-up study (Hugman et al., 2014a), the upgraded hydrogeological conceptual model was implemented into a variable-density groundwater flow numerical model. It confirmed that coastal freshwater discharges are maximum at Olhos de Água and they mostly occur at the offshore boundary between the MIO and the overlying low permeability PQ aquitard. The interchange of information between numerical modeling and the hydrogeophysical-based conceptual models is an iterative 
work towards less uncertain water balances and hydrodynamic aquifer characterization. Together with the information derived from the numerical model and the recommendation of this study to complement the hydrogeophysical survey, more data can be acquired to improve the knowledge of this complex aquifer system. The implementation of a coherent monitoring network of groundwater level and electrical conductivity may also contribute to a better understanding of the aquifer dynamics. The associated costs could be relatively low by making use of existing infrastructure. These several propositions would constitute a significant improvement for the water management of the ARQ coastal aquifer, minimizing the risk of salinization and preserving a groundwater resource that has been shown to be highly relevant in complementing or substituting the single source, surface water supply during drought periods. 


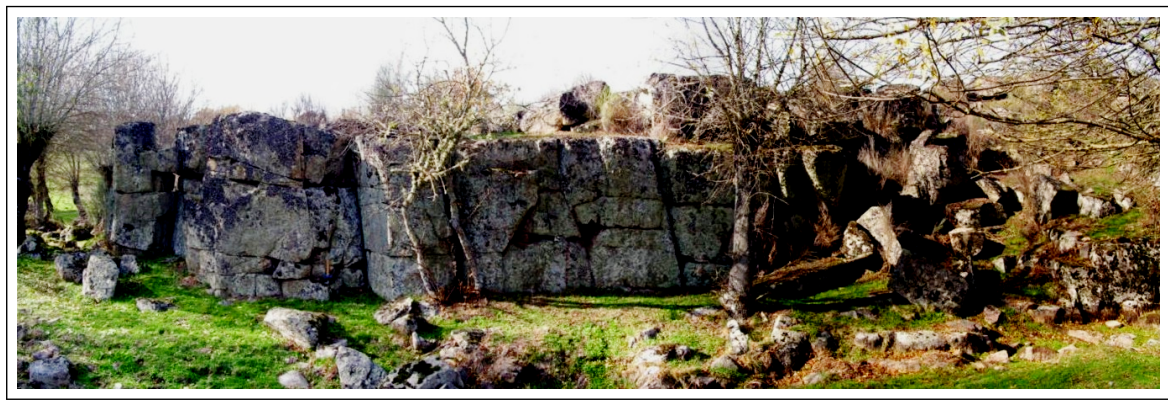

Outcropping fissured granite in Sardón catchment (Salamanca, Spain). 



\title{
Hydrogeophysics and remote sensing for the design of hydrogeological conceptual models in hard rocks - Sardón catchment (Spain)
}

\subsection{Introduction}

\begin{abstract}
Although groundwater resources in hard rock aquifers are generally limited in term of productivity, they are strategically important in many regions of the world because they constitute a unique source of water supply for population and agriculture (Cook, 2003; Singhal and Gupta, 2010). Hard rock aquifers are characterized by high heterogeneity, which leads to difficulties in groundwater prospecting, boreholes implementation and water resources management. This heterogeneity exhibit a complex pattern that results from the interaction of factors such as mineralogy and texture of lithologies, regional and local tectonics, and paleoclimate. An overall layout of the general conceptual model of hard rock aquifers, both from horizontal extent and depth-wise structure, was described by e.g. Lloyd (1999); Lachassagne et al. (2001); Dewandel et al. (2006). Its description includes from top to bottom: (i) an upper weathered layer, so-called saprolite, that has typically a storage function; (ii) an underlying fissured layer that has a transmissive function; and (iii) a fresh basement composed of massive, unaltered rocks with low primary and secondary porosity. The mapping of such structures and retrieval of their hydraulic properties is essential to design a hydrogeological conceptual model of hard rock aquifers.
\end{abstract}

This chapter is based on: Hydrogeophysics and remote sensing for the design of hydrogeological conceptual models in hard rocks Sardón catchment (Spain). Francés, A. P., M. W. Lubczynski, J. Roy, F. A. Monteiro Santos, and M. R. Mahmoudzadeh (2014), Journal of Applied Geophysics, 110, 63-81 
A hydrogeological conceptual model is a pictorial representation of a groundwater flow system that summarizes available geological and hydrogeological information of a study area (Anderson and Woessner, 1992). Its purpose is to help hydrogeologists to understand the behavior of a hydrogeological system and to support quantitative modeling. The more complex the geological setting, the more important is a hydrogeological conceptual model. Therefore, particularly in hard rock aquifers, the design of a reliable hydrogeological conceptual model is a critical step in quantitative hydrogeological system assessment typically carried out by groundwater modeling, as it strongly conditions the reliability of such models.

Besides horizontal and depth-wise heterogeneities, another important challenge in hydrogeological studies of hard rocks is the scale dependence of aquifer parameters. Based on worldwide dataset of different fractured rocks, Illman (2006) observed an asymptotic increase of permeability from laboratory to regional scale. Sánchez-Vila et al. (1996), Neuman and Federico (2003) and de Marsily et al. (2005) presented a theoretical framework to explain this observation in different rock types. They pointed out the relevance of spatial organization and connectivity of low and high hydraulic conductivity $(K)$ zones to explain the scale effect. Dewandel et al. (2012) studied the spatial distribution of aquifer parameters at the catchment scale in a deeply weathered crystalline aquifer in India (Maheswaram catchment). They observed that $K$ was relatively homogeneous in the fissured zone at the scale of few hundreds of meters to around one kilometer. This observation is remarkable because this range is similar to the cell-size of numerical groundwater models at the catchment scale.

The classical, physically based approach aims to analyze hydrological processes at the local scale and to scale-up the results to the catchment scale (Sivapalan et al., 2003a). However, large scale preferential flow paths in the subsurface may not be observed at the local scale, and thus measurement of properties at the local scale may be not adequate to model the catchment scale hydrodynamics. To account for heterogeneities and scale dependence in hard rock aquifers, the concept of top-down approach (Sivapalan et al., 2003b), also known as downward approach, is more adequate. The downward approach consists of analyzing the hydrology of a catchment by interpreting data obtained at the catchment scale to find patterns in the observed data. It is inherently cross-scale and multi-methods approach. Robinson et al. (2008) presented a review of electrical and magnetic geophysical methods to study the hydrology of watersheds using the downward approach. As a general methodology, they proposed to use airborne electromagnetic system to identify the large-scale dominant structures and associated hydrological processes. The zones of interest were afterwards surveyed using ground-based, local geophysical methods. They also presented study cases in different geological settings where geophysics was used to identify the dominant hydrological processes and to quantify hydrological parameters or variables. 
In hard rock aquifers, remote sensing (RS) techniques are frequently used to detect the main hydrogeological features at the catchment scale. Lineament detection based on digital terrain model (DTM) processing allows to identify the main fault zones, while geomorphological classification supports the mapping of pediments (sub-horizontal hard rock erosion front), inselbergs and weathered areas (Srinivasa et al., 2000; Meijerink et al., 2007). Lachassagne et al. (2001) and Vouillamoz (2003) indicated RS and photo interpretation techniques as particularly suitable to obtain a first characterization of a study area to be subsequently complemented at the local scale by geophysical methods. Additionally, Lachassagne et al. (2001) developed a downscaling methodology based on GIS and multi-criteria analysis to map high-yield zones in the hard rock aquifer of Massif Central (France). The applied methodology integrated terrain parameters, such as lithology type, slope map, thickness of weathered and fissured zones, fracture network information, obtained by RS and DTM analysis, conventional field work and geophysical surveys.

Subsurface data are generally scarce because invasive methods such as borehole drilling and associated aquifer tests are expensive and timeconsuming. Hydrogeophysics provides non-invasive, efficient methods of subsurface data acquisition to identify subsurface rock heterogeneities and potential high water yield zones in hard rock aquifers (Lloyd, 1999; Krishnamurthy et al., 2008). Each hydrogeophysical method has its own characteristics and capability with respect to aquifer characterization, so the selection of the appropriate one must be done as a function of the objectives of a survey and geological settings. Hydrogeophysical methods such as geoelectric and electromagnetic have been widely used to retrieve hard rock hydrogeological structures (Dutta et al., 2006; Ramalho et al., 2012) and aquifer parameters using empirical, area-specific relationships (Chandra et al., 2008; Kirsch and Yaramanci, 2009). Among the hydrogeophysical methods, the magnetic resonance soundings (MRS) one has definite advantage for quantitative groundwater assessment because of its most direct relation to in-situ subsurface water (Legchenko et al., 2004; Lubczynski and Roy, 2007). Such direct relation is a result of selective excitation of the water molecule's hydrogen nuclei $\left(1 \mathrm{H}^{+}\right)$ and detection of its corresponding precession signal through nuclear magnetic resonance (NMR). The 1D inversion of the measured MRS data allows defining subsurface layers characterized by thickness, MRS water content and decay time constant. The application of the MRS output to surface-based groundwater evaluation is detailed in several articles, such as Roy and Lubczynski (2003), Plata and Rubio (2007) and Yaramanci and Hertrich (2009). In particular, the aquifer flow parameters, hydraulic conductivity $(K)$ and transmissivity $(T)$, are derived from both MRS water content and decay time constant. The storage parameters, i.e. specific yield $\left(S_{y}\right)$ and elastic storativity $\left(S_{e}\right)$, are related with the MRS water content (Legchenko et al., 2004; Vouillamoz et al., 2005; Lubczynski and Roy, 2007; Vouillamoz et al., 2007), although recent studies also included the decay time constant (Vouillamoz et al., 2012b, 2014b,a). The MRS sensitivity of water detection was illustrated with a synthetic study of 
Legchenko et al. (2006) who showed that a $20 \mathrm{~m}$ thick layer with water content of $2 \%$ can be detected down to $\sim 50 \mathrm{~m}$ under low noise conditions ( $\sim 5 \mathrm{nV}$ stacked noise). However, the MRS signal of a deep layer with low water content overlain by a surficial layer with high water content will be attenuated and might not be detected (Vouillamoz et al., 2005; Legchenko et al., 2006). For these reasons, in hard rocks, MRS is suitable to detect groundwater in the saprolite reservoir but the fissured reservoir characterized by low water content is usually hardly detectable (Wyns et al., 2004; Baltassat et al., 2005; Vouillamoz et al., 2005; Legchenko et al., 2006).

In this study, we propose a multi-technique methodology to define the geometry and the hydrogeological parameters of hard rock aquifers as major contribution to the design of hydrogeological conceptual models. The proposed methodology is based on the downward approach and focuses on the integration of RS techniques and hydrogeophysical methods with hydrogeological field data acquisition methods. Our specific objective was to identify the main hydrogeological features such as high and low hydraulic conductivity zones, their spatial distribution and connectivity and characterize them in the context of groundwater flow at the catchment scale. The proposed method is particularly suitable for areas with borehole data scarcity, such as the granitic Sardón Catchment $\left(\sim 80 \mathrm{~km}^{2}\right.$, Figure 4.1$)$ where this study was realized. That catchment was selected as pilot research area due to hard-rock hydrogeology, semi-arid climate and scarcity of groundwater resources. By applying the proposed method, we revised the former hydrogeological conceptual model of the Sardón catchment (Lubczynski and Gurwin, 2005a) with the aim to upgrade the existing numerical groundwater model in a follow up study (not part of this chapter), quantifying typically underestimated subsurface fluxes such as groundwater evaporation and groundwater transpiration (Lubczynski, 2011).

\subsection{Study area}

The Sardón catchment $\left(\sim 80 \mathrm{~km}^{2}\right.$, Figure 4.1$)$ is located west of Salamanca, in the Castilla y León province (Spain). The terrain elevation ranges from 730 to $860 \mathrm{~m}$ a.s.l. (Figure 4.2). Geologically, the study area belongs to the Central Iberian Zone of the Iberian Meseta. The Sardón catchment is predominantly covered by anatexic granites of the Hercynian megastructure known as the Tormes Gneiss Dome (Instituto Geológico y Minero de España, 1991a,b; López, 2004). These fine to medium particlesize granites and biotitic leucogranites are primarily composed of quartz, plagioclases, potassium feldspars and biotite, while secondary minerals are cordierite and muscovite. Some intrusions of basic rocks (tonalites) outcrop following E-W stripes (Figure 4.1 and Table 4.1). At the regional scale, the folding axes are oriented along the NW-SE direction while the predominant fracture system follows the NNE-SSW direction. The faults along this fracture system originated from the tardi-hercinian brittle 
deformation. Some of these faults are associated with quartzite dykes that, together with adjacent rocks, show a strong tectonic activity (breccia and mylonitization), which testify the Mesozoic and alpine deformation phase. The centrally located Sardón stream (Figure 4.1) extends along the main NNE-SSW fault zone (F1), with regional expression. A set of faults with NE-SW direction (F2) also affects the catchment hydrology, controlling the direction of secondary, tributary streams. The F1 fault zone was characterized as brittle shear zone while the F2 fault set as ductile shear zone (Attanayake, 1999; Habtemariam, 2000). The brittle shear zone F1 has larger hydrogeological potential because fracturing enhances the weathering and increases the connectivity and storage. The F2 ductile shear zones are locally associated with quartz dykes that may have an important role in conducting groundwater.

The landscape is characterized by a pediment with gentle slopes that corresponds to present and old planation surfaces. It is erratically interrupted by inselbergs, exposed corestones and granite outcrops. The rocky escarpment flanking the east bank of the Sardón stream corresponds to the geomorphologic expression of the eastern block tectonic uplift along the F1 central fault zone. The landscape is also marked by a dense drainage network of incised streams along faults, typical of hard rock catchment. While the pediment is covered by a thin ( 0.10 to $0.75 \mathrm{~m}$ ) sandy-loam inceptisol (eluvium), alluvial deposits 1 to 3 $\mathrm{m}$ thick are located along the thalweg (line defining the deepest channel in a valley). The main part of the alluvium profile is composed of silty sand above a $\sim 0.5 \mathrm{~m}$ thick layer of centimeter to decimeter size pebbles. The alluvium is hydraulically connected to the saprolite.

The groundwater table fluctuation is monitored in the catchment with: (i) 10 shallow piezometers (depth between 0.5 and $3.2 \mathrm{~m}$ ) and 1 shallow borehole (7.9 m deep) drilled along the thalweg; and (ii) 4 large diameter, shallow wells ( $\sim 3 \mathrm{~m}$ deep) excavated in the outcropping fissured zone. The groundwater table depth varies between 0.0-3.0 meter below ground surface (m b.g.s.) along the thalweg and between 1.0-12.0 $\mathrm{m}$ b.g.s. at the watershed divides. The average electrical conductivity of the groundwater measured in the monitoring network at several seasons is $\sim 150 \mu \mathrm{S} . \mathrm{cm}^{-1}$, i.e. an electrical resistivity of $\sim 67 \Omega$.m. The groundwater table follows the topography and has a concentric pattern largely influenced by the Sardón fault drainage line. The groundwater pattern is natural because the groundwater use in the study area is negligible, limited mainly to manmade, groundwater-connected ponds used for livestock water supplies. 


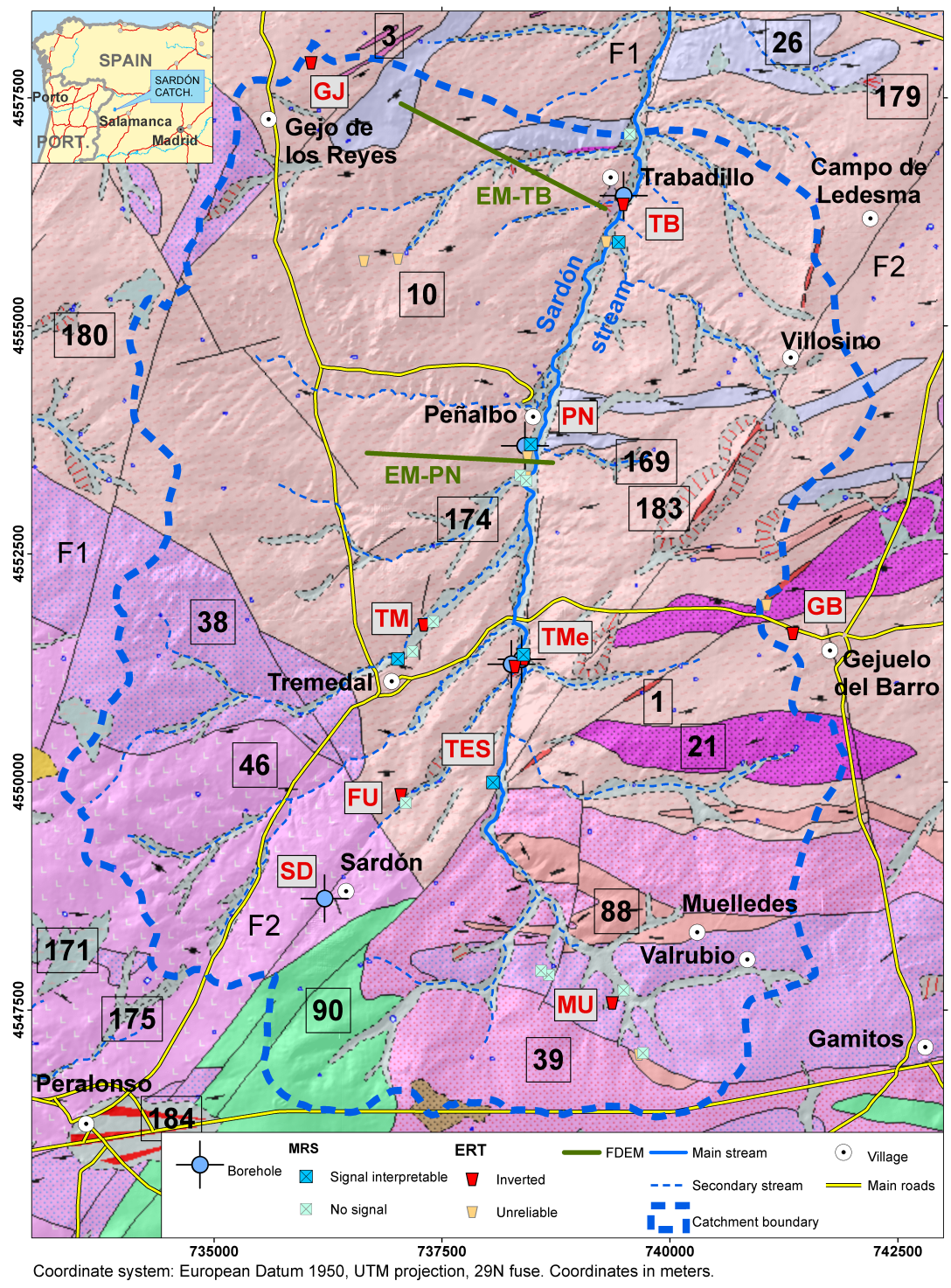

Figure 4.1: Geological map of the Sardón catchment (Villar Alonso et al., 2011) and geophysical surveys (red labels). Numbers of the geological formations refer to the original map and are explained in Table 4.1. F1 and F2: main fault sets oriented NNE-SSW and NE-SW respectively. 
Table 4.1: Geology of the Sardón catchment (Villar Alonso et al., 2011).

\begin{tabular}{lll}
\hline Group & ID & Description \\
\hline $\begin{array}{l}\text { Cenozoic } \\
\text { rocks }\end{array}$ & 156 & $\begin{array}{l}\text { Arkoses, conglomerates and pebbles (Eocene- } \\
\text { Oligocene) }\end{array}$ \\
\cline { 2 - 3 } & $\begin{array}{l}169 \text { to } \\
184\end{array}$ & $\begin{array}{l}\text { Pebbles, gravels, sands and silts from terraces, } \\
\text { depressions and endoreic areas, valley bottom, } \\
\text { alluvium and colluvium, recent cones and fans, } \\
\text { coluvium, and glacis (Pliocene to Holocene) }\end{array}$ \\
\hline $\begin{array}{l}\text { Paleozoic } \\
\text { rocks (Ollo de } \\
\text { Sapo domain) }\end{array}$ & 90 & $\begin{array}{l}\text { Schists, meta-arenites and calcium silicate rocks } \\
\text { (Cambrien-Ordovician) }\end{array}$ \\
\hline $\begin{array}{l}\text { Prevariscan } \\
\text { plutonic } \\
\text { rocks }\end{array}$ & 88 & Feldspathic orthogneisses \\
\hline $\begin{array}{l}\text { Variscan } \\
\text { plutonic } \\
\text { rocks }\end{array}$ & 10 & Inhomogeneous granites \\
\cline { 2 - 3 } & 21 & Two-mica granites \\
\cline { 2 - 3 } & 26 & $\begin{array}{l}\text { Intermediate and basic rocks (granodiorites and } \\
\text { tonalites) }\end{array}$ \\
\cline { 2 - 3 } & 38,39, & Two-mica granites \\
\hline $\begin{array}{l}\text { Dikes } \\
46\end{array}$ & 1 & Quartz \\
\hline
\end{tabular}


Figure 4.2: Lineament detection and interpretation. a) DTM and fault set derived from high pass filter application on the DTM; b) first derivative in $\mathrm{x}$; c) first derivative in $\mathrm{y}$; d) gradient NE; e) gradient NW; f) gradient N; g) gradient $\mathrm{W}$. 


\subsection{Methodology}

The proposed methodology is based on 3 steps: (1) detection of the main hydrogeological features of the catchment based on remote sensing (RS) techniques of digital image processing; (2) characterization of the main hydrogeological features at the local scale using qualitative and quantitative hydrogeophysics; and (3) drilling of 5 boreholes (25 to $48 \mathrm{~m}$ deep) and performing of slug tests to verify the hydrogeophysical interpretation and to calibrate the MRS parameters. The results from RS and hydrogeophysics were finally merged in a GIS environment, defining estimates for: spatial resolution, aquifer geometry, zones of hydrogeological homogeneity together with the aquifers parameters distribution and range. This allowed designing the Sardón aquifer hydrogeological conceptual model.

\subsubsection{Remote sensing techniques}

Remote sensing (RS) techniques were applied to map: (i) fractures and faults; and (ii) granite outcrops, using digital image processing on digital terrain model and high-resolution, multispectral satellite images. Fractures and faults were identified using lineament detection through the application of high-pass filters (Meijerink et al., 2007) on a DTM (Figure 4.2) of the Spanish Centro Nacional de Informacíon Geográfica (www.cnig.es) with $5 \mathrm{~m}$ horizontal resolution and centimetric vertical accuracy that was validated in this study against differential GPS survey. High-pass filters highlight edges in images by calculating at each cell a new brightness value that is equal to the weighted average of the original brightness value of the adjacent cells. Using the tools available in ESRI ${ }^{\circledR}$ ArcGIS 10.0 for Desktop Advanced, we applied a kernel with format $3 \times 3$ cells, applying the following weight matrices: first derivative in $\mathrm{x}$ and $y$ directions and gradients in N, W, NW and NE directions. Based on the resultant sharpened images, we digitized manually the lineaments.

Granite outcrops, i.e. the outcropping fissured layer, were mapped using two high-resolution, multispectral satellite images: QuickBird from September 2009 and WorldView-2 from December 2012 (Figure 4.3). Both images were composed of 4 standard color bands, i.e. red, blue, green and near-infrared, and had similar resolution (2.4 m for QuickBird and $1.8 \mathrm{~m}$ for WorldView-2). A supervised classification technique based on object-oriented fuzzy-logic analysis (Benz et al., 2004) using eCognition software was used to process the RS images in order to delineate fissured layer outcrops from the pediment. The description of this classification technique, applied to soil mapping, is presented in Chapter 2 and Francés and Lubczynski (2011). 
Figure 4.3: Mapping of granite outcrops with remote sensing (RS) image processing. Left: extracts of OuickBird from September 2009 (top) and WorldView-2 from December 2012 (bottom) images (false color composites, bands 4/2/3 as RGB). Right: classified outcrops in light pink (see Figure 4.1 for keys); the red outlined rectangle indicates the localization of the 2 RS image excerpts. 


\subsubsection{Hydrogeophysics}

The hydrogeological features detected in the previous step (fault zones, saprolite, fissured layer) were analyzed at the local scale using hydrogeophysics. The locations of the surveyed sites were based on the following criteria: (i) to clearly belong to one of the representative hydrogeological features mapped by RS; (ii) availability of ground truth subsurface information such as lithology and depth of water table (piezometer, well, pond); (iii) accessibility to geophysical and drilling surveys.

\subsubsection{Ground penetrating radar method}

Ground penetrating radar (GPR) was applied to retrieve the spatial distribution of groundwater table and soil thickness over the catchment (Mahmoudzadeh et al., 2012). A pulse radar with a single $200 \mathrm{MHz}$ bowtie antenna was selected and combined with a differential GPS and a survey wheel for accurate positioning. The measurements were performed in transects transversal to stream beds, which were dry during the survey period (September 2009). The acquired field data of the GPR reflection were interpreted by comparison with GPRMax2D forward modeling of the GPR signal with several hypothetical configurations of the subsurface, i.e. relative positions of soil, saprolite and groundwater table interfaces. The GPR data were locally transformed from time domain into depth by acquiring the soil dielectric constant with a frequency domain reflectometry probe (Seyfried et al., 2005). Details on that procedure can be obtained from Mahmoudzadeh et al. (2012).

\subsubsection{Electrical method}

In 2009 and 2010, we performed 16 electrical resistivity tomography (ERT) profiles (Figure 4.1) to retrieve the hydrostratigraphy and detect vertical heterogeneities. The ERT method is described in details in several textbooks as for instance Ernstson et al. (2009). We used a programmable, commercial resistivity-meter Supersting R8 from Advanced Geosciences Inc. (AGI). This 8-channel instrument was equipped with a central switch box and 4 passive cables, each one with 14 electrodes (56 electrodes in total) and maximum basic electrode spacing of $6.25 \mathrm{~m}$. We programmed two single spread Schlumberger arrays (i.e. without roll-along configuration), each one with basic electrode spacing of 3 and $5 \mathrm{~m}$. The A-B current electrodes separation ranged from 9 to $162 \mathrm{~m}$ for the $3 \mathrm{~m}$ basic electrode spacing and from 15 to $270 \mathrm{~m}$ for the $5 \mathrm{~m}$ basic electrode spacing.

Due to the overall project logistics, the field surveys were done during the end of the dry period in September and October. Although this period was favorable to obtain the highest resistivity contrast between unsaturated and saturated zones, the topsoil was very dry which resulted in frequent high contact resistances $(>5000 \Omega)$. Not much improvement was obtained by pouring salty water at each electrode due to the low 
water content of the soil and significant thickness of the very dry unsaturated layer. The poured water was absorbed by the soil around the electrode, creating a bigger soil electrode, but with no contact with the significant soil moisture content located much deeper (Lloyd, 1999). Similar problem was encountered by Danielsen et al. (2007) that had galvanic contact problems in Kalahari sands, even while watering and using 0.5$1 \mathrm{~m}$ long electrodes. In our case, we filtered the dataset before inversion by removing the data with high contact resistance using the "Exterminate bad datum points" option of the RES2DINV software (Geotomo software, 2010). When the number of removed electrodes was too high (i.e. $>1 / 3$ of the full dataset), the inversion was not performed. Otherwise, the inversion was performed following the recommendations for noisy data as specified in the RES2DINV manual (Geotomo software, 2010). We applied the robust method of the RES2DINV software because sharp boundaries between the unsaturated and saturated zone and between weathered, fissured and fresh granite were expected. After the first inversion, all points with root-mean-squared error between calculated and measured apparent resistivities higher than 50\% were removed and the final inversion was performed to obtain a vertical cross-section of the electrical resistivity.

To retrieve the hydro-layering of the saprolite and the fissured layers based on the obtained resistivity cross-sections, we interpreted the resistivity contrasts in subsurface. Based on the surface geology knowledge (field observation, geological map and remote sensing mapping), we defined range of resistivity characteristics of the saprolite and the fissured layer.

\subsubsection{Electromagnetic method}

One of the specific objectives of this study was to map the spatial and depth-wise extension of saprolite, fissured layer and fault zones. For that purpose, we required an efficient method that would allow detecting vertical and horizontal subsurface resistivity contrasts across the catchment. Time domain electromagnetic (TDEM) systems are frequently used to determine the subsurface geoelectrical 1D profiles. There are however practical limitations in the use of such configurations at shallow depths and where high lateral resolution is expected (Christiansen et al., 2009). Instead, for such tasks, electromagnetic systems using dipolar sources and normally operated in the frequency domain (FDEM) have been used. One well-known implementation of an electromagnetic system designed for high resolution shallow work is the electromagnetic conductivity meter (McNeill, 1980). Detailed surveys using this type of instrument are reported for the mapping of near surface conductivity changes with high spatial resolution (Triantafilis and Monteiro Santos, 2010; Francés and Lubczynski, 2011). Electromagnetic conductivity meter data provides information on the lateral changes in conductivity but its sounding capability (i.e. vertical distribution of conductivities) is limited.

In this study, we used a multi-frequency electromagnetic horizontal 
coplanar loop system (Slingram). The 1D soundings were performed at a regular distance along transects, using several coil distances. Such device and configuration allowed us to determine the vertical distribution of resistivity below the ground surface while at the same time, as data were acquired along transects, the lateral changes were also detectable. The selected device was Apex Parametrics Ltd. MAX-MIN I8S equipment with 8 frequencies from $444 \mathrm{~Hz}$ to $56 \mathrm{kHz}$. This device measured at each frequency the quadrature and in-phase components of the secondary electromagnetic field. To ensure high quality data, a rigid frame was used for operation of the Slingram electromagnetic set with short $5 \mathrm{~m}$ coil spacing to minimize the difficulties in maintaining a constant intercoil coupling (distance and orientation) in the coplanar configuration (Parasnis, 1966).

The dataset of 1D FDEM soundings along the transects was processed using a laterally constrained inversion (LCI) algorithm (Monteiro Santos, 2004) to obtain subsurface resistivity cross-sections. The LCI algorithm is a modified $1 \mathrm{D}$ inversion with $2 \mathrm{D}$ smoothness constraints between adjacent $1 \mathrm{D}$ models, i.e. the inverted value in each cell is computed taking into account the measured values in the 4 adjacent cells (top, bottom, right, left). Electromagnetic forward and derivative calculations were performed using the full solution of the Maxwell equations (Keller and Frischknecht, 1966). Based on the inversion of the quadrature and the in-phase components of the MAX-MIN data, the algorithm retrieves the electrical resistivity cross-section. The quality of the inversion is assessed by the quality of the fit between the observed and simulated curves of in-phase and out-phase. The two FDEM transects (Figure 4.1), one at the latitude of Peñalbo (EM-PN) and another at the latitude of Trabadillo (EM-TB), were realized in November 1996. The EM-PN was performed with both $5 \mathrm{~m}$ (rigid frame) and $120 \mathrm{~m}$ coil separations while the EM-TB only with $120 \mathrm{~m}$ coil separation. For both transects, the data were acquired every $60 \mathrm{~m}$.

\subsubsection{Magnetic resonance sounding method}

We performed 15 MRS surveys organized in 3 campaigns in years 1997, 2001 and 2009 (Table 4.2 and Figure 4.1), aiming to define hydrostratigraphy and aquifer parameters. In all the campaigns and at every site investigated, the measurement of the Earth magnetic field $(B)$ was carried out with a magnetometer just before and during the MRS survey to calculate the Larmor frequency $\left(f_{l}\right)$. In the 2001 campaign, it turned out that the local value of the Earth's magnetic field expressed as Larmor frequency was very near $1900 \mathrm{~Hz}$, i.e. one of the $50 \mathrm{~Hz}$ power line frequency harmonics, which resulted in very noisy, non-interpretable signal in most of the surveys of that year. As explained in Bernard (2007), $f_{l}$ outside the $50 \mathrm{~Hz}$ harmonics and local scale magnetic homogeneity are required to successfully acquire magnetic resonance signal. Thus, to minimize the risk of unsuccessful MRS data acquisition during the 2009 campaign, one month before the MRS surveys, we measured the natural 
Table 4.2: Summary of the three MRS campaigns.

\begin{tabular}{|c|c|c|c|c|c|c|}
\hline \multirow[t]{2}{*}{ Camp. } & \multirow{2}{*}{ Equip. } & \multicolumn{2}{|c|}{ Performed } & \multicolumn{3}{|c|}{ Successful } \\
\hline & & $\begin{array}{l}\text { Number } \\
\text { of MRS }\end{array}$ & Sites & $\begin{array}{l}\text { Number } \\
\text { of MRS }\end{array}$ & Sites & Loop \\
\hline $\begin{array}{l}1^{\text {st }}- \\
1997\end{array}$ & NUMIS & 3 & $\begin{array}{l}\text { TB, PN, } \\
\text { TM }\end{array}$ & 3 & $\begin{array}{l}\text { TB, PN, } \\
\text { TM }\end{array}$ & $40 \mathrm{~m}$ square \\
\hline $\begin{array}{l}2^{\text {nd }}- \\
2001\end{array}$ & NUMIS & 4 & $\begin{array}{l}\text { MU, TES, } \\
\text { TB }\end{array}$ & 1 & TES & $\begin{array}{l}56 \mathrm{~m} \\
\text { square-eight }\end{array}$ \\
\hline $\begin{array}{l}3^{\text {rd }}- \\
2009\end{array}$ & NUMIS $^{L I T E}$ & 8 & $\begin{array}{l}\text { FU, MU, } \\
\text { PN, TB, } \\
\text { TMe }\end{array}$ & 2 & TMe & $\begin{array}{l}30 \mathrm{~m} \\
\text { square-eight, } \\
60 \mathrm{~m} \text { square }\end{array}$ \\
\hline
\end{tabular}

Earth magnetic field $(B)$ and its spatial variability to detect potential local scale magnetic inhomogeneity and to ensure that $f_{l}$ was outside the $50 \mathrm{~Hz}$ harmonics. The spatial magnetic field measurements were made using a magnetometer Geometrics G856 as rover and the temporal measurements were acquired every minute with a Geometrics G816 as base. The values of the magnetic field measured with the rover were corrected from the diurnal drift measured with the base magnetometer, using the software Geometrics MagMap2000. To locate the measurements we used a standard GPS with synchronized time between the rover and the base to allow the correction. At each selected site, 36 magnetometric measurements were carried out within $100 \times 100 \mathrm{~m}$ rhomboid area. In total we made 629 measurements distributed over 20 sites. $B$ showed to be quite homogeneous, with a mean of $44805 \mathrm{nT}$, small standard deviation of $7 \mathrm{nT}$ and difference between maximum and minimum values of $34 \mathrm{nT}$. The corresponding $f_{l}$ was $1908 \mathrm{~Hz}$, i.e. outside the problematic intervals of the $50 \mathrm{~Hz}$ of electrical power line harmonics. We also measured the magnetic susceptibility of granite outcrops and soils at 6 sites (GB, PN, TM, MU, TMe, FU in Figure 4.1) using a SM-20 device from GF Instruments. The magnetic susceptibility measured on 37 outcrops and soils was less than $10^{-3} \mathrm{SI}$ (average of $0.06 \times 10^{-3}$ with minimum and maximum $0.01 \times 10^{-3}$ and $0.2 \times 10^{-3}$ respectively), so suitable for MRS surveys.

In the first and the second MRS campaigns (1997 \& 2001, Table 4.2), we used the original NUMIS version (Iris Instrument) equipment with a single DC/DC converter and the evolving version of its NUM data acquisition software. At that time, using the equipment and software available for this project, MRS was implemented in a single pulse mode allowing detection and measurement of the signal from free induction decay (FID). The data processing at acquisition time yielded the signal amplitude $\left(E_{0}\right)$ and the FID time constant $\left(T_{2}^{*}\right)$. Following a data inversion step, the MRS data set yielded two aquifer related parameters as a function of depth: MRS free water content $\left(\theta_{M R S}\right)$ and $T_{2}^{*} . T_{2}^{*}$ is dependent on: (i) the transversal decay time constant $\left(T_{2}\right)$, itself dependent on the sampled 
volume petrophysical properties such as pores-size; (ii) inhomogeneity of the ambient magnetic field (Fukushima and Roeder, 1981):

$$
1 / T_{2}^{*}=1 / T_{2}+\gamma \Delta B_{0}
$$

where $\gamma$ is the gyromagnetic ratio and $\Delta B_{0}$ is the ambient magnetic field inhomogeneity typically caused by the 3D spatial distribution of materials ranging in scale from geological structure, such as dyke, down to fine-grain minerals with significant magnetic susceptibility higher than background. In contrast to $T_{2}^{*}$, the longitudinal decay time constant $\left(T_{1}\right)$ is not sensitive to local inhomogeneity of the Earth magnetic field $B$, so it is more reliable than $T_{2}^{*}$ for pore size estimation and related hydrogeological system parameterization (Legchenko et al., 2004; Roy and Lubczynski, 2005; Vouillamoz et al., 2007). For the 2009 campaign (Table 4.2), we used the newer NUMIS ${ }^{L I T E}$ equipment together with its data acquisition software Prodiviner which, although less powerful than the original NUMIS, allowed more complex data acquisition modes. In particular, this MRS system allows estimating $T_{1}$ using a modified nuclear magnetic resonance (NMR) saturation recovery scheme Legchenko et al. (2004). More recently, Legchenko (2013) reviewed different ways of exploiting NMR for MRS purposes. All three data sets of the three MRS campaigns (Table 4.2) were then processed with the version 11.3 of the Samovar software tool (Legchenko, 2011), applying its "complex amplitude mode", to ensure consistency among the inversion results of the three different campaigns. The geoelectrical models supporting the MRS inversions were built using the ERT cross-sections, complemented in some cases with 1D inversion of TDEM data acquired with a TEM-FAST 48 from Applied Electromagnetic Research (50 m loop).

To retrieve the flow parameters from the MRS data, we used the following relationship (Lubczynski and Roy, 2007; Vouillamoz et al., 2007):

$$
\begin{aligned}
& T_{M R S}=C_{T} \sum_{i=1}^{n} \Delta Z_{M R S i} \theta_{M R S i} T_{1 i}{ }^{2} \\
& K_{M R S}=T_{M R S} / \sum_{i=1}^{n} \Delta Z_{M R S i}
\end{aligned}
$$

where $T_{M R S}$ is the transmissivity $\left(\mathrm{m}^{2} . \mathrm{s}^{-1}\right), K_{M R S}$ is the MRS hydraulic conductivity $\left(\mathrm{m} . \mathrm{s}^{-1}\right), \Delta Z_{M R S i}, \theta_{M R S i}$ and $T_{1 i}$ are thickness $(\mathrm{m})$, free water content $\left(\mathrm{m}^{3} \cdot \mathrm{m}^{-3}\right)$ and longitudinal decay time constant $(\mathrm{ms})$ of each water bearing layer retrieved by the MRS inversion ( $i$ is the index of a layer and $n$ is the total number of layers) respectively, and $C_{T}$ is an area-specific, empirical transmissivity multiplier that can be computed at sites where both aquifer tests and MRS surveys are available.

As $T_{1}$ was not acquired in the first two campaigns of 1997 and 2001, we used the measurements of the 2009 campaign with measurements 
of both $T_{1}$ and $T_{2}^{*}$ to derive the ratio $D_{T}=T_{1} / T_{2}^{*}$, considered representative for the granitic Sardón area. In practice, we reviewed all 2009 measurements and eliminated extreme, unreliable $T_{2}^{*}$ by selecting only inversion results that ensured the following arbitrary conditions:

$$
50<T_{2}^{*}<750 \mathrm{~ms} \text { and } \theta_{M R S}>1.5 \% \text { and } T_{1}>T_{2}^{*}
$$

Finally, we used the ratio $D_{T}$ to compute backward $T_{1}$ using $T_{2}^{*}$ measurements acquired during the 1997 and 2001 surveys.

Slug tests were performed in the drilled boreholes (Figure 4.1 and next section) to derive the transmissivity $\left(T_{S T}\right)$ and then $C_{T}$ following Equation (4.5) (Vouillamoz et al., 2005, 2007):

$$
C_{T}=T_{S T} / \sum_{i=1}^{n} \Delta Z_{M R S i} \theta_{M R S i} T_{1 i}^{2}
$$

The relationship between MRS parameters and groundwater storage parameters is still not well established (Vouillamoz et al., 2012b). The computing of extractable groundwater storage in unconfined aquifers requires the specific yield $\left(S_{y}\right)$ while in confined aquifers the elastic storativity $\left(S_{e}\right)$. The MRS survey provides $\theta_{M R S}$, which is an estimate of the free water content $\left(\theta_{f}\right)$ that is composed of both extractable, gravitational water and immobile, non-extractable capillary water (Lubczynski and Roy, 2007). Thus neither $S_{y}$ nor $S_{e}$ are equivalent to $\theta_{M R S}$ although there are empirical relations between them (Lubczynski and Roy, 2004, 2007; Vouillamoz et al., 2007; Boucher et al., 2009b; Vouillamoz et al., 2012b). In this study, to calculate unconfined and confined storage parameters we used the empirical Equations (4.6) and (4.7) respectively (Vouillamoz et al., 2007):

$$
\begin{aligned}
& S_{y_{M R S}}=C_{y} \theta_{M R S} \\
& S_{e M R S}=\rho_{w} g \Delta Z_{M R S}\left(\alpha+\beta \theta_{M R S}\right)=C_{e}\left(\theta_{M R S} \Delta Z_{M R S}\right)
\end{aligned}
$$

where $S_{y_{M R S}}$ is the MRS specific yield, $S_{e M R S}$ is the MRS elastic storativity, $C_{y}$ and $C_{e}$ are empirical storage multipliers of the specific yield and elastic storativity respectively, $\rho_{w}$ is water density, $g$ is gravitational acceleration and $\alpha$ and $\beta$ are aquifer and water compressibilities respectively. $C_{y}$ and $C_{e}$ estimates derived in granites of Burkina Faso and in other lithological formations are available in Vouillamoz et al. (2005) and Vouillamoz et al. (2007).

\subsubsection{Boreholes drilling and slug tests}

The borehole drilling sites were selected following the geological context and when possible by using the interpretations of the ERT and FDEM, aiming to intersect either the saprolite or the fissured layer. At some 
sites, it was not possible to drill due to land owner restrictions. In total, we could drill 5 boreholes down to depths ranging from 25 to $48 \mathrm{~m}$ at 4 sites (TB, PN, $2 \times \mathrm{TMe}$, SD, Figure 4.1) with the following objectives: (i) to confirm the hydrostratigraphy derived from hydrogeophysical surveys; (ii) to analyze the hydraulic connection between saprolite and fissured zone; (iii) to perform aquifer tests to compute the aquifer parameters and calibrate the MRS parameters. The borehole at PN (24 m deep) and the two at TMe (38 and $42 \mathrm{~m}$ deep) were drilled in heavily weathered granite (saprolite). They showed very small yield $<0.1 \mathrm{l} . \mathrm{s}^{-1}$. Another borehole at the TB site was intended to intersect the saprolite following the interpretation of the ERT cross-section. However, as we could not drill exactly at the intended location due to the land owner restriction, the borehole intersected fissured granite already at $3 \mathrm{~m}$ b.g.s. and continued down to $40 \mathrm{~m}$ b.g.s. (total depth of the borehole). At the last, fifth SD site, the borehole was intentionally drilled in fissured granite and extended down to $48 \mathrm{~m}$ b.g.s. Both TB and SD boreholes intersected small fractures which produced total yields between 0.1 and $0.31 . \mathrm{s}^{-1}$.

Due to the generally low borehole yield, in all 5 boreholes, we performed slug tests instead of pumping tests (Butler and Healey, 1998). Slug tests allow determining efficiently the hydraulic conductivity but are generally considered to be only representative of a small volume of aquifer material around the well and do not provide storage properties. Slug tests were interpreted with the Rice-Bouwer method (Kruseman and de Ridder, 1991) using programmed spreadsheets of Tonder et al. (2002).

\subsection{Results and discussion}

\subsubsection{Aquifer geometry}

\subsubsection{Lineament mapping}

The images obtained by the application of high-pass filters on the high resolution digital terrain model (DTM) from the Centro Nacional de Informacíon Geográfica are presented in Figure 4.2. The images of Figures $4.2 \mathrm{~b}$-g highlight clearly the lineaments that were manually digitized and interpreted as presented in Figure 4.2a. By using high-pass filters over DTM, the linear contrasts in terrain elevation of adjacent cells were enhanced. The obtained lineaments corresponded explicitly to geological and geomorphological features (e.g. lithological boundaries and faults). In contrast, optical satellite images or aerial photography also incorporate man-made, linear infrastructures, such as roads or fences. As these structures have a different brightness than surrounding terrain, they are enhanced by high-pass filters, being mapped as lineaments, so potentially misinterpreted as natural geological features. This is why previous attempts, performed using LANDSAT TM and aerial photography (Attanayake, 1999), were less satisfactory than the current results obtained with the DTM. 
In Sardón study area, fractures are mainly oriented in the NE-SW direction (F2 fault set), being connected to the central fault zone oriented NNE-SSW (F1 fault zone). A third fault set (F3), oriented E-W is also connected to the F1 fault zone. We also identified a fourth and fifth sets of fractures in the directions NW-SE (F4) and NNW-SSE (F5) respectively. However, only the F1 fault zone and the F2/F3 fault sets showed a close relationship with the stream network, being therefore responsible for groundwater drainage of the catchment. These results are in agreement with field observations made by Habtemariam (2000) and with the lineament analysis at the regional scale made by López (2004) who found that the stream network was mainly associated with faults of direction between $\mathrm{N} 10^{\circ} \mathrm{E}$ and $\mathrm{N} 50^{\circ} \mathrm{E}$.

\subsubsection{Horizontal extent of saprolite and fissured layers}

The horizontal extent of the granite outcrops that was mapped using a supervised classification method applied on high-resolution remote sensing images is presented in Figure 4.3. The outcrops were associated with the fissured layer while the non-outcrops with saprolite. The classification method used in this study with two high resolution, multispectral satellite images improved the outcrop mapping presented in Lubczynski and Gurwin (2005a) that was done by manual digitizing on stereoscopic aerial photographs. The improvements were mainly due to the availability of near-infrared band and combination of two images, one from dry and the other from wet periods (Figure 4.3 left-top and left-bottom respectively), which allowed enhancing the color contrasts between land cover features. The applied technique showed to be repeatable, faster and more accurate than the former manual interpretation.

\subsubsection{Water table depth}

The 5 boreholes drilled in this study allowed to complement the information provided by the monitoring network mainly restricted to the shallow alluvium and saprolite along the central Sardón stream. Boreholes drilled in the saprolite at PN and TMe confirmed the presence of shallow, unconfined water table at $\sim 2 \mathrm{~m}$ depth. The boreholes drilled directly in fissured granite at TB and SD sites intersected productive, confined fissures at $\sim 20 \mathrm{~m}$ depth with water table stabilized at $\sim 2 \mathrm{~m}$ depth, i.e. at similar depth as the water table in the saprolite. This indicated that the fissured layer is hydraulically connected with the saprolite layer.

To extend the groundwater table depth information available from piezometers, wells and groundwater-linked ponds to areas not covered by the observation network, Mahmoudzadeh et al. (2012) applied GPR technique along number of transects. Using forward modeling of the GPR signal, they demonstrated that the groundwater table interface returns a strong microwave reflection signal. Less visible in the presence of shallower water table was the contact between the soil (either alluvium $<2$ m thick or eluvium $<1 \mathrm{~m}$ thick) and the saprolite. Comparing these 
forward modeling results with the GPR field data, it was evidenced that the water table was present in both alluvium and eluvium and that it followed the topography. In the shallow or outcropping fissured zones, the GPR detection of the water table in discrete, thin fracture zones was not possible due to multiple ambiguous reflections of the GPR signal. The depth assessment of both water table and eluvium/saprolite interface was uncertain because the time-depth transformation was done using a single, bulk dielectric constant value. At sites where both GPR data and water table depth measurements were available, the value of the dielectric constant was calibrated, which allowed to estimate the water table occurring at the depth of $\sim 1-3 \mathrm{~m}$ b.g.s.

The ERT and FDEM methods were not able to detect accurately the water table depth. In this study the applied methods were optimized to retrieve the aquifer layering, i.e. the measurements were made with electrodes and coil separations at the multi-meter scale while the depth resolution requirement for the groundwater models was at the centimeter or at least decimeter scale.

The MRS method has the capability to assess the water table depth in hard rock aquifers (Wyns et al., 2004; Legchenko et al., 2004; Vouillamoz et al., 2005; Legchenko et al., 2006), but only if the aquifer water content is above the technique's sensitivity threshold. New, smaller MRS instrumentation (Walsh et al., 2014) optimized to water table depth detection in the shallow $(<30 \mathrm{~m})$ subsurface may successfully contribute to mapping of the water table depth, keeping in mind the water content sensitivity threshold of such instruments.

\subsubsection{Hydrostratigraphy of saprolite and fissured layers}

\section{Electrical resistivity tomography profiles}

Out of the 16 electrical resistivity tomography (ERT) profiles performed (Figure 4.1), we could only invert and interpret 8 that resulted in the resistivity cross-sections presented in Figure 4.4. The 2D resistivity cross-sections ranged from 165 to $275 \mathrm{~m}$ length and extended from 20 to $45 \mathrm{~m}$ b.g.s., depending on whether the profiles were implemented with 3 or $5 \mathrm{~m}$ electrode separation. The root-mean-squared error between the calculated and measured apparent resistivity values, as indicated in Figure 4.4 , was between $2.6 \%$ at TB and $12.6 \%$ at TM.

The TMe and TB cross-sections were carried out across the main central F1 fault zone (Figure 4.1). At TMe, two ERT profiles were performed, $\mathrm{TMe}(\mathrm{NE})$ and TMe(SW). As shown in Figure 4.4, the two cross-sections show in their western and central part a conductive layer with resistivity between 5 and $75 \Omega$.m extending down to $\sim 40 \mathrm{~m}$ b.g.s. and overlain by a thin, resistive unsaturated zone. That layer is interpreted as heavily weathered granite (saprolite layer). In both TMe, the saprolite layer is underlain by more resistive layer of 150-200 $\Omega$.m interpreted as fissured zone granite. The main difference between the two TMe is observed in their eastern sections. In contrast to $\mathrm{TMe}(\mathrm{SW})$, the TMe(NE), located more 

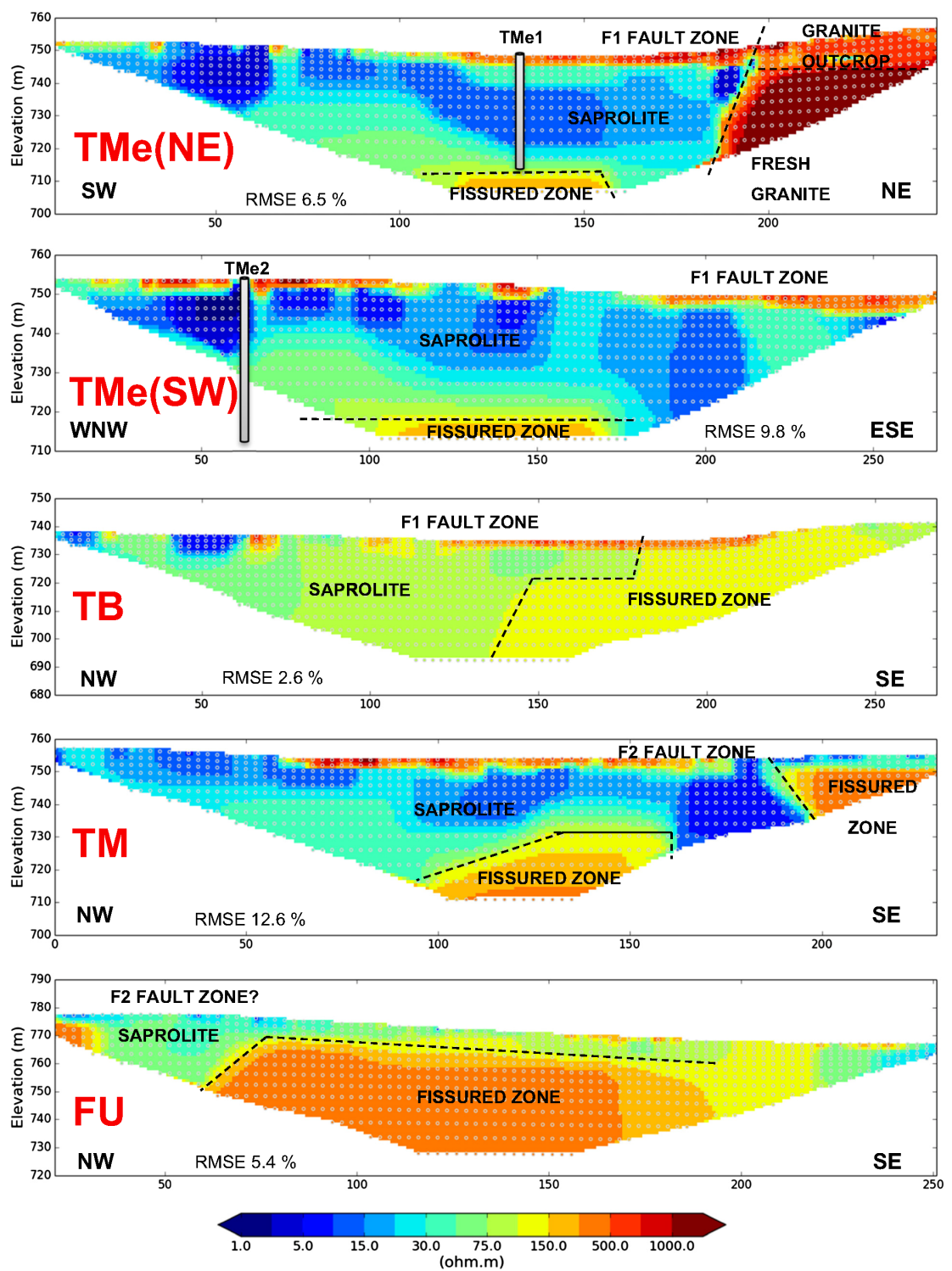

Figure 4.4: Inverted electrical resistivity cross-sections of ERT data (see location in Figure 4.1). Circles indicate the position of the inversion cells. RMSE is the root-mean-squared error, expressed in percent, between the calculated and measured apparent resistivity values. 

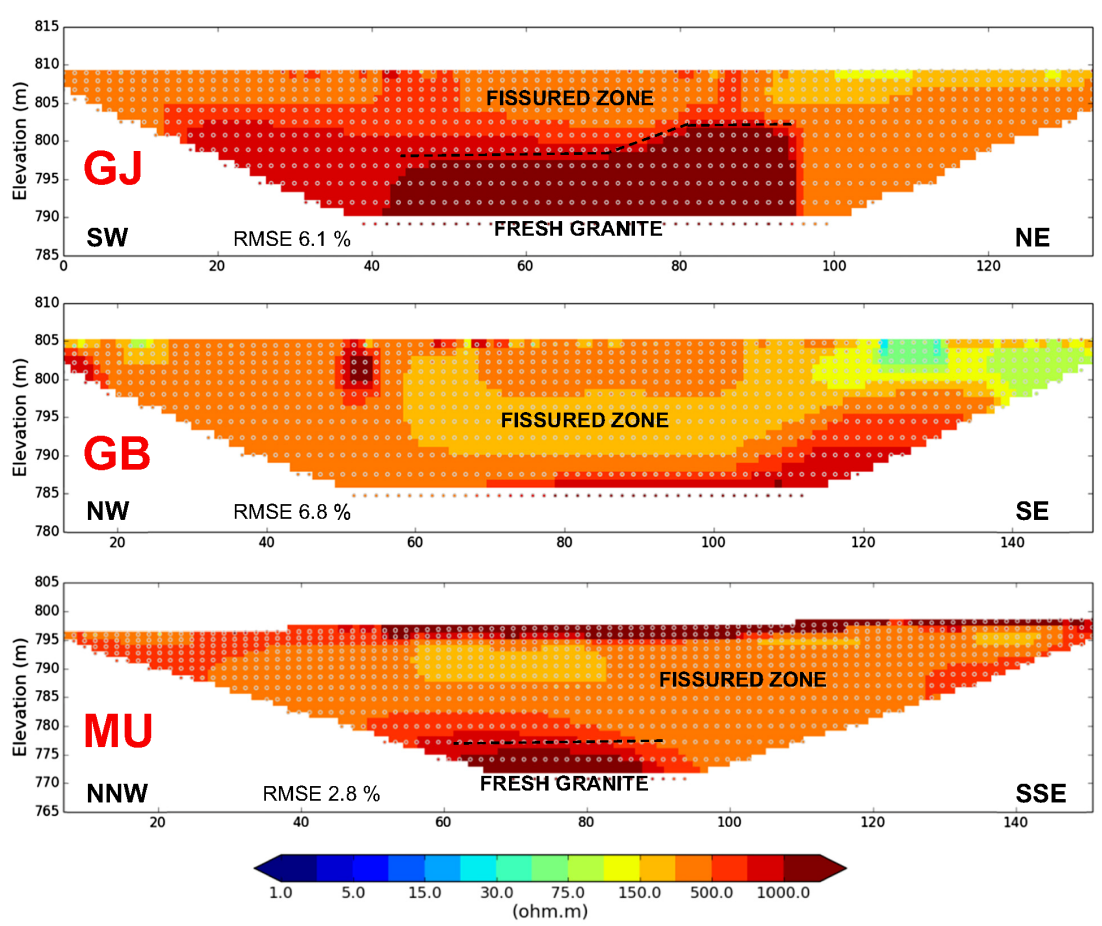

- continued from previous page

to the east, intersects granite outcrop at the eastern margin of the F1 fault zone. This is marked by generally larger resistivity of shallow fissured granite extending down to $\sim 15 \mathrm{~m}$ b.g.s. with resistivity $\sim 500 \Omega . \mathrm{m}$ and unaltered fresh granite underneath with resistivity $>1000 \Omega$.m, sharply bordering with saprolite along the eastern edge of the F1 fault zone. In the TB cross-section, the saprolite layer identified with resistivity between 50 and $100 \Omega$.m extends below the bottom of the inverted resistivity cross-section. At its SE side, the higher resistivity block (150-200 $\Omega . m)$ corresponds to fissured granite, as observed on outcrops. The TM crosssection carried across the F2 fault shows a saprolite layer with resistivity between 5 and $50 \Omega$.m and a thickness of $\sim 35 \mathrm{~m}$. Like in TMe along F1 fault zone, the saprolite layer is underlain by fissured zone with similar resistivity but occurring at shallower depth of 25-35 m b.g.s. Like TM, the FU cross-section was made across the discontinuity depicted by RS and field investigation as F2 fault. The F2 fault zone is at the NW side of the cross-section and is less pronounced than in TM cross-section. The central part of the FU cross-section is occupied by resistivity between 100 and $500 \Omega$.m, which corresponds to the fissured zone. Finally, the cross-sections GJ, GB and MU located at the top of the hills, far from the fault zones, show a layer 10 to $20 \mathrm{~m}$ thick with resistivity between 150 and $750 \Omega . m$, indicating the fissured zone and absence of saprolite. Note that at these 3 sites the presence of groundwater was confirmed in 
shallow dug wells belonging to local farmers. These wells contain water all year long and recover after pumping. They however show a low yield and are not used for farming activities.

The use of ERT in the Sardón catchment area allowed to depict qualitatively and to certain extent also quantitatively the thickness and horizontal extent of the saprolite and fissured layers. Within this project, our ERT profiles with single spread Schlumberger configuration of 56 electrodes yielded limited profile length and depth reach. In particular, the ERT profiles did not characterize the bottom part of the F1-related deep saprolite zone. Another caveat is the use of electrical method in semi-arid to arid environment. The dryness of the topsoil layer resulted in very high contact resistance that made difficult data acquisition and decreased ERT data quality. In the wet season, more reliable signal can be acquired in areas within valley bottoms due to the presence of clay-enriched thick and conductive top soils. However, along the granitic slopes covered by sandy-loam eluvium with poor clay content, ensuring an adequate electrode contact resistance can remain a challenge.

\section{Frequency domain electromagnetic transects}

The two frequency domain electromagnetic (FDEM) transects EM-PN (Figure 4.5a) and EM-TB (Figure 4.5b) with lengths $1620 \mathrm{~m}$ and $2160 \mathrm{~m}$ respectively, are transversal with respect to the main Sardón valley (Figure 4.1). The two FDEM inverted electrical resistivity cross-sections (Figure 4.5 ) showed a similar depth extension ( $\sim 50 \mathrm{~m}$ b.g.s.) as compared to the ERT cross-sections. In the FDEM data inversions we did not use the lowest frequency of $444 \mathrm{~Hz}$ due to incoherent values. In general the goodness of fit between observed and simulated values was good, having the largest discrepancy at high frequency (shallow subsurface), which may be due to the strong contrast between high resistivity of the dry unsaturated zone and low resistivity of the saturated alluvium or saprolite.

The EM-PN cross-section (Figure 4.5a) crosses the F1 fault zone between 850 and $1450 \mathrm{~m}$, along the main Sardón valley. The F1 fault zone shows a surficial, $\sim 10 \mathrm{~m}$ thick lens of very low resistivity material (1 to $15 \Omega . \mathrm{m}$ ) that corresponds to clayey deposits (alluvium or heavily weathered granite). This clay deposit was observed south of Peñalbo village by drilling down to $6 \mathrm{~m}$ depth (without reaching bottom of that clay layer) with a portable gasoline powered percussion hammer. Below the clay, there is a zone of low to moderate resistivity (15 to $100 \Omega . m$ ), likely corresponding to saprolite. East of the F1 fault zone, the high resistivity block ( $>500 \Omega . \mathrm{m}$ ) corresponds to the outcropping fissured granite of the eastern block, uplifted along the F1 fault observed in the field in the form of escarpment and also by the RS images (Figure 4.3). The same, high resistivity block is also defined by ERT cross-section $\mathrm{TMe}(\mathrm{NE})$ in Figure 4.4. West of the $\mathrm{F} 1$ fault zone between 0 and $600 \mathrm{~m}$, the outcropping fissured granite is characterized by large resistivities 

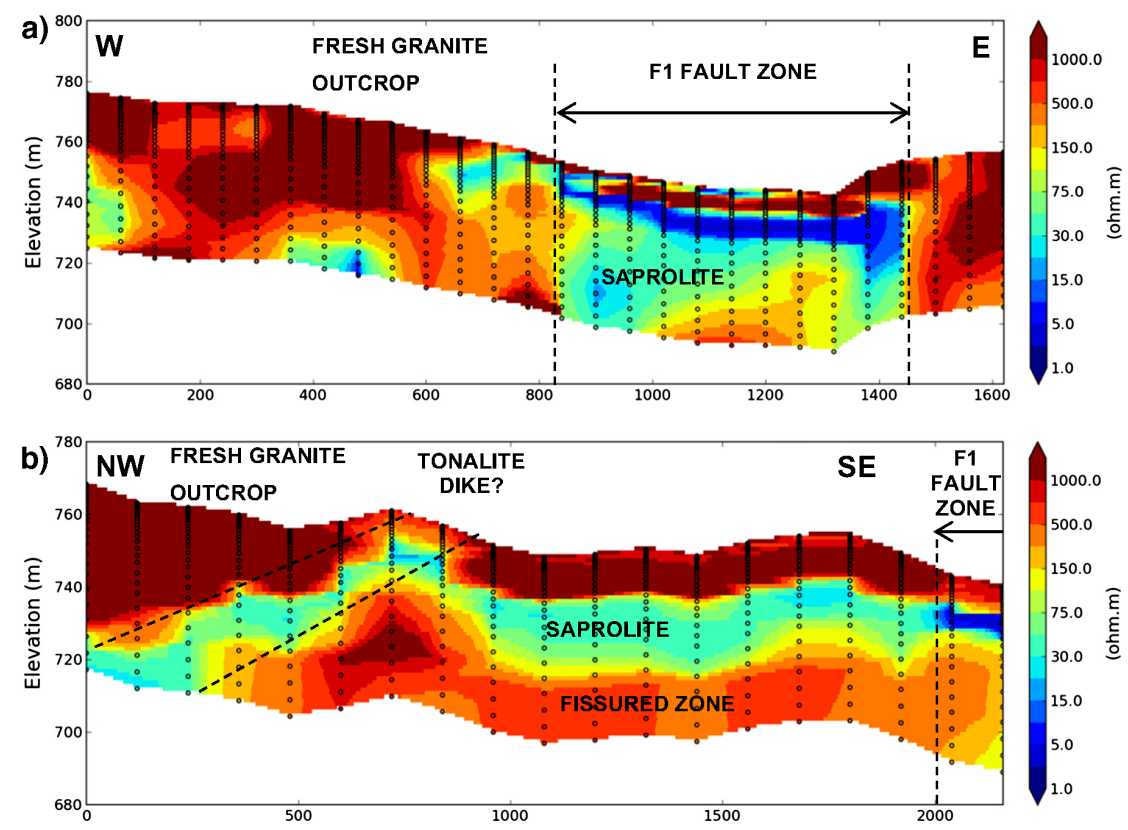

Figure 4.5: Inverted electrical resistivity cross-sections of FDEM data (see location in Figure 4.1): a) EM-PN; b) EM-TB. Circles indicate the position of the inversion cells.

$>1000$ S.m which is in agreement with the outcrop mapping presented in Figure 4.3.

The EM-TB transect (Figure 4.5b) is located in the northern part of the Sardón catchment. In its SE limit, it reaches the western extent of the F1 fault zone that shows the same resistivity characteristics as in the EM-PN cross-section. To the west of the F1 fault zone, i.e. between 900 and $2000 \mathrm{~m}, 3$ layers can be clearly identified from top to bottom: (i) a $\sim 10 \mathrm{~m}$ thick, surficial layer with very high resistivity of $\sim 1000 \Omega$.m; (ii) a $\sim 20 \mathrm{~m}$ thick sub-horizontal layer with resistivity from 30 to $75 \Omega . \mathrm{m}$; and (iii) a high resistivity layer (250-750 $\Omega . \mathrm{m})$. These three layers likely correspond respectively to unsaturated and saturated sections of the saprolite underlain by fissured granite. Between 600 and $900 \mathrm{~m}$, a low resistivity layer (30-75 $\Omega$.m) sloping towards NW separates high resistive layers ( $>1000 \Omega$.m) from above and below. That layer likely corresponds to the extension in depth of the outcropping tonalite dike visible in Figure 4.1, while the resistive, overlying layer corresponds to outcropping granite (see also Figures 4.1 and Figure 4.3).

The results of the 2 FDEM cross-sections are coherent with the ERT results and with the general geological knowledge synthetized in Figure 4.1. The FDEM method was very efficient, allowing to cover large distance in short time as for example it took only $\sim 5 \mathrm{~h}$ to measure the resistivity data with $5 \mathrm{~m}$ coil separation along the EM-PN transect $(1620 \mathrm{~m}$ 
long, data acquired every $60 \mathrm{~m}$ ). Although the spatial resolution of data acquisition was quite coarse - every $60 \mathrm{~m}$ - it was sufficient to identify the main geological features such as the F1 fault zone and the resistivity contrast between saprolite and fissured layers. We thus highly recommend this method for the hydrostratigraphy assessment in hydrogeological prospecting of hard rock areas.

\section{Magnetic resonance soundings}

Out of the 15 magnetic resonance sounding (MRS) surveys performed in 3 different campaigns (Table 4.2), we obtained only 6 interpretable MRS surveys at 5 sites (Figure 4.1) with signal to noise ratio (S/N) between 2 and 9 (Figure 4.6). Among them 5 were located along the central F1 fault zone ( 1 at TB, 1 at PN, 2 at TMe and 1 at TES) and 1 along a F2 fault zone (TM). The first 3 columns from the left of Figure 4.6 present the MRS data acquired in the field while the $4^{\text {th }}$ and $5^{\text {th }}$ columns represent the inverted depth-wise variability of the MRS free water content $\left(\theta_{M R S}\right)$ and decay time constants $\left(T_{1}\right.$ and $\left.T_{2}^{*}\right)$ respectively. In both Figure $4.6\left(4^{\text {th }}\right.$ and $5^{\text {th }}$ columns) and Table 4.3 we only presented the inversion results that respected the conditions enunciated in Equation (4.4).

The combination of the $\theta_{M R S}$ and decay time constant plots allowed to identify the depth-wise hydrostatigraphy (Lubczynski and Roy, 2003, 2007). All the plots of the 6 sites present a similar pattern, i.e. a surficial, thin layer with high water content above a thicker, deeper layer with lower water content. We interpreted the surficial layer as alluvial deposits, being characterized by a MRS thickness between $\sim 2$ and $\sim 5 \mathrm{~m}$ and relatively large $\theta_{M R S}$ between $\sim 4$ and $\sim 27 \%$ (Figure 4.6 ). The deeper and thicker layer, corresponding to saprolite, is also identified in all soundings (Table 4.3). The saprolite showed an average $\theta_{M R S}$ of $\sim 7 \%$ (maximum and minimum respectively of $\sim 3$ and $\sim 16 \%$ ) and an average $T_{2}^{*}$ of $\sim 180 \mathrm{~ms}$ (maximum and minimum respectively of $\sim 75$ and $\sim 320 \mathrm{~ms}$ ). Only the PN site (Figure 4.6a and Table 4.3) showed an atypical, high saprolite $\theta_{M R S}$ of $16.3 \%$. 
a) site PN, loop: 4 - $40 \mathrm{~m}, \mathrm{~S} / \mathrm{N}=9.03, f_{L}=1897.1 \mathrm{~Hz}$
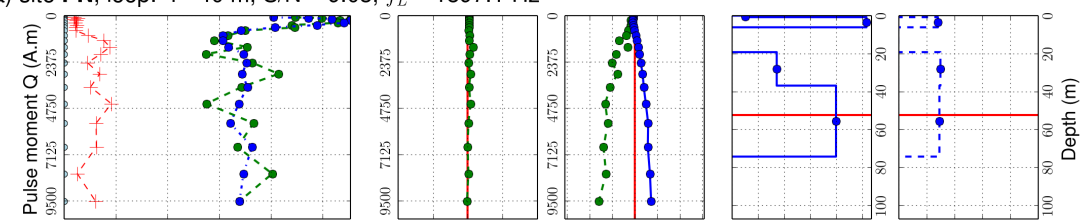

b) site TB, loop: 4 - $40 \mathrm{~m}, \mathrm{~S} / \mathrm{N}=2.28, f_{L}=1897.1 \mathrm{~Hz}$
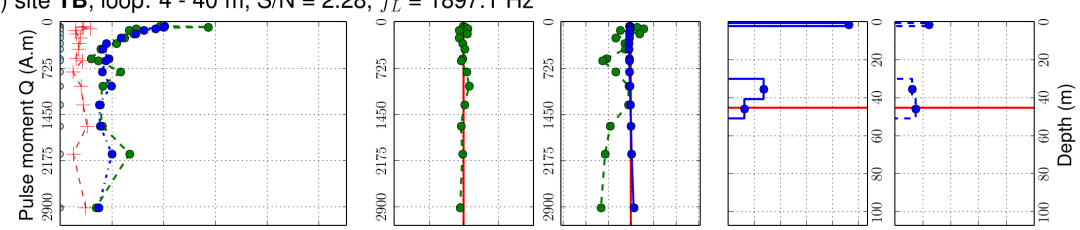

c) site TM, loop: 4 - $40 \mathrm{~m}, \mathrm{~S} / \mathrm{N}=4.64, f_{L}=1896.8 \mathrm{~Hz}$
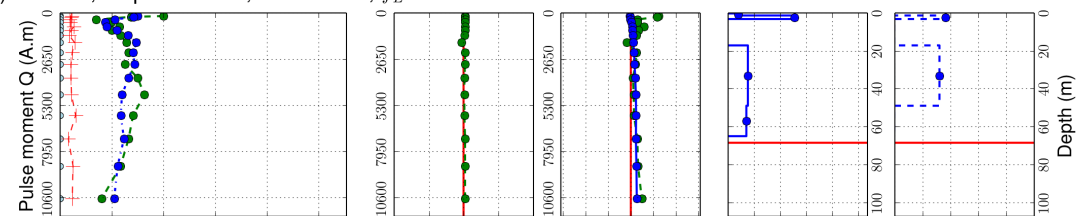

d) site TES, loop: 4 - $56 \mathrm{~m}, \mathrm{~S} / \mathrm{N}=2.22, f_{L}=1900.0 \mathrm{~Hz}$
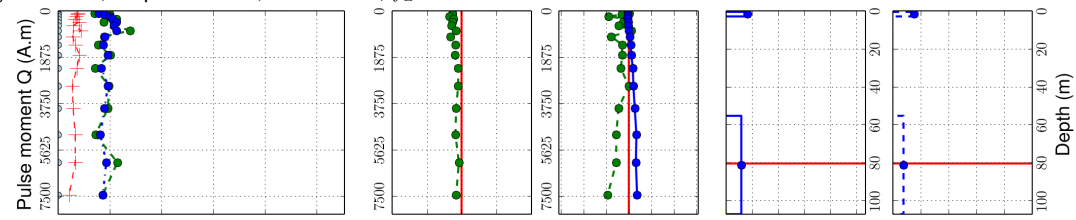

e) site TMe sq8, loop: 4 - $30 \mathrm{~m}, \mathrm{~S} / \mathrm{N}=2.05, f_{L}=1908.7 \mathrm{~Hz}$
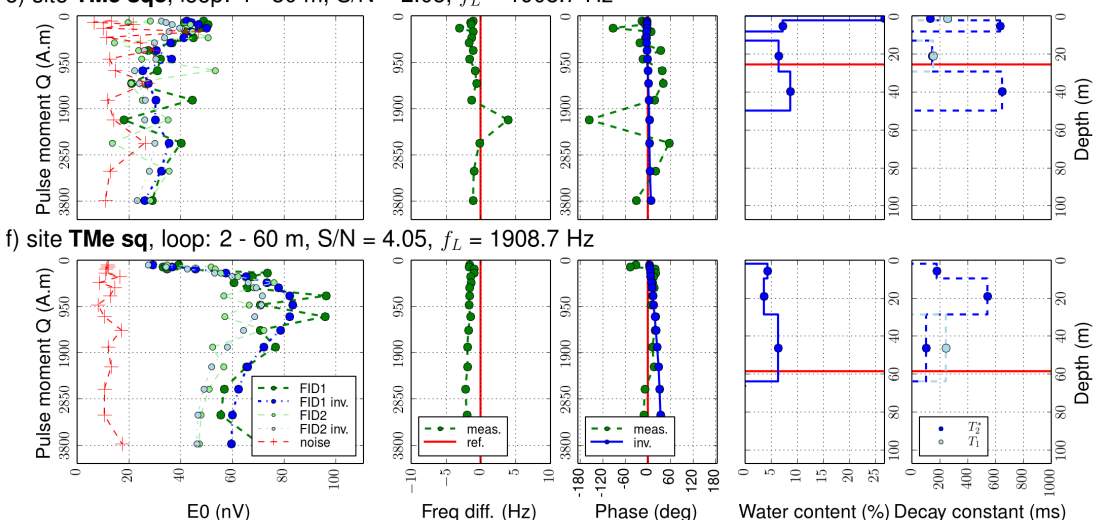

Figure 4.6: MRS data and inversion results (survey locations in Figure 4.1): (a-c): 1997 campaign; (d): 2001 campaign; (e-f): 2009 campaign. Each row corresponds to different MRS survey, with header indicating: (i) site ID; (ii) loop shape ( $2=$ square, $4=$ square-eight) - loop side size; (iii) signal to noise ratio $(\mathrm{S} / \mathrm{N})$; (iv) Larmor frequency $\left(f_{l}\right)$. FID means free induction decay. The horizontal red line of the two most right plot columns indicates the MRS-estimated maximum depth of investigation. 
At TMe, located within the F1 fault zone, we performed 2 interpretable soundings using 2 overlapping MRS loops (Table 4.2): i) $30 \mathrm{~m}$ squareeight loop (Figure 4.6e); ii) $60 \mathrm{~m}$ square loop (Figure 4.6f). Remarkable was that the surficial, alluvial layer detected by the $30 \mathrm{~m}$ square-eight loop was not detected by the $60 \mathrm{~m}$ square loop (Figure 4.6). This was probably because: (i) the saturated alluvial deposits are organized in narrow, shallow stream channels flanked by dry soil; (ii) the $30 \mathrm{~m}$ squareeight loop was placed right on top and along the alluvial channel; (iii) the narrow, saturated alluvial layer was located on the periphery of the $60 \mathrm{~m}$ square loop, so its contribution to the sensed signal was weak.

In several other sites along the fault zones, although saturated deposits were observed with the groundwater observation network, we obtained weak or null MRS signal. This may be due to a low water content and/or fine particle size, which produced respectively low MRS signal and short decay time constant that was close to or below instrument dead-time (40 ms for NUMIS). At the other sites outside the fault zones (GJ, GB, MU), no valid MRS signal was obtained, which was explained by too low water content in fissured granite.

\section{Hydrostratigraphy data integration}

Using hydrogeophysics, we could retrieve the following hydrostratigraphic units in the Sardón area, from top to bottom: (i) a thin surficial layer of alluvium with relatively high water content in the valleys; (ii) a saprolite layer; and (iii) a fissured layer (not detected with MRS). Along the F1 fault zone (TB, PN, TMe, TES), we identified the saprolite layer with the 3 hydrogeophysical methods ERT, FDEM, MRS. MRS also indicated a thin surficial layer of alluvium with relatively high water content above a deeper and thicker saprolite layer. A saprolite thickness larger than $45 \mathrm{~m}$ was depicted along the F1 fault zone while along the F2 faults, it reached $35 \mathrm{~m}$. Along the pediment, the saprolite thickness was $\sim 20 \mathrm{~m}$ and locally absent at the planation of the hill tops. The width of the F1 fault zone was $\sim 100 \mathrm{~m}$ although locally, as for example at PN location, it could be even wider than $500 \mathrm{~m}$. The width of the F2 fault zones was much lower, in order of $30 \mathrm{~m}$. The fissured layer was only identified by ERT and FDEM methods. It was located below the saprolite, at depth starting from 20 to $40 \mathrm{~m}$ b.g.s. (sites TMe, TM, EM-TB). At the other sites (GJ, GB, MU), outside the F1 and F2 fault zones, the ERT showed the absence of the saprolite layer (Figure 4.4). At these sites, we could not acquire any valid MRS signal due to too low water content.

Table 4.4.4 presents the summary of the hydrostratigraphy results obtained by hydrogeophysical hard rock investigations in various world locations including our Sardón site. The saprolite and fissured layers in the Sardón area are characterized by resistivity values of 10 to $100 \Omega . m$ and 250 to $750 \Omega . m$ respectively, while the fresh granite showed resistivity above $1000 \Omega . \mathrm{m}$. These values are in the same range as those observed by other authors in other hard rock areas (Table 4.4). Also the MRS estimates $\left(\theta_{M R S}, T_{2}^{*}\right)$ for saprolite are in the same range if we 
exclude the PN site that show unexpectedly high, saprolite $\theta_{M R S}=16.3 \%$.

The hydrostratigraphy retrieved by hydrogeophysics was confirmed by the drilling. A borehole at PN site intersected the saprolite down to $24 \mathrm{~m}$ depth but we obtained a low borehole water yield that did not corroborate the particularly high $\theta_{M R S}$ estimate. The borehole could not be made exactly at the same location as the MRS, which can explain this difference. Other 2 drillings next to TMe (Figure 4.1) also confirmed the presence of saprolite down to $38 \mathrm{~m}$ depth. Both of them also revealed very low water yield. At GJ, GB and MU, shallow boreholes and wells belonging to the local farmers allowed to observe directly the fissured zone at shallow depth ( 1-2 m b.g.s.). These observations are in agreement with what we observed at SD borehole site (Figure 4.1), where drilling intersected the fissured layer, starting at $\sim 2$ to $3 \mathrm{~m}$ b.g.s. down to the borehole bottom at $48 \mathrm{~m}$ b.g.s. A disagreement between ERT interpretation and borehole log was encountered at the TB site. The borehole, located at $\sim 100$ m north-east of the western part of the ERT cross-section TB (Figure 4.4, at $\sim 75 \mathrm{~m}$ horizontal scale), intersected the fissured zone, while ERT indicated the saprolite. This is likely due to the presence of a F2 fault located between the ERT and the borehole (see TB site on Figure 4.2) that brings in contact saprolite on the $S$ block with fissured granite on the $\mathrm{N}$ block. 
Table 4.4: Hydrogeophysical results and comparison with other studies. $\rho$ : electrical resistivity; $\theta_{M R S}$ : MRS free water content; $T_{2}^{*}$ : free induction decay time constant.

\begin{tabular}{|c|c|c|c|c|c|c|}
\hline \multirow[t]{2}{*}{ Catchment. } & \multicolumn{3}{|l|}{ Saprolite } & \multicolumn{3}{|c|}{ Fissured granite } \\
\hline & $\rho(\Omega . \mathrm{m})$ & $\theta_{M R S}(\%)$ & $T_{2}^{*}(\mathrm{~ms})$ & $\rho(\Omega . \mathrm{m})$ & $\theta_{M R S}(\%)$ & $T_{2}^{*}(\mathrm{~ms})$ \\
\hline $\begin{array}{l}\text { Ringelbach }^{(a)} \\
\text { (Brittany, France) }\end{array}$ & $50-800$ & $<1.4$ & $110-140$ & $>800$ & $<1.3$ & n.a. \\
\hline $\begin{array}{l}\text { Margeride }^{(a)} \\
\text { (Central Massif, France) }\end{array}$ & $30-500$ & $3-7$ & $150-350$ & $>500$ & n.a. & n.a. \\
\hline $\begin{array}{l}\text { Kerbennez }^{(a)} \\
\text { (Brittany, France) }\end{array}$ & $80-600$ & $2.7-5.5$ & $150-350$ & $>600$ & $<2$ & n.a. \\
\hline $\begin{array}{l}\text { Andalatanousy }{ }^{(a)} \\
\text { (Madagascar) }^{\text {Madal }}\end{array}$ & n.a. & $2.2-5.5$ & $50-180$ & n.a. & $<1$ & n.a. \\
\hline $\begin{array}{l}\text { Maheshwaram }^{(a)} \\
\text { (India) }\end{array}$ & $\begin{array}{l}10-200 \\
30-120^{(b)}\end{array}$ & $2-6$ & $50-150$ & $\begin{array}{c}>200 \\
120-500^{(b)}\end{array}$ & $<1$ & n.a. \\
\hline $\begin{array}{l}\text { Several in Brittany }{ }^{(a)} \\
\text { (France) }\end{array}$ & n.a. & $1.6-6.0$ & $100-300$ & n.a. & $<2$ & n.a. \\
\hline Burkina Faso $^{(c)}$ & n.a. & $\begin{array}{r}1-6 \\
(3)\end{array}$ & $\begin{array}{c}180-600 \\
(400)\end{array}$ & n.a. & $\begin{array}{r}0.2-2.5 \\
(1.0)\end{array}$ & $\begin{array}{c}350-1500 \\
(650)\end{array}$ \\
\hline $\begin{array}{l}\text { Moole Hole }{ }^{(d)} \\
\text { (India) }\end{array}$ & $20-400$ & 2.7 & & $400-1000$ & $1-2$ & \\
\hline $\begin{array}{l}\text { Sardón }^{(e)} \\
\text { (Salamanca, Spain) }^{\text {Salang }}\end{array}$ & $10-100$ & $\begin{array}{c}2.9-16.3 \\
(6.8)\end{array}$ & $\begin{array}{l}75-320 \\
(178)\end{array}$ & $250-750$ & $<0.5$ & n.a. \\
\hline
\end{tabular}

n.a.: not available; when available, the average value is shown between parentheses. ${ }^{(a)}$ Baltassat

$\sim \quad$ et al. (2005). ${ }^{(b)}$ Dewandel et al. (2012). ${ }^{(c)}$ Vouillamoz et al. (2005). ${ }^{(d)}$ Legchenko et al. (2006); Descloitres et al. (2008); Chaudhuri et al. (2013). ${ }^{(e)}$ This study. 


\subsubsection{Aquifer parameters}

Aquifer parameters were assessed by the MRS method, using Equations (4.2), (4.3) and (4.6) after MRS inversion and calibration against the slug test transmissivities.

\subsubsection{Flow parameters}

In the MRS inversion results, we observed cases where basic nuclear magnetic resonance (NMR) assumptions were not met so the $T_{1}$ estimator yielded a value that was lower than $T_{2}^{*}$. Such inversion results were rejected using the criteria of Equation (4.4). We assumed that part of the problem was that the data inversion algorithm retrieved an overestimated $T_{2}^{*}$ when both water content and $\mathrm{S} / \mathrm{N}$ were too low. Based on 5 valid MRS measurements of the 2009 campaign, we obtained a saprolite $D_{T}$ value representative of the Sardón area of 1.83. Similar saprolite value $D_{T}=1.72$ (mean of 6 values) was found in granites in Brittany (France) by Legchenko (2001). In contrast, Vouillamoz (2003) found significantly different saprolite $D_{T}=3.3$ and $D_{T}=6.5$ in fissured granite with a dataset composed of measurements in Brittany (France) and Burkina Faso. However, he explained such high $D_{T}$ values by uncertainties in MRS measurement due to unfavorable $\mathrm{S} / \mathrm{N}$ ratio and by heterogeneity of the magnetic field that influences $T_{2}^{*}$.

Out of the 5 boreholes with slug tests (Table 4.5 and Figure 4.1), 3 were drilled in saprolite but only 2 were used for MRS calibration as 1 site was without MRS survey. We found very low saprolite slug test hydraulic conductivity $\left(K_{S T}\right)$ values, ranging from $5 \times 10-4$ to $2 \times 10^{-3} \mathrm{~m} \cdot \mathrm{d}^{-1}$ and with geometric mean of $7 \times 10^{-4} \mathrm{~m} \cdot \mathrm{d}^{-1}$. We used the geometric mean because it is more representative than arithmetic mean or median when the dataset spreads over several orders of magnitude, which is the case of hydrogeological parameters such as hydraulic conductivity. The low saprolite $K_{S T}$ was consistent with field observations as the drilling cuttings showed fine particle size. 
Table 4.5: Slug test hydraulic conductivity $\left(K_{S T}\right)$ and transmissivity $\left(T_{S T}\right)$ and derived $C_{T}$ values (see text for other abbreviations).

\begin{tabular}{lllllll}
\hline Borehole & $K_{S T}$ & $T_{S T}$ & $\sum_{i=1}^{n} \Delta Z_{M R S i} \theta_{M R S i} T_{1 i}{ }^{2}$ & $C_{T}$ & $C_{T}$ g.m. & Layer \\
\hline TMe1 & $2.0 \times 10^{-3}$ & $6.0 \times 10^{-2}$ & $1.3 \times 10^{5}$ & $5.3 \times 10^{-12}$ & $4.6 \times 10^{-13}$ & Saprolite \\
TMe2 & $3.0 \times 10^{-4}$ & $1.0 \times 10^{-2}$ & No MRS & No MRS & & \\
PN & $5.0 \times 10^{-4}$ & $1.0 \times 10^{-2}$ & $2.9 \times 10^{6}$ & $4.0 \times 10^{-14}$ & & \\
\hline TB & $8.0 \times 10^{-3}$ & $9.0 \times 10^{-2}$ & No MRS & No MRS & N.A. & Fissured \\
SD & $5.0 \times 10^{-3}$ & $6.0 \times 10^{-2}$ & No MRS & No MRS & N.A. & granite \\
\hline
\end{tabular}

$K_{S T}$ in m.d ${ }^{-1}, T_{S T}$ in $\mathrm{m}^{2} . \mathrm{d}^{-1}$; g.m.: geometric mean; No MRS: site without MRS survey. N.A.: not applicable. 
The saprolite $C_{T}$ (Table 4.5) was computed according to Equation (4.5) at boreholes PN and TMe with saprolite layer down to $24 \mathrm{~m}$ and $40 \mathrm{~m}$ respectively. The saprolite layer was also depicted by the MRS (Figure 4.6a, e and f). The geometric mean of our two available $C_{T}$ estimates equals to $4.6 \times 10^{-13}$. That estimate is significantly lower than the $C_{T}=8.2 \times 10^{-10}$ estimate of the weathered granite of Burkina Faso (Vouillamoz et al., 2007). A possible reason could be in the method of hydrogeological system parameterization, as Vouillamoz et al. (2007) defined $C_{T}$ using pumping test hydraulic conductivities $\left(K_{P T}\right)$ while we used slug tests. Slug tests are prone to underestimation of $K$ because they are representative of a smaller volume around the borehole so the interconnectivity is not well represented, and therefore possibly underestimated. In contrast, the volume of long-term pumping test is large enough to activate interconnectivity over much larger volume than in slug test, resulting in larger water release to the pump. The latter hypothesis can be debated as for example in the granitic catchment of Maheswaram (India), Maréchal et al. (2004) found pretty low ratio of only 3:1 between average $K$ from pumping tests and slug tests based on 6 boreholes with pumping tests and slug tests, although their hydrogeological conditions were quite different than ours. Their geometric mean of saprolite $K_{S T}$ of 30 slug tests was $0.4 \mathrm{~m} \cdot \mathrm{d}^{-1}$, i.e. 3 orders of magnitude larger than our $K_{S T}=$ $7 \times 10^{-4} \mathrm{~m} \cdot \mathrm{d}^{-1}$. Another possible explanation of substantially lower values of $K_{S T}$ as compared to $K_{P T}$ was provided by Butler and Healey (1998) who attributed it to insufficient borehole-development prior slug test. That could be particularly relevant at typical low yield of the saprolite in our case. Finally, our substantially lower $K_{S T}$ could be also because the hydrogeological conditions of our investigated sites were poorer than those of other authors mentioned above.

The saprolite MRS transmissivity ( $T_{M R S}$ ) and hydraulic conductivity $\left(K_{M R S}\right)$ defined using Equations (4.2) and (4.3) and $C_{T}=4.6 \times 10^{-13}$ are presented in Table 4.3. The geometric mean of saprolite $K_{M R S}$ was $1.6 \times 10^{-4} \mathrm{~m} . \mathrm{d}^{-1}$ with minimum and maximum values $2.3 \times 10^{-5}$ and $1.8 \times 10^{-3} \mathrm{~m} . \mathrm{d}^{-1}$ respectively. These values are very low as compared to other studies possibly because of slug test related underestimation of $C_{T}$ as suggested earlier. Dewandel et al. (2006) presented a compilation of several studies in which the geometric mean of saprolite $K$ was $0.2 \mathrm{~m} . \mathrm{d}^{-1}$ with minimum and maximum of 0.01 and $3.52 \mathrm{~m} . \mathrm{d}^{-1}$ respectively. Legchenko et al. (2004) performed 11 MRS and 2 pumping tests to retrieve the transmissivity of a weathered-fissured granite aquifer in Brittany (France). They obtained an average saprolite $K_{M R S}$ similar order of magnitude, i.e. $4.1 \mathrm{~m} . \mathrm{d}^{-1}$ with minimum and maximum values were 0.2 and $11.2 \mathrm{~m} . \mathrm{d}^{-1}$ respectively. Although the $K_{M R S}$ that we found in the Sardón area is much lower than the above quoted $K_{M R S}$ values, it is in agreement with the low yield observed in the boreholes. Besides, many wells drilled by the local farmers in the saprolite were abandoned due to low yield and long recovery time.

The fissured layer was identified at sites GJ, FU, GB and MU with ERT. The MRS surveys targeting at fissured rocks at the FU and MU locations 
did not result in any valid MRS signal. The available information about possible flow system parameterization originates from two borehole slug tests (Table 4.5). The $K_{S T}$ of the fissured granite layer in TB and SD slug test sites were $8 \times 10^{-3} \mathrm{~m} \cdot \mathrm{d}^{-1}$ and $5 \times 10^{-3} \mathrm{~m} \cdot \mathrm{d}^{-1}$ respectively (Table 4.5 ), corresponding to a geometric mean of $6 \times 10^{-3} \mathrm{~m} . \mathrm{d}^{-1}$, so one order of magnitude higher than the $K_{S T}$ of the saprolite layer.

It is not only in this study but overall that there is scarcity of successful MRS measurements in fissured rocks (Table 4.4). The only published data we found (Table 4.4) originates from Burkina Faso study (Vouillamoz et al., 2005). Based on a dataset composed of 13 MRS measurements, they presented an average, fissured rock $T_{1}=650 \mathrm{~ms}$ (average $\theta_{M R S}=1 \%$ ) that was larger than saprolite $T_{1}=400 \mathrm{~ms}$ (average $\theta_{M R S}=3 \%$ ), indicating a higher transmissivity in the fissured layer than in the saprolite and thus confirming the hard rock general conceptual model.

\subsubsection{Storage parameters}

As the saprolite aquifer at the Sardón catchment was unconfined, we computed $S_{y_{M R S}}$ using Equation (4.6) with a $C_{y}$ value of $2.8 \times 10^{-1}$ assigned in weathered granite in Burkina Faso (Vouillamoz et al., 2007). The average $S_{y_{M R S}}$ was $1.9 \%$ with minimum of $0.8 \%$ and maximum of $4.6 \%$. However, it is expected that our $S_{y}$ may be lower due to the fine particle size of the saprolite in the Sardón area. To our knowledge the saprolite $C_{y}$ value for weathered granite found in Vouillamoz et al. (2005) and Vouillamoz et al. (2007) are the only available hard rock $C_{y}$ estimates in the scientific literature.

In the fissured layer, as it was not possible to acquire MRS signal, it was assumed that its water content was $<0.5 \%$, i.e. the considered MRS detectability threshold (Legchenko et al., 2006). Fissured rock estimates of $C_{y}$ and $C_{e}$ are not available yet in the literature. This is likely because computing $C_{y}$ and/or $C_{e}$ multipliers, requires cumbersome and expensive estimation of $S_{y}$ and/or $S_{e}$ by piezometric pumping tests.

\subsubsection{Perspectives of aquifer parameterisation}

Although we had some difficulties in acquiring MRS data of the saprolite layer, the most challenging was to acquire valid MRS signal of the fissured layer. The fissured layer constitutes a low storage but significant hydraulic conductivity target. In this regard, the first item to consider is the optimization of the loop size, shape and for some shapes, orientation to the particular targets i.e. sometimes layers parallel to ground but other times to structural features such as sub-vertical linear features or intersection of such features. Moreover, given the low water content of the fissure zone, various strategies to improve $\mathrm{S} / \mathrm{N}$ must be considered to optimize signal level while noise attenuation/compensation strategies must be improved. Large bandwidth instrumentation allows detecting water in thin fractures, in the unsaturated zone and also in the more clayey sands than what was possible with the "classical" MRS. The in- 
strumentation power output capability is also a relevant consideration to allow driving large inductance loops with higher excitation moment to detect in-situ water at significant depth (Roy and Lubczynski, 2014). All these capabilities are already available to some extent in the current MRS instrumentation but any further improvement on these capabilities will bring the MRS system nearer to the routine use of MRS equipment for the evaluation and particularly hydrogeological parameterization of the fissured rocks. The new advances in MRS imaging (Hertrich, 2008; Legchenko et al., 2011) are also encouraging to retrieve the 2D and 3D structures of hard rock aquifers, especially to detect the depth wise boundaries of fault zones and thickness of saprolite (Legchenko et al., 2006). The ongoing improvement of MRS instrumentation will undoubtedly contribute to more successful MRS survey investigations of hard rocks and to the scarce knowledge on hydrogeology of the fissured rocks.

\subsubsection{Contribution to the Sardón hydrogeological conceptual model}

We compiled the acquired information of the Sardón catchment to characterize spatially the geometry and parameters of the Sardón hard rock aquifer and to contribute to its hydrogeological conceptual model. Using RS digital image processing and hydrogeophysics, we identified two aquifer layers in line with the general conceptual model of hard rock aquifers: the saprolite (L1) and the fissured granite (L2) layers. As the heterogeneities of the Sardón catchment are spatially controlled by the F1 fault central zone and F2/F3 faults and by the weathering, we were able to define six internally uniform zones that control the dynamics of the hydrogeological system at the catchment scale as presented in Figure 4.7 and 4.8 and characterized in Table 4.6:

- L1-F1: saprolite along the F1 fault zone;

- L1-F2/3: saprolite along the F2/F3 fault sets;

- L1: saprolite outside the fault zones;

- L2-F1: fissured layer along the F1 fault zone;

- L2-F2/3: fissured layer along the F2/F3 fault sets;

- L2: fissured layer outside the fault zones.

For each of the six zones we defined the geometry and aquifer parameters. As there were only few hydrogeophysical measurements in these zones, we could not apply descriptive statistics or stochastic modeling, as for instance it was performed in a small catchment $\left(\sim 6 \mathrm{~km}^{2}\right)$ in South India using a high density ERT measurements (Chaudhuri et al., 2013). Instead, in our study case, minimum, maximum and intermediate values were used to define ranges (Table 4.6) to be used during future calibration of numerical models. Using the fault map (Figure 4.2), the granite outcrops map (Figure 4.3) and the geophysical results (Figures 4.4 to 4.6), we defined the horizontal and depth-wise extent of these zones in GIS in a grid $100 \times 100 \mathrm{~m}$ (Figure $4.7 \mathrm{c}$ ) that in a follow up study will be used as a 
reference for distributed numerical groundwater model. The width of the fault zones, as retrieved by ERT and FDEM, was between $30 \mathrm{~m}$ and $600 \mathrm{~m}$. As the fracture spacing observed in the field was between few centimeters to several meters (Attanayake, 1999), the $100 \mathrm{~m}$ grid resolution insured that the connectivity between fractures was taken into account. L1 is only present where L2 is not outcropping (Figure 4.7a) while L2 is assumed to extend over the entire catchment (Figure 4.7b). The saprolite layer L1 is hydrogeologically defined as an unconfined layer while the fissured layer L2 as confined layer when not outcropping. We assumed that L2 is underlain by non-fractured bedrock that constitutes the impervious bottom boundary. The fault zones fully control the hydrogeology of the catchment and connect hydraulically L1 and L2 layers. This fact was confirmed by borehole drillings that showed consistent, similar water levels in both fissured and saprolite layers. Groundwater is drained along the F2/F3 fault zones towards the main F1 fault zone and then along that F1 fault zone towards the catchment outlet at the north of the catchment. 

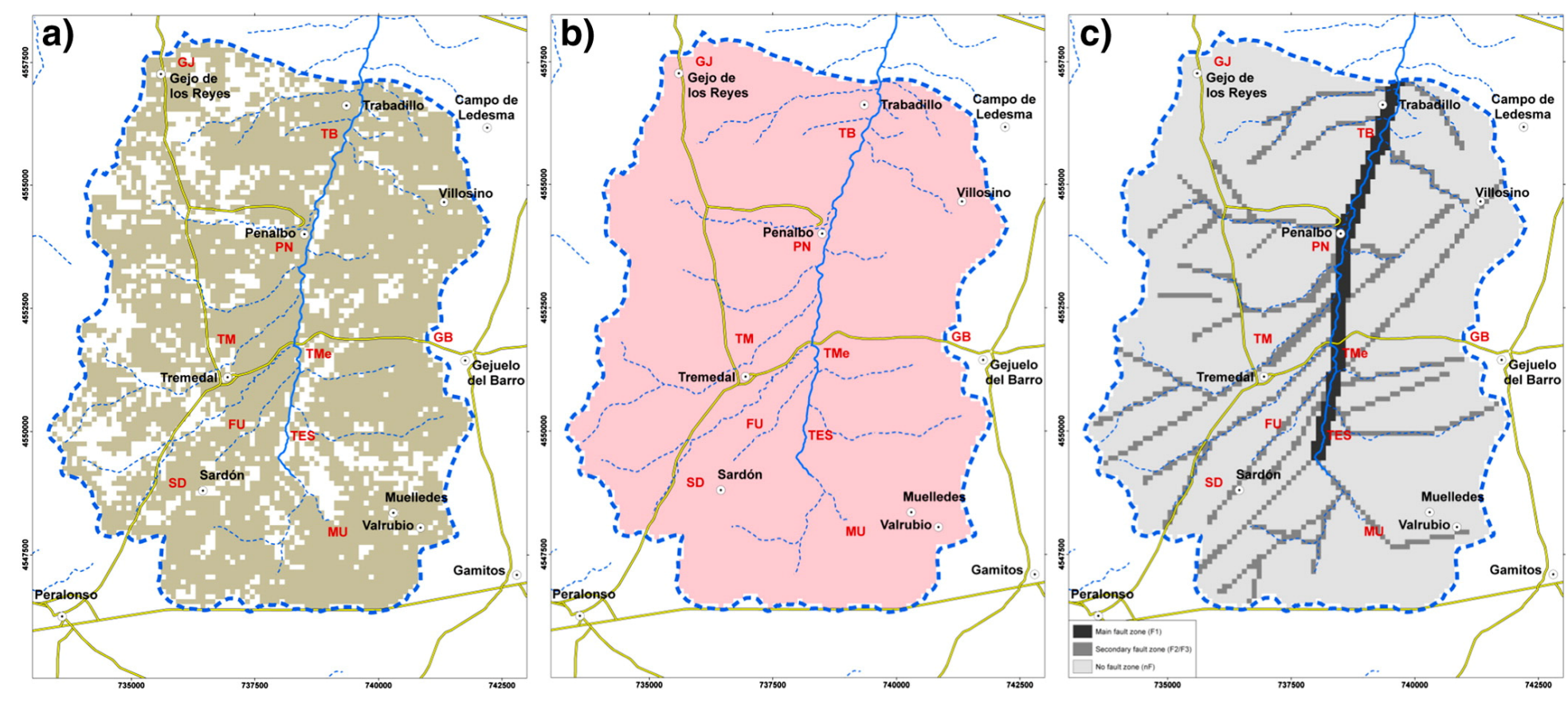

Figure 4.7: Hydrogeological conceptual model maps: a) active cells of layer L1 (saprolite), indicated in light brown; b) active cells of layer L2 (fissured layer), indicated in pink; c) fault zones within the L1 and L2 layers (see corresponding parameters in Table 4.6). 


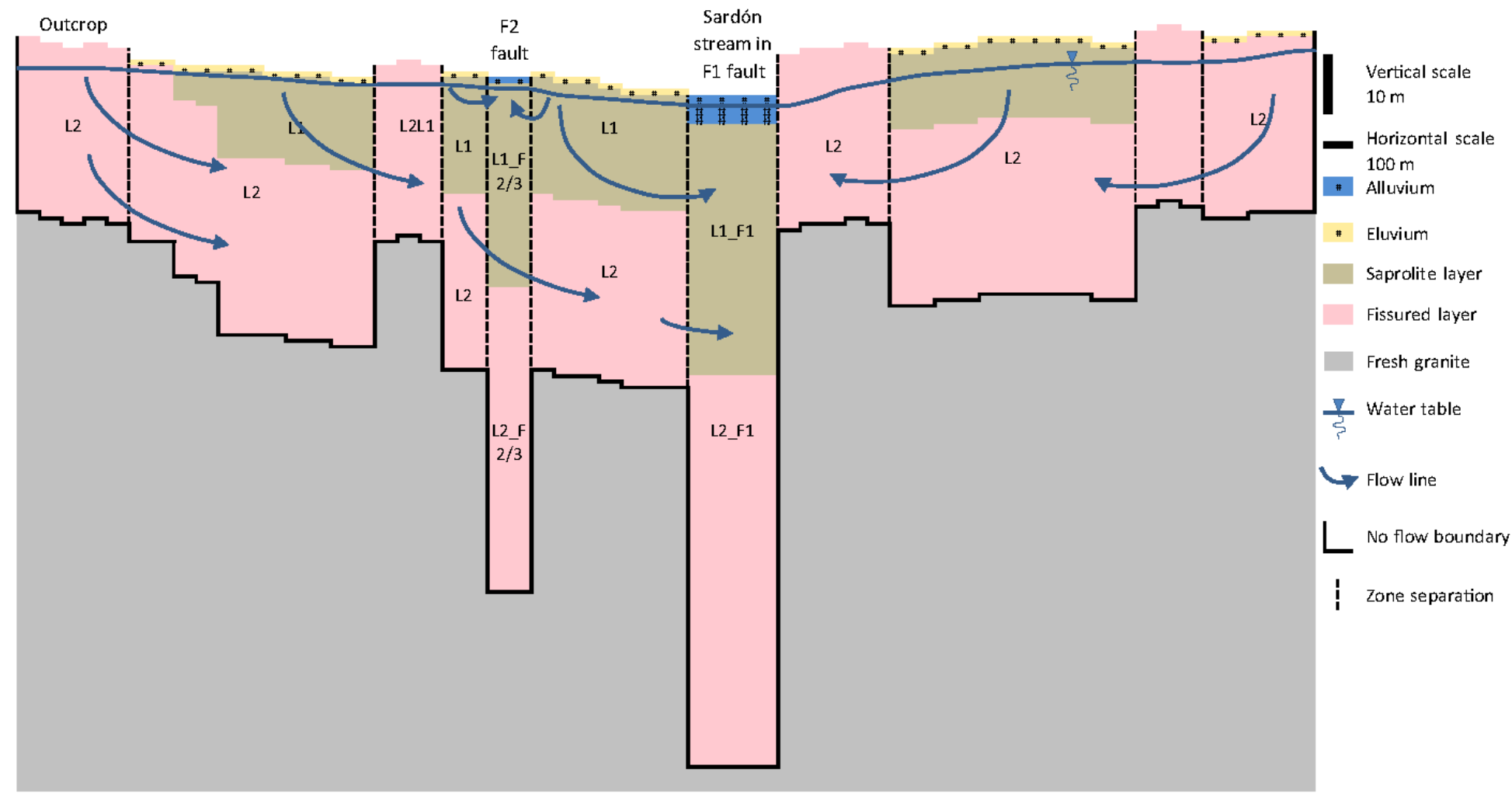

Figure 4.8: Schematic cross-section transversal to the main catchment valley of the hydrogeological conceptual model of the 


\begin{tabular}{|c|c|c|c|c|c|c|c|c|c|}
\hline \multirow[t]{2}{*}{ Zone } & \multicolumn{3}{|c|}{ Thickness (m) } & \multicolumn{3}{|l|}{$K\left(\mathrm{~m} \cdot \mathrm{d}^{-1}\right)$} & \multicolumn{3}{|l|}{$T\left(\mathrm{~m}^{2} \cdot \mathrm{d}^{-1}\right)$} \\
\hline & int. & $\min$. & max. & int. & $\min$. & max. & int. & $\min$. & max. \\
\hline L1-F1 & 45.0 & 20.0 & 75.0 & & & & $7.4 \times 10^{-3}$ & $4.6 \times 10^{-4}$ & $1.4 \times 10^{-1}$ \\
\hline L1-F2/3 & 35.0 & 5.0 & 50.0 & $1.6 \times 10^{-4}$ & $2.3 \times 10^{-5}$ & $1.8 \times 10^{-3}$ & $5.8 \times 10^{-3}$ & $1.2 \times 10^{-4}$ & $9.0 \times 10^{-2}$ \\
\hline L1-nF(a) & 20.0 & 1.0 & 40.0 & & & & $3.3 \times 10^{-3}$ & $2.3 \times 10^{-5}$ & $7.2 \times 10^{-2}$ \\
\hline L2-F1 & 67.5 & 30.0 & 112.5 & & & & $1.1 \times 10^{-1}$ & $6.9 \times 10^{-3}$ & 2.0 \\
\hline L2-F2/3 & 52.5 & 7.5 & 75.0 & $1.6 \times 10^{-3^{(b)}}$ & $2.3 \times 10^{-4^{(b)}}$ & $1.8 \times 10^{-2^{(b)}}$ & $8.6 \times 10^{-2}$ & $1.7 \times 10^{-3}$ & 1.4 \\
\hline L2-nF & 30.0 & 1.0 & 60.0 & & & & $4.9 \times 10^{-2}$ & $3.5 \times 10^{-4}$ & 1.1 \\
\hline
\end{tabular}

int.,min.,max: intermediate,minimum and maximum values respectively; N.A.: not applicable; ${ }^{(a)}$ : where L2 outcrops, the thickness of the L1 layer is null; ${ }^{b}$ : corresponds to the $K$ value of the L1 layer multiplied by $10 . K$, $T, S_{y}$ and $S_{e}$ are respectively hydraulic conductivity, transmissivity, specific yield and elastic storativity.

Continued on next page 
- continued from previous page

\begin{tabular}{|c|c|c|c|c|c|c|}
\hline \multirow[t]{2}{*}{ Zone } & \multicolumn{3}{|c|}{$S_{y}(-)$} & \multicolumn{3}{|l|}{$S_{e}(-)$} \\
\hline & int. & $\min$. & max. & int. & $\min$. & $\max$. \\
\hline \multicolumn{7}{|l|}{ L1-F1 } \\
\hline L1-F2/3 & 1.90 & 0.80 & 4.60 & N.A. & N.A. & N.A. \\
\hline \multicolumn{7}{|l|}{$\mathrm{L} 1-\mathrm{nF}^{(a)}$} \\
\hline L2-F1 & & & & $1.0 \times 10^{-3}$ & $4.0 \times 10^{-4}$ & $3.0 \times 10^{-3}$ \\
\hline L2-F2/3 & 0.50 & 0.05 & 1.00 & $1.0 \times 10^{-3}$ & $4.0 \times 10^{-4}$ & $3.0 \times 10^{-3}$ \\
\hline L2-nF & & & & $4.0 \times 10^{-3}$ & $2.0 \times 10^{-4}$ & $7.0 \times 10^{-3}$ \\
\hline
\end{tabular}


In the most elevated parts of the catchment, the outcrop mapping (Figure 4.3) and ERT interpretation of the FU, GJ, GB and MU sites (Figure 4.4) showed that the saprolite layer is absent. The absence of saprolite is probably due to tectonic uplift that provoked erosion, while the saprolite was preserved in depressions (López, 2004). The mapping of the erosion surfaces (Instituto Geológico y Minero de España, 1991a,b) supports this hypothesis. The elevation of the top of the L1 saprolite layer was obtained by subtracting the soil thickness (eluvium and alluvium) retrieved by GPR and direct observations (drilling with portable gasoline powered percussion hammer) from the ground surface of the digital terrain model (Figure 4.2a) resampled at $100 \mathrm{~m}$ resolution. The thickness of the L1 saprolite layer (Table 4.6) was defined based on the interpretation of ERT, FDEM and MRS. The assessment of the thickness of the L2 fissured layer is a complex and uncertain matter. Lachassagne et al. (2011) made a review of studies in hard rock aquifers and stated that the "thickness of the fissured layer is approximately two to three times that of the saprolite". Dewandel et al. (2006) presented a ratio of 2 in the description of the hard rock aquifer general conceptual model, considering a single weathering event. In the Maheshwaram catchment (India), the same authors found a ratio of 1 that they explained by the erosion of the saprolite layer before the development of a new, actual weathering front. In Sardón catchment, we assumed that the L2 fissured layer was 1.5 times thicker than the L1 saprolite layer. It is coherent with the geological history of the area, which was affected during the Alpine orogeny by several uplifting events and related erosion of the saprolite (López, 2004). With ratio 1.5 we obtained L2 transmissivity of one order of magnitude higher than the transmissivity of L1 (Table 4.6).

The ranges of aquifer parameters were defined using the results of the hydrogeophysical analysis elaborated in the previous section. Although the flow parameters ( $K_{M R S}$ and $T_{M R S}$ ) computed with the $C_{T}$ value defined for the Sardón site are generally low, they well reflect field observations. As it was not possible in this study to retrieve the parameters of the fissured zone, we used the results and concepts presented in previous studies of Dewandel et al. (2006), Dewandel et al. (2011) and Lachassagne et al. (2011). The model of a hard rock aquifer that these authors defined states that the fissured layer has higher transmissivity than the saprolite layer. They observed that $K$ in the fissured layer was $\sim 1$ order of magnitude higher than $K$ in the saprolite layer (Figure 13 in Dewandel et al. (2006); Figure 8 in Dewandel et al. (2011); Figure 7 in Lachassagne et al. (2011)). As we observed similar relation with slug tests, we estimated the $K$ values of the fissured layer as one order of magnitude higher than our saprolite $K$ values (Table 4.6).

Although we had to make some assumptions to parameterize the L1 and L2 reservoirs, the presented hydrogeological conceptual model is based on field observations and measurements hydrogeophysically and hydrogeologically sound. Similar approach was applied by Boucher et al. (2009a); Chaudhuri et al. (2013); Baroncini-Turricchia et al. (2014). Such methodology allows to avoid in groundwater model design the arbitrary 
and artificial definition of uniform, parametric zones around observation points that ensure a good fit between simulated and observed state variables (soil moisture, hydraulic heads) (Voss, 2011). Indeed, a calibrated model that reproduces accurately the measured state variables is not necessarily a good model, particularly in complex hard rock conditions, in the sense that it will probably fail in validation and prediction. In this study, we limited the number of aquifer parameter zones from what was observed by the downward approach. We designed a hydrogeological conceptual model, defining a range of aquifer parameters and aquifer thicknesses that will allow us to constrain the numerical groundwater model and to reduce the number of equivalent solutions during the calibration process. Nevertheless, there is still a need of a better hard rock system's parameterization, particularly the parameterization of fissured zone. This, instead of expensive boreholes and pumping tests, can probably be achieved by MRS but only after some substantial improvements targeting at fissured rock assessment.

\subsection{Conclusion}

We proposed a multi-technique methodology to contribute to the design of hydrogeological conceptual model in hard rock aquifers. The method is based on a downward approach that combines: (i) remote sensing techniques such as digital image processing on satellite images and digital terrain models; (ii) hydrogeophysics; and (iii) hydrogeological field data acquisition. We applied that method to the hard rock Sardón catchment, contributing to the improvement of the hydrogeological conceptual model of that area. In particular we identified the saprolite and fissured layers and characterized their geometry (i.e. horizontal extent and thickness) as well as the spatial variation of the aquifer parameters (flow and storage properties). We drilled 5 boreholes to validate and calibrate the hydrogeophysical data, showing that the methodology is applicable in data scarce areas. The processing of high-resolution satellite images and digital terrain model allowed mapping efficiently the main fault zones and the horizontal distribution of the hydrostratigraphic layers. The GPR method was able to detect shallow water table although the quantitative assessment of the water table depth could not be made routinely because it required local calibration based on measurements made in piezometers and soils and was restricted to the locations with water table depth $<3 \mathrm{~m}$ b.g.s. The ERT method allowed to confirm local subsurface hydrostratigraphy and provided input for the MRS inversion. The multi-frequency FDEM method combined with the laterally constrained inversion technique showed to be very efficient, providing long cross-sections depicting large hydrogeological structures coherent with direct field observation, geological mapping and drilling. The MRS provided valuable results in the saprolite layer, but only in the locations with sufficient signal to noise ratio. Unfortunately, more than half of the MRS survey locations had too low water content to be sensed with the 
MRS equipment we used. The optimization of MRS loops to this type of targets and the use of improved instrumentation (larger pulse moment, better noise rejection capability and shorter dead-time) is recommended to improve MRS data acquisition in the Sardón catchment and in all hard rock aquifers characterized by low or very low water content.

The method of hydrogeological characterization of complex hard rock catchments presented in this study is time and cost effective, but highly suitable for development of hydrogeological conceptual models in fractured hard rocks which otherwise require large time and cost investments. The iterative process of hydrogeological conceptual model development constitutes a powerful tool to synthetize the knowledge of various sources and to define optimal strategy of complementary data acquisition, providing reliable basis for development of numerical distributed models. 


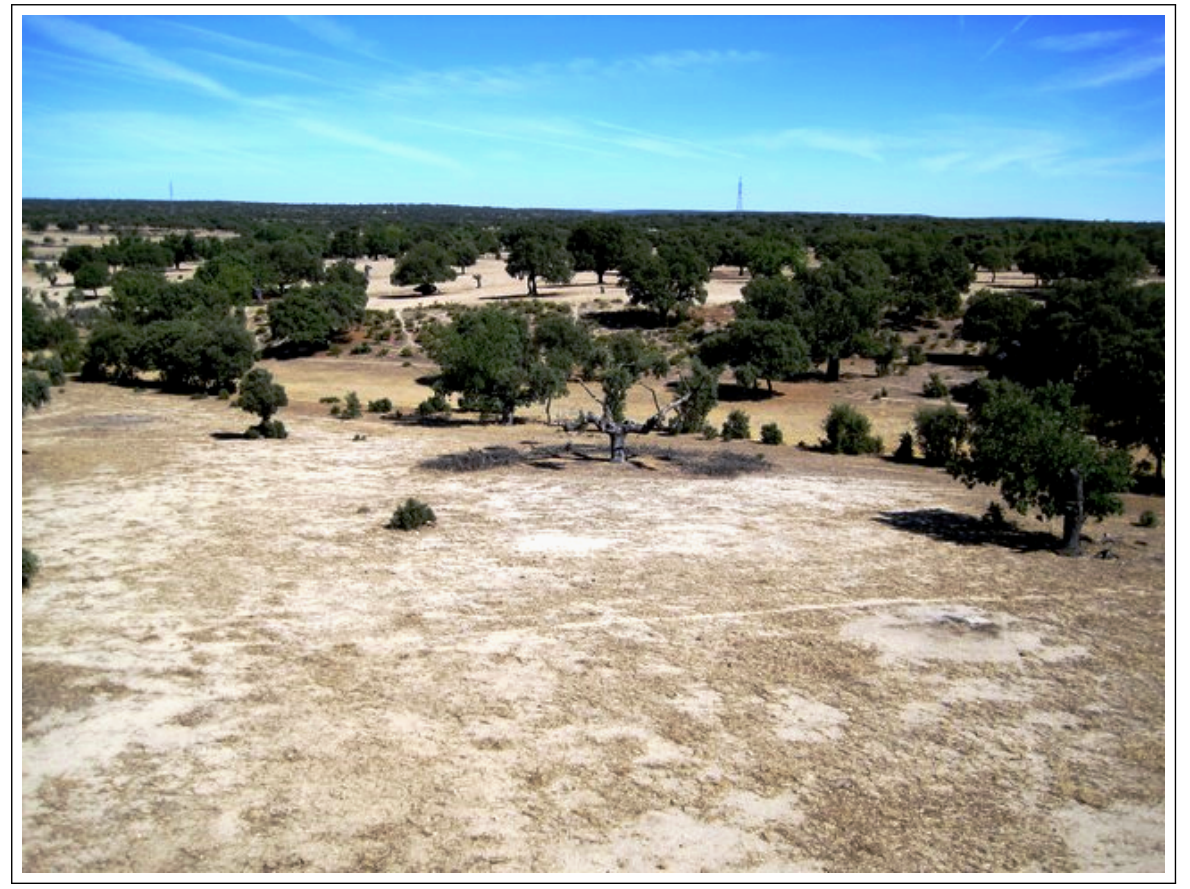

Typical landscape of open woodland composed by oak trees in the Sardón catchment (Salamanca, Spain). 



\section{Partitioning and sourcing of evapotranspiration at the}

catchment scale using coupled MARMITES-MODFLOW model

\subsection{Introduction}

Numerical groundwater flow models constitute a powerful tool for groundwater management as they allow to predict aquifers dynamic responses in relation to climatic, land use and abstraction changes. Groundwater models require both an accurate physical representation of an aquifer system and appropriate boundary conditions. While aquifer parameters as hydraulic conductivity $(K)$ and storativity $(S)$ are spatially dependent and time invariant, groundwater fluxes such as gross recharge $(R g)$, groundwater evapotranspiration $\left(E T_{g}\right)$, groundwater exfiltration $\left(E \times f_{g}\right)$ and groundwater inflow/outflow (respectively $Q i$ and $Q o$ ) can vary in both space and time. Multiplicity of combinations between parameters and fluxes leads to non-uniqueness of model solutions, which limits their reliability and forecasting capability (Moore and Doherty, 2006; Batelaan and de Smedt, 2007).

One possible approach to minimize non-uniqueness of model solutions is to invest in a better spatial parametrization of the subsurface reservoirs, for instance by applying hydrogeophysical techniques (Francés and Lubczynski, 2011; Baroncini-Turricchia et al., 2014; Francés et al., 2014, 2015). Another approach is to constrain groundwater models with spatio-temporally variable groundwater fluxes (Jyrkama et al., 2002; Lubczynski and Gurwin, 2005a), although such assessment is complex (Kinzelbach et al., 2002; Hendricks et al., 2003; Xu and Beekman, 2003; Lubczynski and Gurwin, 2005a; Lubczynski, 2011), because: (i) subsur-

This chapter is based on: Partitioning and sourcing of evapotranspiration at the catchment scale using coupled MARMITES-MODFLOW model. Francés, A. P., and M. W. Lubczynski (2015), submitted to Water Resource Research 
face water fluxes, due to their inaccessibility, are by far more difficult to quantify than surface water fluxes and consequently the methods of their estimation are highly uncertain; (ii) subsurface water fluxes are controlled by spatio-temporal variability of rainfall $(R F)$ and evapotranspiration (ET) but also by surface and subsurface heterogeneity of geology, soil texture, topography, drainage, vegetation, etc.; (iii) groundwater fluxes are generally small and $R g$ cannot be reliably determined (particularly in water limited areas where $R g$ is low) by subtracting $E T$ from $R F$, since unavoidable small errors in the two lead to high inaccuracy of $R g$ (Lubczynski, 2011); (iv) $E T_{g}$ is generally underestimated (Lubczynski, $2000,2009)$, which results in the overestimation of the net recharge $\left(R n=R g-E x f_{g}-E T_{g}\right)$ and therefore erroneous model calibration; and (v) standard groundwater models do not take into account interactions with unsaturated zone so also do not quantify $E x f_{g}$ that can represent important component of groundwater balance (Hassan et al., 2014).

For many years it has been a common modeling practice, while using standalone groundwater models, to apply arbitrary, simplistic estimates of groundwater fluxes (typically $E T_{g}$ and $R g$ ) that were adjusted a-posteriori during model calibration. However, such practices have often been leading to large biases in parameter estimation and erroneous groundwater balances (Batelaan and de Smedt, 2007; Lubczynski, 2009, 2011; Hassan et al., 2014). The relevance of integrating subsurface fluxes, i.e. not only groundwater but also unsaturated zone fluxes, in hydrological modeling and water balancing has recently been emphasized and important advances have been made (Niswonger et al., 2006; Markstrom et al., 2008; Twarakavi et al., 2008; Lubczynski, 2011; Hassan et al., 2014). Distributed and transient water balance models that simulate surface, unsaturated zone and saturated zones processes, so called coupled models, constitute an efficient way to compute spatio-temporally a catchment water balance through partitioning of rainfall into evapotranspiration, runoff, storage and groundwater recharge.

An important component of the coupled models are unsaturated zone models, as they link surface and groundwater domains. The most advanced are physically based unsaturated zone models that involve the Darcy's law and the law of mass conservation expressed through the Richards' equation. Examples of such models are SWAP (Kroes and van Dam, 2003), VSF (Thoms et al., 2006) and HYDRUS (Šimůnek et al., 2011). However, the Richards' equation is highly non-linear and its numerical solution is computationally demanding. It requires a complex parametrization and boundary condition definition, which rather restricts its application to local scale models (Niswonger et al., 2006; Thoms et al., 2006; Sheikh et al., 2009). At the catchment scale, simplified representations of the physical processes are generally applied because they limit the number of parameters to commonly available field information (Yates, 1996; Rushton et al., 2006; Sheikh et al., 2009). Typical simplifications applied in unsaturated zone models are based on the kinematic wave approximation of the Richards' equation (Singh, 1997; Beven and Freer, 2001) and on lumped-parameterization as in WATBAL 
(Yates, 1996), SLURP (Kite, 2000), DREAM (Manfreda et al., 2005), BEACH (Sheikh et al., 2009), INFIL (U.S. Geological Survey, 2008) and others (Finch, 2001; Rushton et al., 2006). Despite the simplification, kinematic wave approximation and lumped parameter models proved to perform at the catchment scale as good as the physically based models (Gehrels, 2000; Sheikh et al., 2009). For instance, Soylu et al. (2011) tested the impact of groundwater depth on ET in a semi-arid grassland region and confirmed that when using standard soil hydraulic parameter datasets, the HYDRUS-1D model (Šimůnek et al., 2008) and a single-bucket soil moisture model performed equivalently well at the large, regional scale. This is because the simplification due to grid-cell averaging of the soil hydraulic parameters makes the two solutions comparable. These authors also showed that both models performed much better when the groundwater depth was introduced as bottom boundary condition.

Relatively simple coupling is when an unsaturated zone model is coupled with an analytical groundwater model. One of such models is Visual Balan (Samper et al., 2005), in which soil water balance is coupled with a simple drainage analytical model that represents an aquifer system. As a lumped model, Visual Balan provides a single flux value of the entire catchment and is thus limited to small, homogeneous areas. Similar solution is the process-based, catchment-scale SWAT model, widely applied in water use and water quality studies (Gassman et al., 2007; DouglasMankin et al., 2010). That semi-distributed model divides a catchment into multiple sub-catchments, which are then further subdivided into hydrologic response units that consist of lumped areas with homogeneous land use, management and soil characteristics. The groundwater reservoir is simplified into two aquifers, one shallow and unconfined and another deep and confined, both modeled using analytical equations.

More sophisticated coupling is when unsaturated zone model is coupled with physically based, distributed numerical model that applies groundwater flow and storage equation (Fetter, 2001), as for instance standalone MODFLOW (Harbaugh et al., 2000). Stanton et al. (2013) showed that the performance of MODFLOW could be improved by its linking to a lumped parameter soil water balance model that provided the spatio-temporal distribution of recharge. Similarly, Batelaan and de Smedt (2007) coupled a distributed water balance model (WetSpass) with steady-state MODFLOW. That modeling approach allowed to integrate the inter-influence between recharge and groundwater depth and to depict high spatial variation of $R n$, with negative values in valleys due to shallow groundwater table and substantial $E T_{g}$ of phreatophytic vegetation. Dams et al. (2012) went further by introducing the temporal variability in the coupling of WetSpa (Wang et al., 1996), a process-based, lumped parameter, transient and distributed hydrological model, with MODFLOW. WetSpa can simulate at daily time step river discharge and percolation out of the root zone, which are further assimilated into MODFLOW groundwater recharge at half-month time-step. In that solution however, the delay between percolation from root zone and groundwater recharge due to water transport through the unsaturated zone was not 
considered. Moreover, the one-way coupling, i.e. exchange of boundary conditions from one model to another, did not allow to include the groundwater table depth effect on the soil reservoir. That problem is well handled for example by Sophocleous and Perkins (2000), Kim et al. (2008) and Chung et al. (2010) who replaced the groundwater analytical module of the quasi-distributed catchment SWAT model with the fullydistributed groundwater MODFLOW model. They applied a two-way coupling between SWAT and MODFLOW, i.e. the two models could exchange between them boundary conditions, which enabled interaction between saturated zone and channel reaches, as well as the simulation of spatiotemporal distribution of groundwater recharge rates, aquifer evapotranspiration and groundwater levels. Another two-way coupled model is the public domain, distributed hydrological model GSFLOW (Markstrom et al., 2008). GSFLOW fully couples PRMS, a lumped-parameter, physicalprocess catchment precipitation-runoff model (Leavesley et al., 1983), with MODFLOW-NWT (Niswonger et al., 2011). In that coupling, the MODFLOW package UZF1 (Niswonger et al., 2006) simulates unsaturated zone flow using a 1D vertical kinematic wave approximation of the Richards' equation. Another similar solution is a distributed version of the onedimensional unsaturated flow package HYDRUS coupled with MODFLOW (Seo et al., 2007; Twarakavi et al., 2008). The HYDRUS package provides MODFLOW with recharge fluxes, while MODFLOW provides HYDRUS with the elevation of the groundwater table that is used as the bottom boundary condition in the package. The integrated catchment MIKE SHE model also integrates groundwater and surface water, taking into account the partitioning of rainfall into runoff, evapotranspiration and groundwater recharge. One important advantage of MIKE SHE is that it allows the user to select the degree of complexity of the application. For instance, vertical unsaturated flow may be modeled either by $1 \mathrm{D}$, finite difference multilayer method based on Richards' equation or by a simpler, two-layer root zone model. This allows to apply MIKE SHE either as fully physical model at the local scale or using simplified physical equations to run the model at the regional scale. However, MIKE SHE is not public domain and parametrically demanding.

The most advanced and complex models are fully integrated hydrologic models such as InHM (van der Kwaak, 1999; van der Kwaak and Loague, 2001), HydroGeoSphere (Brunner and Simmons, 2012; Therrien et al., 2012) and ParFlow (Kollet and Maxwell, 2006, 2008) (for a review and comparison of integrated hydrologic models refer to Maxwell et al. (2014)). These models simulate land surface, unsaturated and saturated zone flow processes based on adapted forms of the Richards' and Saint Venant (overland flow) equations that are mathematically integrated and solved simultaneously. The main restriction to their use, besides the extensive parameterization, is that they are highly demanding in computing resources and require high-performance parallel computers.

The most advanced models of the presented review allow to compute a detailed spatio-temporal water balance at the catchment scale and implement the separation, here referred as sourcing, of ET into 
unsaturated zone and groundwater evapotranspiration (respectively $E T_{u}$ and $E T_{g}$ ). Indeed, it is already well known and scientifically accepted that $E T$ affects not only the surface and unsaturated zones but also the saturated zone, representing important components of water balances (Miller et al., 2010; Lubczynski, 2011; Balugani et al., 2015). However, as the evapotranspiration represents two physically different processes, evaporation $(E)$ and transpiration $(T)$, with two different spatial and temporal characteristics (Guan and Wilson, 2009; Lubczynski, 2011; Orellana et al., 2012), hydrological models need to account them separately. Therefore, not only the sourcing but also the partitioning of $E T$ into $T$ and $E$ have to be implemented into hydrological models, by considering the following subsurface $E T$ components: unsaturated zone evaporation $\left(E_{u}\right)$, groundwater evaporation $\left(E_{g}\right)$, unsaturated zone transpiration $\left(T_{u}\right)$ and groundwater transpiration $\left(T_{g}\right)$. The partitioning and sourcing of evapotranspiration fluxes is relevant not only to improve reliability of models and their water balances but also to understand the role of vegetation and soil processes in the water cycle and to make reliable prediction scenarios of climate and land use changes (Lubczynski, 2011).

This chapter introduces a transient and distributed lumped-parameter model of the land surface and the soil zone MARMITES that is two-way coupled with the groundwater model MODFLOW-NWT (Niswonger et al., 2011). This coupled model computes spatio-temporally a detailed water balance at the catchment scale. The main novelties of the proposed approach are: (i) partitioning of the evapotranspiration into evaporation and transpiration; (ii) sourcing of evaporation and transpiration into unsaturated and saturated zone components; and (iii) integration of (i) and (ii) in the newly developed MARMITES-MODFLOW coupled model. The objective of this study is to present the capacity of the MARMITESMODFLOW model to quantify spatio-temporally surface and subsurface water fluxes with emphasis on partitioning and sourcing of subsurface evapotranspiration. This presentation is done on the base of the small $\left(\sim 4.8 \mathrm{~km}^{2}\right)$ La Mata Catchment case study (Salamanca, Spain).

\subsection{Material and Methods}

\subsubsection{MARMITES-MODFLOW Coupled Model}

\subsubsection{General MARMITES-MODFLOW Description}

MARMITES (MM) is a transient, distributed model of the land surface and the soil zone that is coupled with the groundwater model MODFLOW (MF). Both models share the same spatial and temporal discretization. Figure 5.1 (right) shows the structure of one cell of the two models of the MM-MF coupling. MM is composed of one surface component (MMsurf) and one soil zone component (MMsoil). The unsaturated zone below the bottom of the soil zone and above the groundwater table, referred here as percolation zone, is modeled using UZF1 package (Niswonger et al., 2006), while the groundwater flow in the saturated zone is handled by 
MODFLOW-NWT (Niswonger et al., 2011). The following processes are considered in MM-MF: (i) rainfall interception by vegetation and crops (MMsurf); (ii) irrigation in agricultural fields (MMsurf); (iii) computing of potential evaporation and potential transpiration of several vegetation, crop and soil types (MMsurf); (iv) runoff, surface storage and evaporation from open water (MMsurf); (v) infiltration, evaporation, transpiration, percolation and soil moisture storage of the soil zone (MMsoil); (vi) percolation and storage in the percolation zone (MF-UZF1); (vii) groundwater recharge, evaporation, transpiration, flow and storage in the saturated zone (MF). A detailed description of the MM components and MF packages, including input data, parameters and equations, is available in section 5.2.1.2.

The abbreviations keys of Figure 5.1 are as following:

- Land surface: rainfall $R F$, rainfall excess $R F e$, interception $I$, surface water evaporation $E_{\text {surf } f}$, surface runoff $R o$, storage $S_{\text {surf } f}$.

- Soil zone: infiltration $\operatorname{Inf}$, soil evaporation $E_{\text {soil }}$, soil transpiration $T_{\text {soil }}$, percolation $R_{\text {soil }}$, saturated soil exfiltration $E x f$, storage $S_{\text {soil }}$, $l$ is the number of soil layers.

- Percolation zone: percolation zone evaporation $E_{p}$, percolation zone transpiration $T_{p}$, percolation from the soil zone $R_{p}$, gross recharge $R g$, storage $S_{p}$.

- Saturated zone: groundwater evaporation $E_{g}$, groundwater transpiration $T_{g}$, groundwater exfiltration $E x f_{g}$, inflow/outflow $Q i / Q o$, storage $S_{g}$, L is the number of aquifer layers. 

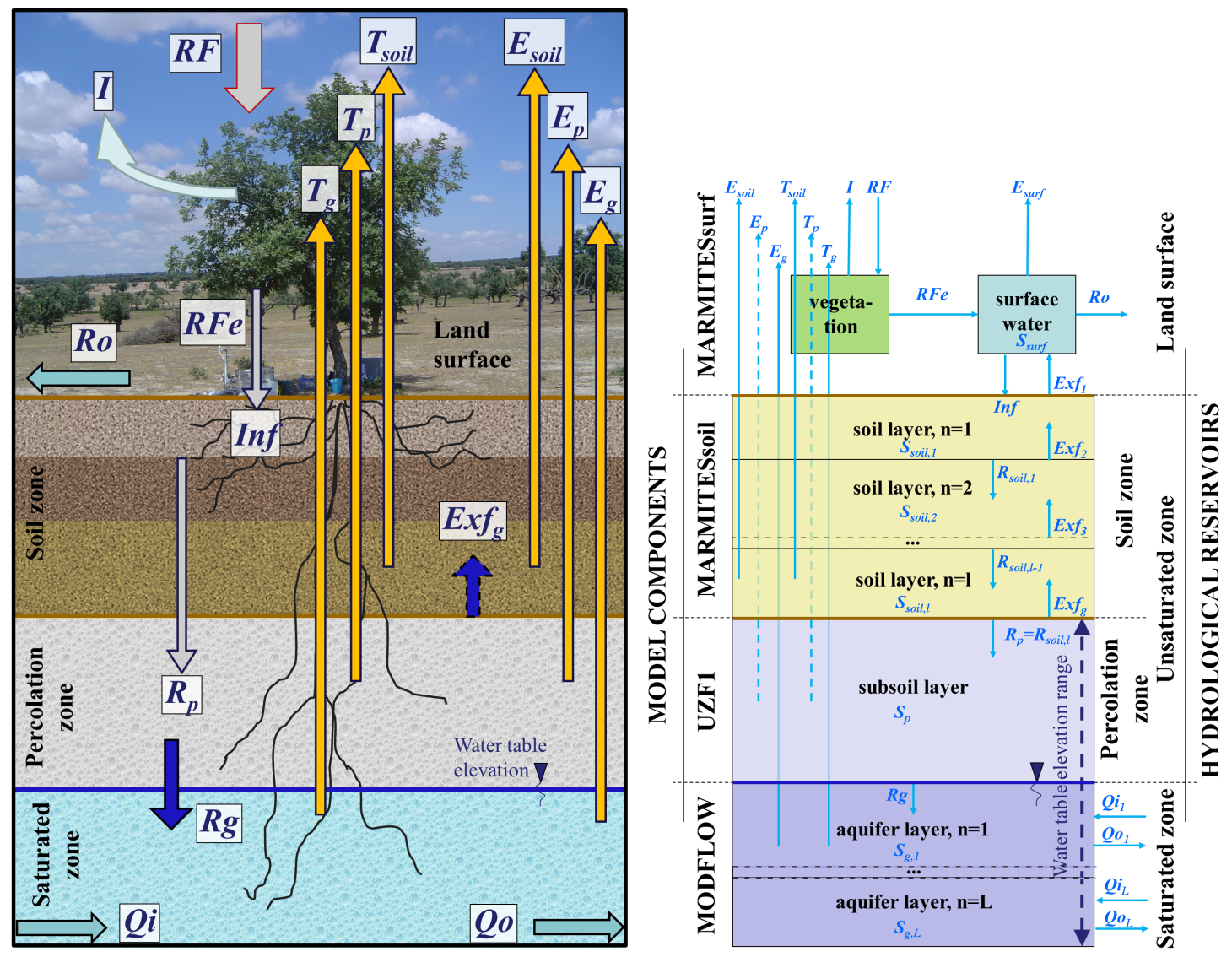

Figure 5.1: Conceptual schema of the coupled MARMITES-MODFLOW models, showing the water flux components and the partitioning and sourcing concepts. Left: general scheme describing the exchange of water fluxes between hydrological reservoirs. Right: structure of one vertical cell showing the exchange of water fluxes. Note that both $E_{p}$ and $T_{p}$ are considered negligible and are not computed (indicated with dash lines). The abbreviations keys are indicated on the previous page. 
A typical MM-MF run is initiated by the MMsurf component (Figure 5.1 and section 5.2.1.2). The main function of MMsurf is to compute on daily basis the driving forces (rainfall, potential evaporation and potential transpiration). Subsequently, the rainfall partitioning and related water balance in the soil zone is computed on daily basis by the MMsoil component using lumped-parameters and linear relationships between fluxes, driving forces and soil moisture (Figure 5.1 and section 5.2.1.2). The soil zone is typically discretized into superimposed layers that are parameterized with basic soil hydraulic properties. Generally these soil layers are defined using textural criterion and correspond to the $\mathrm{A}$ and $\mathrm{B}$ horizons, which are the zones of eluviation and illuviation respectively (Dingman, 2002; Food and Agriculture Organization, 2006). The user can alternatively define one single soil zone corresponding to the root zone. The percolation output from the soil zone is introduced as input of the MF UZF1 package (Niswonger et al., 2006). UZF1 in the MM-MF coupling framework simulates the water flow through the percolation zone, i.e. the zone below the soil bottom and above the groundwater table. This zone corresponds to the $\mathrm{C}$ and $\mathrm{R}$ horizons, i.e. parent material and bedrock respectively. UZF1 considers only one single uniform layer and converts percolation from MMsoil into groundwater recharge by applying a 1D kinematic-wave approximation of the Richards' equation that only incorporates gravitational forces and neglects capillary ones (Niswonger et al., 2006). If the groundwater table rises above the bottom of the MM soil layer, groundwater exfiltration $\left(E x f_{g}\right)$ from the aquifer into the MM soil zone occurs, hypothetically creating runoff if the soil layers turn saturated. If that happens, the MF hydraulic heads are corrected in MM to add the thickness of the saturated soil layers. Finally, water flow and storage in the saturated zone are computed by MF (section 5.2.1.2). The MM-MF coupled model output is a daily, grid-based water balance of the catchment that can be visualized by maps, time series plots and animations (spatio-temporal variability of fluxes). The yearly averaged water balance at the observation plots and at the catchment scale can be plotted as Sankey diagrams. Such representation eases the visualization of the water balance because: (i) the simulated fluxes are represented by arrows with width proportional to the water flux they represent; and (ii) these arrows are connected, representing the exchange of water between the model reservoirs.

\subsubsection{MM-MF Detailed Description}

The water balance at the catchment scale in the MM-MF modeling framework is computed considering storage, flux and exchange of water between the following 4 main reservoirs (Figure 5.1): land surface, soil zone, percolation zone and saturated zone. In the text below, the in$\operatorname{dex}_{\text {surf }}$ refers to the surface, index soil to the soil zone, index $p$ to the percolation zone and the index $g$ to the saturated zone. The full list of input parametric maps is presented in Table 5.1. 
Table 5.1: MM-MF input parametric maps. Each map can be defined as an ASCII ESRI raster file or a unique scalar value. For MF, an input is required for each layer.

\begin{tabular}{lll}
\hline Name & Description & Unit \\
\hline gridMETEO_fn & meteorological zones & {$[-]$} \\
gridIRR_fn & irrigated field & {$[-]$} \\
gridSOIL_fn & soil type & {$[-]$} \\
gridSOILthick_fn & thickness of the soil & $\mathrm{m}$ \\
gridPONDhmax & maximum water height in the cell stream & $\mathrm{m}$ \\
gridPONDw & width of the cell stream & $\mathrm{m}$ \\
elev & topography & $\mathrm{m}$ \\
thick & thickness of the MF layers & $\mathrm{m}$ \\
ibound & MF active cells & {$[-]$} \\
strt & MF initial hydraulic heads & $\mathrm{m}$ \\
$h k$ & MF horizontal hydraulic conductivity & $\mathrm{m} \cdot \mathrm{s}^{-1}$ \\
$v k a$ & MF vertical hydraulic conductivity & $\mathrm{m} \cdot \mathrm{s}^{-1}$ or [-] \\
$S_{y}$ & MF specific yield & $\mathrm{m}^{3} \cdot \mathrm{m}^{-3}$ \\
$S_{s}$ & MF specific storage & {$[-]$} \\
iuzfbnd & MF UZF1 active recharge/discharge cells & {$[-]$} \\
$v k s$ & MF UZF1 saturated vertical hydraulic conductiv- & $\mathrm{m} \cdot \mathrm{s}^{-1}$ \\
& ity of the unsaturated zone & \\
eps & MF UZF1 Brooks-Corey epsilon of the unsatur- & {$[-]$} \\
$t h t s$ & ated zone & \\
thti & MF UZF1 saturated water content of the unsatur-- & $\mathrm{m}^{3} \cdot \mathrm{m}^{-3}$ \\
gbh_head & ated zone & \\
gbh_cond & MF UZF1 initial water content of the unsaturated & $\mathrm{m}^{3} \cdot \mathrm{m}^{-3}$ \\
drn_elev & zone & \\
drn_cond & MF GHB hydraulic head & $\mathrm{m}$ \\
\hline & MF DRN drain elevation & $\mathrm{m}^{2} \cdot \mathrm{m}^{-3}$ \\
& & $\mathrm{~m}$ \\
$\mathrm{~m}^{2} \cdot \mathrm{m}^{-3}$ \\
\hline
\end{tabular}


MARMITES Surface

The surface water balance equation is written as:

$$
\frac{d S_{\text {surf }}}{d t}=R F e+E x f_{1}-\operatorname{Inf}-E_{\text {surf }}-R o
$$

with

$$
R F e=R F-I
$$

and

$$
\text { Inf }=\min \left[S_{\text {surf }} ;\left(\phi_{1} \times \text { thick }_{1}\right)-S_{\text {soil }, 1}\right]
$$

where $S_{\text {surf } f}$ is surface water storage, $R F$ is rainfall, $R F e$ is rainfall excess, $I$ is interception by vegetation, $E x f_{1}$ is exfiltration from the topmost soil layer to the surface, $I n f$ is infiltration into the soil, $E_{\text {sur } f}$ is surface water evaporation, $R o$ is surface runoff, $\phi_{1}$ and $t h i c k_{1}$ are respectively porosity and thickness of the topmost soil layer and $S_{\text {soil }}$ is soil storage, being defined as the product of actual volumetric soil moisture content times the thickness of the layer. All water fluxes are expressed in [L/T] and storage in $[\mathrm{L}]$, generally $\mathrm{mm}$ and day (also in the next equations). The land surface is composed of 2 sub-reservoirs: the vegetation reservoir, that promotes interception from rainfall, and the surface water reservoir, that stores water in land depressions and stream channels. When the maximum capacity of the surface storage is reached, Ro occurs.

The land surface component (MMsurf) also performs the rainfall analysis and computes: (i) hourly interception; (ii) daily bare soil potential evaporation; (iii) daily vegetation potential transpiration (excluding agricultural crop); (iv) daily agricultural crop potential transpiration. These driving forces are next used in MMsoil component to derive $E_{\text {soil }}$ and $T_{\text {soil. }}$. MMsurf requires as input hourly, continuous time series of the following meteorological data: rainfall $(\mathrm{mm})$, wind speed $\left(\mathrm{m} . \mathrm{s}^{-1}\right)$, air relative humidity $(\%)$, air temperature $\left({ }^{\circ} \mathrm{C}\right)$ and incoming solar radiation $\left(\mathrm{MJ} \cdot \mathrm{m}^{-2} \cdot \mathrm{h}^{-1}\right)$. Note that if hourly data are not available, the user can prepare daily $P E, P T, R F, R F e$ and $I$ time series externally and run the MM-MF model. Parameters and variables of the meteorological stations, vegetation, crop and soil are also required (Table 5.2).

The rainfall analysis is hourly based and computes the rainfall intensity and duration. These values are used to compute interception from the several vegetation types, including crops. The storm-based analytical model (Gash, 1979) reformulated by Gash et al. (1995) is applied to account for interception in sparse forest. This model considers unit area of canopy to compute wet canopy evaporation, referred here as rainfall interception. It combines the advantages of low data demand with simplicity, still maintaining a realistic approach of the interception process. 
Table 5.2: MMsurf input parameters and variables.

\begin{tabular}{|c|c|c|}
\hline Group & Parameter/variable & Unit \\
\hline \multirow[t]{6}{*}{ METEO. } & station latitude & $\circ$ \\
\hline & station longitude & $\circ$ \\
\hline & station altitude (asl) & $\mathrm{m}$ \\
\hline & longitude of the center of the local time zone & ${ }^{\circ} \mathrm{W}$ of Greenwich \\
\hline & height of wind speed measurement & $\mathrm{m}$ \\
\hline & height of air humidity measurement & $\mathrm{m}$ \\
\hline \multirow[t]{16}{*}{ VEG. } & height & $\mathrm{m}$ \\
\hline & canopy capacity & $\mathrm{mm}$ \\
\hline & maximum leaf conductance & $\mathrm{mm} \cdot \mathrm{s}^{-1}$ \\
\hline & leaf area index dry season & $\mathrm{m}^{2} \cdot \mathrm{m}^{-2}$ \\
\hline & leaf area index wet season & $\mathrm{m}^{2} \cdot \mathrm{m}^{-2}$ \\
\hline & shelter factor dry season & {$[-]$} \\
\hline & shelter factor wet season & {$[-]$} \\
\hline & vegetation albedo dry season & {$[-]$} \\
\hline & vegetation albedo wet season & {$[-]$} \\
\hline & julian day dry season & N.A. \\
\hline & julian day wet season & N.A. \\
\hline & transition period between dry and wet season & days \\
\hline & maximum root depth & $\mathrm{m}$ \\
\hline & $T_{g}$ sourcing parameter $k_{T \min }$ & {$[-]$} \\
\hline & $T_{g}$ sourcing parameter $k_{T \max }$ & {$[-]$} \\
\hline & $T_{g}$ sourcing parameter $n$ & {$[-]$} \\
\hline
\end{tabular}


- continued from previous page

\begin{tabular}{lll}
\hline Group & Parameter/variable & Unit \\
\hline CROP & height & $\mathrm{m}$ \\
& canopy capacity & $\mathrm{mm}$ \\
& maximum leaf conductance & $\mathrm{m}^{-1}$ \\
& leaf area index & $\mathrm{m}^{2} \cdot \mathrm{m}^{-2}$ \\
& shelter factor & {$[-]$} \\
& vegetation albedo & {$[-]$} \\
& maximum root depth & $\mathrm{m}$ \\
& $T_{g}$ sourcing parameter $k_{T \text { min }}$ & {$[-]$} \\
& $T_{g}$ sourcing parameter $k_{T \text { max }}$ & {$[-]$} \\
& $T_{g}$ sourcing parameter $n$ & {$[-]$} \\
\hline SOIL & surface (1 ${ }^{\text {st }}$ cm) soil porosity & $\mathrm{m}^{3} \cdot \mathrm{m}^{-3}$ \\
& surface (1 ${ }^{\text {st }}$ cm) soil field capacity & $\mathrm{m}^{3} \cdot \mathrm{m}^{-3}$ \\
& soil albedo dry season & {$[-]$} \\
& soil albedo wet season & {$[-]$} \\
& julian day dry season & $\mathrm{N} . \mathrm{A}$. \\
& julian day wet season & $\mathrm{N} . \mathrm{A}$. \\
& transition period between dry and wet season & days \\
\hline
\end{tabular}

N.A.: not applicable.

Potential transpiration $(P T)$ and potential evaporation $(P E)$ are computed using the Penman-Montheith equation as formulated in Allen et al. (1998). In addition to the 4 meteorological variables listed above, the model requires vegetation, crop and soil parameters and variables (Table 5.2). The definition and values for standard vegetation and soil types of these variables and parameters can be found for instance in Dingman (2002). To compute $P E$, the surface resistance of bare soil was computed using van de Griend and Owe (1994). Soil and vegetation variables (e.g. albedo, leaf area index) are considered constant seasonally and a transition period is defined between seasons. The model also computes the open water evaporation rate as defined by Penman (Gieske, $2003)$ that is used to compute the surface water evaporation $\left(E_{\text {surf }}\right)$ in equation (5.1). Finally, once $P T$ and $P E$ are computed for each vegetation and soil type, a weighted average of $P T$ and $P E$ is defined at each grid cell, taking into account the fractional area of each soil and vegetation type present in that cell. Note that in the cells occupied by crop, it is assumed that the crop coverage is $100 \%$. 
If the irrigation option is activated, the user must provide the following input: (i) one ESRI ASCII file representing irrigation fields, each with an identification code (ID, integer) higher than 0 (if several fields share the same ID the same irrigation schedule will be applied); (ii) for each irrigation field, one ASCII file with the daily applied irrigation (mm); (iii) for each irrigation field, one ASCII file with the schedule of the crop types. The irrigation is added to the rainfall. If in one cell the field ID is higher than 0 , this field will be considered as an irrigation field. Since it is assumed that the crop coverage is $100 \%$ in the irrigation fields, vegetation and soil cover are not considered. Still, soil evaporation is considered when the fields are in fallow (in this case transpiration is null).

\section{MARMITES Soil}

The water balance in the soil zone is computed as:

$$
\sum_{n=1}^{l} \frac{\left(d S_{\text {soil }}\right)_{n}}{d t}=\operatorname{Inf}+E x f_{g}-\sum_{n=1}^{l}\left[\left(R_{\text {soil }}\right)_{n}+E x f_{n}+\left(E_{\text {soil }}\right)_{n}+\left(T_{\text {soil }}\right)_{n}\right]
$$

where $S_{\text {soil }}$ is soil storage, $\operatorname{In} f$ is infiltration into the soil (downward flux), $E x f_{g}$ is groundwater exfiltration into the soil (upward flux), $R_{\text {soil }}$ is percolation between soil layers (downward flux), $E x f$ is exfiltration between soil layers (upward flux), $E_{\text {soil }}$ is bare soil evaporation, $T_{\text {soil }}$ is vegetation transpiration and $l$ is the total number of soil layers.

$R_{\text {soil }}, E_{\text {soil }}$ and $T_{\text {soil }}$ are computed for each soil layer $n$ using linear relationships between water fluxes and soil moisture (Figure 5.2) as following:

$$
\left(R_{\text {soil }}\right)_{n}=(\text { Ksat })_{n}\left(\frac{\theta_{n}-\left(\theta_{f c}\right)_{n}}{\phi_{n}-\left(\theta_{f c}\right)_{n}}\right)
$$

where Ksat is soil saturated hydraulic conductivity, $\theta$ is actual volumetric soil moisture, $\phi$ is porosity and $\theta_{f_{c}}$ is soil moisture at field capacity;

$$
\left(E_{\text {soil }}\right)_{n}=P E_{n}\left(\frac{\theta_{n}-\left(\theta_{w p}\right)_{n}}{\phi_{n}-\left(\theta_{w p}\right)_{n}}\right)
$$

with

$$
P E_{n}=P E_{n-1}-\left(E_{\text {soil }}\right)_{n-1} \text { if } n>1
$$

and

$$
\left(T_{\text {soil }}\right)_{n}=P T_{n}\left(\frac{\theta_{n}-\left(\theta_{w p}\right)_{n}}{\phi_{n}-\left(\theta_{w p}\right)_{n}}\right)
$$

with

$$
P T_{n}=P T_{n-1}-\left(T_{\text {soil }}\right)_{n-1} \text { if } n>1
$$


where $\theta_{w p}$ is permanent wilting point. Equation (5.4) is applied in bare soil and equation (5.5) is applied for each vegetation type, taking into account the fractional grid cell area.

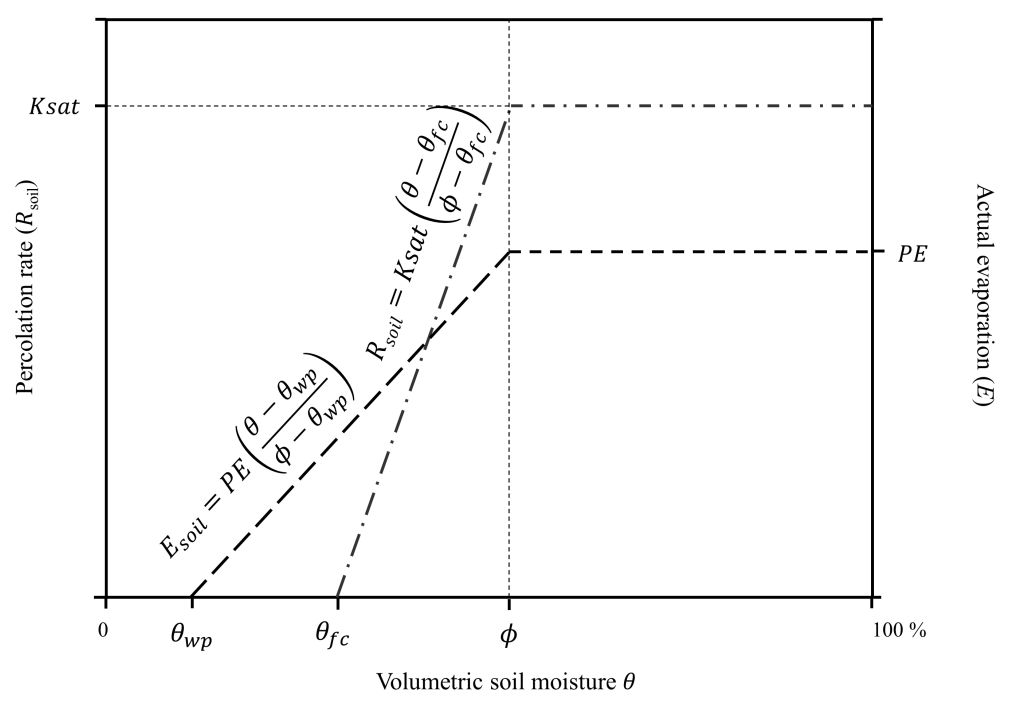

Figure 5.2: Linear relationships between actual soil moisture $(\theta)$ in the root zone and: (i) $R_{\text {soil }}$, see Equation (5.3); and (ii) evaporation ( $E_{\text {soil }}$ ), see equation (5.4). $\phi$ is porosity, $\theta_{f c}$ is soil moisture at field capacity, $\theta_{w p}$ is permanent wilting point, Ksat is saturated hydraulic conductivity and $P E$ is potential evaporation. Note that $T_{\text {soil }}$ is computed the same way as $E_{\text {soil }}$ in equation (5.5) by replacing the term $P E$ by $P T$ (potential transpiration).

Note that $R_{\text {soil }}$ is computed assuming that the pressure head in the soil reservoir is constant over depth and thus the potential gradient approximates zero. This approximation is valid if the potential flux term is negligible in relation to the gravitational term (van der Lee and Gehrels, 1997; Gehrels and Gieske, 2003).

\section{MODFLOW and UZF1}

The water balance in the unsaturated zone is:

$$
\frac{d S_{p}}{d t}=R_{p}-R g
$$

where $S_{p}$ is percolation zone storage, $R_{p}$ is percolation from the soil zone and $R g$ is gross groundwater recharge.

The relationships between unsaturated hydraulic conductivity and water content used in UZF1 to simulate the water percolation between the soil zone and the groundwater table are based on the Brooks-Corey equation (Niswonger et al., 2006). This equation requires only 4 variables: initial and saturated water content, saturated hydraulic conductivity and 
the Brooks-Corey function exponent (respectively thti, thts, $v k s$ and eps, see Table 5.1).

The groundwater balance is:

$$
\frac{d S_{g}}{d t}=\sum_{n=1}^{L}\left[R g_{n}+Q i_{n}\right]-\sum_{n=1}^{L}\left[Q o_{n}-\left(E_{g}\right)_{n}-\left(T_{g}\right)_{n}-\left(E x f_{g}\right)_{n}\right]
$$

where $S_{g}$ is groundwater storage, $E_{g}$ is groundwater evaporation, $T_{g}$ is groundwater transpiration, $Q i$ and $Q o$ are respectively groundwater inflow and outflow, $E x f_{g}$ is groundwater exfiltration into the soil zone and $L$ is the total number of MF layers. $E_{\mathfrak{g}}$ and $T_{\mathfrak{g}}$ are computed by Equations (5.14) and (5.15) respectively.

The groundwater flow in the saturated zone is computed in MF through the following partial-differential equation (Harbaugh, 2005):

$$
\frac{\delta}{\delta x}\left(\mathrm{~K}_{x x} \frac{\delta h}{\delta x}\right)+\frac{\delta}{\delta y}\left(\mathrm{~K}_{y y} \frac{\delta h}{\delta y}\right)+\frac{\delta}{\delta z}\left(\mathrm{~K}_{z z} \frac{\delta h}{\delta z}\right)+W=S_{s} \frac{\delta h}{\delta t}
$$

where $\mathrm{K}_{x x}, \mathrm{~K}_{y y}$ and $\mathrm{K}_{z z}$ are the values of hydraulic conductivity along the $x, y$ and $z$ coordinate axes (assumed to be parallel to the major axes of the hydraulic conductivity tensor $\mathrm{K}$ ), $h$ is hydraulic head, $W$ is water sources or sinks (e.g. $R g, E_{g}, T_{g}$ ), $S_{s}$ is specific storage and $t$ is time.

This equation is numerically solved in MODFLOW-NWT using the finite-difference method and is applied to both confined and unconfined aquifers after proper correction of the storage term (Harbaugh, 2005). The time domain is divided into stress periods (SP) during which the water fluxes are constant. When the SP correspond to several days, the MM water fluxes provided to MF are averaged.

\section{Mass Balance}

The mass balance discrepancy (MB) is computed as following (Harbaugh, 2005):

$$
M B=\frac{100 \times(I N-O U T)}{(I N+O U T) / 2}
$$

where $I N$ and $O U T$ are respectively the sum of fluxes entering and leaving the system.

The mass balance of MMsurf is computed as:

$$
I N_{\text {surf }}=R F+E x f_{1}+\Delta S_{\text {surf }}
$$

with

$$
\Delta S_{\text {surf }}=\left(S_{\text {surf } f}\right)_{k}-\left(S_{\text {surf }}\right)_{1}
$$

and

$$
O U T_{\text {surf }}=I+R o+E_{\text {surf }}+\operatorname{Inf}
$$


where $k$ is the number of stress periods and the index 1 corresponds to the first stress period (initial conditions) in the storage change equation.

The mass balance of MMsoil is computed as following:

$$
I N_{\text {soil }}=\operatorname{Inf}+E x f_{\mathcal{g}}+\sum_{n=1}^{l}\left[\left(\Delta S_{\text {soil }}\right)_{n}\right]
$$

with

$$
\Delta S_{\text {soil }}=\left(S_{\text {soil }}\right)_{k}-\left(S_{\text {soil }}\right)_{1}
$$

and

$$
O U T_{\text {soil }}=\sum_{n=1}^{l}\left[\left(R_{\text {soil }}\right)_{n}+E x f_{n}+\left(E_{\text {soil }}\right)_{n}+\left(T_{\text {soil }}\right)_{n}\right]
$$

The mass balance in the percolation zone is extracted from UZF1 outputs as following:

$$
I N_{p}=R_{p}+\Delta S_{p}
$$

with

$$
\Delta S_{p}=\left(S_{p}\right)_{k}-\left(S_{p}\right)_{1}
$$

and

$$
O U T_{p}=R g
$$

The mass balance in the groundwater reservoir is extracted from MF outputs as following:

$$
I N_{g}=\sum_{n=1}^{L}\left[R g_{n}+Q i_{n}+\left(\Delta S_{g}\right)_{n}\right]
$$

with

$$
\begin{aligned}
& \Delta S_{g}=\left(S_{g}\right)_{k}-\left(S_{g}\right)_{1} \\
& Q i=F F F+F R F+F L F
\end{aligned}
$$

and

$$
O U T_{\mathfrak{g}}=\sum_{n=1}^{L}\left[Q o_{n}+\left(E_{\mathfrak{g}}\right)_{n}+\left(T_{\mathfrak{g}}\right)_{n}+\left(E x f_{\mathfrak{g}}\right)_{n}\right]
$$

with

$$
\begin{aligned}
& Q o=F B F+F L f F+F U F+D R N \\
& W E L=E_{g}+T_{g}
\end{aligned}
$$

where $Q i$ and $Q o$ are respectively total groundwater flux in and out coming from adjacent MF cells, FFF, FRF, FLF, FBF, FLfF, FUF are respectively groundwater fluxes from front, right, lower, back, left and upper face of the MF cells, being extracted through the MF cell water budget, $D R N$ is the flux corresponding to the MF drain package and $W E L$ is the flux corresponding to the MF well package (Harbaugh, 2005). 


\subsubsection{Coupling}

The two-way coupling schema of MM-MF Figure 5.3) is sequential. MM and MF are run during the whole modeled period one after the other, exchanging boundary conditions, until the convergence criteria are met. The convergence criteria are defined as the average and the maximum differences of groundwater heads computed by the two last sequential runs. The thresholds of these convergence criteria are defined by the user. The boundary flux exchange between MM and MF is completed as following: MM produces the spatio-temporally variable soil percolation $\left(R_{p}\right)$ and the two components of groundwater evapotranspiration $\left(E T_{g}\right)$, i.e. $E_{g}$ and $T_{g}$, and provides them to MF. While $R_{p}$ is converted into groundwater recharge $(R g)$ by the UZF1 package, $E T_{g}$ is inserted into MF using the well package (WEL). MF computes groundwater heads and exfiltration $\left(E x f_{g}\right)$ that in turn constitutes the bottom boundary of MM in the next loop. In practice, an initialization run of MF, executed using a fixed, arbitrary, user-defined percolation value, computes groundwater heads and exfiltration. Next, a first sequential loop of MM and MF run is started. In that loop, first MM is executed, followed by MF. After the second loop, the average and the maximum differences of groundwater heads between the two loops are computed. If the average and maximum differences are both lower than the user-defined threshold, the program exits the loop and produces output files. Otherwise the loop is run again until models convergence is achieved or the user-defined maximum number of loops is reached.

\subsubsection{Partitioning and Sourcing}

To perform the partitioning and the sourcing of the evapotranspiration $(E T)$, the potential evaporation $(P E)$ and potential transpiration $(P T)$ are first computed as explained in section 5.2.1.2. Next, soil evaporation $\left(E_{\text {soil }}\right)$ and soil transpiration $\left(T_{\text {soil }}\right)$ are computed based on linear relationships between available soil moisture and $P E$ and $P T$ respectively (Equations (5.4) and (5.5) in section 5.2.1.2). At each time step of MM, $E_{\text {soil }}$ and $T_{\text {soil }}$ are first taken from the most surficial layer, then from the second soil layer and then further from subsequent layer down to the lowest layer. At each soil layer, evaporation and transpiration extracted from that layer are subtracted from $P E$ and $P T$. If after depleting the deepest MM soil layer, $P E$ and $P T$ are not satisfied, $E_{g}$ and $T_{g}$ are computed. Note that in the current MARMITES version, evaporation and transpiration from the percolation zone ( $E_{p}$ and $T_{p}$ respectively) are not considered, although in UZF1 it is possible to compute evapotranspiration from the percolation zone $\left(E T_{p}\right)$. 


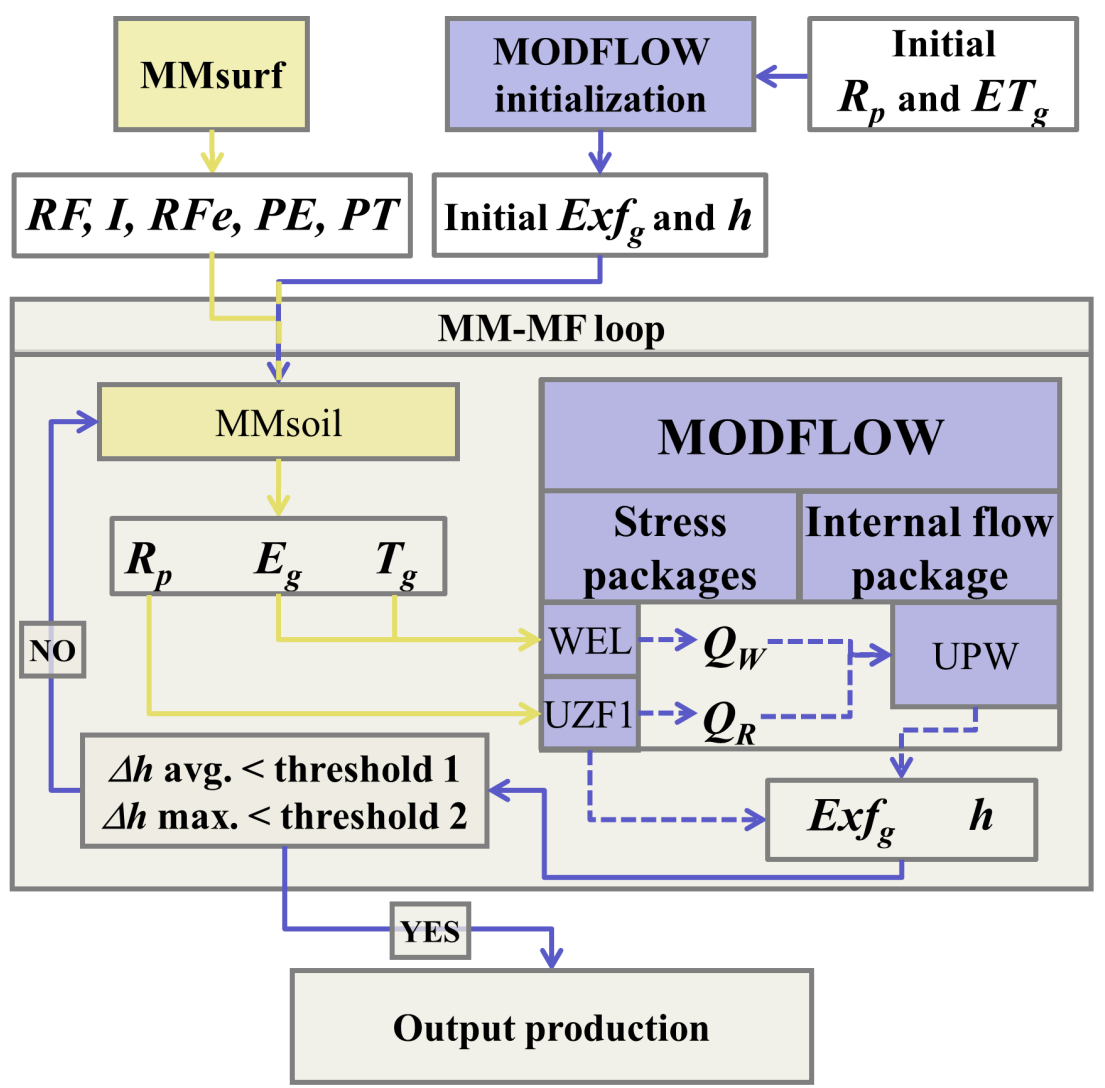

Figure 5.3: Sequential coupling of MARMITES and MODFLOW models. $h$ is hydraulic head, $\Delta h$ is the difference of hydraulic heads between two successive MM-MF loops (avg. stands for average and max. for maximum), $Q_{w}$ and $Q_{R}$ are the flows produced by the WEL and UZF1 packages respectively, $P E$ is potential evaporation and $P T$ is potential transpiration. See Figure 5.1 for other abbreviations. 
In relation to $E_{g}$, Shah et al. (2007) found a soil texture dependent exponential relationships between $E_{g}$ and the groundwater table depth (d) using numerical simulations of HYDRUS-1D (Šimůnek et al., 1998). In $\mathrm{MM}$, their Equation (17) was applied to compute bare soil $E_{g}$ as following:

$$
E_{g} / P E_{g}= \begin{cases}1 & \text { if } d \leq d^{\prime \prime}, \\ y_{0}+e x p^{-b\left(d-d^{\prime \prime}\right)} & \text { if } d>d^{\prime \prime}, \\ 0 & \text { if } d \geq D .\end{cases}
$$

where $P E_{g}=P E-E_{\text {soil }}$ is the groundwater potential evaporation $\left(E_{\text {soil }}\right.$ is first computed using Equation (5.4)), $d^{\prime \prime}$ is the decoupling depth, $y_{0}$ is a correction, $b$ is the decay coefficient and $D$ is the extinction depth. At depth lower than $d^{\prime \prime}, P E_{g}$ is fully satisfied by groundwater, i.e. $E_{g} / P E_{g}=1$. Otherwise the exponential relationship is applied up to the extinction depth $D$. Equation (5.14) is applied on bare soil using specific set of parameters $d^{\prime \prime}, b$ and $y_{0}$ defined by Shah et al. (2007) for several soil texture classes (Table 5.3 and Figure 5.4).

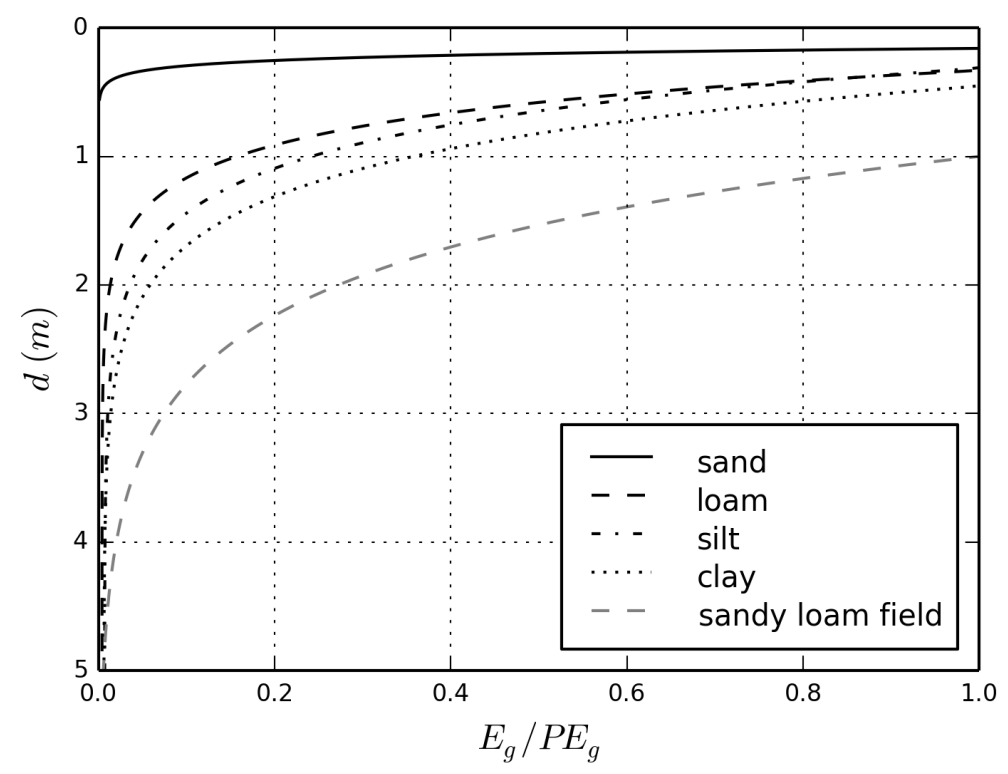

Figure 5.4: Groundwater evaporation $\left(E_{g}\right)$ curves (Equation (5.14)) of the main soil texture classes (after Shah et al., 2007). The soil texture class labeled "sandy loam field" corresponds to the results of Balugani et al. (2014) obtained from the La Mata catchment. $P E_{g}$ is groundwater potential evaporation and $d$ is groundwater table depth. Refer to Table 5.3 to consult the corresponding parameters and to section 5.2.1.4 for detailed explanations. 
Table 5.3: Parameters of equation (5.14) of: (a) standard soil type (Shah et al., 2007); and (b) La Mata catchment soil type (Balugani et al., 2014). $d^{\prime \prime}$ is the decoupling depth (cm), $y_{0}$ is a correction ([-]), $b$ is the decay coefficient $\left(\mathrm{cm}^{-1}\right)$ and $D$ is the extinction depth $(\mathrm{cm})$.

\begin{tabular}{|c|c|c|c|c|}
\hline Soil type & $d^{\prime \prime}$ & $y_{0}$ & $b$ & $D$ \\
\hline $\operatorname{sand}^{(a)}$ & 16.0 & 0.000 & 0.171 & 50.0 \\
\hline $\operatorname{loam}^{(a)}$ & 33.0 & 0.004 & 0.028 & 265.0 \\
\hline $\operatorname{silt}^{(a)}$ & 31.0 & 0.007 & 0.021 & 430.0 \\
\hline $\operatorname{clay}^{(a)}$ & 45.0 & 0.006 & 0.019 & 620.0 \\
\hline sandy loam field $^{(b)}$ & 100.0 & 0.000 & 0.013 & 475.0 \\
\hline
\end{tabular}

The computing of $T_{g}$ depends first on the root depth $(Z r)$ defined for each vegetation type. If the groundwater table depth is higher than $Z r$, then $T_{g}$ is set to zero. Otherwise, the following relationships linking $T_{g}$ to soil moisture $(\theta)$ and groundwater potential transpiration $\left(P T_{g}\right)$ is applied:

$T_{g} / P T_{g}= \begin{cases}k_{T \max } & \text { if } \theta=\phi, \\ k_{T \min }+\left[k_{T \max }-k_{T \min }\right]\left[1-\left(\frac{\phi-\theta}{\phi-\theta_{w p}}\right)^{n}\right]^{1 / n} & \text { if } \theta_{w p}<\theta<\phi, \\ k_{T \min } & \text { f } \theta=\theta_{w p},\end{cases}$

with

$$
0<k_{\text {Tmin }}<k_{\text {Tmax }} \leq 1,
$$

where $P T_{g}=P T-T_{\text {soil }}\left(T_{\text {soil }}\right.$ is computed first using Equation (5.5)), $k_{T \text { min }}, k_{\text {Tmax }}$ and $n$ are vegetation-dependent $T_{g}$ sourcing parameters, $\phi$ is soil porosity and $\theta_{w p}$ is permanent wilting point. The vegetationspecific sourcing parameters $k_{T \text { min }}, k_{T \max }$ and $n$ allow to control the phreatophytic behavior of the plants by tuning the amount of groundwater that they can uptake, as discussed in section 5.3.1.2.

\subsubsection{Space and Time Discretization}

The catchment is divided into squared-grid cells, all of them with the same size. Each cell is parametrized with vegetation, soil and aquifer parameters and supports only one soil type but several vegetation types characterized by fractional area of their cell occupancy. The time discretization is automatically performed by MMsurf based on the rainfall time series analysis. For each day with $R F>0$ one stress period is defined while when there is no rainfall, fluxes are averaged with the period in between the two successive events with $R F>0$, up to a maximum time interval defined by the user (typically 10 days). 


\subsubsection{Technical Specifications}

MM is developed using the Python programming language (version 2.7) and related libraries (SciPy and matplotlib). The code is open source, available at https://code.google.com/p/marmi tes/. The MF files are implemented using the FloPy code (Post, 2008), also developed in Python (source code available at https://code.google.com/p/f7opy/). As input, MM requires 3 types of ASCII files to run. The $1^{\text {st }}$ type corresponds to INI files that are required to initialize the $3 \mathrm{MM}-\mathrm{MF}$ components (MMsurf, MMsoil and MF). The $2^{\text {nd }}$ file type are ESRI ASCII grid format maps of parameters and variables. The $3^{\text {rd }}$ type provides the time series of driving forces (meteorological and irrigation data) and state variables (observations). The output spatio-temporal water fluxes are stored in multidimensional grids in HDF5 format (http://www.hdfgroup.org/HDF5/), being automatically exported into ASCII file format at user-defined observations points to allow their import into software such as Microsoft Excel or GoldenSoftware Grapher. MM also produces maps and time series of fluxes to visualize the model output (see examples in section 5.3.2).

\subsubsection{Model Implementation}

\subsubsection{La Mata Catchment Study Case}

This study uses the La Mata catchment ( $\sim 4.8 \mathrm{~km}^{2}$, see Figure 5.5$)$, located in Western Spain (West of Salamanca), to present the functionality of the MM-MF model. The La Mata catchment is a sub-catchment of the Sardón catchment $\left(\sim 80 \mathrm{~km}^{2}\right)$ where extensive research on subsurface water fluxes at the catchment scale has been carried out (Lubczynski and Gurwin, 2005a; Lubczynski, 2009, 2011; Reyes-Acosta and Lubczynski, 2013; Balugani et al., 2014; Francés et al., 2014; Hassan et al., 2014). This catchment was selected because of a semi-arid, water-limited environment, negligible groundwater use, availability of monitoring data and shallow groundwater table ( $\sim 2 \mathrm{~m}$ depth) enhancing $E_{g}, T_{g}$ and $E x f_{g}$. Its granitic rock medium is characterized by large heterogeneity, low to moderate permeability and low storage, typical of hard rock water scarce condition.

The La Mata sub-catchment has been equipped with an automatic data acquisition system (ADAS, located at P0, Figure 5.5) that records hourly hydro-meteorological variables since 1996. The groundwater table fluctuation is monitored in one piezometer at the P0 location (automatic, hourly measurement) and at several groundwater-connected ponds (P1 to P5, with manual, seasonal measurement). Besides, an $18 \mathrm{~m}$ high eddy covariance tower (ECT) (Figure 5.5) was installed at $140 \mathrm{~m}$ ENE from the ADAS between June 2009 and June 2012 to record ET (van der Tol, 2012). 


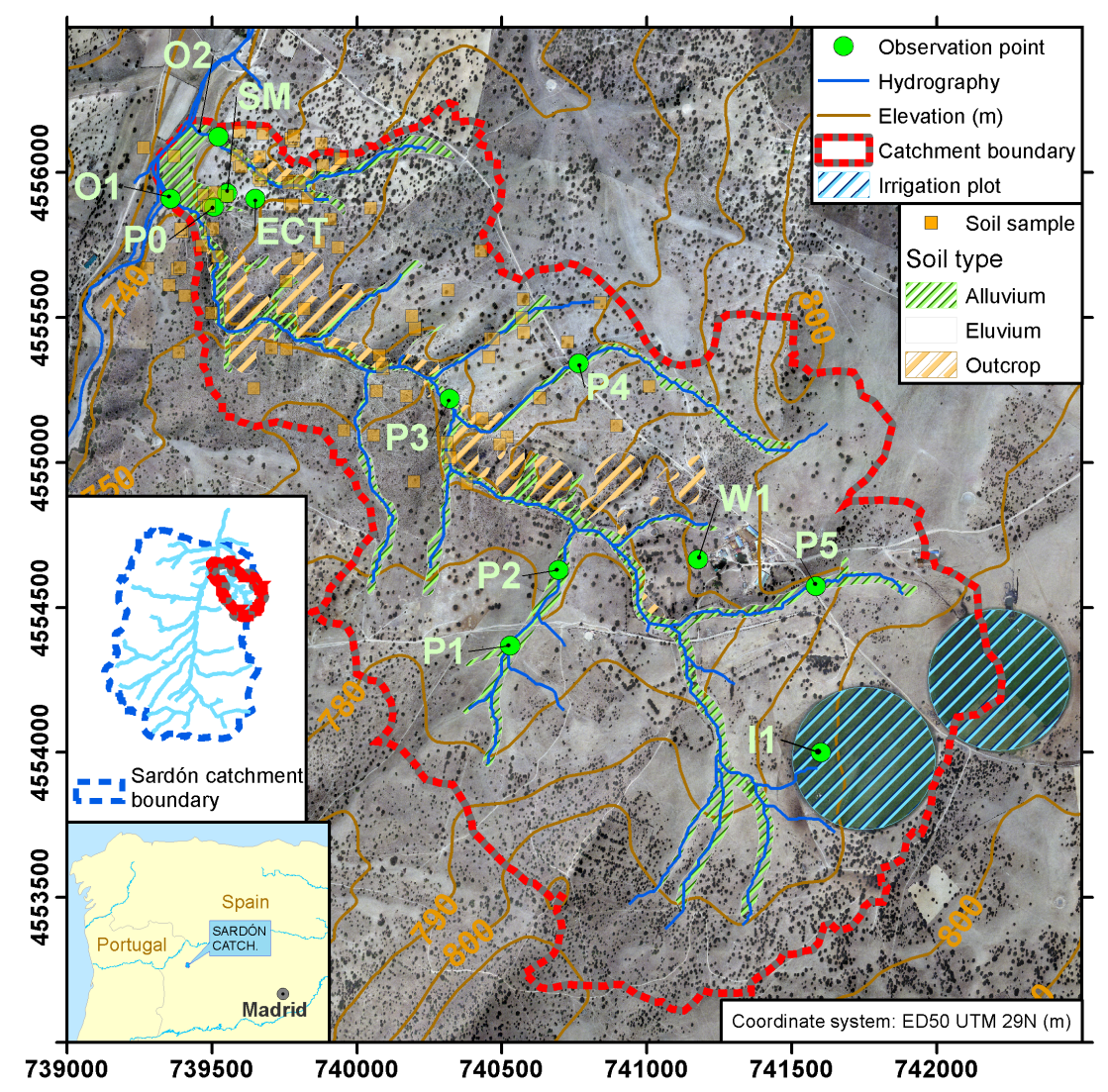

Figure 5.5: La Mata sub-catchment. Labels indicate observation points.

The semi-arid climate of the study area is typical for the central part of the Iberian Peninsula, being affected by relatively high elevation $(\sim 800 \mathrm{~m}$ a.s.l.). The long-term, 23-years mean rainfall estimated on the base of six Spanish Meteorological Institute rain gauges located in the surroundings of the study area is $\sim 500 \mathrm{~mm} . \mathrm{y}^{-1}$ while the potential evapotranspiration (PET) is $\sim 1015 \mathrm{~mm} \cdot \mathrm{y}^{-1}$. The warmest and the driest months in the study area are July and August with an average temperature of $\sim 22^{\circ} \mathrm{C}$, average PET of $\sim 5 \mathrm{~mm} . \mathrm{d}^{-1}$ and rainfall less than $20 \mathrm{~mm} . \mathrm{month}^{-1}$. The coldest months are January and February with an average temperature of $\sim 5^{\circ} \mathrm{C}$ and the lowest PET $\sim 0.5 \mathrm{~mm} . \mathrm{d}^{-1}$, while November and December are the wettest with rainfall above $100 \mathrm{~mm} . \mathrm{month}^{-1}$ (Lubczynski and Gurwin, 2005a). The ECT estimates of actual evapotranspiration ranged from $0.2 \mathrm{~mm} . \mathrm{d}^{-1}$ in dry September to $3.5 \mathrm{~mm} . \mathrm{d}^{-1}$ in wet April (van der Tol, 2012).

The landscape of the catchment is characterized by a pediment with gentle slopes that corresponds to present and old planation surfaces. It is erratically interrupted by inselbergs, exposed corestones and granite 
outcrops. A dense drainage network of incised streams, typical of hard rock catchments, developed along faults. Those are ephemeral streams, with water flowing only in wet season and only after substantial rainfall events. While the pediment is covered by a thin $(0.10$ to $0.75 \mathrm{~m})$ sandyloam inceptisol (eluvium), alluvial deposits 1 to $3 \mathrm{~m}$ thick are located along the thalweg (line defining the deepest channel in a valley). The main part of the alluvium profile is composed of silty sand above a $0.5 \mathrm{~m}$ thick layer of centimeter to decimeter size pebbles. The shallow subsurface was documented by invasive field methods (portable percussion hammer with sampling gauge, augering and digging). The collected soil samples were analyzed in laboratory to retrieve the hydraulic properties and soil texture.

The land cover consists of sparsely distributed open woodland composed of evergreen oak Quercus ilex (Q.i.) subsp. ballota Desf. (Samp.) and broad-leafed deciduous oak Quercus pyrenaica (Q.p.). The canopies of these two oak trees cover $\sim 7 \%$ of the La Mata sub-catchment. The shrub known as Scotch Broom (Cytisus scoparius) is also present locally. The entire area is covered by grasses that sprout in March-May, start to wilt in June and next disappear due to the drying soil and cattle grazing.

The groundwater table depth, as monitored in the study area, varies between 0.0 and $3.0 \mathrm{~m}$ below ground surface ( $\mathrm{m}$ b.g.s.) along the thalweg and between 1.0 and $5.0 \mathrm{~m}$ b.g.s. at the catchment divides. As the groundwater system is unconfined, the groundwater table follows the topography and is largely influenced by the surficial drainage network. The groundwater pattern is natural due to negligible groundwater extraction.

\subsubsection{Discretization}

The spatial discretization of the La Mata sub-catchment was made on a regular square grid of $50 \mathrm{~m}$ resolution, corresponding to 60 columns and 65 rows. The model simulation was carried out during two successive hydrological years, i.e. from 01/10/2008 to 31/09/2010. According to the long-term yearly rainfall average of $500 \mathrm{~mm} . \mathrm{y}^{-1}$, the first year was dry, with only $306 \mathrm{~mm} \cdot \mathrm{y}^{-1}$ of rainfall, while the second was mediumwet, with $593 \mathrm{~mm} . \mathrm{y}^{-1}$. An initialization period was applied between $31 / 05 / 2008$ and 31/09/2008 to allow the model to reach equilibrium under applied driving forces. The first time step was run in steady-state conditions, allowing to start the model with average, long-term initial conditions of UZF1 soil moisture and MF hydraulic heads.

\subsubsection{MM boundary conditions and parametrization}

The basic hydro-meteorological variables necessary to obtain the time series of driving forces ( $R F, P E$ and $P T$, see section 5.2.1.2 for details) were acquired from the ADAS station. The soil types and granite outcrops were mapped as in Francés and Lubczynski (2011); Francés et al. (2014) using a supervised classification technique applied on two highresolution, multispectral satellite images: QuickBird from September 
2009 and WorldView-2 from December 2012. The classification method is based on object-oriented fuzzy-logic analysis (Benz et al., 2004), available in the eCognition software. Two main soil types, i.e. the alluvium and elluvium, were identified and differentiated from granite outcrops (Figure 5.5). The soil data obtained by sampling campaigns (Figure 5.5) and processed in laboratory allowed to retrieve the soil texture and hydraulic properties (Table 5.4). The lack of sampling at the top of the catchment is due to the prohibition of the land-owner to access his area. Alfalfa crop growing in March and cropped in October was attributed to the two crop fields located in the eastern part of the La Mata subcatchment(Figure 5.5). The related irrigation schedule was defined using the program CROPWAT v8.0 (Food and Agriculture Organization, 2009).

Table 5.4: Calibrated soil hydraulic properties of the 2 soil types of La Mata catchment. $\phi$ : porosity, $\theta_{f c}$ : soil moisture at field capacity, $\theta_{w p}$ : soil moisture at wilting point, $\theta_{i}$ : initial soil moisture, Ksat: soil saturated hydraulic conductivity, Thick: thickness of the soil layer. Units in $\mathrm{m}^{3} \cdot \mathrm{m}^{-3}$ expect Ksat and Thick, respectively in $\mathrm{mm} \cdot \mathrm{d}^{-1}$ and $\mathrm{m}$.

\begin{tabular}{lrrrrrrr}
\hline Soil type & Layer & $\phi$ & $\theta_{f c}$ & $\theta_{w p}$ & $\theta_{i}$ & Ksat & Thick. \\
\hline Alluvium & 1 & 0.15 & 0.125 & 0.075 & 0.145 & 1.5 & 0.75 \\
& 2 & 0.19 & 0.175 & 0.100 & 0.190 & 1.5 & 0.25 \\
\multirow{3}{*}{ Eluvium } & 1 & 0.22 & 0.150 & 0.070 & 0.215 & 5.0 & 0.35 \\
& 2 & 0.35 & 0.200 & 0.125 & 0.250 & 3.0 & 0.15 \\
\hline
\end{tabular}

\subsubsection{MF boundary conditions and parametrization}

Francés et al. (2014) presented a hydrogeological conceptual model of the Sardón catchment, to which the La Mata sub-catchment belongs, using a combination of remote sensing, non-invasive hydrogeophysics and hydrogeological field data acquisition. They identified two main hydrostratigraphic layers, the saprolite and the fissured layers, that they geometrically and parametrically characterized. For the sake of simplicity, in the present La Mata case study focused on demonstration of the MM-MF capability, one aquifer layer schematizing both saprolite and fissured layers was defined.

The La Mata catchment divide was defined as no-flow boundary. The catchment outlet was represented using drain (DRN) cells to simulate the groundwater outflow of the catchment. The parameters required by the MF model are listed in Table 5.5. The initial hydraulic heads were defined at the base of the soil layer. Due to the lack of dense, uniformly distributed piezometric network and small size of the catchment, the aquifer was parametrized with a single value for each of the hydraulic property. 
Table 5.5: MODFLOW parameters of La Mata catchment. $h k$ is horizontal hydraulic conductivity $\left(\mathrm{m} . \mathrm{s}^{-1}\right), S_{y}$ is specific yield $\left(\mathrm{m}^{3} \cdot \mathrm{m}^{-3}\right), S_{s}$ is specific storage ([-]), DRN cond. is drain conductivity $\left(\mathrm{m}^{2} \cdot \mathrm{d}^{-1}, v k s\right.$ is saturated vertical hydraulic conductivity $\left(\mathrm{m} \cdot \mathrm{s}^{-1}\right)$ and eps is Brooks-Corey epsilon $([-])$.

\begin{tabular}{lrrrrrr}
\hline Parameter & $h k$ & $S_{y}$ & $S_{s}$ & DRN cond. & $v k s$ & $e p s$ \\
\hline Value & 0.15 & 0.020 & $1 E^{-5}$ & 0.225 to 0.375 & 0.01 & 2.0 \\
\hline
\end{tabular}

\subsubsection{Partitioning and Sourcing Parameterization}

The partitioning of ET was made possible thanks to the definition of the vegetation and soil fractional coverages at each cell. The fractional coverage areas were retrieved using the mapping of bare soil described in section 5.2.2.3 and the mapping of the tree canopies made by ReyesAcosta and Lubczynski (2013). The later was carried out for each tree species, using the same remote sensing technique and images as used for the soil classification. The fractional area of the tree canopies was derived from the mapped canopy cover following assumption that tree roots water uptakes affect areas equal to the canopy areas (Naumburg et al., 2005). Based on the fractional areas occupied by each tree species and by soil at every grid cell, $E_{\text {soil }}, E_{g}, T_{\text {soil }}$ and $T_{g}$ fluxes were converted into volume and extracted from the respective reservoir.

The sourcing of $E$ was performed using Equations (5.4) and (5.14). Both equations were parameterized based on the soil analysis described in section 5.2.2.3. Balugani et al. (2014) presented a sourcing framework in a Python SOURCE script that defined the bare soils $E_{g}$ and $E_{u}\left(E_{u}=\right.$ $E_{\text {soil }}+E_{p}$ ) from the output of HYDRUS-1D model for various boundary conditions. Based on their results and field data of the La Mata catchment (soil texture, soil moisture and matric potential), a set of parameters $d^{\prime \prime}, y_{0}, b$ and $D$, specific for the La Mata soil texture (Table 5.3), was computed using the same methodology as in Shah et al. (2007).

The sourcing of $T$ was performed on both tree species Q.i. and Q.p.. Equation (5.15) was parameterized using the results of site-specific experiments based on sap flow measurements of $T$ combined with stable isotope (deuterium) tracing of groundwater, soil moisture and sap of the tree xylem (Reyes-Acosta, 2015). These authors derived the proportional contributions of $T$ from groundwater and unsaturated zone sources using a mixing model solution. This experiment was conducted during the dry season of years 2008, 2009 and 2010 on Q.i. and Q.p. To reproduce that phreatophytic behavior of each oak species, simulations using equation (5.15) were performed by varying parameters $k_{T \text { min }}$, $k_{T \max }$ and $n$. 


\subsubsection{Calibration}

The transient calibration of the MM-MF coupled model was done against: (i) soil moisture in MM; and (ii) hydraulic heads in MF. Two soil moisture profiles were available in the study area, one located in the alluvium at P0 and the other in the eluvium at SM (Figure 5.5). Hydraulic heads were monitored with automatic water level recorders installed at piezometer P0 ( $3 \mathrm{~m}$ b.g.s.). Episodic records of the water level measured in groundwater linked-ponds and in a shallow well (respectively observation points P1 to P5 and W, Figure 5.5) were also used for calibration. ET measurements from the ECT were also compared with the model output.

The calibration process was carried out first using trial and error method and next using the PEST algorithm (Doherty, 2005) to obtain fine tuning and parameter uncertainties (not discussed here). Both methods were used in order to obtain a balanced calibration that produced a meaningful water balance and respected the observation data. The MMsoil component was calibrated by updating the soil hydraulic parameters and thickness. The MF model was calibrated on hydraulic conductivity $(h k)$, specific yield $\left(S_{y}\right)$, DRN conductance, UZF1 vertical saturated hydraulic conductivity and UZF1 epsilon factor ( $v k s$ and eps respectively, see table 5.1). In PEST, weighting of the observations was made to ensure representativeness of all observation types in the objective function.

To analyze the goodness of fit between simulated and observed curves of soil moisture and hydraulic heads, 3 calibration criteria were used (Moriasi et al., 2007): (i) Pearson's correlation coefficient ( $r$ ); (ii) root mean square error (RMSE); and (iii) ratio of the RMSE to the standard deviation of the observed heads (RSR). While RMSE and RSR measure the discrepancy between simulated and observed curves, $r$ shows how well model and observation trends fit each other. The calibration process focused on minimizing RMSE and RSR and maximizing $r$. The calibration criteria are automatically computed and plotted in MM by the Python code.

\subsection{Results and discussion}

\subsubsection{Partitioning and sourcing of evapotranspiration}

The partitioning of $E T$ was implemented at the model cell scale using soil and vegetation fractional area, retrieved using a supervised classification technique applied on high-resolution satellite images. This method was very efficient, allowing to map at the catchment scale: (i) different soil types, differentiating them from granite outcrop; (ii) canopy shape and canopy area of every single tree with $90 \%$ probability of being well classified (Reyes-Acosta and Lubczynski, 2013). 


\subsubsection{Groundwater evaporation function}

The soil texture retrieved by the analysis of the soil samples collected in the La Mata catchment was sandy loam. The field sandy-loam soil parameters of Equation (5.14), computed based on the results of Balugani et al. (2014), are shown in Table 5.3, while the corresponding curve is shown in Figure 5.4. The main difference between our parameters and those defined by Shah et al. (2007) is in the decoupling depth parameter $\left(d^{\prime \prime}\right)$. The $d^{\prime \prime}$ value of the sandy-loam soil of La Mata catchment is $1 \mathrm{~m}$, while the maximum $d^{\prime \prime}$ value of Shah et al. (2007) is $0.45 \mathrm{~m}$ for clay soil (Table 5.3). The estimates of $E_{g}$ were also carried out experimentally by Johnson et al. (2010). These authors used semi-spherical chamber in sand and loam soils, with water table depth varying between 0.1 and $3.3 \mathrm{~m}$, in arid and semi-arid areas of Northern Chile. They also found an exponential relationship relating $E_{g}$ with groundwater table depth, but using power laws fit at their deepest water table. Their $d^{\prime \prime}$ was low, i.e. between 2 and $12 \mathrm{~cm}$, while $b$ varied between 0.036 and $0.072 \mathrm{~cm}^{-1}$. The differences between parameters of the equation (5.14) in the present study, in Shah et al. (2007) and in Johnson et al. (2010) suggest that these parameters are strongly site-specific and should be defined using field data.

\subsubsection{Groundwater transpiration function}

Figure 5.6a shows the $T_{\mathfrak{g}} / P T_{\mathfrak{g}}$ ratio as function of soil moisture (Equation (5.15)) and its sensitivity to the transpiration sourcing parameter $n$. This parameter defines the shape of the $T_{g} / P T_{g}$ dependence on $\theta$ and thus the relative importance of $T_{g}$ in relation to $P T_{g}$ and indirectly to $T_{\text {soil }}$ and $P T$, since $P T_{g}=P T-T_{\text {soil }}$. The control of the $n$ parameter is also illustrated in the time series presented in Figure 5.6b: (i) with $n=0.5, T_{g}$ is restricted to small values $<0.5 \mathrm{~mm}$; while (ii) with $n=2.0$, $T_{g}$ increases rapidly as $T_{\text {soil }}$ decreases and becomes the main source of transpiration after $\sim 80$ days, reaching $\sim 50 \%$ of $P T$ around day 100 .

The parameters $k_{T \min }$ and $k_{T \max }$ control the total amount of $T_{g}$ in relation to $T$. $T_{g}$ sensitivity to $k_{T \min }$ and $k_{T \max }$ was tested firstly applying $k_{T \min }=0.1$ and $k_{T \max }=0.9$ (Figure 5.6b); secondly, increasing $k_{T \text { min }}$ to 0.8 while keeping the same high $k_{T \max }$ as in b) (Figure 5.6c); and thirdly, keeping the same low $k_{T \min }$ as in b) and reducing $k_{T \max }$ to 0.2 (Figure $5.6 \mathrm{~d}$ ). In the first case (c), $T_{g}$ was close to $P T_{g}$, satisfying $\sim 85 \%$ of PT at day 350 . In contrast, in case (d), $T_{g}$ was low all the times representing $\sim 14 \%$ of $P T$ at day 350 . Note that in both cases (c) and (d), parameter $n$ had little influence on $T_{g}$. The use of the 3 parameters, i.e. $k_{T \min }, k_{T \max }$ and $n$, allows to simulate well the phreatophytic behavior of the modeled plants.

To parameterize Equation (5.15) in relation to the two tree species found in La Mata catchment, the work of Reyes-Acosta (2015) was used. The author found that at the end of the dry season (August-September 2009), $T_{g}$ of Q.i. varied between $42 \%$ and $75 \%$ of $T$ during the day, while 
$T_{g}$ of Q.p. varied between 25 and $35 \%$ of $T$. To obtain the same $T_{g} / T$ proportion as experimentally estimated, we defined the transpiration sourcing parameters presented in Table 5.6 for the two tree species. Such parameters were also defined for the non-phreatophytic alfalfa crop and grass, ensuring that $T_{\mathfrak{g}}$ was null or negligible.

Table 5.6: Vegetation parameters of equation (5.15) defined for the La Mata catchment. $k_{T \min }, k_{T \max }$ and $n$ are vegetation-dependent $T_{g}$ sourcing parameters (unitless) and $Z r$ is root depth (m).

\begin{tabular}{lrrrr}
\hline Veg. type & $k_{T \min }$ & $k_{T \max }$ & $n$ & $Z r$ \\
\hline Q.i. & 0.10 & 0.80 & 2.0 & 15.0 \\
Q.p. & 0.50 & 0.90 & 2.0 & 10.0 \\
Grass & 0.01 & 0.02 & 0.5 & 0.4 \\
Alfalfa & 0.01 & 0.02 & 0.5 & 1.2 \\
\hline
\end{tabular}



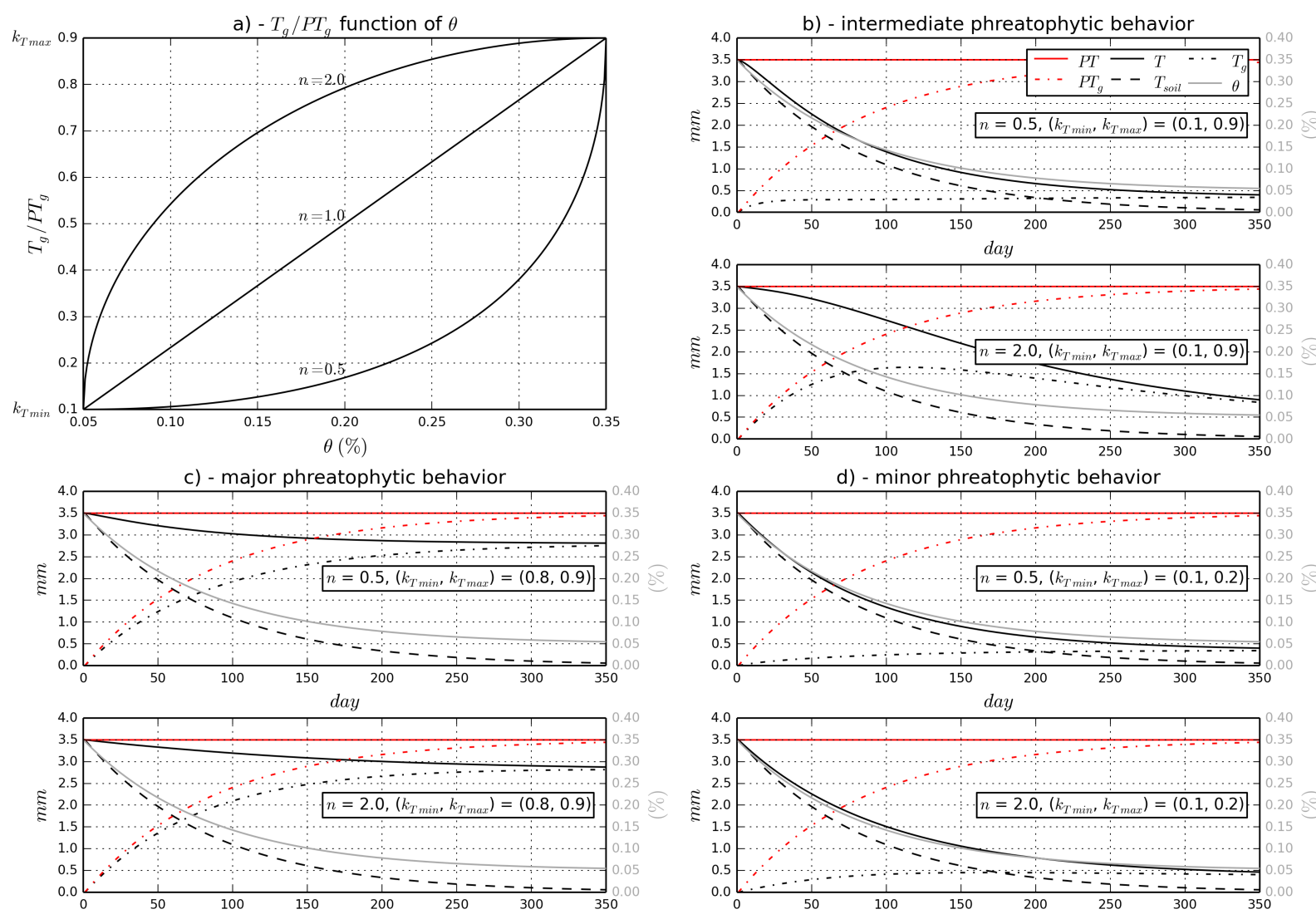

$\vec{\sigma} \quad$ Figure 5.6: Sourcing transpiration function and sensitivity of Equation (5.15): a) $T_{g} / P T_{g}$ ratio as function of soil moisture $(\theta)$ and its sensitivity to parameter $n\left(k_{T \min }=0.1\right.$ and $\left.k_{T \max }=0.9\right)$; b), c) and d) are time series of groundwater potential
transpiration $\left(P T_{g}\right)$, total transpiration $(T)$, soil transpiration $\left(T_{\text {soil }}\right)$ and groundwater transpiration $\left(T_{g}\right)$ computed with variable set of $n, k_{T \min }$ and $k_{T \max }$ to simulate intermediate (b), major (c) and minor (d) phreatophytic behavior. In this example, $P T=3.5 \mathrm{~mm} . \mathrm{d}^{-1}$, porosity $\phi=0.35$, soil moisture at wilting point $\theta_{w p}=0.05$ and soil thickness $=1.0 \mathrm{~m}$. 
The $T_{g}$ solution proposed in this study based on Equation (5.15) is groundwater table depth independent but driven by climatic conditions and soil moisture availability. The only study of that type which proposed partitioning of transpiration is by Baird and Maddock III (2005). However, they proposed different transpiration-related approach. They developed a MF package to compute riparian $T_{g}$ based on plant physiological characteristics, applying a bell-shaped $T_{g}$ relation with GWTD that requires vegetation specific parameters. That solution was developed for riparian and wetland ecosystems, i.e. environments with very shallow water table frequently rising above the land surface and creating unfavorable anaerobic conditions leading to a $T$ reduction and dead of the plant by anoxia. The bell-shaped function, developed for such ecosystems, reflects well this behavior by simulating a $T_{g}$ decline that follows the water rise to the surface. However, it is questionable if their solution is applicable to open oak woodland ecosystems or any other ecosystems characterized by deeply rooted trees with access to both unsaturated and saturated zones reservoirs. For such settings, it is assumed in this study that if a tree is phreatophytic, i.e. have roots deep enough to be able to tap groundwater, and if soil moisture is not sufficient to fulfill the tree water demand, then $T_{g}$ occurs with rate independent on GWTD (equation (5.15)). This assumption is in agreement with experimental results of Balugani et al. (2015) who partitioned and sourced ET based on field measurements (ECT, sap flow, soil moisture, groundwater level, isotopes tracing) and HYDRUS modeling. They found an almost invariant transpiration rate during late spring and summer period, while the soil moisture was progressively depleted and the water table dropped more than $1 \mathrm{~m}$ (maximum GWTD was $3 \mathrm{~m}$ ). Throughout that period, $T$ was stable because the decrease of $T_{\text {soil }}$ was compensated by the increase of $T_{g}$. That increase took place despite lowering of water table, which confirmed that water table depth had no or negligible influence on $T_{g}$ and that the trees are adapted to tap water from any accessible reservoir in order to satisfy the transpiration requirements. These results are in agreement with several other studies such as David et al. (2004); Paço et al. (2009); Miller et al. (2010) that independently found that oak trees in savanna environment could compensate low soil moisture in dry season by taping groundwater at depth of 8 and $13 \mathrm{~m}$. These authors also found that groundwater uptake was thermodynamically favorable over soil water uptake during dry seasons and that such behavior was compatible with the tree physiology. However, as the transpiration rates were below the atmospheric water demand, groundwater uptake constitutes a tree strategy to subsist during dry season and not a mechanism for continued plant growth.

\subsubsection{MM-MF output and case study results}

The capability and potential of the MM-MF model are presented on the base of the real case study simulation of the surface groundwater interactions in the La Mata catchment in Spain for hydrological years 
from October 2008 to September 2010 (respectively called from here onwards as $1^{\text {st }}$ and $2^{\text {nd }}$ year). The calibrated time series and calibration criteria relative to soil moisture and hydraulic heads at observation points P0 and SM are respectively shown in Figure 5.7 and Table 5.7. The fitting between simulated and observed curves of soil moisture is characterized by relatively high $r$ varying between 0.7 and 0.8 . $R S R$ and $R M S E$ are also satisfactory, indicating small deviation in relation to observed data. The hydraulic head at P0 is also well calibrated, respecting the trend and amplitude of the observed data. Its relatively low $r=0.5$ and high RMSE $=0.7 \mathrm{~m}$ can be explained by a temporal shift between simulated and observed data. The calibration also ensured consistent simulated water levels at the catchment outlet (O1 and O2) and at the ponds (P1 to $\mathrm{P} 5$ ) in relation to the observed values (Figures S7 to S18). The model simulations of ET time series are also in agreement with measurements at the ECT (Figure 5.8). The simulated daily ET varied between $0.05 \mathrm{~mm}$ (October 2009) and $2.1 \mathrm{~mm}$ (July 2010), which is within the range and shows the same trend as ET measured by the EC tower (van der Tol, 2012). However, the measured ET amplitude was larger than the simulated $E T$ because the $E T$ measurements at the $E T$ tower correspond to acquisition of almost instantaneous values while ET computed by MM was based on daily simulation.

Table 5.7: Calibration criteria results on soil moisture and hydraulic heads. $r$ is the Pearson's correlation coefficient (unitless values varying between 0 and 1$)$, RMSE is the root mean square error $\left(\mathrm{m}^{3} \cdot \mathrm{m}^{-3}\right.$ for soil moisture and $m$ for heads) and RSR is the ratio of RMSE to the standard deviation of the observed heads (unitless).

\begin{tabular}{llrrr}
\hline Obs. pt. & State variable & $r$ & RMSE & RSR \\
\hline P0 & soil. moist layer 1 & 0.73 & 0.190 & 0.78 \\
& soil. moist layer 2 & 0.82 & 0.220 & 0.66 \\
& heads MF layer 1 & 0.49 & 0.660 & 1.04 \\
\hline SM & soil. moist layer 1 & 0.83 & 0.025 & 0.62 \\
& soil. moist layer 2 & 0.77 & 0.043 & 0.75 \\
\hline
\end{tabular}

Daily time series of simulated surface and subsurface fluxes averaged at the catchment scale are presented in Figure 5.9. The $1^{\text {st }}$ plot from the top shows the daily rainfall $(R F)$ and rainfall excess $(R F e$, see Equation (5.1)). As interception in the study area was low due to the low spatial coverage of the trees $(\sim 7 \%)$ and low storage capacity of alfalfa crops and grass, $R F e$ differs very little from $R F$. The $2^{\text {nd }}$ plot shows surface runoff $(R o)$, infiltration into soil $(\operatorname{Inf})$ and other surface water fluxes. Significant $R o$ occurred only during the $2^{\text {nd }}$, wet hydrological year, which is in agreement with the field observations. Note that surface water is not routed in the current version of the MM-MF model, thus the simulated runoff is instantaneous. In such a small catchment as La 

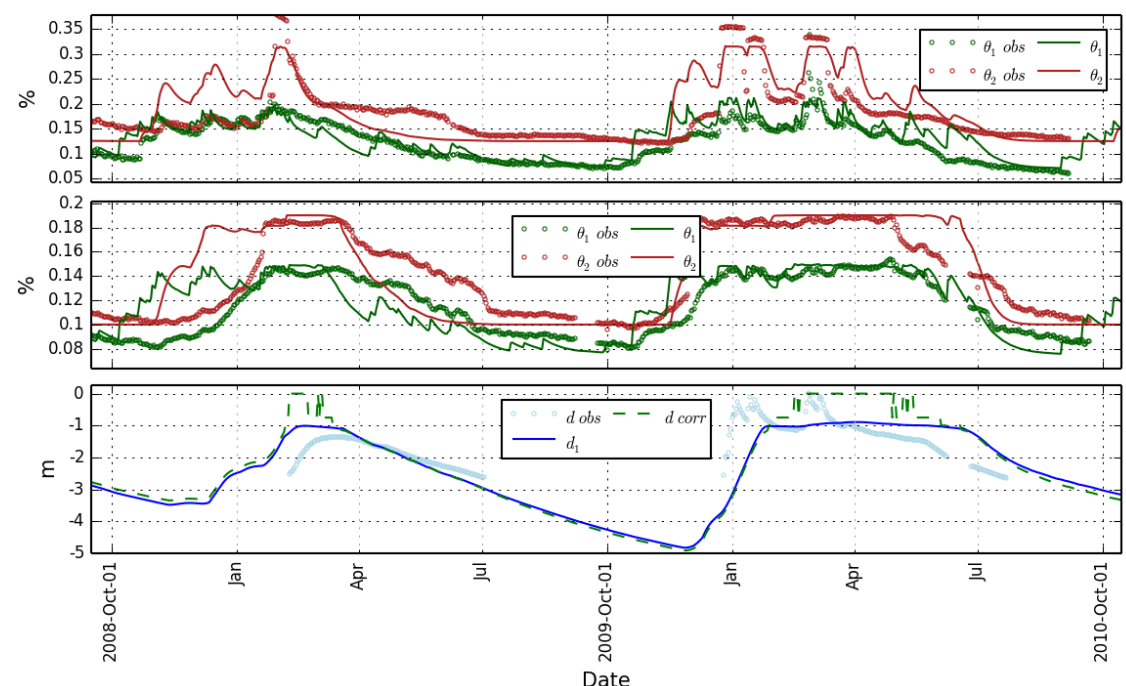

Figure 5.7: Observed (dot curves) and simulated (line curves) soil moisture and groundwater table depth time series at SM (top) and P0 (middle and bottom) observation points. Location of SM and P0 points in Figure 5.5. Soil moisture: $\theta_{n}$ obs is observed soil moisture in the field, $\theta_{n}$ is simulated soil moisture and $n$ is the soil layer index varying between 1 and the total number of soil layers (in this case 2). Groundwater table depth: $d o b s$ is observed hydraulic head in the field, $d_{n}$ is simulated hydraulic head, $d$ corr is simulated hydraulic head corrected to take into account saturated soil layers and $n$ is the MF layer index varying between 1 and the total number of soil layers (in this case 1).

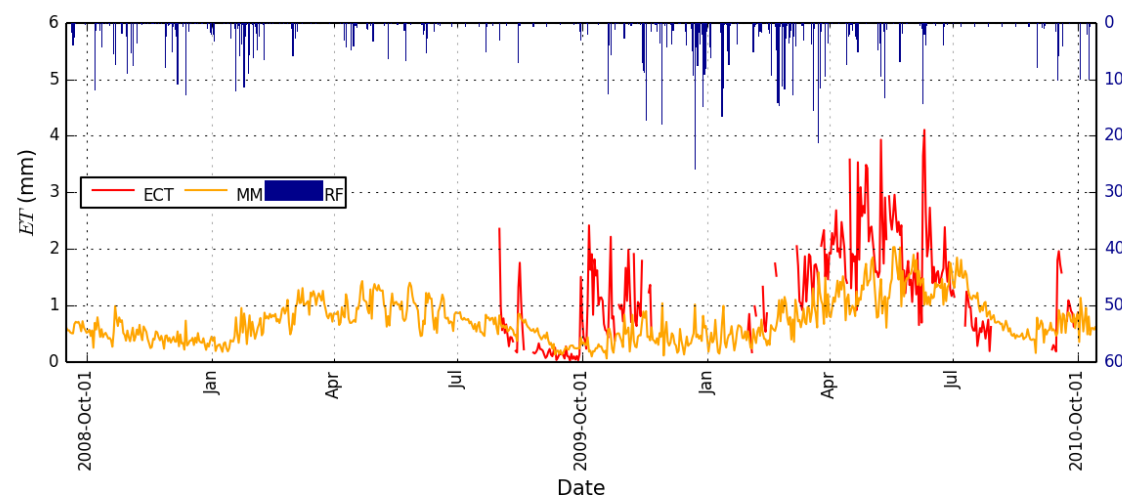

Figure 5.8: ET observed at the eddy covariance tower (ECT) and simulated by MM-MF (MM). Rainfall $(R F)$ is also indicated. 
Mata, the routing is not very relevant because the residence time in the streams is short, i.e. less than one day, although in bigger catchments this limitation should be resolved. The $3^{\text {rd }}$ plot shows the evaporation fluxes, i.e. soil evaporation $\left(E_{\text {soil }}\right)$ and groundwater evaporation $\left(E_{g}\right)$, together with potential evaporation $(P E)$. The $4^{\text {th }}$ is similar, but for transpiration, i.e. soil transpiration $\left(T_{\text {soil }}\right)$, groundwater transpiration $\left(T_{g}\right)$ and potential transpiration $(P T)$. During the two dry seasons neither $P E$ nor $P T$ were satisfied, despite the contribution of groundwater. In the $1^{\text {st }}$ year, $E$ reached maximally $1.0 \mathrm{~mm} \cdot \mathrm{d}^{-1}$ while in the $2^{\text {nd }}$ year $1.5 \mathrm{~mm} \cdot \mathrm{d}^{-1}$, both at the peak of the dry season. The $T$ contribution to $E T$ was much lower than $E$, showing a maximum of $0.4 \mathrm{~mm} \cdot \mathrm{d}^{-1}$. This is due to the low vegetation coverage in the catchment, which also explains the low value of $T_{g}$ (maximum of $\left.0.1 \mathrm{~mm} . \mathrm{d}^{-1}\right)$ and relatively high $E_{g}\left(0.5 \mathrm{~mm} . \mathrm{d}^{-1}\right.$ in July-August 2010). Comparing the two years analyzed, $E, T, E_{\text {soil }}, T_{\text {soil }}$ and $E_{g}$ were larger in the $2^{\text {nd }}$ year than in the $1^{\text {st }}$ year because of higher $R F$. Exception was $T_{g}$ that was pretty similar in both years, despite the water table in the $1^{\text {st }}$ year was deeper than in the $2^{\text {nd }}$ (Figure 5.7). This behavior was expected due to the $T_{g}$ independence on GWTD implemented in equation (5.15). Percolation $\left(R_{p}\right)$, gross recharge $(R g)$, groundwater exfiltration $\left(E x f_{g}\right)$ and groundwater evapotranspiration $\left(E T_{g}\right)$ are shown in the last, $5^{\text {th }}$ plot of Figure 5.9. Note that the difference between $R g$ and $R_{p}$ is attributed to percolation zone storage. $R g$ occurred between December and May, reaching a maximum of $2 \mathrm{~mm} \cdot \mathrm{d}^{-1}$ in January 2010. $R g$ is only slightly delayed in relation to $R_{p}$, due to shallow water table condition and related short travel time across the percolation zone. $E x f_{g}$ is more delayed, indicating a subsurface travel time from the recharge area to the discharge area of around one month.

The yearly, catchment scale water balances over each hydrological year are presented in Figure 5.10 as 2 Sankey diagrams. Yearly $E_{\text {soil }}$ in $1^{\text {st }}$ and $2^{\text {nd }}$ year were 139 and $175 \mathrm{~mm}$ respectively, which represented 45 and $29 \%$ of $R F$. Yearly $E_{g}$ was constant during both years with a value of $38 \mathrm{~mm}$, corresponding to 12 and $6 \%$ of $R F$, representing an important water balance component, in particular during the $1^{\text {st }}$ dry year. $T_{g}$ showed the same tendency, but with lower values due to the earlier mentioned low catchment vegetation coverage. As expected, Ro was lower in the $1^{\text {st }}$ year than in the $2^{\text {nd }}$, with a value of $63 \mathrm{~mm}$ in the $1^{\text {st }}$ year, i.e. $21 \%$ of $R F$, and $241 \mathrm{~mm}$ in the $2^{\text {nd }}$, i.e. $41 \%$ of $R F . R g$ was $88 \mathrm{~mm} . \mathrm{y}^{-1}$ in the $1^{\text {st }}$ and $169 \mathrm{~mm} . \mathrm{y}^{-1}$ in the $2^{\text {nd }}$ year, in both cases representing $29 \%$ of $R F$. In contrast to stable $R g, R n=R g-E T_{g}-E x f_{g}$ was quite different in both years: in the $1^{\text {st }}$, dry year, $R n$ was negative $(-15 \mathrm{~mm})$ while in the $2^{\text {nd }}$, wet year was positive $(22 \mathrm{~mm})$. Groundwater storage change $\left(\Delta S_{g}\right)$ had similar tendency, loosing $22 \mathrm{~mm}$ in the $1^{\text {st }}$ year and gaining $15 \mathrm{~mm}$ the $2^{\text {nd }}$. Despite two years with totally different rainfall, the groundwater outflow of the catchment $(D R N)$ remained nearly the same, which confirms a limited system storage capacity and the predominance of evapotranspiration and/or exfiltration processes.

The spatial variability of water fluxes can be visualized in MM-MF as for example in the maps of Figures 5.11-5.13. These maps show selected 


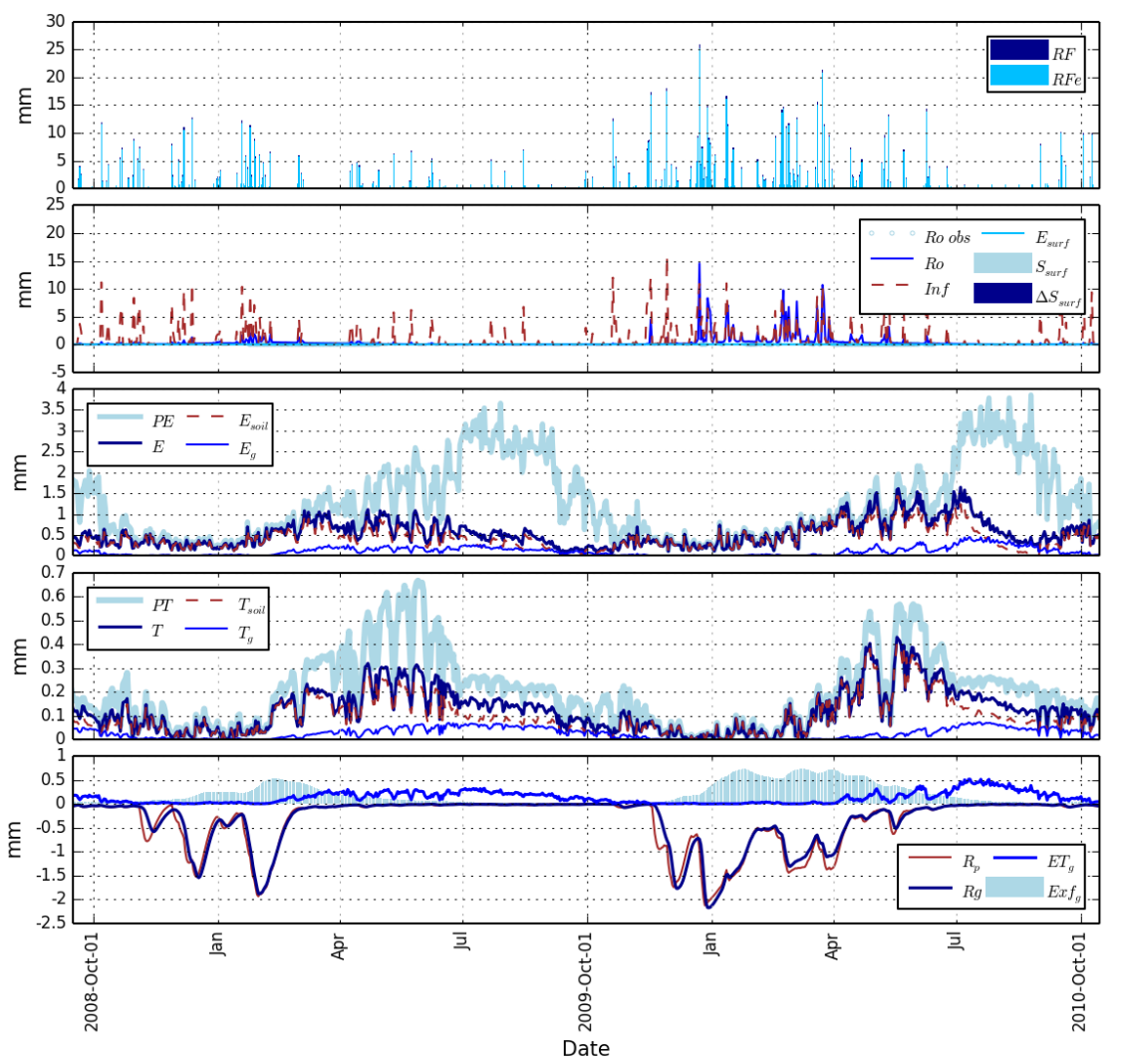

Figure 5.9: Time series of surface and subsurface water fluxes averaged at the catchment scale. $P E$ and $P T$ are potential evaporation and potential transpiration respectively, obs means observed value in the field, symbol $\Delta$ means change in storage. Note that to improve readability of the last, $5^{\text {th }}$ plots, downward fluxes $R_{p}$ and $R g$ are artificially shown with negative values. See Figure 5.1 for other abbreviations.

water fluxes averaged for the two hydrological years of model simulation. Such maps can also be plotted at regular time steps and compiled to create animations representing spatio-temporal variability of fluxes. In Figure $5.11, E_{\text {soil }}$ is dominant over $E_{g}$ because in dry season, when $E_{\text {soil }}$ is depleted and $E_{g}$ can gain more importance, $E_{g}$ is limited by the depth of the water table (i.e. below $3 \mathrm{~m}$ in dry season, between July and September, see Figure S19). $E_{\text {soil }}$ is dominant and uniformly distributed within the eluvium soil type (Figure 5.5), while $E_{g}$ is high along the stream courses where the groundwater table is the shallowest (Figure S20) and downstream of the agricultural crops due to the irrigation leakage into the groundwater system. The largest $T_{\text {soil }}$ is observed within the two irrigation plots located at the SE catchment water divide and along the stream courses. $T_{g}$ is much lower than $T_{\text {soil }}$, being concentrated essentially at 
SE of the catchment where the density of trees is the highest (Figure S5). Finally, Figure 5.13 (left) shows the spatial distribution of the net recharge, separating catchment into recharge areas $(R n>0$, bluish color) and discharge areas $(R n<0$, reddish color). Figure 5.13 (right) presents the spatial distribution of groundwater exfiltration, closely related to $R o$ (Figure S21) and concentrated along the streams, showing the dynamic relationship between surface and groundwater in the catchment. 


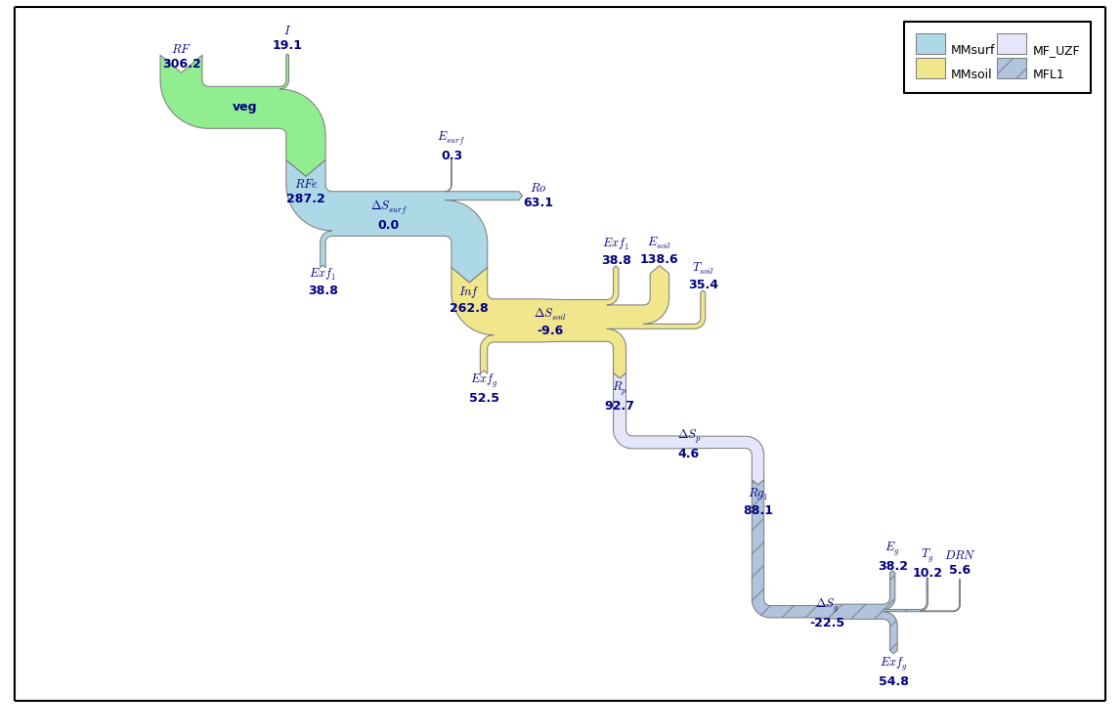

Hydrological year 2008/2009

Water balance closure (\%)
MMsurf $=-0.0$, MMsoil $=6.1$, MFUZF $=-0.0$ // MFL1 $=1.6$

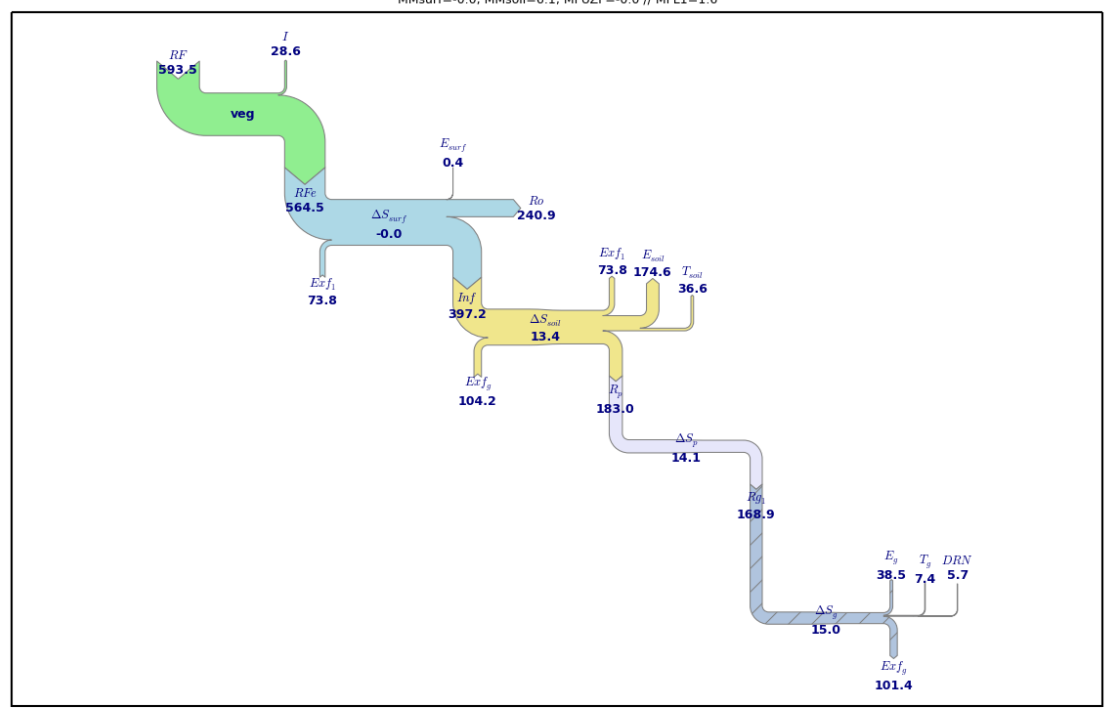

Hydrological year 2009/2010

Water balance closure $(\%)$
MMsurf $=-0.0$, MMsoil $=4.1$, MFUZF $=-0.0 / /$ MFLI $=0.5$

Figure 5.10: Sankey diagrams representing the yearly water balance at the catchment scale. Abbreviations in Figure 5.1, units in mm. $\mathrm{y}^{-1}$, fluxes lower than $1 E^{-6} \mathrm{~mm} . \mathrm{y}^{-1}$ not shown. See Figure 5.1 for abbreviations. 

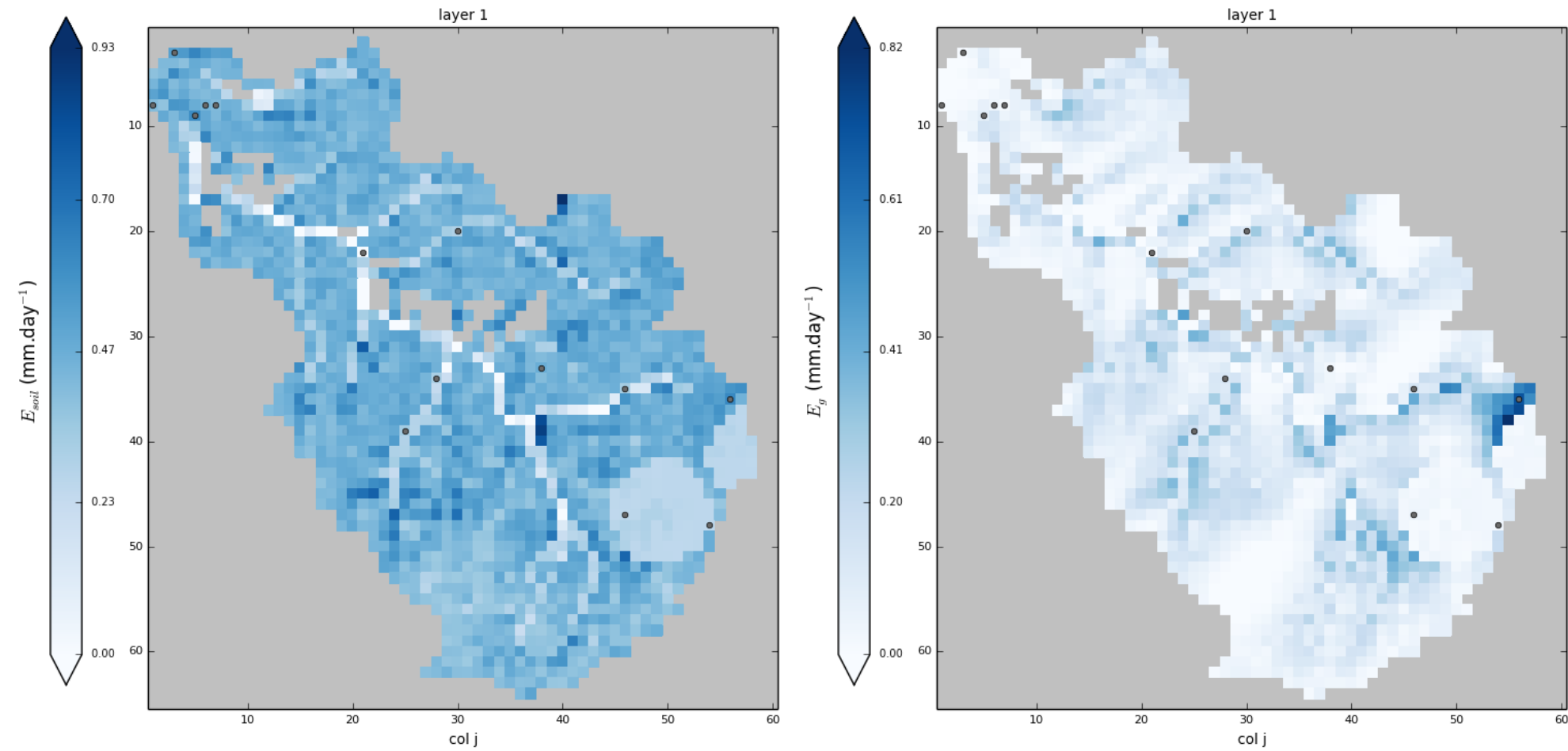

Figure 5.11: Two-year average of soil evaporation $\left(E_{\text {soil }}\right.$, on the left) and groundwater evaporation $\left(E_{g}\right.$, on the right). Note that each map has its own color scale. 
Figure 5.12: Two-year average of soil transpiration ( $T_{\text {soil }}$, on the left) and groundwater transpiration ( $T_{g}$, on the right). Note that each map has its own color scale. 

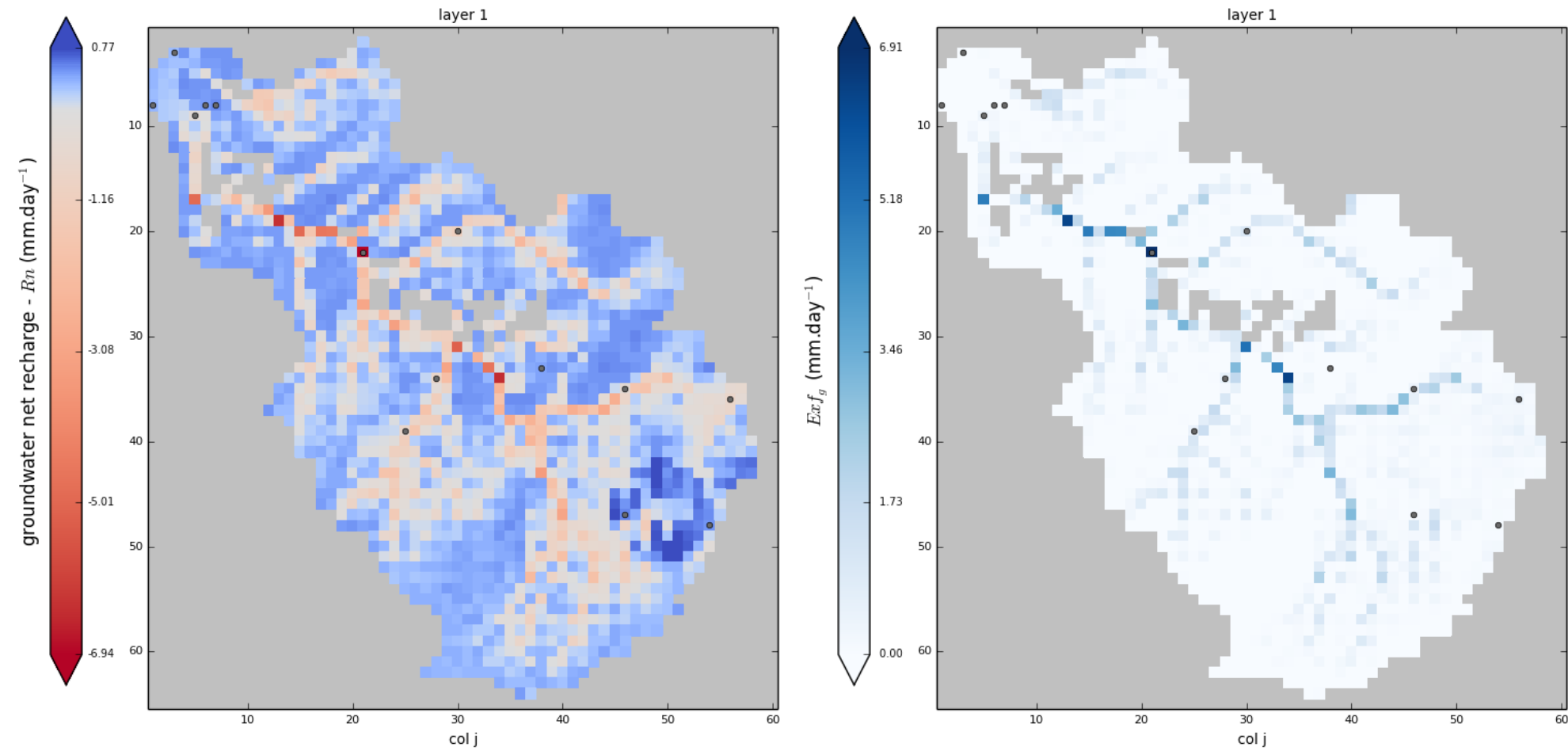

Figure 5.13: Two-year average groundwater net recharge $\left(R n\right.$, on the left) and groundwater exfiltration $\left(E x f_{g}\right.$, on the right). Note that each map has its own color scale. 


\subsubsection{Comparison with other studies}

In parallel work to this study, Balugani et al. (2015) implemented experimentally the partitioning and sourcing of evaporation and transpiration, also in the same La Mata catchment. The study was carried out during the dry season between days 29 of July and 7 of September of years 2009 and 2010 , i.e. when grass was dormant so could be excluded from $E T$ calculation. The following $E T$ fluxes were quantified within the footprint area of the ECT: (i) total ET based on EC tower measurement (van der Tol, 2012); (ii) tree transpiration ( $T$ ) by remote sensing upscaling of sap flow measurements (Reyes-Acosta and Lubczynski, 2013), further sourced into $T_{u}$ and $T_{g}$ based on stable isotopes experiments (ReyesAcosta, 2015); and (iii) bare soil evaporation (E) sourced into $E_{u}$ and $E_{g}$ based on soil texture and HYDRUS-SOURCE modeling (Balugani et al., 2014) using data from soil profiles of temperature, moisture and matric potential. The four components obtained as a result of experimental partitioning and sourcing of $E T\left(E_{u}, E_{g}, T_{u}\right.$ and $\left.T_{g}\right)$ were compared with the EC tower estimates of the total $E T$, that we also compared in this study with the MM-MF modeled fluxes ( $E_{\text {soil }}, E_{g}, T_{\text {soil }}, T_{g}$, see Table 5.8 ). The results showed a good agreement, particularly in year 2009, between experimentally partitioned and sourced fluxes and the corresponding MM-MF modeled ET fluxes, as well as between ET experimental, MM-MF modeled and measured by the EC tower. The partitioning and sourcing results confirmed the large importance of groundwater evaporation in savannah type of environments as La Mata oak woodland study area. Moreover, the consistency between the results of the 3 methods is a favorable indicator of the good quality of the fluxes assessment by the MM-MF modeling approaches. 
Table 5.8: Comparison between the results of: (a) the experimental approach of Balugani et al. (2015); (b) the modeling approach of this study; and (c) eddy covariance tower (ECT) measurements of evapotranspiration (ET). Values in mm.d ${ }^{-1}$. Period of comparison between 29/07 and 07/09 of years 2009 and 2010. See Figure 5.1 for abbreviations.

\begin{tabular}{cccccccccccc}
\hline Year & \multicolumn{4}{c}{ Experimental approach } & \multicolumn{4}{c}{ Modeling approach } & \multicolumn{2}{c}{ ECT } \\
& $E_{\mathfrak{g}}$ & $E_{u}$ & $T_{\mathfrak{g}}$ & $T_{u}$ & $E T$ & $E_{\mathfrak{g}}$ & $E_{\text {soil }}$ & $T_{\mathfrak{g}}$ & $T_{\text {soil }}$ & $E T$ & $E T$ \\
\hline 2009 & 0.14 & 0.39 & 0.02 & 0.02 & 0.56 & 0.15 & 0.28 & 0.05 & 0.08 & 0.56 & 0.57 \\
2010 & 0.17 & 0.48 & 0.02 & 0.02 & 0.69 & 0.25 & 0.16 & 0.05 & 0.08 & 0.53 & 0.52 \\
\hline
\end{tabular}


Subsurface water fluxes in the Sardón area, which includes La Mata catchment, were recently assessed by Hassan et al. (2014) using the transient, distributed GSFLOW model (Markstrom et al., 2008). As there is a relative uniformity of geology, soil, land use and climatic conditions between the two areas, and because GSFLOW is likely the most similar to MM-MF code, the results of both models could be compared. In general, there is a good agreement between the two models, particularly in $E T$ and $R n$ fluxes assessment. A relevant results of the GSFLOW solution was that $E T_{p}$ was found to be negligible (mean of 18 years was $1.14 \mathrm{~mm} . \mathrm{y}^{-1}$ ), which justified the exclusion of the $E T_{p}$ option in MM-MF for the hydrogeological settings of this study. However, in areas with several meters thick unsaturated zone, e.g. the Kalahari Desert, $E T_{p}$ may be a significant component of the water balance (Lubczynski, 2009, 2011), so for such simulations appropriate MM-MF coding adjustment have to be added.

\subsubsection{Model Performance}

The run time of MM applied to the La Mata catchment at daily time step took about $2 \mathrm{~min}$ for MMsurf, $42 \mathrm{~min}$ for MMsoil, 4 min for MF (PC with Intel ${ }^{\circledR} \mathrm{Core}^{\mathrm{TM}} 2$ Duo CPU @2.40GHz, 4GB RAM). The code of the MM model in general and the module MMsoil in particular are based on conditions (if...then...else) to test the state of the soil reservoir (saturated or not) and its relation with the groundwater reservoir (percolation or exfiltration). Due to these conditions, the code is much slower to solve the equations than a numerical scheme based on matrix computing. The MM running time is comparable to other models with similar structure as for instance INFIL or GSFLOW. Note that MF running time may be significantly increased while using the UZF1 package if the groundwater levels rise above land surface in a large number of model cells. This is due to the additional calculations required to compute the groundwater discharge to the land surface (Niswonger et al., 2006).

Due to the sequential coupling that obliges to run MM-MF repetitively until the head difference between two successive runs is less than a userdefined threshold (Figure 5.3), the total run time of the MM-MF model is pretty long. In general 3 or 5 MM-MF loops are sufficient to reach equilibrium, which requires a full run time of 138 to $230 \mathrm{~min}$. This time could be drastically reduced by running sequentially MM and MF at each time step, but it requires the recording of UZF1 soil moisture profiles at each cell to be used as initial condition for the next time step, which is not possible in the current version of UZF1. Another possibility is to implement a full coupling of MM and MF by rewriting MM in FORTRAN and integrate MM as MF package. 


\subsection{Conclusions}

This study presented a two-way coupled model that computes spatiotemporally the surface and subsurface fluxes at the catchment scale. The coupled model is composed of the novel water balance model of the soil zone, MARMITES, and USGS MODFLOW-NWT code. The novelty of the proposed solution resides in the implementation of partitioning and sourcing of the evapotranspiration fluxes. In particular, a novel function based on soil moisture availability and transpiration demand driven by climatic conditions is proposed to quantify the groundwater transpiration $\left(T_{g}\right)$. The computing of groundwater evaporation $\left(E_{g}\right)$ on bare soils was implemented following the methodology proposed by Shah et al. (2007).

The model was applied to the small La Mata catchment (Spain), characterized by water limited environment, and calibrated against state variables of the soil and saturated zones (soil moisture and hydraulic heads respectively). The results showed the importance of $E_{g}$, larger in the first, dry year (12.5\% of $R F)$ and smaller in the second, wetter year (6.5\% of $R F$ ). Also $T_{g}$ was larger in dry year than in the wet but with generally much lower values (3.3\% of RF and $1.2 \%$ of $R F$ respectively) than $E_{g}$ because of low vegetation coverage. Considering seasonal variability, $E_{g}$ and $T_{g}$ were the largest in dry seasons when soil moisture was the most depleted. This points at regulating role of groundwater fluxes and predominant role of climate as driving force of $E$ and $T$. A relevant aspect with respect to transpiration was also that during both dry seasons the $T / P T$ ratio was almost constant when the decline of soil moisture and $T_{\text {soil }}$ were compensated by increase of $T_{g}$ occurring simultaneously with decline of water table. This indicates that once tree roots have access to groundwater, $T_{g}$ is then independent (or negligibly dependent) on water table fluctuation and that the trees can tap water interchangeably from any accessible reservoir in order to satisfy the transpiration requirements driven by the climatic conditions. This behavior reproduced well the results of experimental studies carried out in the same area (van der Tol, 2012; Reyes-Acosta and Lubczynski, 2013; Balugani et al., 2014) and is in agreement with other studies performed in other, similar open oak woodland ecosystems (David et al., 2004; Paço et al., 2009; Miller et al., 2010).

The MM-MF model constitutes an effective tool to integrate at the catchment scale surface, unsaturated zone and groundwater fluxes and to provide a detailed, spatio-temporal water balance, including partitioning and sourcing of ET. The MM-MF allows also for easy integration of the results of local experimental studies to calibrate or validate model simulation. The specific ability of MM-MF model to partition and source subsurface fluxes constitutes a particularly valuable and novel modeling option to analyze the role of tree water uptake and bare soil evaporation in hydrology, particularly in water limited environments. Such option is expected to be a critical support for water management, particularly in 


\section{Coupled MARMITES-MODFLOW model}

assessing the impact of climate and land cover changes on groundwater resources and for mapping groundwater dependent ecosystems. 


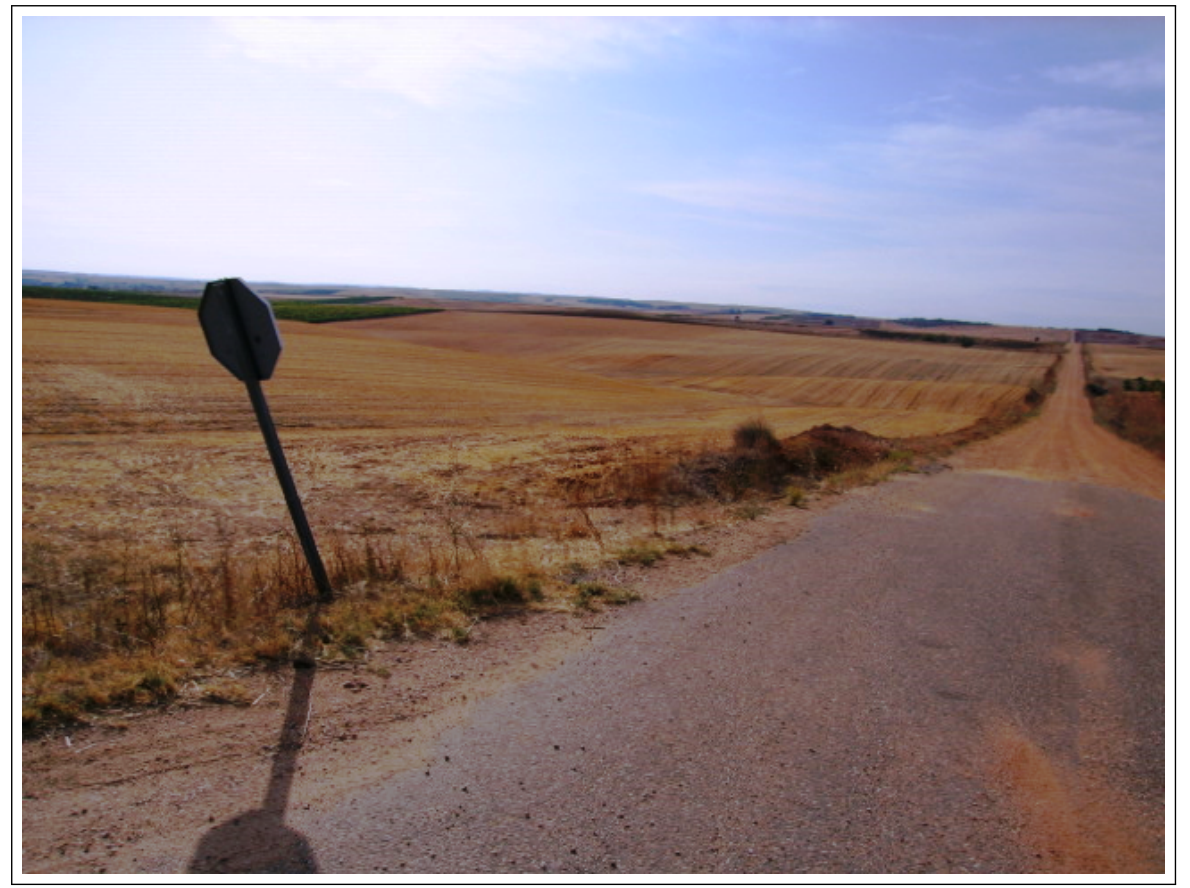

Harvested cereal fields in the Carrizal catchment (Salamanca, Spain). 



\section{Integrating MRS data with hydrologic model - Carrizal Catchment (Spain)}

\subsection{Introduction}

In the last decades groundwater became widely used for water supply because of its better quality as compared to surface water and because of reduction of water abstraction cost (Llamas and Martínez-Santos, 2005). However the prospection and quantification of groundwater is difficult due to subsurface heterogeneity. An improvement in the efficiency of evaluation and management of groundwater resources is needed to mitigate the increasing pressure of the demand, particularly in arid and semi-arid water limited environments.

For quantification of groundwater resources at the catchment scale, distributed numerical hydrological models are considered optimal. However, to provide a valuable management tool, such models need appropriate acquisition of reliable spatial and temporal input data (Lubczynski and Gurwin, 2005a; Lubczynski, 2011). A classic way to gather subsurface parameters to set up hydrological models is through borehole drilling and pumping tests. However, that method is invasive, expensive and time consuming. Non-invasive hydrogeophysical methods allow to complement the invasive methods, in efficient and economically sound way. The application of such methods as a support for catchment scale, distributed hydrogeological models has recently received significant attention. Dam and Christensen (2003) demonstrated that an improvement of the

This chapter is based on: Integrating MRS data with hydrologic model Carrizal catchment (Spain). Baroncini-Turricchia, G., A. P. Francés, M. W. Lubczynski, J. Martínez-Fernández, and J. Roy (2014), Near Surface Geophysics, 12, doi: $10.3997 / 18730604.2014003$. The author of this thesis participated or realized the following tasks: (i) acquisition and processing of magnetic and MRS data; (ii) writing of the geological description; (iii) development of the MARMITES model and its coupling with MODFLOW (see Chapter 5); (iv) writing of the MARMITES-MODFLOW model description; (v) model calibration; (vi) revision of the manuscript. 
hydraulic conductivity field is possible using non-invasive techniques but depends on number, location and uncertainty of the geophysical observations. The disadvantage of classical non-invasive geophysical techniques is that they often cannot be used as a straightforward support for hydrogeological models. For instance Andersen et al. (2012) showed that relying on transient electromagnetic (TEM) can lead to different interpretations of hydrogeology of buried valleys when different inversion processes are applied. This is the main reason that many researchers, except of exploration purpose, apply nowadays classical, non-invasive hydrogeophysics only for qualitative assessment, to interpret the reality with the aim of building conceptual hydrogeological models. For example, an integrated study of Francese et al. (2009), combining geological data with three-dimensional resistivity tomography and shallow seismic surveys, was carried out in fractured sandstone aquifer in Tuscany (Italy) to assess interrelation between tectonics and groundwater circulation. In the northern Matabeleland (Zimbabwe), TEM and continuous vertical electrical sounding (CVES) were used to upgrade the hydrogeological conceptual model: CVES was applied to define the near surface geological structures and TEM to define the deeper structures (Danielsen et al., 2007). In Okavango Delta (Botswana), time domain electromagnetic method (TDEM) was used to study three dimensional salinity anomalies (Bauer-Gottwein et al., 2010) otherwise difficult to define and interpret. In the Föhr Island (Germany) airborne electromagnetics (SkyTEM) and seismic reflections were compiled into a 3D model (Burschil et al., 2012) that was meant as a basis for a groundwater flow model. In Denmark, a strong effort in near-surface geophysical data integration resulted in development of Sequential Hydrogeophysical Inversion (SHI), in which inverted geophysical models provided information for hydrologic models (Herckenrath, 2012).

In contrast to classical geophysical methods, the magnetic resonance sounding (MRS) is the only geophysical method that can provide quantitative assessment of water in subsurface. Through assessment of signal amplitude, the MRS is sensitive to the quantity of water in subsurface and through the signal decay, to permeability of the medium in which the subsurface water is stored and flows. The MRS technique is already known and well accepted as non-invasive, quantitative evaluation of water in subsurface rather than prospecting hydrogeophysical tool. More information about principles of the MRS technique with emphasis on quantification of groundwater resources can be found in: Lubczynski and Roy (2003); Roy and Lubczynski (2003); Lubczynski and Roy (2004, 2007); Plata and Rubio (2007, 2008); the parameterization of aquifers in Lubczynski and Roy (2005, 2007); Vouillamoz et al. (2007); Boucher et al. (2009b); Vouillamoz et al. (2012b); and parameterization of unsaturated zone in Roy and Lubczynski (2005); Mohnke and Yaramanci (2008); Walsh et al. (2014).

The ability of MRS to retrieve the subsurface flow and storage parameters of hydrological systems makes it suitable not only for site-specific studies but also for distributed modeling studies, for example focusing 
at groundwater resources assessment at the catchment scale. To our knowledge the first such application was documented by Lubczynski and Gurwin (2005a) in their groundwater modeling study case of granitic Sardón Catchment in Spain. Later, Lubczynski and Roy (2007) provided a detailed and systematic protocol on how to integrate MRS output in distributed groundwater models. The follow up of practical implementation of such MRS integration in groundwater model was provided by Boucher et al. (2009a) who later extended that study (Boucher et al., 2012) integrating information obtained from 35 MRS soundings in a groundwater model of $5000 \mathrm{~km}^{2}$ in a sedimentary aquifer in Niger. In that model previously calibrated using TDEM data but without MRS support, it was possible to narrow down the uncertainty related to water content and hydraulic conductivity of investigated aquifer by integrating MRS and TDEM inversion results in the groundwater model.

In this study, we also propose MRS data integration in a hydrologic model, however in contrast to previous studies we do not consider MRS output as implicitly known input of hydrologic model but instead we apply novel data integration method and optimize MRS-hydrogeological parameters (hydraulic conductivity and specific yield) in the hydrological model calibration. The proposed MRS data integration is carried out applying distributed, coupled, hydrologic MARMITES-MODFLOW (MMMF) model (Francés and Lubczynski, 2015, ; Chapter 5) in the Carrizal Catchment study area in Spain. The catchment is well characterized by availability of time series of water table and soil moisture records but there is a lack of borehole logs and pumping tests. Besides, the position of aquifer bottom is unknown as the Carrizal hydrogeological system is permeable down to more than $100 \mathrm{~m}$, deeper than the penetration depth of the Numis ${ }^{L I T E}$ MRS instrument we used and there are no boreholes penetrating that depth.

Before this study, the Carrizal Catchment had been investigated by MRS technique within collaboration project (Plata et al., 2009) carried out between IGME, University of Madrid and ITC Faculty of University Twente, as documented in Uriarte Blanco et al. (2011). In this study, we used the previously acquired MRS data as well as our newly acquired MRS data, and reprocessed all using the newest MRS inversion tool Samovar 11.3 (Legchenko, 2011).

\subsection{Material and methods}

\subsubsection{Study area}

The Carrizal Catchment of $\sim 73 \mathrm{~km}^{2}$ (corner geographic coordinates $41^{\circ} 19^{\prime} \mathrm{N}-5^{\circ} 38^{\prime} \mathrm{W}$ and $41^{\circ} 12^{\prime} \mathrm{N}-5^{\circ} 27^{\prime} \mathrm{W}$ ) is located in the center of Duero Basin (Figure 6.1). The main Carrizal stream is a left tributary of the Guareña River, tributary of the Duero River. The Carrizal Catchment is characterized by hilly landscape that varies from 745 to 924 m.a.s.l. Climate is dry, Mediterranean, with semi-arid characteristics (Ceballos et al., 
2002), precipitation of $485 \mathrm{~mm} \cdot \mathrm{y}^{-1}$ and FAO 56 Reference Evapotranspiration (Allen et al., 1998) of $1093 \mathrm{~mm} \cdot \mathrm{y}^{-1}$, as measured at Villamor weather station. The Carrizal Catchment belongs to the REMEDHUS Soil Moisture Network of Salamanca University (Martínez-Fernández and Ceballos, 2005).

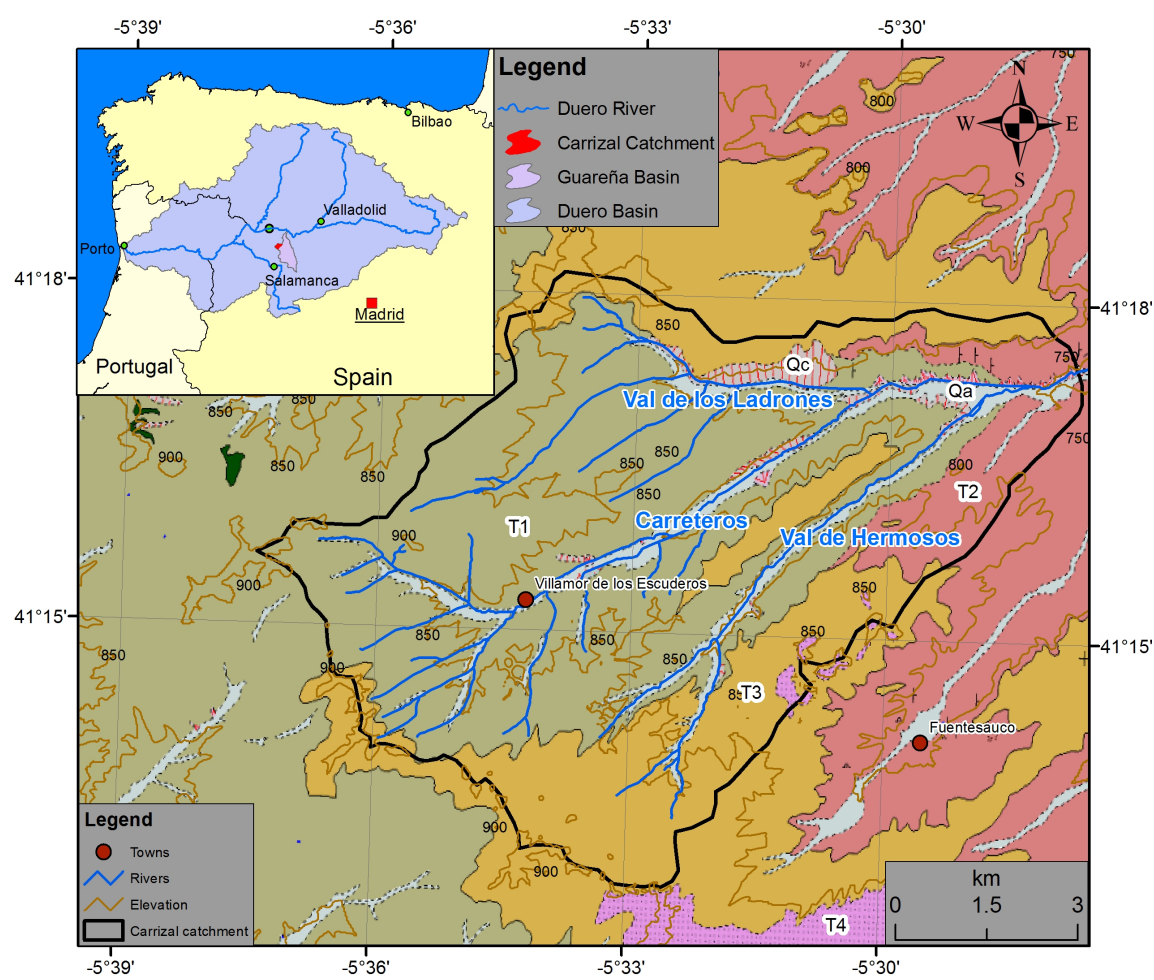

Figure 6.1: Geology of the study area (Instituto Geológico y Minero de España, 1978, 2000): T1 - Cabrerizos Sandstones (Middle Eocene Oligocene), silts and sandstones with conglomeratic levels; T2 - Low Palaeogene Group (Middle Eocene - Oligocene), thin layers of sandstones, conglomerates and silts; T3 - High Palaeogene Group (High Eocene Oligocene), thick layers of sandstones, microconglomerates, siltites and arkoses with cobbles; T4 - Red Series (High Eocene - Lower Miocene), conglomerate, quartzite and silts; Qc - Coluvium (Pliocene - Holocene), cobbles, boulder sands, silts and clays; Qa - Alluvium (Middle Pleistocene - Holocene), cobbles, pebbles, sands, silts and clays.

The geology of the area (Figure 6.1) is characterized by continental deposits from Palaeogene and Quaternary. The Palaeogene formations are sub-horizontal and constitute detritical, fluvial deposits mainly composed of conglomerates, sandstones and siltstones with carbonate or clay cement. These formations result from the lateral motion of stream channels across a floodplain, which explains the high lateral and depth- 
wise lithofacial variability. The thickness of the Palaeogene formations is around $100 \mathrm{~m}$, although it reaches $500 \mathrm{~m}$ at Tarazona de Guareña, located $15 \mathrm{~km}$ from the study area in the east direction (Instituto Geológico y Minero de España, 1978). The bottom of the valleys in the Carrizal Catchment is covered by thin alluvial deposits and colluvium of Quaternary age composed of sandstones, silts, cobbles and clays that result from erosion and sequential deposition of the Tertiary rocks. These geological settings result in a heterogeneous hydrogeological configuration, particularly in the Tertiary formations. Although some lenticular levels relatively shallow can produce interesting yields and can be explored by boreholes, many drillings (none in the Carrizal Catchment) are negative. Following the hydrogeological map of IGME at the scale 1:200 000 available at www.igme.es/infoigme/vi sor/, the hydraulic conductivity $(K)$ is intermediate in the Tertiary formations and high in the Quaternary ones. The transmissivity of the Palaeogene is between 10 and $150 \mathrm{~m}^{2}$.day ${ }^{-1}$ with average of $50 \mathrm{~m}^{2}$.day ${ }^{-1}$ (Instituto Geológico y Minero de España, 2000). The Quaternary formation is unconfined and in direct hydraulic connection with Tertiary formation. Because of its large $K$, the Quaternary aquifer is widely exploited using large diameter wells for agricultural use.

The potentiometric surface of the shallow unconfined aquifer (Figure 6.2) was defined based on field measurements of water table depth and the linear relationship established between topography and hydraulic head following the method described in Kuniansky et al. (2009). An intense field campaign was carried out in November 2009 when hydraulic head was defined in 136 shallow wells by conjunctive measurements of well elevations using a differential GPS (Leica GPS model 1200 using Real Time Kinematics protocol) and water table depths in these wells.

As this study is part of a broader project focused on groundwater recharge in the shallow unconfined aquifer, a significant effort was dedicated not only to saturated but also to unsaturated zone assessment. The soil investigations carried out at $5 \mathrm{~cm}$ depth in a regular grid of $3 \times 3 \mathrm{~km}$ within the REMEDHUS area were spatially densified within the scope of this study in a grid of $1 \mathrm{~km}^{2}$, to better describe soil texture spatially. These investigations defined quite homogeneous sandy loam soil type, characterized by typical composition of $66 \%$ sand, $18 \%$ clay and $16 \%$ of silt. The depth-wise homogeneity of the soil hydraulic properties and texture was also confirmed at piezometer locations down to a depth of $3 \mathrm{~m}$. The thickness of the unsaturated zone varied in the study area from some tens of $\mathrm{cm}$ in the bottom valley near the Carreteros stream at the center of the Carrizal Catchment, up to more than $10 \mathrm{~m}$ in the Val de los Ladrones valley in the north of the Carrizal Catchment (Figure 6.1). Aquifer parameters were not available in this study due to the lack of boreholes to perform pumping test. The few available, shallow (1-14 m depth), wide dimension wells (2-6 m wide) were not pump tested because it would require heavy logistic (e.g. high performance pump) and financial investments not available in this study.

The Carrizal study area was equipped with a monitoring network (Fig- 


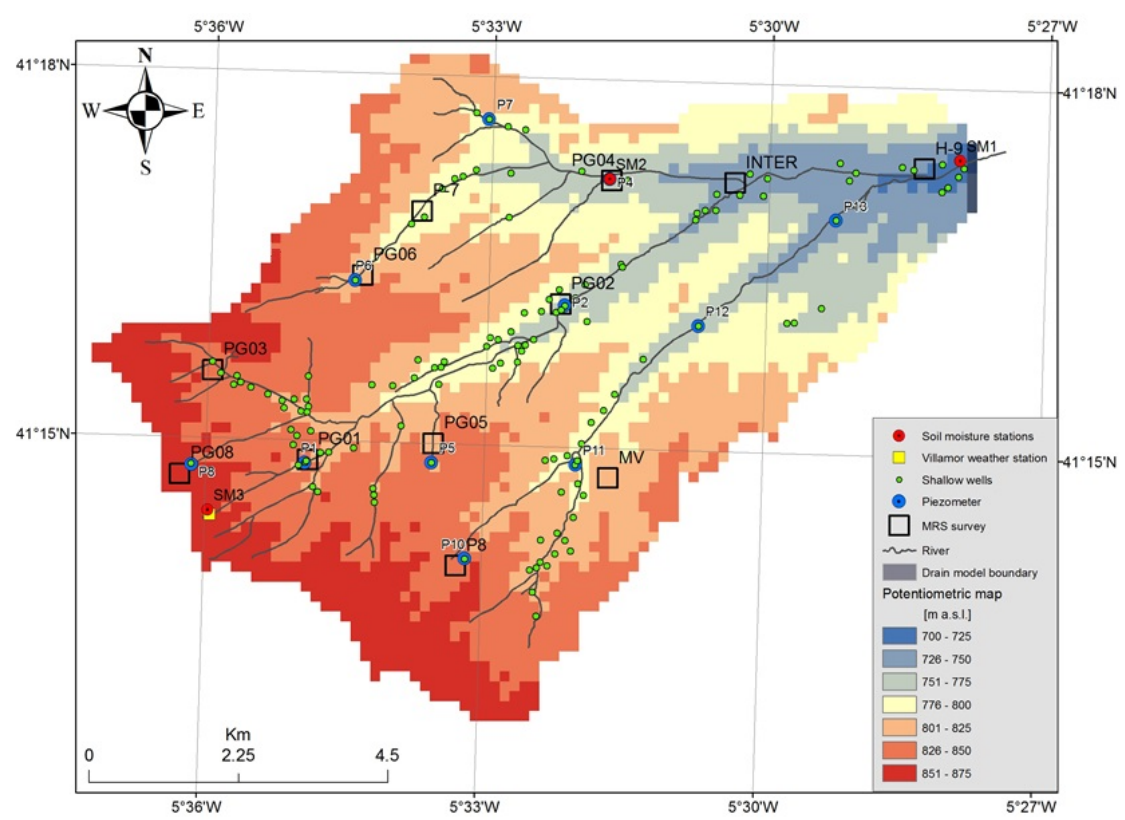

Figure 6.2: Monitoring network of the Carrizal Catchment. The background represents the groundwater potentiometric map.

ure 6.2) that allowed to retrieve the driving forces (rainfall and potential evaporation and transpiration) and the state variables (soil moisture and hydraulic heads) necessary to run and calibrate the distributed hydrologic model of this study. The monitoring network involved: i) 3 soil moisture profiles, each one with moisture probes installed at 5, 25, 50 and $100 \mathrm{~cm}$ depths, all recording hourly since November 2009; ii) automated microclimatic weather station at the Villamor location $\left(41^{\circ} 14^{\prime} \mathrm{N}\right.$ $5^{\circ} 36^{\prime} \mathrm{W}$ ), measuring precipitation, air temperature, incoming radiation, wind speed and relative humidity every 10 minutes, with 9 years of data available (2002/2010); and iii) 11 automated groundwater level recorders installed in 11 piezometers, recording hourly since November 2009.

\subsubsection{General description of the MM-MF model}

Groundwater model solutions are generally affected by non-uniqueness due to the multiplicity of combinations between parameters, such as hydraulic conductivity or storativity, and fluxes, such as groundwater evapotranspiration, exfiltration and recharge. Not only realistic system parameterization but also introduction of realistic spatio-temporally variable water fluxes verified in transient model calibration allow restricting non-uniquness and improve reliability of models (Lubczynski and Gurwin, 2005a). In this study, the spatio-temporal variability of water fluxes was simulated by the coupled MARMITES-MODFLOW (MMMF) model (Francés and Lubczynski, 2015, ; Chapter 5) as the coupled 
models are known to better handle the calibration non-uniqueness than standalone models such as the MODFLOW alone (Furman, 2008). The reader is invited to consult Chapter 5 of this thesis for a full description of the MM-MF model.

\subsubsection{Setup and calibration of the Carrizal MM-MF model}

The distributed Carrizal MM-MF hydrological model consisted of 91 columns and 69 rows of quadratic grid, with 3267 active cells, 150 $\times 150 \mathrm{~m}$ each. The topographic surface was defined by a $5 \mathrm{~m}$ high resolution digital elevation model provided by the STIG (Servicio Transfronterizo de Información Geográfica) of Salamanca University resampled to $150 \times 150 \mathrm{~m}$ MM-MF model grid. Following the results of the soil survey described earlier, we defined three soil types, one in the top part of the catchment, one in the lower part and one along the main streams (i.e. alluvium). The top boundary of the aquifer was defined as topographical elevation minus the soil thickness. The piezometric surface (Figure 6.2) represented by altitude of the shallow water table (hydraulic head) on November 2009, was used as initial head condition for the model. The lateral boundaries of the model were assigned along the Carrizal Catchment watershed divide that matches groundwater divide, except of the eastern catchment outflow section simulated by MF Drain Package boundary condition (Figure 6.2). As there were no borehole logs available and the regional hydrogeological knowledge suggested the presence of a thick, permeable, sedimentary sequence, down to the depth significantly larger even than $100 \mathrm{~m}$ b.g.s., based on the analysis of the 12 MRS soundings, we decided to schematize arbitrarily that system into one, unconfined layer of fixed thickness of $35.5 \mathrm{~m}$. That thickness was assigned as equal to the shallowest depth among all the MRS-inverted profiles, counting from the water table depth defined by direct field measurements. Further reasoning of that assignment can be found below in the Results and Discussion.

The first two years of data were used in the transient model simulation as spinoff (initialization) period, i.e. giving the model time to reach equilibrium under applied forces, while other three years for calibration process. The soil moisture in the MMsoil module of the MM-MF model was manually calibrated against daily soil moisture measurements in 3 Stevens Water Hydra Probe soil moisture sensors (Seyfried et al., 2005), each located at $25 \mathrm{~cm}$ depth. That calibration aimed at definition of spatio-temporally variable net recharge. Two indexes were calculated to analyze the goodness of fit between simulated and observed soil moisture curves: (i) the RSR of Moriasi et al. (2007) that is the root mean square error (RMSE) normalized by standard deviation (SD) of the observed heads; and (ii) the Pearson's correlation coefficient $(r)$. While the RSR is a measure of discrepancy between the simulated and observed soil moisture, the $r$ shows how well model and observation trends fit each other. The soil moisture calibration was carried out by adjustment of soil field capacity and soil thickness towards laboratory 
and field defined ranges, focusing on minimizing RSR and maximizing the Pearson's correlation coefficient $(r)$.

The groundwater MODFLOW module of the MM-MF model was calibrated against time series of hydraulic head measurements in 11 piezometers. The water levels in piezometers were recorded by Keller (www. ke11er-druck. com) automated water table recorders. The head calibration was done by adjustment of multipliers of MRS estimates of specific yield $\left(S_{y, M R S}\right)$ and MRS estimates of hydraulic conductivity $\left(K_{M R S}\right)$. In every calibration run, one multiplier for the $12 S_{y, M R S}$ and another one for the $12 K_{M R S}$ were assigned, which guaranteed the original proportionality between the MRS estimates of specific yield and hydraulic conductivity. The MODFLOW calibration of heads was carried out by trial and error adjustment of the two MRS multipliers focusing on minimizing RSR at the 11 monitored piezometers and maximizing the Pearson's correlation coefficient $(r)$. That calibration allowed finally, to select a pair of MRS multipliers further used to estimate specific yield $\left(S_{y}\right)$ and hydraulic conductivity $(K)$ at the 12 MRS survey locations as explained below.

\subsubsection{MRS contribution to hydrogeological parameterization}

Distributed hydrological models, such as MM-MF, require definition of hydrostratigraphic layers, aquifer parameters and water fluxes. The main aim of the MRS measurements in this study was to characterize spatial variability of hydraulic parameters of the shallow unconfined aquifer by integrating the MRS measurements in a coupled hydrological MM-MF model optimizing the MRS estimates of specific yield $\left(S_{y, M R S}\right)$ and hydraulic conductivity ( $\left.K_{M R S}\right)$.

\subsubsection{Hydrogeophysical pre-MRS field measurements}

Pre-MRS field measurements were carried out prior the MRS surveys assessing: i) natural magnetic field (B); ii) electromagnetic noise; and iii) geoelectrical subsurface profiles using Vertical Electrical Sounding (VES) or TDEM. The magnetic field and noise measurements were carried out to confirm suitability of the selected site for the MRS survey and to optimize that survey (Lubczynski and Roy, 2004) whereas the geoelectrical profiles to support the MRS inversion process. The assessment of natural magnetic field was executed to determine the local scale magnetic inhomogeneity and to determine Larmor frequency $\left(f_{l}\right)$ necessary for the MRS survey. The magnetometric survey was carried out with two magnetometers: G856 as rover and a G816 as a base in 12 selected MRS survey sites. In each selected MRS site, 36 magnetometric measurements were carried out within $100 \times 100 \mathrm{~m}$ quadratic or rhomboid area. The electromagnetic noise and the VES/TDEM measurements were performed in the pre-selected MRS-survey locations. The noise measurements were done with a coil especially designed for the noise investigation (Plata et al., 2009). The VES investigations were executed with Syscal R2E res- 
istivity meter from IRIS Instruments while the TDEM measurements with a $50 \mathrm{~m}$ square loop using a TEM-FAST 48 from Applied Electromagnetic Research (AEMR).

\subsubsection{MRS field measurements}

The selection of the MRS sounding locations was a result of careful GIS-based analysis of the land cover, available subsurface information and pre-MRS field measurements. That selection attempted also to cover hydrological variability within the Carrizal Catchment and to have shallow wells nearby, to provide direct information on the groundwater table depth as auxiliary data in the MRS water detection process. As a result 12 MRS locations were selected. In each site, the magnetic field $(B)$ was measured directly before the MRS survey and the retrieved value was used to calculate the Larmor frequency required for the MRS survey. Since $B$ varied with time, we also monitored its temporal variations during the MRS survey. The 12 selected MRS locations were surveyed in two field campaigns, the first in April 2009 with 8 soundings (Uriarte Blanco et al., 2011) and the second in November 2009 with 4 soundings. In both campaigns, the NUMIS ${ }^{L I T E}$ MRS equipment manufactured by IRIS Instruments was used. The locations of the MRS sounding experiments are presented in Figure 6.2. The 12 MRS surveys resulted in satisfactory data coverage of 1 MRS survey per $\sim 6 \mathrm{~km}^{2}$, essential for appropriate constrain of the distributed hydrological model. In 8 MRS surveys, a $60 \mathrm{~m}$ square-shaped loop was used while in 4 sites, due to lower signal to noise $(\mathrm{S} / \mathrm{N})$ ratio, a square-eight loop of $30 \mathrm{~m}$ side each, oriented parallel to adjacent electric power lines, was used with the aim to improve the $\mathrm{S} / \mathrm{N}$ ratio. That configuration allowed to work in areas with relatively low $\mathrm{S} / \mathrm{N}$ ratio, where standard $60 \mathrm{~m}$ square-shape loop would not permit to perform MRS sounding correctly (Trushkin et al., 1994).

\subsubsection{MRS data processing}

For the inversion of the MRS sounding data, the new Samovar 11.3 (Legchenko, 2011) was used. At each MRS survey location, the geoelectrical profiles acquired through VES and/or TDEM were used in the calculation of the Samovar "linear filter". The linear filter is a pre-calculation of the MRS response at the given location for a suite of theoretical layers at increasing depth levels, taking into account the MRS loop shape and size, the range of excitation moment $(Q)$, the subsurface geoelectrical layering in terms of resistivity and thickness, the Earth's magnetic field magnitude and its inclination.

The transient model of the unconfined Carrizal aquifer required pre-assignment of spatial variability of the specific yield. Following Lubczynski and Roy (2003); Legchenko et al. (2004); Lubczynski and Roy (2005, 2007); Vouillamoz et al. (2012b), in medium to coarse grain materials such as the composition of the shallow Carrizal aquifer, the 
following MRS assumption is valid:

$$
\Theta_{M R S} \approx n
$$

where $\Theta_{M R S}$ is MRS free water content obtained as a result of MRS survey and $n$ porosity.

From standard hydrogeology (Fetter, 2001):

$$
n=S_{y}+S_{r}
$$

where $S_{y}$ is specific yield and $S_{r}$ is specific retention, also known as field capacity.

Therefore combining Equations 6.1 and 6.2 we obtain:

$$
\Theta_{M R S} \approx S_{y}+S_{r}
$$

In Equation 6.3, the unknown $S_{r}$ prevents direct estimation of $S_{y}$ from $\Theta_{M R S}$. Equation 6.3 indicates also that $S_{y} \leq \Theta_{M R S}$, where the difference between the two increases towards finer material of the aquifer, i.e. larger $S_{r}$. This observation is reflected in empirical Equation 6.4 from Vouillamoz et al. (2012b) that presents linear relation of MRS estimates of specific yield $\left(S_{y, M R S}\right)$ with $\Theta_{M R S}$ as follows:

$$
S_{y, M R S}=0.4 \times \Theta_{M R S}+0.0056
$$

According to Vouillamoz et al. (2012b), Equation 6.4 is valid for sandy deposits if $0.7<\Theta_{M R S}<5.4 \%$. Boucher et al. (2009b) suggested that for such low values of $\Theta_{M R S}$ the linearity of the equation is fairly well maintained but for larger $\Theta_{M R S}$ the relationship is not always perfectly linear. Because the Carrizal study area is relatively small and hydraulically uniform, it can be assumed that the variability of the specific yield is well resembled by the 12 MRS surveys available. Therefore the $12 S_{y, M R S}$ values were calibrated (by trial and error) by optimizing the storage multiplier $(m)$ :

$$
S_{y}=m S_{y, M R S}
$$

where $m$ is storage multiplier, the same for all MRS measurements.

Initially, the $12 S_{y, M R S}$ values were estimated according to the Equation 6.4. These values were spatially interpolated using inverse distance weighted method with power 1 (IDW1), this way creating preliminary MM-MF model input matrix. The IDW1 method was selected based on Kravchenko and Bullock (1999); Robinson and Metternicht (2006) because of the low skewness distribution of our data suggesting low exponent. Next the multiplier $m$ was introduced as proposed in Equation 6.5 and further optimized by trial and error in the MM-MF transient model calibration to find optimal $m$ specific for the Carrizal aquifer that best facilitates the agreement between the simulated and measured heads i.e. having the lowest RSR and highest $r$.

Another parameter that is required by the MM-MF model is hydraulic conductivity $(K)$. To obtain it, first, for each of the 12 MRS-surveys, the 
MRS estimates of aquifer transmissivity $\left(T_{M R S}\right)$ were derived according to Equation 6.6 applying Samovar 11.3 inversion with its default $C_{T 0}=$ $7 \times 10^{-9}$ :

$$
T_{M R S}=C_{T 0} \times \sum \Theta_{M R S}(z) \times\left(T_{1}\right)^{2} \Delta z
$$

where $C_{T 0}$ is Samovar 11.3 default MRS-transmissivity multiplier, $\Theta_{M R S}(z)$ is MRS free water content at depth $z, T_{1}$ is longitudinal relaxation time in milliseconds and $\Delta z$ is thickness of individual layer in meters.

In the next step, each transmissivity value was converted to hydraulic conductivity according to Equation 6.7:

$$
K_{M R S}=T_{M R S} / z_{t o t}
$$

where $K_{M R S}$ is hydraulic conductivity derived by MRS and $z_{\text {tot }}=\sum \Delta z$ is total thickness of the aquifer in meters. The final aquifer transmissivity and hydraulic conductivity are expressed by Equations 6.8 and 6.9 respectively:

$$
\begin{aligned}
& T=C_{T} \times \sum \Theta_{M R S}(z) \times\left(T_{1}\right)^{2} \Delta z \\
& \mathrm{~K}=T / z_{\text {tot }}
\end{aligned}
$$

After defining $12 T_{M R S}$ values according to Equation 6.6 i.e. applying $C_{T 0}=7 \times 10^{-9}$, the $12 K_{M R S}$ were calculated according to Equation 6.7 and further interpolated using IDW1 method creating preliminary $K_{M R S}$ MM-MF model input matrix. Next the multiplier $C_{T}$ was introduced as in Equation 6.8 and 6.9 and further optimized in the MM-MF transient model calibration in order to find optimal $C_{T}$ value that facilitates best the agreement between the simulated and measured heads (lowest RSR and highest $r$ ).

\subsection{Results and discussion}

An overview of the environmental conditions of the 12 MRS surveys characterizing their suitability for MRS soundings is presented in Table 6.1. The magnetic inhomogeneity $(\Delta B)$ varied among the MRS-sites from 2 to $12 \mathrm{nT}$ (Table 6.1). Two of the twelve sites are presented in Figure 6.3 as examples of the Carrizal Catchment magnetic field variability within the MRS loop scale. It can be observed that in the INTER $60 \times 60 \mathrm{~m}$ square loop (Figure 6.3a), the magnetic field was fairly constant $(\Delta B=6 \mathrm{nT}$ ), while in the PG05 with square-eight loop (Figure 6.3b), variability of the magnetic field was larger $(\Delta B=10 \mathrm{nT})$. In general the magnetic inhomogeneity within the MRS survey sites of the Carrizal Catchment was low as the largest $\Delta B$ in H-9 location (Table 6.1) did not exceed $12 \mathrm{nT}$, i.e. $\Delta f_{l}=0.5 \mathrm{~Hz}$ on the Larmor frequency which can be considered nearly homogeneous field condition. 
Table 6.1: Description of the MRS surveys: $L s$ - loop shape and size; $B_{a v g}$ - magnetic field averaged in each MRS survey location $\Delta B$ - range of magnetic field inside the loop in each MRS survey location (magnetic inhomogeneity).

\begin{tabular}{lrrrcrrrr}
\hline Site & $\begin{array}{r}\text { UTM X } \\
(\mathrm{m})\end{array}$ & $\begin{array}{r}\text { UTM Y } \\
(\mathrm{m})\end{array}$ & $\begin{array}{r}\text { Survey date } \\
\mathrm{dd} / \mathrm{mm} / \mathrm{yy}\end{array}$ & $\begin{array}{c}\text { LS } \\
(\mathrm{m})\end{array}$ & Stacking & $\begin{array}{r}B_{\text {avg }} \\
(\mathrm{nT})\end{array}$ & $\begin{array}{r}\Delta B \\
(\mathrm{nT})\end{array}$ & $\begin{array}{r}\text { Noise } \\
(\mathrm{nV})\end{array}$ \\
\hline PG01 & 283669 & 4569517 & $4 / 21 / 2009$ & SQ-60 & 64 & 44877 & 9 & $450-650$ \\
PG02 & 287486 & 4571856 & $4 / 27 / 2009$ & SQ8-30 & 120 & 44875 & 9 & $550-650$ \\
PG03 & 282246 & 4570870 & $4 / 30 / 2009$ & SQ-60 & 96 & 44882 & 4 & $400-550$ \\
PG04 & 288259 & 4573714 & $4 / 23 / 2009$ & SQ-60 & 96 & 44905 & 7 & $500-600$ \\
PG05 & 285569 & 4569759 & $11 / 4 / 2009$ & SQ8-30 & 120 & 44908 & 10 & $445-465$ \\
PG06 & 284502 & 4572292 & $11 / 3 / 2009$ & SQ-60 & 100 & 44897 & 6 & $380-540$ \\
P-7 & 285402 & 4573260 & $4 / 21 / 2009$ & SQ-60 & 96 & 44889 & 7 & $375-475$ \\
P-8 & 285900 & 4567914 & $11 / 3 / 2009$ & SQ8-30 & 96 & 44871 & 3 & $410-490$ \\
PG08 & 281744 & 4569307 & $11 / 3 / 2009$ & SQ8-30 & 100 & 44877 & 7 & $300-400$ \\
H-9 & 292973 & 4573888 & $4 / 28 / 2009$ & SQ-60 & 96 & 44895 & 12 & $450-550$ \\
M-V & 288197 & 4569233 & $4 / 28 / 2009$ & SQ-60 & 96 & 44875 & 2 & $400-550$ \\
INTER & 290121 & 4573677 & $11 / 4 / 2009$ & SQ-60 & 120 & 44915 & 6 & $410-510$ \\
\hline
\end{tabular}


The pre-MRS noise survey indicated low electromagnetic noise ranging from 375 to $650 \mathrm{nV}$ (Table 6.1) suitable for MRS surveys in 11 out of the 12 selected locations. The only one location where the noise was too high was discarded and replaced with a new, nearby location, H-9, with lower, comparable with other sites noise. In PG02, PG05, PG08 and P-8, due to the presence of adjacent electric power lines, a square-eight loop configuration parallel to the power line had to be used to reduce the noise influence. During the MRS experiments the environmental noise did not vary much, typically staying within $200 \mathrm{nV}$ difference (Table 6.1); however, in the two cases, i.e. PG04 and P-7, the MRS measurements had to be repeated because of temporally variable noise.
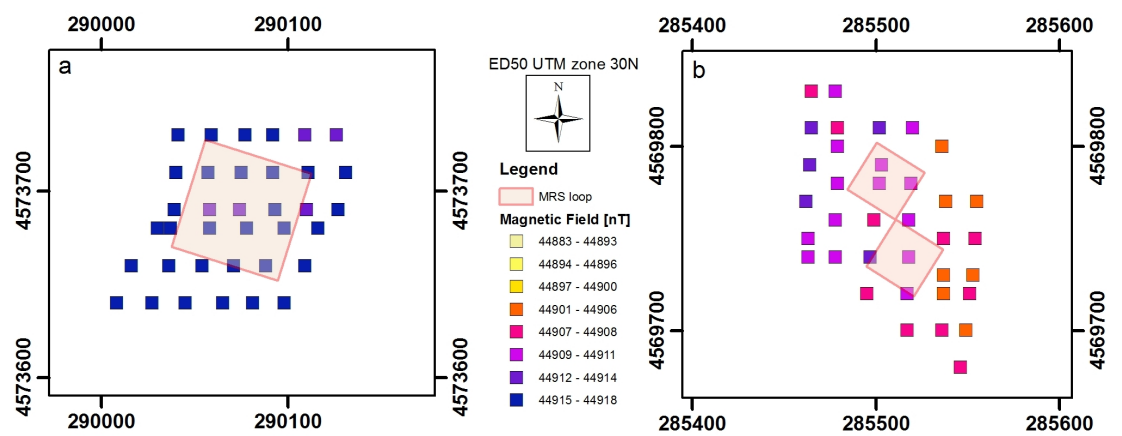

Figure 6.3: Magnetic field in MRS experiments: a) MRS-loop location with medium magnetic field variability (INTER); b) MRS-loop location with higher magnetic field variability (PG05).

The VES and TDEM results inverted into resistivity layers were used as support of the MRS inversions. In order to characterize variability of the resistivity attributed to the modelled, shallow aquifer extent, for each MRS survey location, the aquifer resistivity (Table 6.2) at each surveyed site was estimated by weighted average of the resistivity layers within the aquifer thicknesses as defined by the MRS soundings. Except of the M-V locations with relatively large resistivity of $190 \Omega \mathrm{m}$, in all other locations, the resistivities were low, in order of 10-30 $\Omega \mathrm{m}$.

The results of the 12 MRS surveys, inverted with Samovar 11.3 using preliminary standard $C_{T 0}=7 \times 10^{-9}$ and corresponding geoelectrical profiles are presented in Table 6.2 and Figure 6.4 whereas the location of the 12 MRS surveys can be found in Figure 6.2. In order to enhance readability of the MRS survey results, all the MRS profiles were presented within the same depth range, water content and decay time scale. Due to the excitation limit of the NUMIS ${ }^{L I T E}$ MRS equipment and the loop size up to $L s=60 \mathrm{~m}$, the Samovar inversions of the MRS surveys allowed for the maximum investigation depth $<90 \mathrm{~m}$ b.g.s., which for the four surveys with square-eight loop (PG02, PG05, PG08 and P-8) was still significantly lower. 

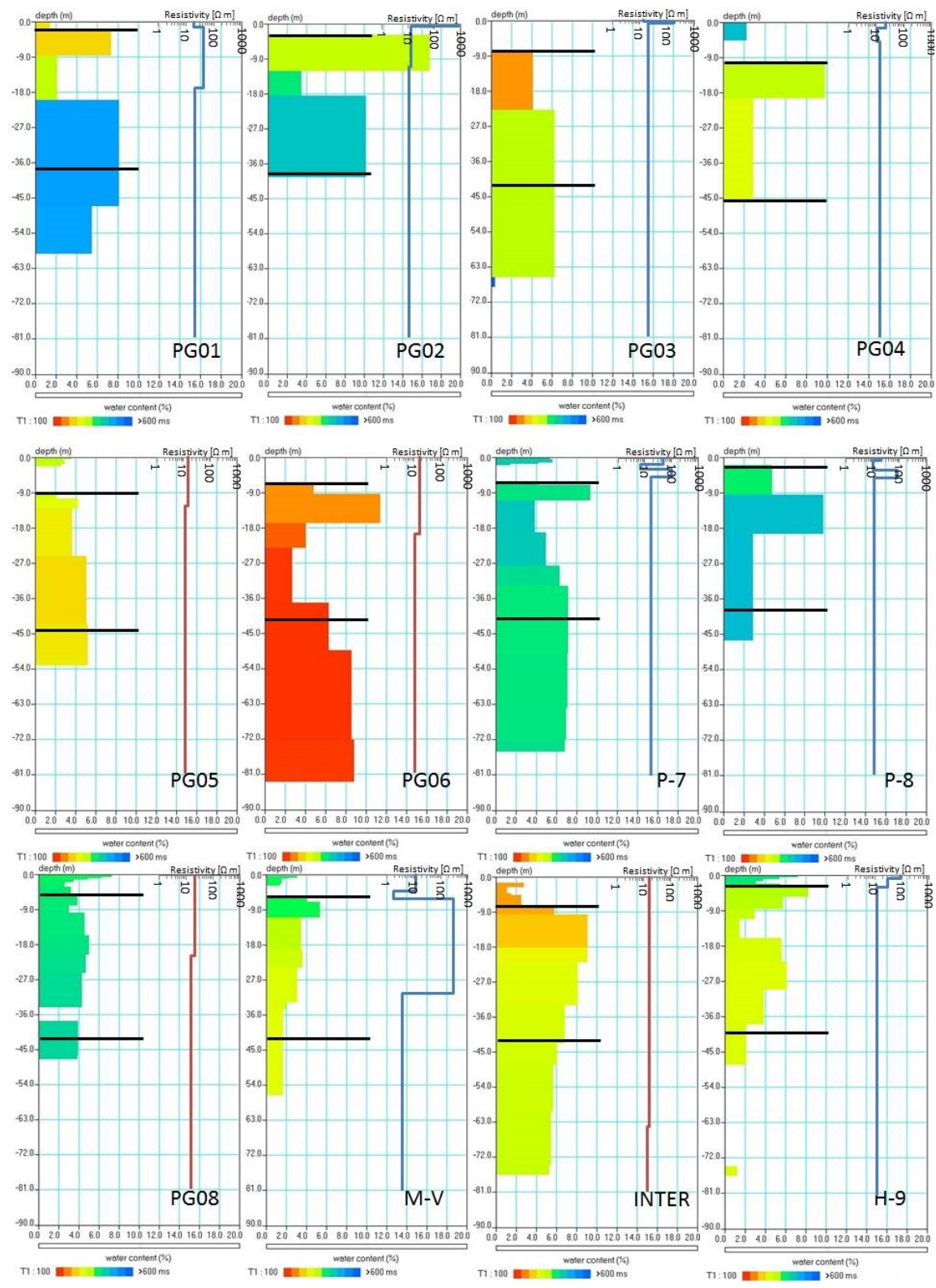

Figure 6.4: Scaled MRS inversion results of $\Theta_{M R S}$ and $T_{1}$ with preliminary, standard, $C_{T 0}=7 \times 10^{-9}$. Black lines show the assigned in the hydrologic model top and bottom aquifer boundaries. On the right side of each image, resistivity profiles in logarithmic scale are shown by blue line for VES and brown line for TDEM method. 
Table 6.2: MRS survey results: GWTD - groundwater table depth; $D_{a q}$ - thickness of the aquifer; $\rho$ - resistivity of the aquifer; $\Theta_{M R S}$ - MRS water content of the aquifer; $T_{1}$ - decay time constant; $S_{y, M R S}$ - MRS estimate of specific yield; $K_{M R S}, T_{M R S}$ - MRS estimate of hydraulic conductivity and aquifer transmissivity based on standard multiplier $C_{T 0}=7 \times 10^{-9} ; S_{y}$ - calibrated specific yield; $K$ - calibrated hydraulic conductivity using optimized MRS transmissivity multiplier $C_{T}$.

\begin{tabular}{lrrrrrrrrrrr}
\hline Site & $\begin{array}{r}\text { Altitude } \\
\text { (m.a.s.l.) }\end{array}$ & $\begin{array}{r}\text { GWTD } \\
(\mathrm{m})\end{array}$ & $\begin{array}{r}D_{a q} \\
(\mathrm{~m})\end{array}$ & $\begin{array}{r}\rho \\
(\Omega \mathrm{m})\end{array}$ & $\begin{array}{r}\Theta_{M R S} \\
(\%)\end{array}$ & $\begin{array}{r}T_{1} \\
(\mathrm{~ms})\end{array}$ & $\begin{array}{r}S_{y, M R S} \\
(\%)\end{array}$ & $\begin{array}{r}T_{M R S} \\
\left(\mathrm{~m}^{2} . \mathrm{d}^{-1}\right)\end{array}$ & $\begin{array}{r}K_{M R S} \\
\left({\left.\mathrm{~m} . \mathrm{d}^{-1}\right)}\right)\end{array}$ & $\begin{array}{r}S_{y} \\
(\%)\end{array}$ & $\begin{array}{r}K \\
\left({\left.\mathrm{~m} . \mathrm{d}^{-1}\right)}\right.\end{array}$ \\
\hline PG01 & 850 & 1.9 & $>57$ & 30 & 6.1 & 390 & 2.4 & 246 & 6.9 & 2.4 & 3.4 \\
PG02 & 792 & 2.8 & $>37$ & 10 & 10.8 & 400 & 4.3 & 357 & 10.1 & 4.3 & 5.0 \\
PG03 & 872 & 7.7 & $>58$ & 22 & 5.3 & 262 & 2.2 & 95 & 2.7 & 2.2 & 1.3 \\
PG04 & 777 & 10.5 & 35.5 & 13 & 4.6 & 274 & 1.8 & 83 & 2.3 & 1.8 & 1.1 \\
PG05 & 846 & 9.1 & $>44$ & 11 & 4.4 & 229 & 1.8 & 49 & 1.4 & 1.8 & 0.7 \\
PG06 & 825 & 6.5 & $>76$ & 13 & 5.5 & 124 & 2.2 & 23 & 0.6 & 2.2 & 0.3 \\
P-7 & 810 & 6.2 & $>69$ & 16 & 5.9 & 415 & 2.4 & 213 & 6.0 & 2.4 & 3.0 \\
P-8 & 853 & 2.0 & $>44$ & 15 & 5.2 & 440 & 2.1 & 218 & 6.2 & 2.1 & 3.1 \\
PG08 & 877 & 5.4 & $>42$ & 17 & 3.9 & 409 & 1.6 & 134 & 3.8 & 1.6 & 1.6 \\
M-V & 835 & 4.0 & $>53$ & 190 & 3.2 & 296 & 1.3 & 65 & 1.8 & 1.3 & 0.9 \\
INTER & 763 & 6.5 & $>70$ & 15 & 7.9 & 245 & 3.2 & 102 & 2.9 & 3.2 & 1.4 \\
H-9 & 751 & 3.0 & 45 & 15 & 4.7 & 302 & 1.9 & 84 & 2.4 & 1.9 & 1.2 \\
\hline Mean & & 6.3 & & 31 & 5.6 & 315 & 2.3 & 137 & 3.4 & 2.3 & 1.9 \\
St.Dev & & 2.8 & & 31 & 2.0 & 96 & 0.8 & 97 & 2.8 & 0.8 & 1.4 \\
\hline
\end{tabular}


All the MRS surveys were realized next to shallow wells or piezometers with known groundwater table depth (GWTD) of $<6 \mathrm{~m}$ b.g.s. In all survey locations, the MRS detected GWTD with an acceptable error of some tens of centimeters. For example GWTD at PG01 was $1.9 \mathrm{~m}$ while the corresponding depth manually measured in the nearby well was $2.2 \mathrm{~m}$. Such high MRS accuracy in GWTD detection was expected as the MRS survey conditions were favorable (Table 6.1) and also because MRS detectability at shallow depth is typically very good.

In the MODFLOW model, we assigned unconfined layer with spatially uniform thickness $35.5 \mathrm{~m}$ delimited by two black lines in Figure 6.4, upper representing phreatic water table and lower, arbitrarily assigned aquifer bottom based on the shallowest (counting from the water table) penetration depth of the MRS-inverted sounding profiles. Such schematization was made because: 1) in the Carrizal Catchment there is no impermeable layer within the depth range of the MRS investigation that could be assigned as bottom boundary of the model; 2) spatially uniform thickness guaranteed that the estimated transmissivity is not influenced by uncertain MRS estimate of aquifer depth; 3) the assigned thickness had to have the largest possible depth to cover the largest possible spectrum of groundwater flow; 4 ) the model aquifer top, i.e. the water table, was defined with high confidence and confirmed by direct measurements in nearby wells; 5) the model aquifer bottom was restricted by data availability, i.e. the lack of sufficiently deep boreholes and by MRS penetration depth in PG04 and PG02 (Figure 6.4); 6) the groundwater flow in aquifers such as the unconfined Carrizal aquifer, is typically shallow and laterally dominant, as horizontal hydraulic conductivity is typically of an order of magnitude larger than vertical (Fetter, 2001) so the shallow lateral streamlines contribute the most to the overall groundwater flow of the catchment.

The applied uniform aquifer thickness schematization discards some valuable information provided by MRS at the deepest parts of some MRS sounding profiles but offers the following advantages: i) assures that the optimized transmissivity is only hydraulic conductivity dependent so not biased by subjective selection of aquifer bottom; ii) creates possibility of applying the method we propose in this chapter, requiring that the proportions between the 12 MRS estimates are valid; iii) captures the most MRS-trustable and hydrogeologically-important for the model performance, shallow section of the aquifer.

The proposed schematization of the Carrizal model has important implications. The assignment of only one layer implies 2D groundwater model solution with only lateral component of flow. Besides, in MODFLOW, the bottom boundary of the lowest aquifer is automatically assigned impermeable. In reality, the Carrizal aquifer extends deeper than the assigned bottom boundary of our model. This implies that the calibrated net recharge applied to the aquifer compensates the eventual bottom boundary flux that would occur if there was no arbitrary no-flow bottom boundary at depth of $35.5 \mathrm{~m}$ from the water table; nevertheless it is expected that the bottom flux in the Carrizal Catchment is low or even 
negligible as the shallow aquifer has quite large horizontal hydraulic conductivity in order of $10 \mathrm{~m} \cdot \mathrm{d}^{-1}$, favoring shallow-lateral flow with short residence time (Fetter, 2001).

The MMsoil model calibration of soil moisture provided good match between measured and simulated soil moisture, and as a result generated spatio-temporally variable net recharge that was further used as input in MODFLOW calibration. An example of soil moisture calibration for the selected time series SM1 sensor measurements is presented in Figure 6.5. That calibration shows good agreement between simulated and measured soil moisture records and was characterized with $r=0.87$ and RSR $=0.51$. The head calibration in MODFLOW was completed after 49 runs, each time with a different values of $m$ and $C_{T}$, although not all the runs were stable. The unstable runs are marked in white in the two left panels in Figure 6.5. The best, optimized model solution based on three years of head calibration with the lowest RSR $=4.28$ and the highest $r=0.74$, was obtained for $m=1$ and $C_{T}=3.5 \times 10^{-9}$. The $S_{y, M R S}$ is best defined using $r$ while the $K_{M R S}$ using RSR. This is because $S_{y, M R S}$ variations influence the amplitude of the piezometric curve, thus the trend and the fitting between simulated and observed curve to which $r$ is sensitive, while $K_{M R S}$ variations modify the distance (offset) between the two curves, which is reflected in the RSR value. An example of modeled and observed head in one piezometer P1 with well-retrieved pattern of temporal variability of water table fluctuation is shown in Figure 6.5. The shift between modeled and observed heads is a consequence of model scale: the Carrizal model is setup with a resolution of $150 \times 150 \mathrm{~m}$, so the $\mathrm{P} 1$ head observation has likely a shift due to the topographically constrained head variability within the grid cell. Nevertheless, the most important in transient model calibration temporal pattern of head measurements (Lubczynski and Gurwin, 2005a) was well retrieved.

The $S_{y, M R S}$ input parameter of the MM-MF model estimated using Equation 6.4 (Vouillamoz et al., 2012b) is listed in Table 6.2 and presented spatially in Figure 6.6. We used Equation 6.4 to estimate $S_{y, M R S}$ even though our average $\Theta_{M R S}$ was $5.6 \%$, i.e. slightly above the range adopted by Vouillamoz et al. (2012b). The estimated $S_{y, M R S}$ varied from $1.3 \%$ in PG04 to $4.3 \%$ in PG02, with a mean of $2.3 \%$ and standard deviation $\sigma=0.8 \%$. It is remarkable that through the model calibration, the $m$ multiplier was not changed $(m=1)$ so that $S_{y, M R S}$ did not need any adjustment in the process of transient model calibration, implying $S_{y, M R S} \approx S_{y}$ according to Equation 6.5. The difference between $S_{y}$ and $S_{y, M R S}$ was within the resolution of calibration process, which shows that the MRS estimate of specific yield $\left(S_{y, M R S}\right)$ computed using Equation 6.4 provided a good guess of $S_{y}$ in the Carrizal Catchment. Figure 6.6 shows spatial distribution of $S_{y}$ in the Carrizal Catchment that ranged from 1\% to $4.5 \%$, pointing at significant aquifer homogeneity.

The $K_{M R S}$ input parameter of the MM-MF model estimated using Equations 6.6 and 6.7 is listed in Table 6.2. The $K_{M R S}$ varied from 0.6 m.d $\mathrm{d}^{-1}$ in PG06 to $10.1 \mathrm{~m} . \mathrm{d}^{-1}$ in PG02 with a mean of $3.9 \mathrm{~m} . \mathrm{d}^{-1}$ and standard deviation $\sigma=2.8 \mathrm{~m}^{-1}{ }^{-1}$. The optimized in the calibration of 

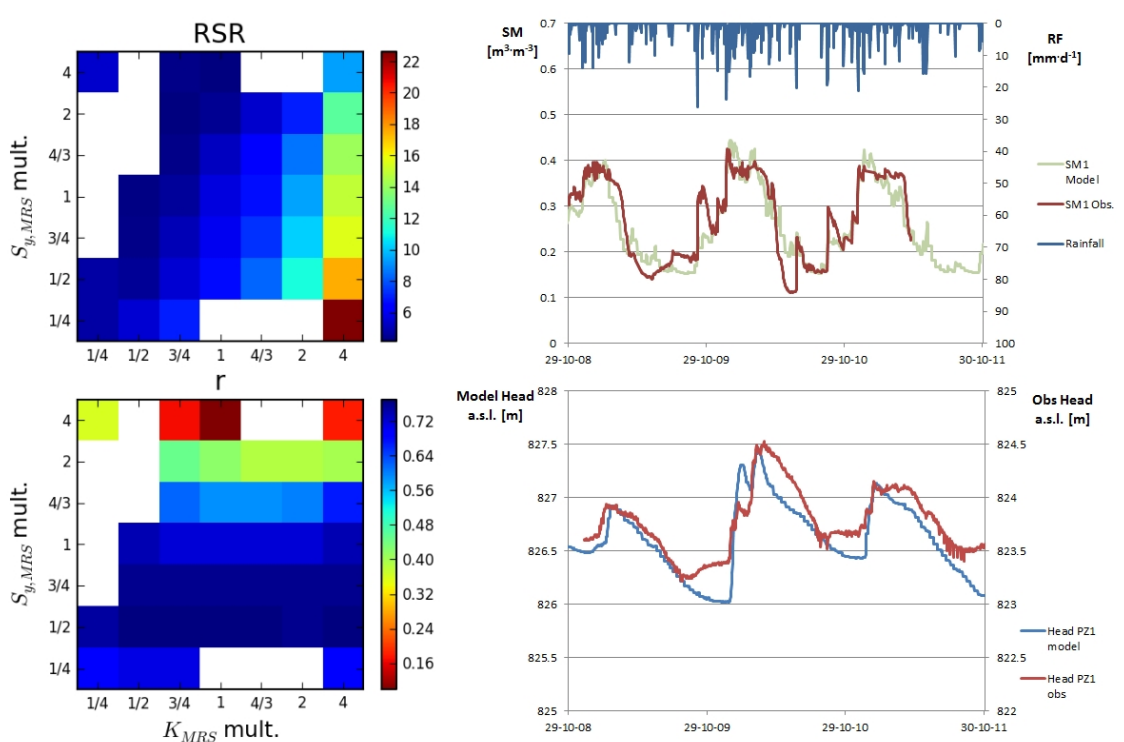

Figure 6.5: Calibration analysis. The two panels at the left show RSR (upper panel) and $r$ (lower panel) computed in relation to simulated and observed hydraulic heads and varying the multipliers of MRS estimates of specific yield $\left(S_{y, M R S}\right)$ and hydraulic conductivity $\left(K_{M R S}\right)$; in white combination of parameters that do not provide a stable solution in MMMF model, in dark blue best solution. The two panels at the right present examples of model calibration of soil moisture at SM1 location (upper part) and hydraulic head at PG1 (lower part).

groundwater model $C_{T}=3.5 \times 10^{-9}$ is specific for the Carrizal Catchment. Considering that initially used in the calibration $C_{T 0}=7 \times 10^{-9}$, the optimized in MM-MF $K$ was only twice lower than $K_{M R S}$ (Table 6.2). The optimized $K$ varied from 0.3 m.d ${ }^{-1}$ in PG06 to 5.0 m.d ${ }^{-1}$ in PG02 with a mean of $1.9 \mathrm{~m} . \mathrm{d}^{-1}$ and standard deviation $\sigma=1.4 \mathrm{~m} \cdot \mathrm{d}^{-1}$. Considering that hydraulic conductivity is spatially log-normally distributed (Fetter, 2001), the spatial variability of the Carrizal Catchment $K$ presented in Figure 6.7 can be considered as very low pointing at significant aquifer homogeneity.

Despite low spatial variability of $S_{y}$ and $K$, there was still some internal variability in the estimates of $S_{y, M R S}$ and $K_{M R S}$, although not large. The maximum differences within $S_{y, M R S}$ and $K_{M R S}$ were observed between PG02 and PG05 locations (Table 6.2). We analyzed the granulometry of the soil samples from $3 \mathrm{~m}$ depth in these two locations to see if what was depicted by MRS $\Theta_{M R S}$ and $T_{1}$ did indeed properly reflect field lithological and hydrogeological differences. We found that the soil material in the PG02 contained 79\% of sand and was coarser than in the PG05 that contained 56\% of sand. This was in line with the MRS estimates of $S_{y, M R S}$ and $K_{M R S}$ and confirmed that MRS was well able to depict the 
hydrogeological differences between different survey locations despite these differences were quite low.

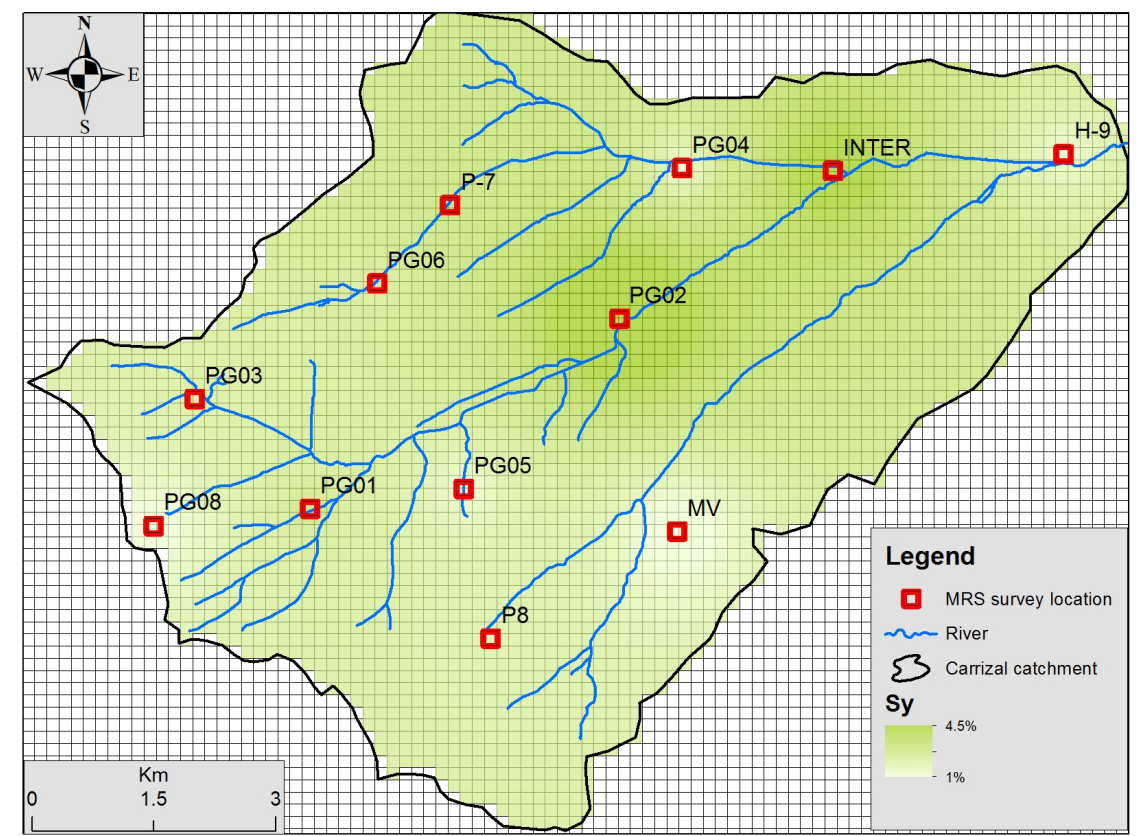

Figure 6.6: Spatial distribution of the calibrated specific yield $\left(S_{y}\right)$.

The comparison of our optimized $C_{T}=3.5 \times 10^{-9}$ with Uriarte Blanco et al. (2011) of the same Carrizal Catchment is not straightforward as for the inversion they applied different Samovar version 6.2 while we used Samovar version 11.3. The two inversions led to different results because of different software characteristics and different investigated thicknesses. Nevertheless, their $C_{T}$ value was quite similar to ours, varying from $0.18 \times 10^{-9}$ to $25.4 \times 10^{-9}$. Even more similar were $C_{T}$ values derived in clayey-sands in France $\left(4.9 \times 10^{-9}\right)$ by Vouillamoz (2003) and in sands in Niger $\left(17 \times 10^{-9}\right)$ by Vouillamoz et al. (2007).

When comparing our study to the similar study integrating MRS in the distributed groundwater model presented by Boucher et al. (2012), we had larger spatial density of the MRS surveys, much smaller area investigated and different method of MRS data integration in groundwater model. Instead of facilitating groundwater model with data provided by MRS, we used transient groundwater model to optimize MRS multipliers, $m$ and $C_{T}$, which allowed us to optimize $S_{y}$ and $K$ based on $S_{y, M R S}$ and $K_{M R S}$ respectively. In our Carrizal case, the $S_{y}$ and $K$ did not change much as compared to corresponding $S_{y, M R S}$ and $K_{M R S}$, which confirmed appropriate performance of MRS in the hydrogeological conditions of Carrizal Catchment although in other more heterogeneous areas the same methodology can also be applied. The proposed methodology of 


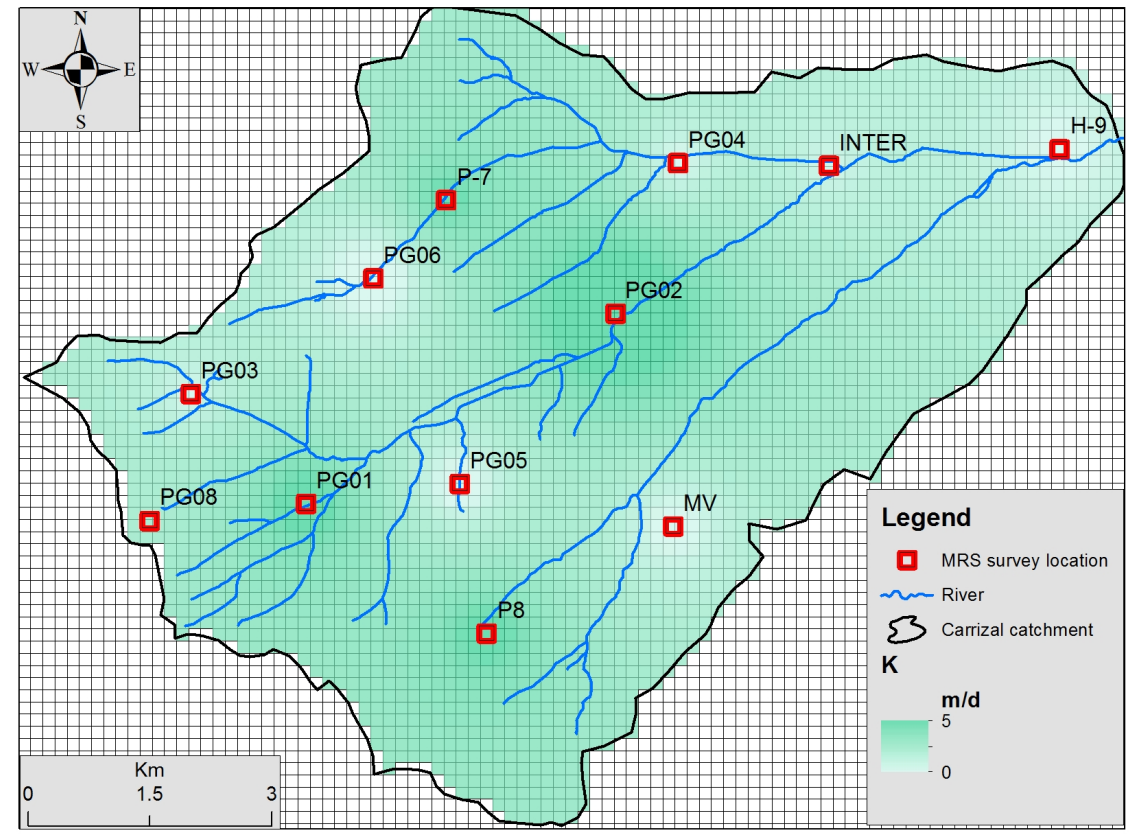

Figure 6.7: Spatial distribution of the calibrated hydraulic conductivity $(K)$.

aquifer parameterization based on optimizing $m$ and $C_{T}$ multipliers in distributed hydrological models represents an alternative to the method of cross referencing MRS surveys with pumping test data. As the other method that uses pumping test data implicitly, our method also offers an opportunity of defining $m$ and $C_{T}$ multipliers which are characteristic for the investigated area so in case of follow up MRS surveys in that area (or adjacent, hydrologically similar areas), these multipliers can be used for direct estimation of aquifer $S_{y}, T$ and $K$. The proposed method does not need pumping test data, but requires a good quality input data, preferably long time series data, allowing for a tight constrain of a calibrated, distributed and preferably coupled, transient hydrological model, although solution applying standard, standalone groundwater model would also suffice.

When calibrating steady-state model, only $C_{T}$ multiplier can be derived. Both $m$ and $C_{T}$ multipliers can be derived in transient models. The most effective hydrological model constrain and therefore the highest reliability can be achieved in transient and coupled models such as the presented Carrizal model - in transient, because calibration against temporal data optimally reduces hydrological model non-uniqueness (Lubczynski, 2011) and in coupled, because such models handle the aquifer input fluxes in more reliable manner than stand alone models (Furman, 2008; Francés and Lubczynski, 2015, ; Chapter 5). If in an 
investigated area pumping tests are available, then certainly they should be used as model input, because they enhance reliability of models. However, if not available, then the proposed optimization method is an opportunity that should be considered if appropriate data to setup a model is available. The important question related to the applied optimization method, but also to the common practice of calibrating MRS results with pumping test data is, when and under which conditions in an investigated area, only one storage $(m)$ and only one transmissivity multiplier $\left(C_{T}\right)$ representative for that investigated area can be applied. We hypothesize that $m$ and $C_{T}$ depend on the hydraulic model of water flow at the pore scale of the analyzed aquifers. In that respect there are 4 main types of such hydraulic models: primary porosity (e.g. unconsolidated sand), secondary porosity (e.g. fractured granite), double porosity (e.g. sandstone) and karst (e.g. limestone). If in an investigated study area, there are rocks of different hydraulic models, then certainly different $m$ and different $C_{T}$ have to be introduced. However, whether within investigated rock types of the same hydraulic model but differing for example by texture or lithology, only one $m$ and one $C_{T}$ can be used, this requires further testing and cross-referencing with pumping tests that unfortunately were not available in this study.

\subsection{Conclusions}

The MRS technique is highly suitable for its integration with distributed, hydrological models because: i) it provides quantitative estimates of storage and flow parameters $\left(S_{y}, T, K\right)$ at the survey location; ii) the volumes investigated by MRS survey can be easily adjusted in a distributed hydrological model by grid and layering adjustment so that the two are comparable in scales.

We proposed a novel method of integrating MRS results in a distributed, coupled transient hydrological model using Carrizal Catchment study area as an example. In that method we assumed that individual MRS sounding results can be biased but the relative differences between MRS survey results at different locations of the catchment reflect real hydrological differences between these locations. Following that assumption, we assigned specific yield and transmissivity multipliers ( $m$ and $C_{T}$ respectively) to the corresponding MRS-specific yield and MRS transmissivity estimates and optimized the two multipliers in the transient, coupled hydrological model calibration.

The MRS integration with hydrological model of the Carrizal Catchment area allowed to: i) calibrate that model; ii) derive $m=1$ and $C_{T}=$ $3.5 \times 10^{-9}$ that can be used in future MRS investigations in the Carrizal Catchment (and/or adjacent areas with similar hydrogeological conditions) to convert MRS survey results into hydrogeological output; iii) acquire spatial variability of specific yield and transmissivity/hydraulic conductivity data in the Carrizal Catchment that showed to be pretty low 
pointing at significant aquifer homogeneity; iv) present and explain the proposed, novel method of MRS data integration in hydrological model.

The values of MRS estimates of $S_{y, M R S}, T_{M R S}$ and $K_{M R S}$ defined in the Carrizal Catchment were close to the corresponding, finally optimized values of specific yield $\left(S_{y}\right)$ and hydraulic conductivities $(K)$; this confirmed functional capability of MRS in quantitative aquifer parameterization.

If pumping tests are available, then they should be used to define MRS multipliers of the hydrogeological parameters; however if not available, but there is enough data to setup coupled, distributed hydrological model or at least standalone groundwater model, then the proposed in this study MRS integration method provides a valuable alternative that should be further tested in various hydrogeological conditions against pumping test data. 


\section{Conclusions}

The performance of coupled hydrological models is dependent on quality and amount of data available. In this study, various non-invasive hydrogeophysical methods were tested regarding subsurface parametrization and their potential contribution to the design of conceptual models. The hydrogeophysical applications were optimal when integrated with remote sensing and standard field invasive methods of data acquisition, used for interpolation or extrapolation and calibration. In particular, remote sensing was crucial to detect and map the main hydrogeological features at the catchment scale (Chapters 2 and 4). The geoelectrical method allowed to depict the hydrostratigraphy of the hard rocks (Chapter 4) and coastal aquifers (Chapter 3) . Performed at key sites, they highlighted important characteristics for the understanding of aquifer hydrodynamic relationships between hydrostratigraphical units. The geoelectrical method can be complemented by 1D time domain (TDEM) and 2D frequency domain (FDEM) electromagnetic methods that are faster to implement in the field, although more sensitive to ambient electromagnetic noise induced for example by human activities and sea dynamic. For shallow subsurface investigation, the 2D FDEM method retrieved efficiently the spatial variation of subsurface electrical conductivity related with clay content in the Pisões study case (Chapter 2) and freshwater-saltwater interface in the coastal aquifer case (Chapter 3). The multi-frequency 2D FDEM method, combined with the laterally constrained inversion technique, applied in the hard rock study case of Sardón (Chapter 4), showed to be very efficient, providing long cross-sections depicting large hydrogeological structures. The MRS technique was the only geophysical method that could provide quantitative assessment of subsurface. The MRS signal processing allows to determine storage and flow parameters, such as specific yield and hydraulic conductivity, although in new assessment areas, these parameters require calibration which typically is done by pumping tests. In contrast, in the sedimentary aquifer of the Carrizal catchment (Chapter 6), such calibration was carried out within the MARMITES-MODFLOW model. The magnetic resonance sounding (MRS) technique proved to be particularly suitable for integration with distributed, hydrological models because it provides quantitative estimates of storage and flow parameters at the scale of the hydrological model. In hard rocks, as in the Sardón area (Chapter 4), not every sounding 
provided valid signal due to low quantities of subsurface water involved and high clay content. Particularly difficult was data acquisition over the fresh fractured rocks where low quantities of water were attributed to secondary porosity only, but surveys carried out over saprolite were more successful.

The joint use of different but complementary hydrogeophysical methods, adapted to different hydrogeological settings, showed to be highly beneficial in the presented study cases, thus future research will follow in that direction. For instance, the joint use of FDEM/TDEM and MRS, since they target at different, complementary subsurface properties, namely electrical conductivity and water content, showed to be very efficient, particularly in coastal areas where MRS retrieves the quantitative characteristics of the water bearing subsurface layers while TDEM retrieves the qualitative (salinity) characteristics. However, as the ambient electromagnetic noise is particularly high in urbanized coastal areas, its filtering should be improved for both methods. Ground-based electric and electromagnetic methods present low mobilization cost and high spatial resolution so are suitable for rather small areas. Due to these characteristics, they can also beneficially complement, at the local scale, airborne electromagnetic surveys that are nowadays frequently applied for hydrogeological studies at regional or national scale. Related with the complementarity of the hydrogeophysical methods, the MRS technique has its particular importance to complement the airborne electromagnetic surveys because of its unique capability to retrieve quantitative information regarding aquifer parameters. In hard rocks, the success of MRS survey is still limited but could be improved by optimizing: (i) the MRS loops and the instrumentation (larger pulse moment, better noise rejection capability and shorter dead-time); (ii) the retrieval of the storage parameters, namely the separation of gravitational water from capillary water based on MRS measurements. The latter issue showed recently a progress with the introduction of the concept of apparent cutoff time, which relates the MRS decay time with the aquifer storage property (Vouillamoz et al., 2012b, 2014a,b). In parallel, laboratory studies were also performed to establish better relationships between aquifer and MRS parameters (Stingaciu et al., 2010; Boucher et al., 2011; Costabel and Yaramanci, 2011, 2013), showing that MRS capacity can also be extended to the investigation of water percolation and storage in the vadose zone. Moreover, in hard rock aquifers and other heterogeneous geological medium, the new 3D MRS data acquisition and inversion (Legchenko et al., 2011; Chevalier et al., 2014) can make possible to retrieve the aquifer structures at the local scale, which may be of great help in solving critical issues for water supply and borehole sitting, as well as for understanding the hydraulic functioning of structurally complex aquifers. All these progresses confirm that the MRS technique can be used as a tool to routinely parameterize aquifers at lower cost than by drilling and pumping tests.

The coupled hydrological modeling approach is sophisticated and data demanding technique but, in return, provides a detailed assessment of surface and subsurface water fluxes and a better understanding of 
complex dynamics of hydrological systems than by applying standard, standalone groundwater models. This study proposes a novel hydrological conceptualization of coupled models of surface, unsaturated and saturated zones, involving numerical implementation of subsurface evapotranspiration built in the newly developed MARMITES code coupled with MODFLOW-NWT model (Chapter 5). The novelty of that conceptualization involves partitioning and sourcing of subsurface evapotranspiration, in which transpiration, in contrast to evaporation, is water table depth independent and driven mainly by the climatic conditions, while contributions of water sources (saturated or unsaturated zone) are dependent on water potential schematized by set of lumped parameters. The appropriate performance of MARMITES-MODFLOW was confirmed on the La Mata hard rock study case (Chapter 5) and validated against independent studies (van der Tol, 2012; Balugani et al., 2015; Reyes-Acosta, 2015 ) and states variables measured in the field (soil moisture and hydraulic heads). The capability of MARMITES-MODFLOW in integrating MRS method in the model calibration was also tested in the Carrizal sedimentary rock study case. The model-based optimization of the MRSestimates of aquifer hydraulic parameters turned to be very promising and created alternative to expensive pumping test parameterization.

As an open source code, the MARMITES model can be easily improved and modified. In future, it would be relevant to implement the following features: (i) currently, the transpiration assessment is lumped at the grid cell; it could be optionally attributed to each vegetation species in order to assess their individual impacts on water resources; (ii) the routing of surface water and the re-infiltration of produced runoff should be implemented in order to separate better surface runoff from groundwater runoff and introduce them as variables in the calibration process; (iii) more studies are required to define the vegetation parameters of the groundwater transpiration defined in Chapter 5; seasonal monitoring of sap flow, soil moisture, water potential and groundwater level at trees located in various topographical positions, such as drainage area and top of hill, may provide important information to calibrate the parameters of the novel groundwater transpiration function. In this study the application of remote sensing was limited to the extrapolation of the investigated property and to the mapping of terrain characteristics. However, remote sensing can also be used for quantitative, spatio-temporal assessment of soil moisture (Jackson et al., 1996; Houser et al., 1998) and evapotranspiration (Su, 2002) that can be directly integrated as input in the MARMITES model to constrain the calibration process.

Sensitivity analysis and uncertainties assessment related with the water fluxes and water balance retrieved by the coupled MARMITESMODFLOW model are still to be implemented. Automatic parameter optimization algorithm such as singular value decomposition and Tikhonov regularization, for instance applied in PEST (Doherty, 2015), and hybrid genetic algorithms (Başokur et al., 2007; Yao and Guo, 2014) should be applied in the MARMITES-MODFLOW calibration of catchment scale models. However, the practical implementation of such algorithms 
in standard personal computers is currently hardly feasible, as the optimization methods require many model runs and the running time of complex coupled models is very long. Alternative solutions based on parallel computing implemented on clusters of individual computers or on cloud computing using virtual machines are being developed (Hunt et al., 2010; Muffels et al., 2012; Welter et al., 2012; Fienen and Hunt, 2015), allowing this way to reduce drastically the total time of parameter optimization. It is expected that these solutions will allow in few years to compute routinely the crucial sensitivity analysis and uncertainties assessment of complex hydrological models. 


\section{Using Ground Penetrating Radar to investigate the groundwater table depth in weathered granites - Sardón case study, Spain}

\section{A. 1 Introduction}

Groundwater modeling is nowadays recognized as the best tool to support management of groundwater resources (Lubczynski and Gurwin, 2005b). Presently, information on the depth and movement of groundwater is collected from a limited number of often widely spaced, piezometers and observation wells (Bentley and Trenholm, 2002; Doolittle et al., 2006) to prepare the potentiometric map which can be used to estimate groundwater flow direction, flow velocities, and the location of discharge and recharge areas (Livari and Doolittle, 1994). These methods of data acquisition provide information in specific, drilled boreholes where access to groundwater is relatively easy. In that respect, ground penetrating radar (GPR) offers promising perspectives for high resolution, continuous and large scale characterization and monitoring of hydrological systems.

GPR has been primarily used to image the subsurface and detect buried objects (Annan, 2002; Lambot et al., 2008; Slob et al., 2010) by radiating electromagnetic waves into the ground and recording the reflections from boundaries of subsurface material having different electromagnetic parameters. Because of rapid rates of signal attenuation, the penetration depth of GPR is greatly reduced in soils that have high electrical conductivity (Doolittle et al., 2007). The amount of electromagnetic energy that is

This chapter is based on: Using ground penetrating radar to investigate the water table depth in weathered granites - Sardón case study, Spain. Mahmoudzadeh, M., A. Francés, M. Lubczynski, and S. Lambot (2012), Journal of Applied Geophysics, 79, 17-26. The author of this thesis participated or realized the following tasks: (i) acquisition, processing and interpretation of the ERT data; (ii) acquisition of the GPR and associated DGPS data; (iii) definition of the general methodology, which mainly consisted to interpret the field GPR data by comparing them with GPR forward models. 
reflected by an interface is dependent upon the electromagnetic contrast between the two media. The reflection coefficient of the subsurface represents the ratio between the reflected and incident fields. Abrupt boundaries that separate contrasting materials reflect more energy than gradual boundaries that separate layers with similar electrical properties (Lambot et al., 2004; Bano, 2006).

The dielectric constant of soil materials is principally dependent upon soil moisture but also varies to some extent with temperature, density, and frequency. In low conductive materials, the soil moisture is the major contributor to the soil dielectric constant (Bentley and Trenholm, 2002; Topp et al., 1980). Nakashima et al. (2001) showed that when there is water in a medium, like a groundwater layer, whose dielectric constant is quite different from the non-saturated media, it is possible to identify the medium within a multitude of ambiguous media. In coarse-textured soils, the capillary fringe is narrow (Doolittle et al., 2006) which typically leads to a strong radar reflection. While on the contrary, in fine-textured soil materials, the height of the capillary fringe is larger than in coarsetexture materials with a smooth transition between the dry and saturated soils. Bentley and Trenholm (2002) showed that GPR can measure the top of the capillary fringe and obtained an accuracy of $\sim 20 \mathrm{~cm}$ under favorable conditions. They also investigated most of the error sources on the estimation of the groundwater table depth (GWTD) and found that the main sources of uncertainty are due to GPR velocity estimates and predicting the height above the groundwater table of the capillary fringe reflection.

Our objectives in this research are: (1) to find the spatial distribution of the groundwater table depth in the granitic Sardón catchment (Spain) with the continuous coverage along a transect, (2) to investigate the ability of GPR to detect the reflection from the underlying fissured granite or bedrock and (3) to validate the GPR data using different geophysical techniques. In that respect, we used a pulse radar to collect the GPR data along 37 transects, with some of them crossing perpendicularly the streams of the Sardón river which was dry during the survey period. GPR simulations based on the stratigraphy of the Sardón subsurface were performed using GprMax2D (Giannopoulos, 2005) to provide some insights for better interpreting the radar images. Electrical resistivity tomography (ERT) was used along several GPR transects at the same period to investigate the groundwater table and the bedrocks. Soil sampling in the shallow surface was performed throughout the study area at the same period to give us information regarding the soil physical properties. The water level depth of the existent wells was used to verify the GPR results and calibrate the time-depth relation in the relevant GPR profiles. In order to estimate the shallow soil electrical properties, we used frequency domain reflectometry (FDR) for the profiles when the exact WTD information from the observation wells was not available. 


\section{A.2 Materials and Methods}

\section{A.2.1 The study area}

The Sardón catchment study site is located in the central-western part of Iberian Peninsula in Spain (Fig. A.1). The size of the catchment is $\sim 80$ $\mathrm{km}^{2}$ characterized by well defined boundaries. It has low human impact because of low human population. The study area has a fault line along the main stream of Sardon river and typical fractured granite rocks with standard hard rock hydrology (Lubczynski and Gurwin, 2005b).

The climate in Sardón is semi-arid and it is typical for the central part of the Iberian Peninsula. The 23-year mean rainfall, estimated on the base of 6 Spanish Meteorological Institute rain gauges located in the surroundings of the study area was $\sim 500 \mathrm{~mm}^{\text {year }}{ }^{-1}$. The warmest and the most dry months in this catchment are July and August when the average temperature is $\sim 22 \check{\mathrm{r} C}$ and rainfall is less than $20 \mathrm{~mm} . \mathrm{month}^{-1}$ (Lubczynski and Gurwin, 2005b). Sardón river is dry from mid-June to mid-October and in the rest of the year performs a role of a drain, specially for direct runoff. The land cover in Sardón is characterized by natural woody-shrub vegetation.

Granite compositions of the rocks influence on the geology and hydrogeology in the study area. The hydrology of Sardón is strongly influenced by weathering and fracturing process. We can generally recognize three hydrogeological layers in Sardón catchment. The top layer which is not consolidated because of the weathered and alluvial deposits, has a thickness on average 0-5 $\mathrm{m}$ up to $10 \mathrm{~m}$ (Lubczynski and Gurwin, 2005b). The soil texture of this layer is coarse which includes $52-90 \%$ sand, $7-26 \%$ silt, and $4-22 \%$ clay obtained by soil sampling. Calculating the transition zone and capillary fringe for this type of soil led to $\sim 10 \mathrm{~cm}$ thickness which is negligible compared to our used GPR signal wavelength. The second layer is fractured granite with intercalations of granodiorites, schists, gneises and quartzites that straggly outcrops in the study area (Lubczynski and Gurwin, 2005b). The thickness of this layer varies between $\sim 60$ $\mathrm{m}$ in the central part of the catchment to a few meters in the upland areas (Lubczynski and Gurwin, 2005b). Last layer is massive granite with some gneiss inclusions that has formed impermeable rock basement. This layer is deepest in the center of catchment and near the Sardón boundaries is shallowest and can outcrop locally (Fig. A.2). The groundwater table as typical for granitic areas is shallow and mostly occurs in unconsolidated rocks.

\section{A.2.2 Data acquisition}

We used a time-domain GPR system (model SIR-20, Geophysical Survey Systems, Inc., GSSI, Salem, Massachusetts, USA) combined with a transmitting and receiving $200 \mathrm{MHz}$ shielded bowtie antenna as an impulse radar and a survey wheel for positioning. The used configuration type for our survey provided 512 samples/scan and each sample included 16 bits 


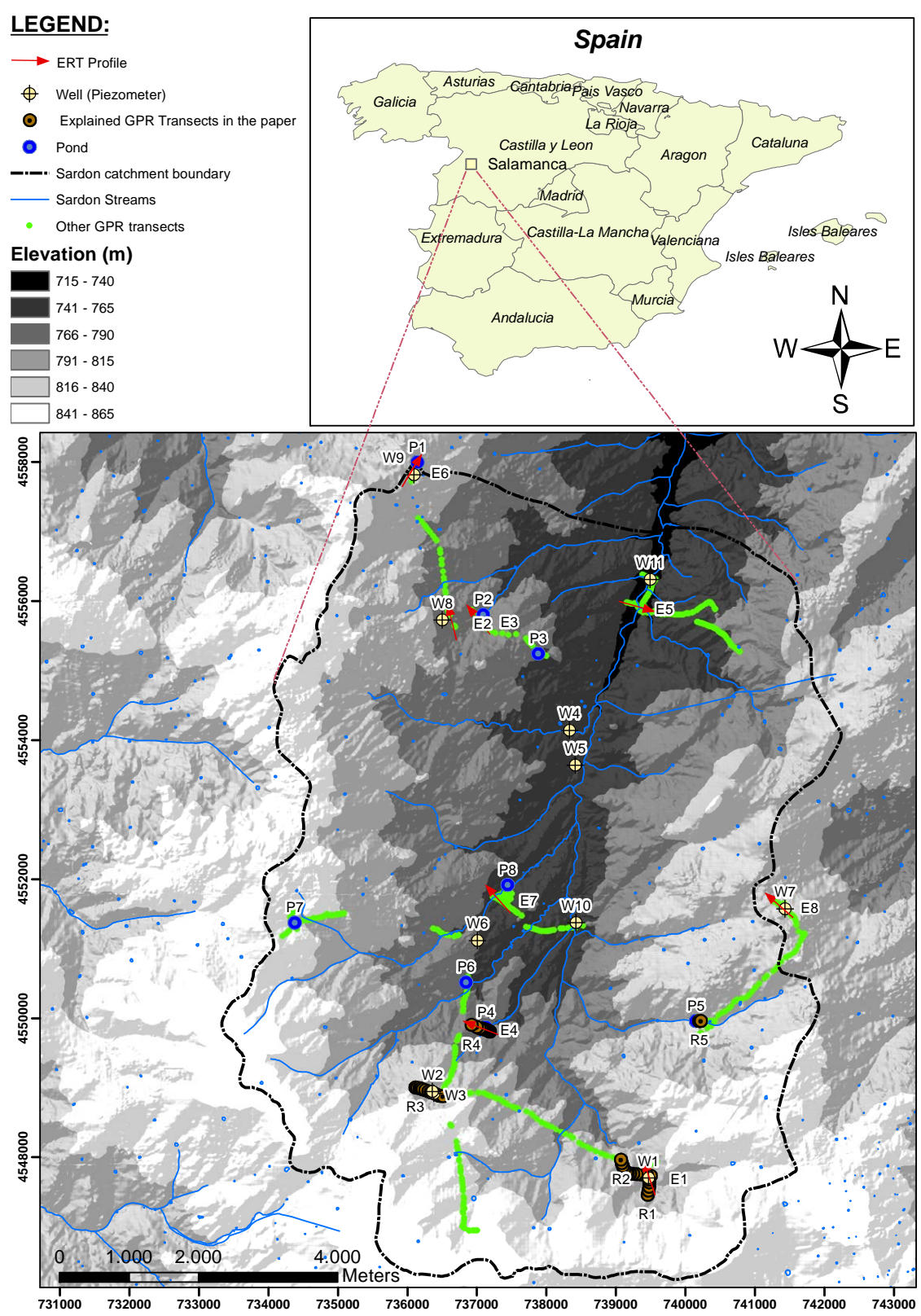

Figure A.1: Location of the study area (Sardón catchment, Salamanca, Spain) and the GPR profiles. The blue solid lines represent the Sardón streams which were dry during the survey period, the green meshes show the GPR profiles while the brown meshes show the GPR profiles which are discussed in this chapter, cream crossed and blue circles show the location of wells and ponds, respectively, and the red arrows show the location and direction of the ERT profiles. Abbreviations: $\mathrm{R}=\mathrm{GPR}$ profile, $\mathrm{E}=\mathrm{ERT}$ profile, $\mathrm{W}=$ well, and $\mathrm{P}=$ pond. 


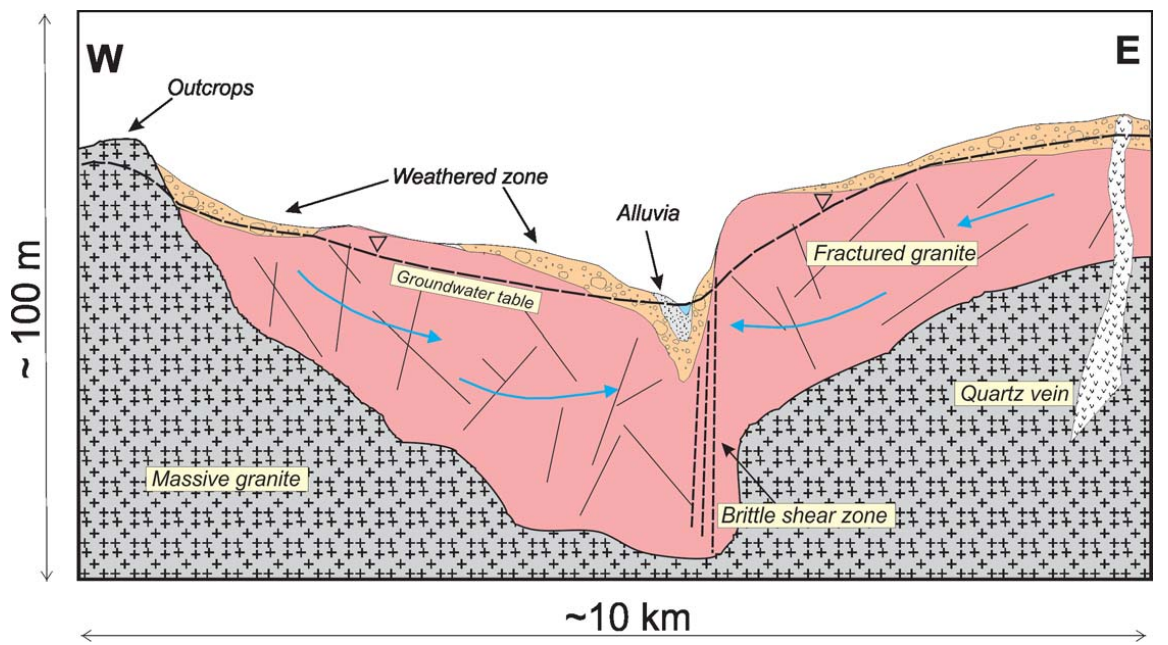

Figure A.2: Schematic of E-W cross-section of the Sardón catchment based on 3-layered granite compositions (Lubczynski and Gurwin, 2005b).

to record. GPR produces a Ricker-type pulse with frequency bandwidth of 50-600 MHz. Gain functions were applied to highlight subsurface reflections and practically the time window was limited to $100 \mathrm{~ns}$ in order to get better contrasted and less noisy signals.

The reasons for choosing a $200 \mathrm{MHz}$ antenna are:

1. Bano (2006) showed that the transition zone above the groundwater table has significant effects on the GPR reflections. The groundwater table reflection is the reflection from the top of the capillary fringe (Bentley and Trenholm, 2002). This reflection can be affected by the transition zone, and the reflection contrast decreases by decreasing the wavelength (increasing the antenna frequency, up to $1200 \mathrm{MHz}$ ). Therefore groundwater table can not be seen even if shallow for relatively high frequencies.

2. Harari (1996) showed that the groundwater table can be detected easily with a judicious selection of the antenna frequency and he observed that the lower frequency antenna (100 MHz) was more effective for locating the groundwater table, but the higher resolution of the $500 \mathrm{MHz}$ antenna was more suitable for delineating the wetting fronts and visualizing the cross-strata.

3. Annan (1991) suggested to use the longer wavelength (lower frequency) antenna for groundwater table detection, because he pointed out when the ratio between the thickness of the transition zone and the wavelength exceeds 0.3 , the amplitude of the reflected wave is significantly low and the groundwater table reflection can not be seen.

Equation (A.1) describes how to choose the GPR center frequency $(f)$ as a function of the transition zone thickness $\left(h_{T}\right)$ and the averaged soil 
dielectric constant $\left(\varepsilon_{r}\right)$. In this equation $R$ illustrates the Annan's ratio ( $R=0.3$ ) (Annan, 1991) where $\lambda$ and $c$ are the GPR effective wavelength and the speed of the light in free space, respectively.

$$
\left.\begin{array}{c}
\frac{h_{T}}{\lambda}<R \\
\lambda=\frac{c}{f \sqrt{\varepsilon_{r}}}
\end{array}\right\} \Rightarrow f<\frac{R . c}{h_{T} \sqrt{\varepsilon_{r}}}
$$

Therefore if we assume that for the worst case the thickness of the transition zone in Sardón catchment equals to $20 \mathrm{~cm}$, the wavelength should be larger than $67 \mathrm{~cm}$ (Equation (A.1)). This means that assuming a soil dielectric constant of 5 (average soil dielectric constant for the ground surface in Sardón), the antenna center frequency should be less than $\sim 200 \mathrm{MHz}(f<201.25 \mathrm{MHz})$.

The main unit combined with a differential GPS (dGPS) from Leica (model GPS1200) was mounted on a jeep (Fig. A.3(Left)). In order to reduce the undesired reflections, the antenna was located relatively far from the jeep $(\sim 12 \mathrm{~m})$. In total the 37 transects were realized within 4 days and for each transect the coordinates were recorded manually by dGPS in a number of points of a transect. The shortest transect was about $14 \mathrm{~m}$ and the longest one was about $3 \mathrm{~km}$. Eleven monitoring wells and 7 observation ponds that were located sparsely in the study area, helped us to measure and validate the elevation of the groundwater table (Fig. A.3(Right) and A.4). The WTD in the wells was measured using a piezometer sensor (Fig. A.4) and the results are summarized in Table A.1.
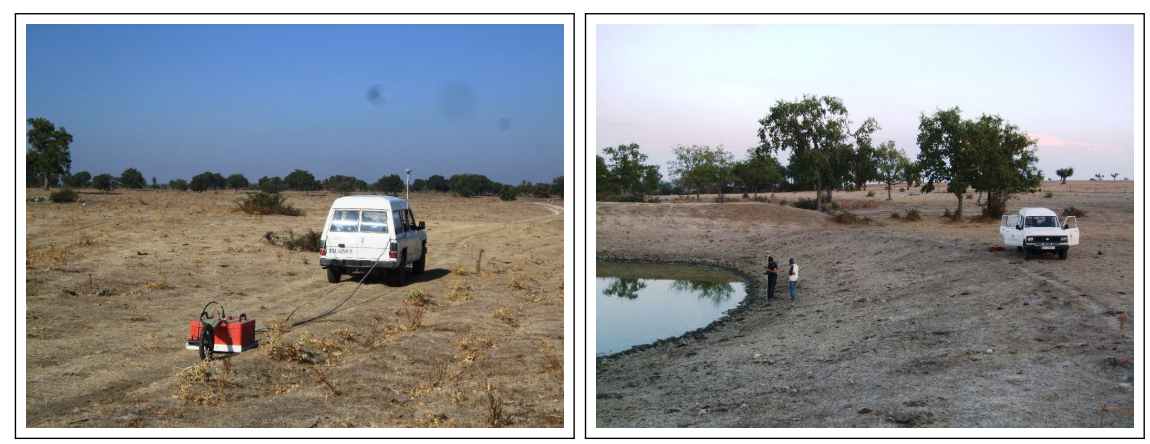

Figure A.3: (Left) Combined GPR and dGPS equipments used in the Sardón study. (Right) The shallow groundwater table is visible in a pond.

In order to measure both the dielectric constant and electrical conductivity of the shallow soil, the Hydra-probe soil sensor (Stevens Water Monitoring Systems, Inc., Beaverton, Oregon, USA), which is a frequency domain reflectometry system (FDR) applying $50 \mathrm{MHz}$ electromagnetic waves (Blonquist et al., 2005), was used.

For performing the electrical resistivity profiles, we used the AGI Supersting R8 system with external switch box and 56 stainless steel 
Table A.1: GWTD in the wells and ponds in Sardón. For the location of each one refer to Fig. A.1.

\begin{tabular}{lcccc}
\hline ID & Type & GWTD $(\mathrm{m})$ & Groundwater Table elevation $(\mathrm{m})$ & Bottom depth $(\mathrm{m})$ \\
\hline & & & & \\
W1 & well & 2.10 & 794.88 & 7.9 \\
W2 & well & 0.00 & 803.50 & 1.6 \\
W3 & well & 1.51 & 802.86 & 2.00 \\
W4 & well & 1.94 & 742.13 & 2.75 \\
W5 & well & 3.23 & 739.92 & Not Measured \\
W6 & well & 2.50 & 761.82 & 3.13 \\
W7 & well & 1.99 & 803.70 & 3.36 \\
W8 & well & dry & dry & 1.08 \\
W9 & well & 2.58 & 805.69 & 3.65 \\
W10 & well & dry & dry & 1.53 \\
W11 & well & 1.00 & 733.35 & 1.8 \\
P1 & pond & 1.61 & 806.39 & Not Measured \\
P2 & pond & 2.27 & 764.04 & Not Measured \\
P3 & pond & 4.11 & 760.71 & Not Measured \\
P4 & pond & 1.34 & 765.67 & Not Measured \\
P5 & pond & 2.01 & 791.69 & Not Measured \\
P6 & pond & 1.42 & 763.11 & Not Measured \\
P7 & pond & 2.21 & 814.34 & Not Measured \\
P8 & pond & 1.56 & 750.35 & Not Measured \\
\hline
\end{tabular}

electrodes as an ERT system, using the Schlumberger configuration. The electrode spacing was set between 3 and 5 meters which led to 165 and 275 meters profile lengths.

\section{A.2.3 Data processing}

\section{A.2.3.1 GPR}

Variable range gain functions were applied to the data to strengthen deeper reflections. In particular, the automated range gain function of the system was removed and a power gain function (typically $t^{2.5}$ ) was applied. To reduce the effect of the undesired signals such as noise and clutter, a band pass frequency filter was applied to most datasets, with a bandwidth of 95-300 MHz. Y-axis was also transformed to depth instead of travel time using Equation (A.2) for all profiles. In this 


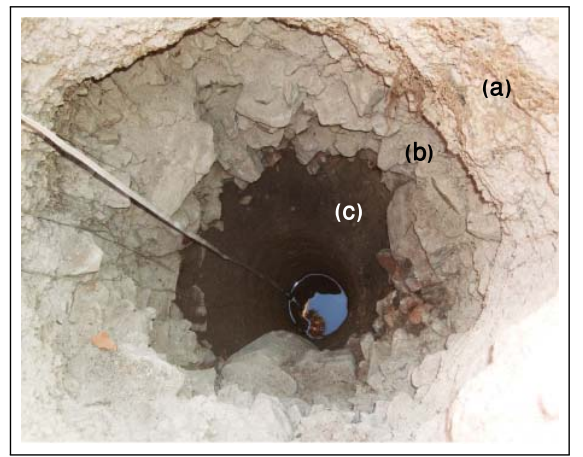

Figure A.4: A well from Sardón study case that shows an example of hydrostratigraphy of a part of Sardón including the saturated zone (W7 well, Fig. A.1). (a) dry soil (coarse-texture). (b) dry pebbles. (c) weathered granite.

equation, $d_{t}$ and $t$ illustrate depth and 2-way travel time, respectively. It is worth noting that for time-depth transformation we used the value of shallow soil dielectric constant where the exact GWTD information from the observation wells was not available. Otherwise this equation was conversely used to estimate the averaged $\varepsilon_{r}$ for the profiles crossing the wells or ponds where GWTD is known.

$$
d_{t}=\frac{c . t}{2 \sqrt{\varepsilon_{r}}}
$$

In order to distinguish the shallow bedrock reflections from the surface reflection, the simple background removal technique was applied to the relevant GPR profiles using

$$
B^{\prime}(x, t)=B(x, t)-\frac{1}{N} \sum_{n=1}^{N} B\left(x_{n}, t\right)
$$

where $B(x, t)$ is the raw GPR B-scan as a function of position $x$ and time $t$ and $B^{\prime}(x, t)$ is the GPR B-scan which the average background has been subtracted while $N$ indicates the total number of scans in the B-scan.

As the altitude of the soil surface provides valuable information regarding the hydrological behavior of the catchment, the GPR profiles were plotted with respect to altitude as provided by the dGPS system. In order to compare the GPR profile with the existed ERT profile using the same scale in $\mathrm{x}$-axis, the desired part of the profile was focused by cropping the beginning or ending of the profile.

\section{A.2.3.2 ERT}

Inversions were done using AGI EarthImager2D http://www.agiusa. com/agi2dimg. shtm7). Data editing was an important issue to filter the 
noisy data of the ERT dataset and to insure the most reliable inversion. We first graphed the contact resistance measured during the current injection at each electrode. A contact resistance value of over $10000 \Omega$ indicates unacceptable data quality. Acceptable values are less than 5000 $\Omega$, ideally less than $2000 \Omega$. We selected and removed the electrodes with all values $>10000 \Omega$ and proceeded with the inversion using the robust method and with no limit in the resistivity bounds. The robust inversion was chosen since it was expected sharp boundaries between the unsaturated and saturated zone and between weathered granite or soil and fresh granite. After the first inversion, we removed all points with misfit (RMSE > 50\%) and proceeded again the inversion.

The ERT images were obtained by the 2-dimensional cubic interpolation of the inverted profiles and plotting with respect to altitude as provided by the dGPS. In order to compare the ERT profile with GPR profile using the same scale in $\mathrm{x}$-axis, the desired part of the profile was focused by cropping the beginning or ending of the profile.

\section{A.2.4 GPR simulations}

In order to provide valuable insights for the radar data interpretation, and in particular better recognize the saturated zone reflection in the GPR images, we used GPR forward modeling by means of GprMax2D software V 1.5 (Giannopoulos, 2005) to model the sublayers and the GPR reflections. GprMax2D applies the Finite-Difference Time-Domain method to solve numerically Maxwell's equations. For modeling the case study, we used the hydrolayer properties summarized in Table A.2. We considered a $4 \mathrm{~cm}$ distance between the GPR antenna phase centers (source and receiver) and the ground surface, with a source-receiver offset of $33 \mathrm{~cm}$. The cell size of the numerical models was assigned $2 \times 2 \mathrm{~cm}$. We used a Ricker pulse with $200 \mathrm{MHz}$ center frequency as an excitation source. The time window was limited to $100 \mathrm{~ns}$ as for the field data. A power gain function of time with a factor 2.5 was applied to better observe the later reflections compared to the surface reflection. 
Table A.2: Measured hydrolayer parameters considered for GPR simulations. The electromagnetic parameters were measured using Hydra-probe soil sensor and the thicknesses were measured using drilling and ERT methods.

\begin{tabular}{|c|c|c|c|c|c|c|c|c|c|c|}
\hline \multirow[t]{2}{*}{ Layer } & \multirow[t]{2}{*}{ Stratigraphy } & \multicolumn{3}{|c|}{$\sigma\left(\mathrm{mS} . \mathrm{m}^{-1}\right)$} & \multicolumn{3}{|c|}{$\varepsilon_{r}$} & \multicolumn{3}{|c|}{ Thickness (m) } \\
\hline & & $\min$ & $\max$ & value & $\min$ & $\max$ & value & $\min$ & $\max$ & value \\
\hline Unsaturated soil & $\mathrm{A}$ & 0.67 & 2.00 & 1.43 & 3 & 9 & 5 & 0.0 & 3.0 & 2.0 \\
\hline Saturated soil & $\mathrm{A} 1$ & 10.0 & 100 & 20.0 & - & - & 25 & 0.0 & 6.0 & 1.0 \\
\hline Unsaturated soil pebbles & B & 1.33 & 5.00 & 2.00 & 7 & 9 & 8 & 0.1 & 0.5 & 0.5 \\
\hline Saturated soil pebbles & $\mathrm{B} 1$ & 13.33 & 200 & 20.0 & - & - & 20 & 0.1 & 0.5 & 0.0 \\
\hline Unsaturated weathered-granite & $\mathrm{C}$ & 1.00 & 2.00 & 1.25 & 5 & 15 & 7 & 0.0 & 2.0 & 1.0 \\
\hline Saturated weathered-granite & $\mathrm{C} 1$ & 2.50 & 5.00 & 4.00 & - & - & 27 & 5.0 & 50.0 & 10.0 \\
\hline Hard-granite & $\mathrm{D}$ & 0.20 & 0.67 & 0.50 & - & - & 4 & - & - & 100 \\
\hline
\end{tabular}




\section{A.3 Results and interpretations}

\section{A.3.1 Semi-homogenous layering}

GPR profile R1 is located in South-East of the study area with S-N orientation and $263 \mathrm{~m}$ long. Observation well (W1), digging, and sampling in this region show a semi-homogenous layering with 4 different geological layers including $\sim 1 \mathrm{~m}$ sandy-loam (76\% sand, $17 \%$ silt, and $7 \%$ clay), $\sim 0.5-\sim 1$ $\mathrm{m}$ soil pebbles, and both unsaturated and saturated weathered granite (Fig. A.4). Figure A.5(b) represents the simulated GPR signal using corresponding configuration shown in Fig. A.5(a) also modeling the capillary fringe with a height of $6 \mathrm{~cm}$. The observed groundwater table reflection at $\sim 48 \mathrm{~ns}$ travel time shows the highest amplitude compared to other reflections above it. Figure A.5(c) shows a part of this GPR profile which crosses the well W1. In order to transform the time axis to the depth we applied Equation (A.2) using the averaged dielectric constant value of 5 obtained by means of Hydra-probe soil sensor. This GPR profile was processed using the processing procedure explained in the Section A.2.3.1. W1 is located at position $78 \mathrm{~m}$ of the profile which has a water level depth of $2.10 \mathrm{~m}$ measured using the piezometer sensor. This water level on the cross-plot indicates the strong reflections ranging between 2-3 m potentially due to the local groundwater table because: (1) based on GPR simulation this reflection is the strongest one after applying the gain, (2) the groundwater table follows the topography smoothly, and this reflection is almost horizontal in this part, and (3) the center of this reflection (negative amplitude) satisfies W1 water level and also shows a good agreement of changing the pressure head around the well which leads to rise the capillary fringe. Figure A.5(d) shows a part of ERT profile E1 with almost the same orientation of R1 (N20W) and electrode spacing of $3 \mathrm{~m}$. This profile shows 3 different layers which are: (1) the resistive unsaturated zone with a resistivity of $1000 \Omega . \mathrm{m}$ and above which is dry and composed by alluvium material with $\sim 2 \mathrm{~m}$ thickness (the shallowest layer after $25 \mathrm{~m}$ along x-axis), (2) slightly saturated weathered granite with a resistivity of less than $200 \Omega . m$, and (3) gradual transition of saturated weathered granite to less weathered granite with lower water content and the resistivity between 200-1000 $\Omega . \mathrm{m}$ along the profile after $25 \mathrm{~m}$ (starting below $\sim 10 \mathrm{~m}$ ). Comparison of the ERT and GPR profiles shows that the groundwater table reflection is mixed with the weathered granite reflection specially at $\mathrm{x}>44 \mathrm{~m}$ which can lead to an uncertainty of $\sim 1 \mathrm{~m}$ in detecting the groundwater table reflection. The ERT profile also shows that in interval of $0-5$ and $26-33 \mathrm{~m}$ the transition zone is shallow and wide leading to less reflection contrast in the GPR profile. The simulated and measured GPR profiles also show that the geological contact between soil and granite is less visible due to the existence of the shallow groundwater table. 

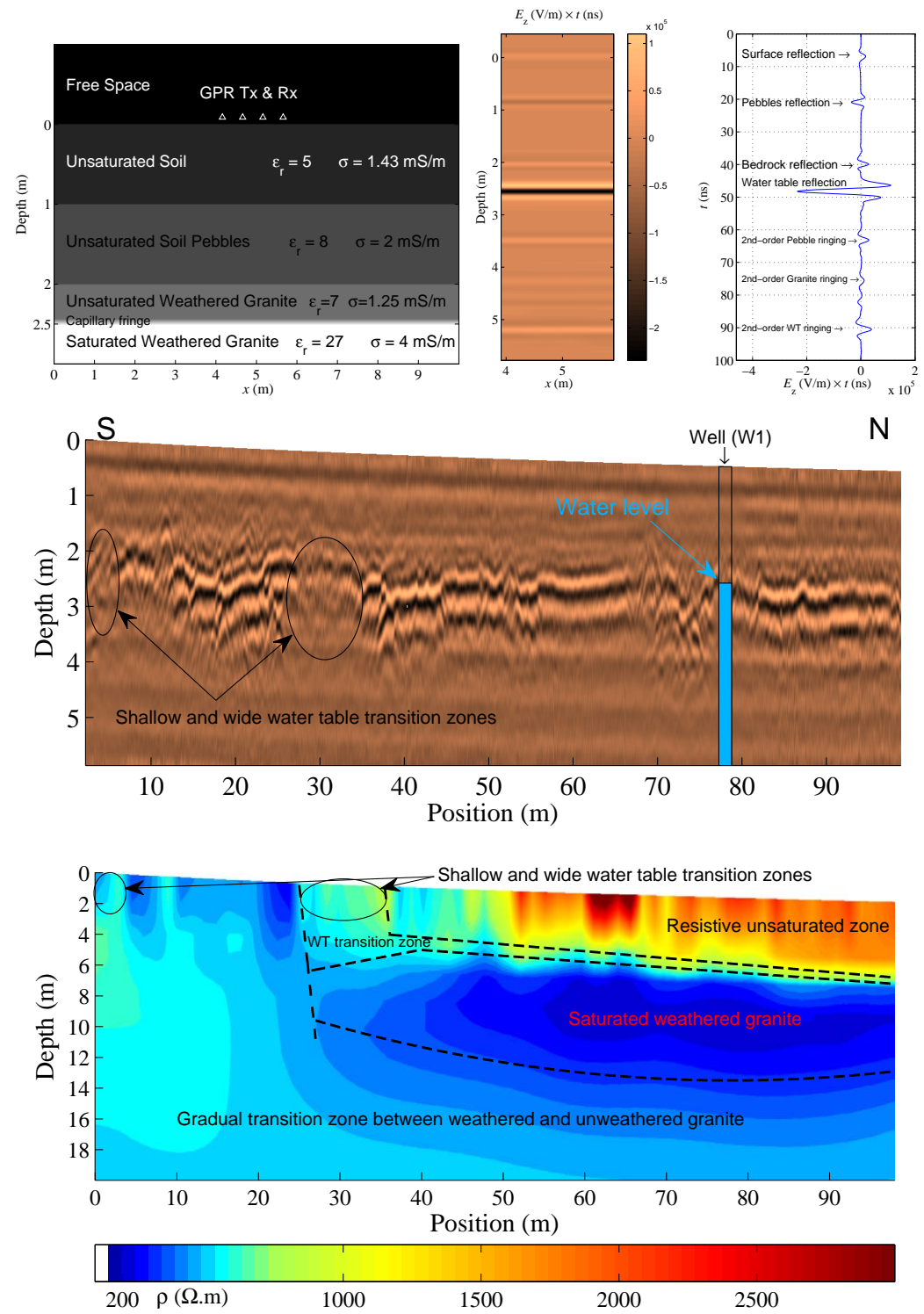

Figure A.5: GPR and ERT profiles (R1 and E1) are located at South-East of with S-N orientation crossing the well W1 (2.10 m of water level depth). (a) The used configuration for GprMax2D, (b) Gained simulated signal, (c) The cropped and processed GPR profile R1 using a dielectric constant equals to 5 inferred from a FDR measurement performed at $\sim 80 \mathrm{~m}$ along the profile, (d) The cropped and processed ERT profile E1. 


\section{A.3.2 Heterogeneity effect}

Figure A.6(c) shows GPR profile R2 obtained by following R1 with E-W orientation until $312 \mathrm{~m}$ in $\mathrm{x}$-axis and S-N orientation from there to the end of profile. The length of this profile is $552 \mathrm{~m}$ and it crosses the hill. The hill has $8.17 \mathrm{~m}$ height and $\sim 350 \mathrm{~m}$ width with the left hillside slope of $\sim 5.14 \check{\text { r }}$ and right hillside slope of $\sim 3.09 \check{r}$. R2 was processed same as $\mathrm{R} 1$ and it also crosses the well W1. We used the dielectric constant value of 5 for time-depth transformation. This profile shows a heterogeneous section of . Figure A.6(a) illustrates the nonhomogeneous configuration which was simulated for this area. The modeled configuration is the same as R1 configuration by replacing the homogeneous pebbles layer with a nonhomogeneous one. 200 cylinders with random size between $10-30 \mathrm{~cm}$ diameter and random location with a cave shape and limited boundary were created to define the nonhomogeneous pebbles layer. Also capillary fringe was modeled with $8 \mathrm{~cm}$ height. Figure A.6(b) shows the B-scan and A-scan of the simulated signal. B-scan is illustrated in depth using a value of 5 for $\varepsilon_{r}$ (the dielectric constant value of the first layer). The groundwater table reflection is visible around 2-2.3 $\mathrm{m}$ depth. Although the groundwater table layer is modeled parallel to the surface, the groundwater table reflection is not smooth because of the effect of the heterogeneity of pebbles layer. Also this heterogeneity affects on the ringings and bedrock reflection, i.e., the bedrock reflection is not visible in B-scan and some ringings after groundwater table reflection appears.

Thanks to the background removal technique, the reflection in Fig. A.6(c) which is highlighted with the red dashed line shows the weathered/fractured bedrock. Referring to the drilled well W1 (Fig. A.4), it shows that the fractured granite in this region is shallow (less than $1.5 \mathrm{~m}$ depth) and covered with pebbles. Also W1 shows that the weathered-fractured bedrock is saturated with water level of $2.10 \mathrm{~m}$ depth. Figure A.6(d) focuses on the $70 \mathrm{~m}$ of the left hillside also showing W1 as a cross-plot. The significant reflections observed around 2-3 $\mathrm{m}$ depth corresponded to the mixed saturated sublayer and bedrock reflections. The reflections are not horizontal probably due to the heterogeneity of the pebbles layer.

\section{A.3.3 The effect of fractures in the saturated granite}

R3 is another GPR profile which was carried out in South-West of with $\mathrm{W}$-E orientation and $418 \mathrm{~m}$ long. In that area, the fractured granite is shallow and saturated ( $\sim 1.5 \mathrm{~m}$ depth). Figure A.7(c) shows the processed profile using topography correction and background removal. This profile crosses 2 wells, namely, W2 and W3. The well W2 which is not deep enough has $0 \mathrm{~m}$ GWTD (not dry), $1.6 \mathrm{~m}$ bottom depth and 803.50 $\mathrm{m}$ groundwater table elevation while W3 has $1.51 \mathrm{~m}$ GWTD, $2.00 \mathrm{~m}$ bottom depth, and $802.86 \mathrm{~m}$ groundwater table elevation. The distance between those wells is $29 \mathrm{~m}$ with a $32 \mathrm{~cm}$ difference in the location elevation. The groundwater table reflection and cross-plot of the wells are shown in the Figure as well. For time-depth transformation, a dielectric 

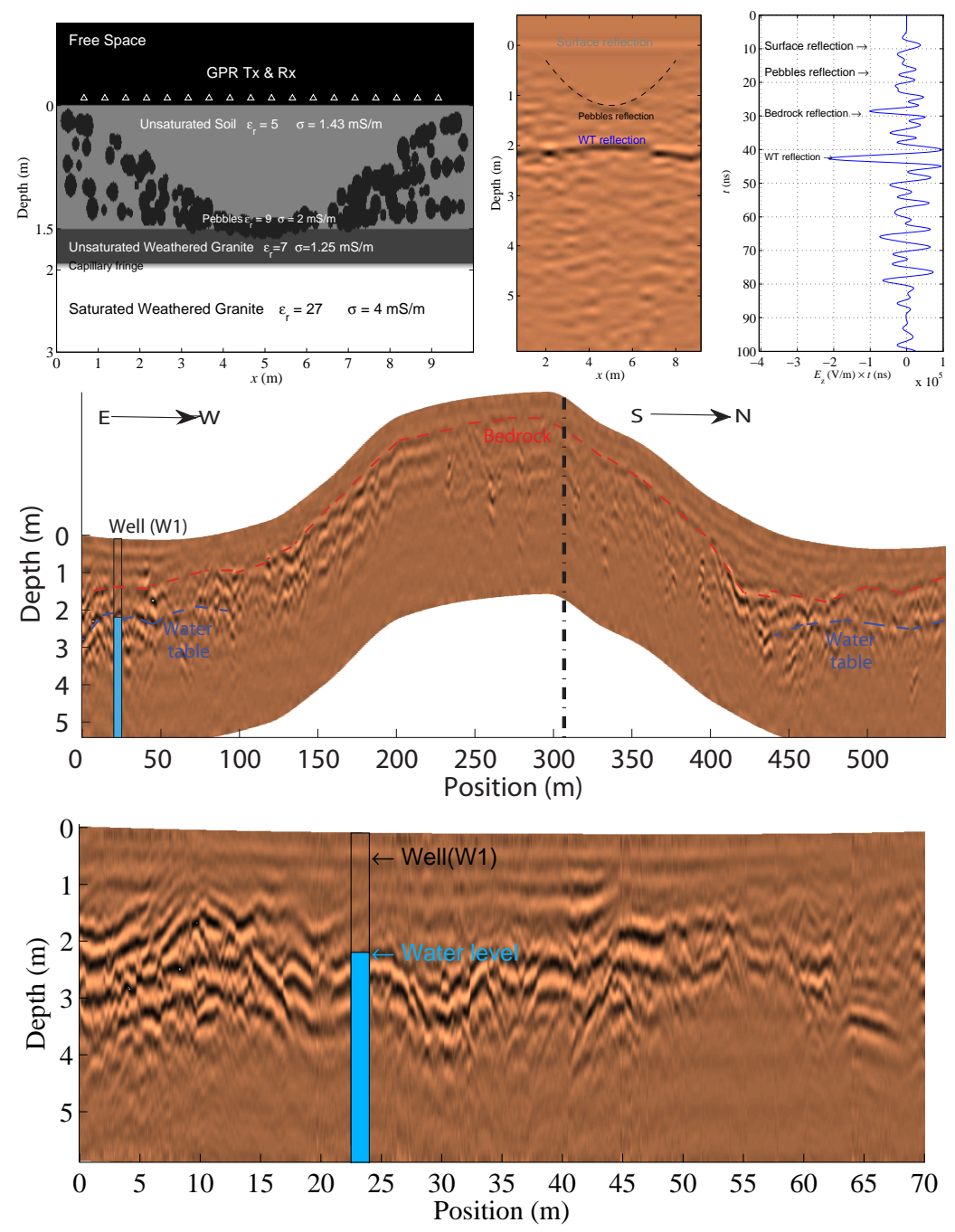

Figure A.6: GPR profile (R2, $552 \mathrm{~m}$ long) is located at South-East of along a E-W orientation until middle and S-N orientation from middle to the end crossing W1 well (2.10 m water level depth). (a) The used configuration for GprMax2D, (b) Gained simulated signal, (c) The GPR profile R2 (focusing on the bedrock reflection) processed using a dielectric constant equals to 5 inferred from a FDR measurement performed at $\sim 25$ $\mathrm{m}$ along the profile, (d) The $70 \mathrm{~m}$ cropped and processed $\mathrm{R} 2$ focused on groundwater table reflection around the W1 well. 
constant value of 6.42 was practically obtained to fit the groundwater table reflection and existent water levels in the wells (using Equation A.2, conversely). In order to better understand the effect of the saturated fractured granite, a relevant configuration was modeled including $1 \mathrm{~m}$ soil layer, $70 \mathrm{~cm}$ weathered granite layer, and saturated fractured granite using 400 horizontal tiny fractures randomly located in the relevant layer. Figure A.7 $(\mathrm{a}, \mathrm{b})$ show the configuration and simulated B-scan and A-scan GPR data, respectively. The result of this simulation shows whenever the fractured granite contains water, multiple reflections may occur (Fig. A.7(b)). These multiple reflections may be caused due to the formation of waveguides for the short wavelengths. Mostly the wavelength inside the water is reduced by a factor of nine as compared to the wavelength in the air. These multiple reflections are visible along almost the entire profile. In the position range of 230-300 $\mathrm{m}$ the multiple reflections are more visible and stronger probably because of the presence of the fractured granite in this zone, i.e., the bedrock is more fractured in this part.

\section{A.3.4 The clay effect}

In the south part of near the pond P4, the GPR profile R4 was carried out with $290 \mathrm{~m}$ long and NW-SE direction. Also in this area the ERT profile E4 was carried out with $275 \mathrm{~m}$ long (5 m electrode spacing for 56 electrodes) and the same direction as R4. In order to match the GPR and ERT profiles, they were cropped in $\mathrm{x}$-axis for $265 \mathrm{~m}$ long. $\mathrm{R} 4$ was processed in the same way as R3 and for time-depth transformation $\varepsilon_{r}=5$ was used practically. The profiles cross a dry stream at $65 \mathrm{~m}$ in x-axis. The lowest and highest elevations are separated by $9.48 \mathrm{~m}$ along $120 \mathrm{~m}$ long which leads to an average $4.52 \check{r}$ slope for the uphill. The stream channel is filled with alluvium material and had a low water content during the survey period. Figure A.8(b) shows E4 and illustrates a high conductive area of . Soil sampling showed that this area is covered by weathered granite with heavy clay which leads to a resistivity of $\sim 25 \Omega$.m. E4 also shows the weathered/fractured granite at a depth of $>12 \mathrm{~m}$ with maximum resistivity of $350 \Omega$.m. This amount of resistivity may refer to saturation of the bedrock. The pond $\mathrm{P} 4$ is close to the location of $70 \mathrm{~m}$ in the $\mathrm{x}$-axis of the profile and had $1.34 \mathrm{~m}$ GWTD (Table A.1) which shows that the groundwater table in this region is relatively shallow. Because of the existence of the clay in the soil of this region capillary fringe rise is high and leads to no sharp boundary for distinguishing the groundwater table as well for R4 GPR profile which is shown in Fig. A.8(a). Nevertheless, there are a few different patterns in both ERT and GPR profiles which are discussed in the following. (1) At the beginning part of E4 a transverse boundary is visible which separates a high conductive part $(<50 \Omega . \mathrm{m})$ and a relatively shallower less conductive part $(>120 \Omega$.m). This transverse boundary leads to a transverse reflection on R4 starting at the depth of $1.35 \mathrm{~m}$ (the expected depth of groundwater table referring to P4) and ending $\sim 4 \mathrm{~m}$ depth. This pattern may refer to a different soil texture. (2) A shallow vertical high conductive layer is visible at $\mathrm{x}=45 \mathrm{~m}$ of $\mathrm{E} 4$ which 

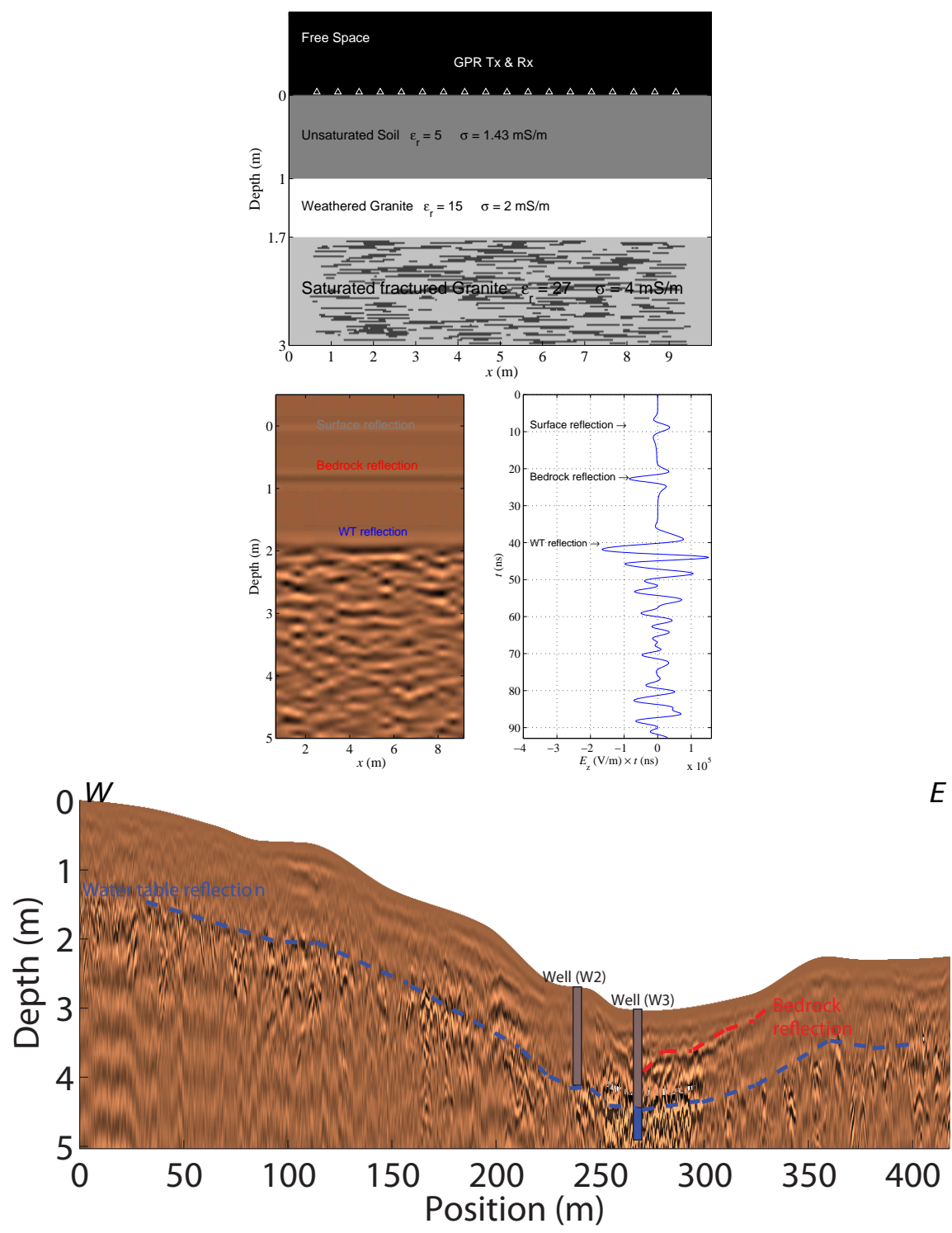

Figure A.7: GPR profile (R3, $418 \mathrm{~m}$ long) from West to East located in South-West of crossing 2 wells and saturated fractured granite zone. (a) The used configuration for GprMax2D, (b) Gained simulated signal, (c) The processed GPR profile R3 using a dielectric constant equals to 6.42 inferred manually by fitting the GWTD of the wells (W2 and W3) and the strong continuous reflection at $\sim 23 \mathrm{~ns}$. 
leads to almost a strong multiple reflections in R4 at the same location and which starts at the depth of $0.5 \mathrm{~m}$. (3) Crossing the stream bed at $65 \mathrm{~m}$ location leads to a different pattern in E4 because of soil textural difference in stream bed compared to the adjacent areas. Thanks to less clay content of this part, the groundwater table reflection is sharp and visible at the depth of $1.35 \mathrm{~m}$ on R4 profile. We used this reflection and P4 GWTD to estimate the averaged soil dielectric constant $\left(\varepsilon_{r}=5\right)$. (4) A high conductive soil exists at the location around $190 \mathrm{~m}$ (resistivity is less than $10 \Omega . \mathrm{m}$ ) which is relatively close to the surface (E4, Fig. A.8(b)). $\mathrm{R} 4$ shows a shallow and sharp reflection at this location which is stronger than adjacent reflections. (5) At the end of ERT profile after the location of $245 \mathrm{~m}$ an abrupt changing on the soil texture appears (resistivity higher than $200 \Omega . m$ ). This changing of the soil texture leads to less capillary rise because of less clay content. A reflection at $1.35 \mathrm{~m}$ depth is visible on R4 of this part which is horizontal and may be attributed to the groundwater table, as compared to the groundwater table reflection at $\mathrm{x}=70 \mathrm{~m}$. The reflection around $3 \mathrm{~m}$ depth up to bottom along almost the entire profile may be caused by the groundwater table ringing and high attenuation of GPR signals. These profiles show that clay content strongly affects the detection of the groundwater table.

\section{A.3.5 GPR data validation and uncertainties}

We represented the topography correction in the GPR data processing section and we used it for all the GPR profiles. However, the length of the GPR profiles are too long leading to sweep a number of different soil types and layering in each profile and therefore making it difficult to elucidate the local horizontal reflections. Also due to the lateral variability in the soil types, the time-depth transformation of the GPR data is critical once using a unique dielectric constant for an entire profile. In that respect we decided to sweep a short transect containing the known GWTD and with a gradient in the altitude. Figure A.9(b) shows the GPR profile R5 (located in the east-south of the study area with $21 \mathrm{~m}$ long) that we obtained close to the pond P5 to evaluate the groundwater table reflection in the GPR data. The Hydra-probe was used in 3 points along the profile to collect the electromagnetic properties of the shallow soil and showed a spacial surface dielectric constant variability of 3-24. The processed GPR profile by means of only topography correction and background removal is shown in the figure. The dielectric constant value of 3.1 (from the surface of the highest part of profile obtained by FDR) was used for timedepth transformation. The continuous and almost horizontal reflection belonging to the groundwater table is clear along the entire profile. Close to the pond because of changing in the pressure head, the top of the capillary fringe rises and leads to a groundwater table reflection gradient in the profile as shown in the 0-7 m of x-axis. In order to evaluate the depth accuracy of the detected reflection and find the total uncertainty of GWTD detection coming from FDR, dGPS and time-depth transformation method we used 2 points along the profile. The points are located at 9 


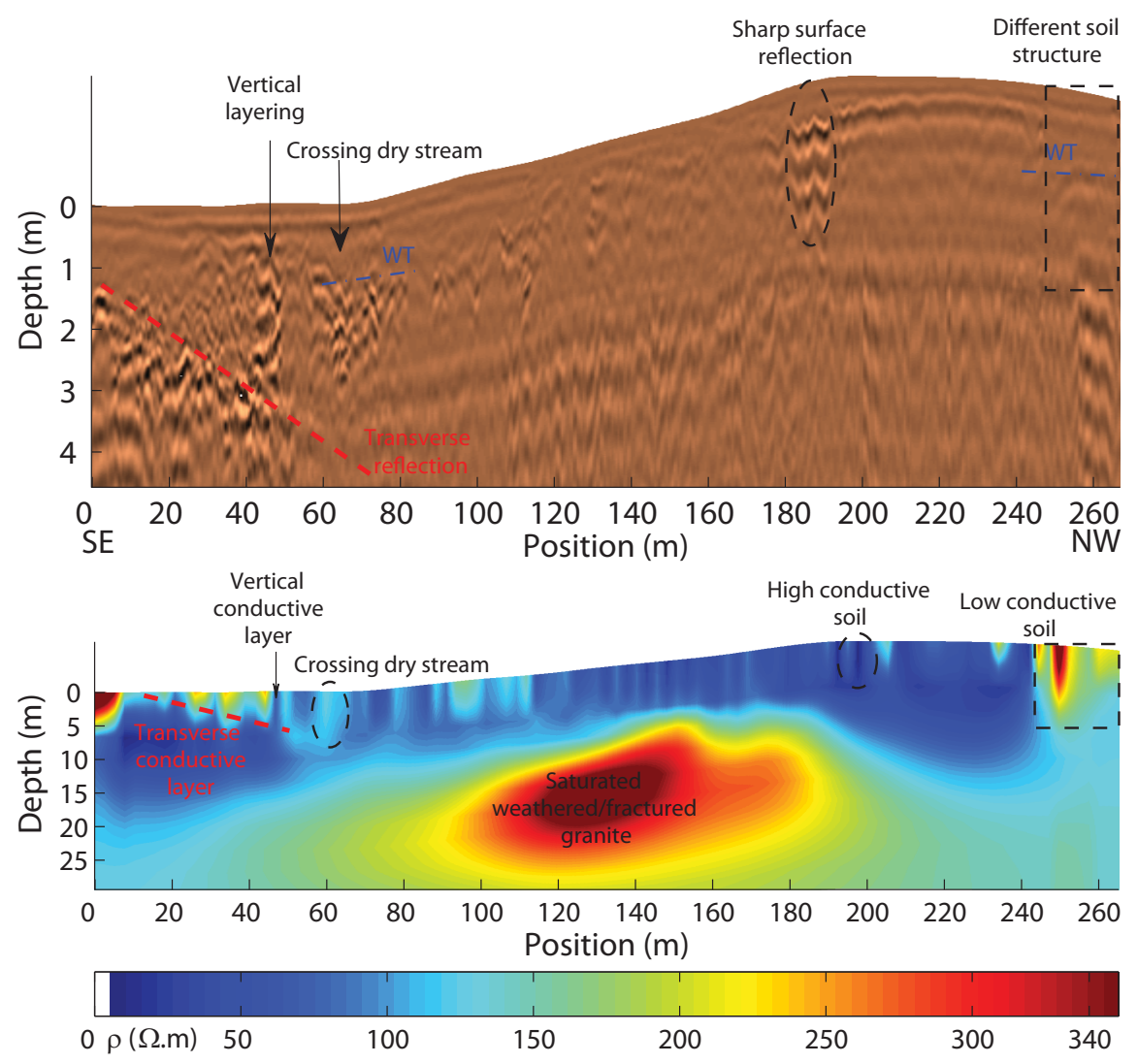

Figure A.8: GPR and ERT profiles (R4 and E4) are located at south part of in a conductive area with heavy clay content and along a NW-SE (N250W) orientation with about $275 \mathrm{~m}$ long for ERT and $290 \mathrm{~m}$ long for GPR profile. (a) The cropped and processed GPR profile using a dielectric constant equals to 5 inferred manually by fitting the GWTD of the pond P4 and the local horizontal reflection at $\sim 19$ ns located at $\sim 255 \mathrm{~m}$ along the profile (this profile crosses the stream at $\sim 65 \mathrm{~m}$ in $\mathrm{x}$-axis), (b) The cropped ERT profile. 
and $17 \mathrm{~m}$ along the profile having the dielectric constant values of 11.5 and 3.1 (obtained by FDR) and the surface elevation values of 792.6 and $793.8 \mathrm{~m}$ (obtained by dGPS), respectively. The respective groundwater table reflection times in the unprocessed GPR profile (the raw GPR profile is not presented) are 20 and $25 \mathrm{~ns}$, and the calculated GWTD for those points are 0.88 and $2.12 \mathrm{~m}$, respectively. Assuming that the groundwater table is horizontal, the difference of the GWTD $(\Delta d)$ for those points should show the difference of the surface elevation $(\Delta \mathrm{Z})$ between them. Referring to the calculated GWTD values leads to $\Delta \mathrm{d}=1.24 \mathrm{~m}$ while the surface elevation values result $\Delta \mathrm{Z}=1.2 \mathrm{~m}$. Therefore the resulting error is $4 \mathrm{~cm}$, which is negligible due to the observational and systematic errors. It is worth noting that time-depth transformation may lead to a significant error of GWTD. The processed GPR profile used the lowest value of $\varepsilon_{r}$ (3.1) for time-depth transformation. Referring to the point which is located at $\mathrm{x}=9 \mathrm{~m}$ shows a GWTD of $1.57 \mathrm{~m}$ while the expected GWTD is $0.88 \mathrm{~m}$ and therefore results to a relative error of $57 \%$ for GWTD. 

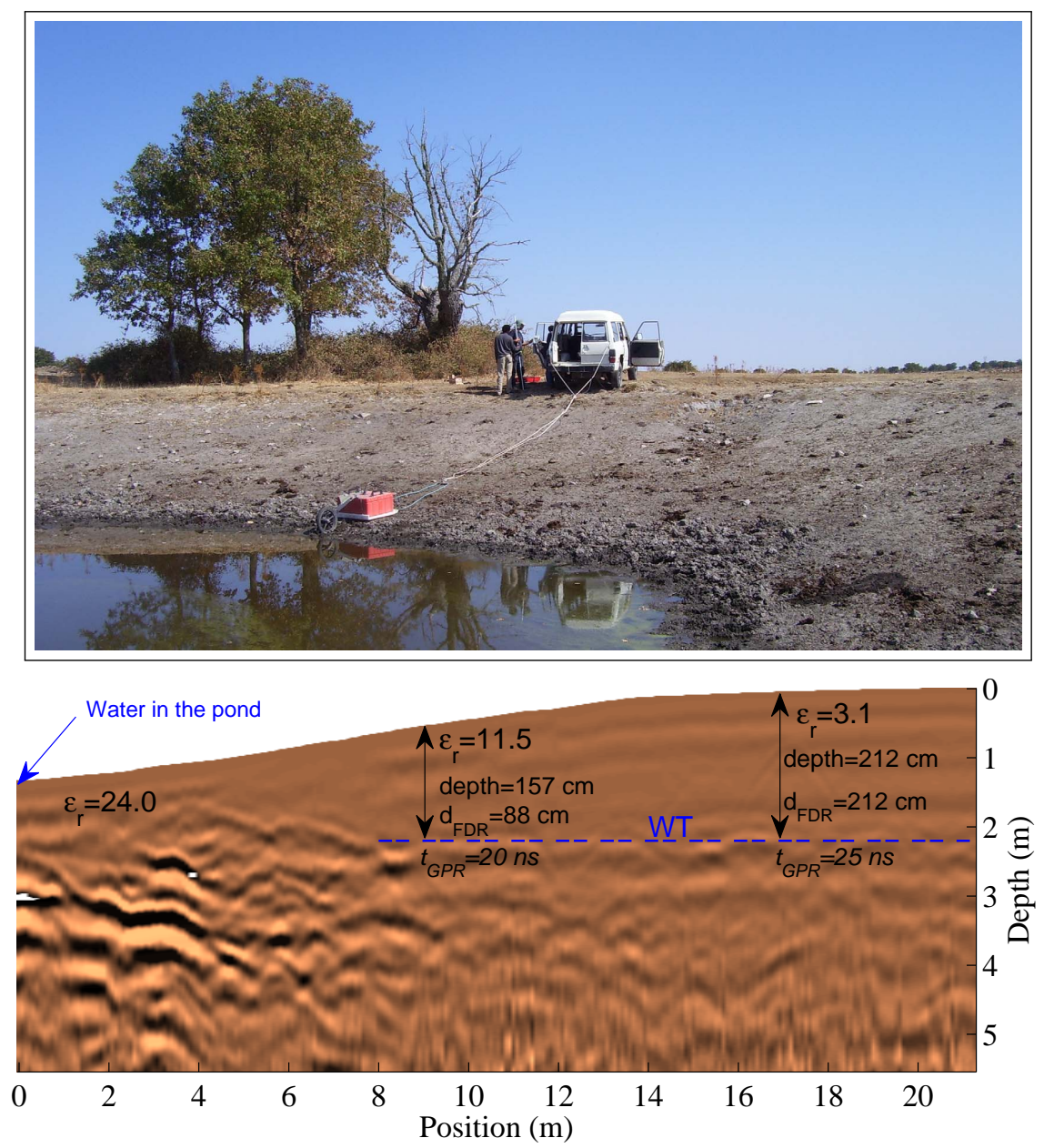

Figure A.9: GPR profile (R5, $21 \mathrm{~m}$ long) carried out in east-south of the for validating the GPR data using FDR and dGPS, starting close to the pond P5. (a) Photograph, (b) The processed GPR profile using a dielectric constant equals to 3.1 inferred from a FDR measurement performed at $17 \mathrm{~m}$ along the profile (this profile starts close to the water and ends on the flat land). The values of $\varepsilon_{r}$ showed in the Figure were inferred from FDR in the indicated locations and $d_{F D R}$ indicates the calculated value of GWTD using the groundwater table reflection travel time obtained from GPR $\left(t_{G P R}\right)$ and the relevant $\varepsilon_{r}$ while depth indicates the GWTD calculated using the unique $\varepsilon_{r}$ measured at $17 \mathrm{~m}$ along the profile. 


\section{A.4 Conclusions}

This study emphasizes on non-invasive and large scale hydrogeological characterization and monitoring techniques in order to investigate the GWTD in weathered granites. In that respect, GPR was applied in a semi-arid catchment () in 37 transects with a total length of $\sim 23 \mathrm{~km}$. In this research we found: (1) the shallow groundwater table returns a strong reflection signal in the GPR images, (2) the geological contact between soil and granite is less visible in the GPR profiles in existence of shallow groundwater table, (3) the groundwater table reflection is almost smooth and it follows quite well the topography but can be affected by the heterogeneity of the layering above it, (4) multiple reflections are expected to happen in presence of saturated fractured granite due to the creation of visible random waveguides for the radar, (5) clay presence in the soil affects the groundwater table reflections and make them nonvisible because of high capillarity and signal attenuation, (6) timedepth transformation using a single dielectric constant value may lead to a significant error of GWTD, and (7) the groundwater table type is local and it is sparsely distributed in the entire catchment by depth ranging between $\sim 1$ to $\sim 3 \mathrm{~m}$. It is worth noting that the common-mid-point (CMP) method of GPR data acquisition would have improved the estimates of the soil dielectric constant where the strong lateral variability in soil dielectric constant does not exist. In the future, research will focus on the full-waveform inversion of the radar data for a more accurate layer reconstruction and interpretation. 



\section{Bibliography}

Al Fugara, A., Pradhan, B., Ahmed Mohamed, T., 2009. Improvement of land-use classification using object-oriented and fuzzy logic approach. Applied Geomatics 1, 111-120.

Alcalá, F.J., Custodio, E., 2008. Using the $\mathrm{Cl} / \mathrm{Br}$ ratio as a tracer to identify the origin of salinity in aquifers in Spain and Portugal. Journal of Hydrology 359, 189-207.

Allen, R.G., Pereira, L., Raes, D., Smith, M., 1998. Crop evapotranspiration: guidelines for computing crop water requirements. Technical Report. Food and Agriculture Organization of the United Nations. Rome.

Almeida, C., Crispim, J., 1987. Traçagens com uranina no Algar do Escarpão (Albufeira, Algarve). ALGAR, Bol. Soc. Portuguesa de Espeleologia 1, 9-16.

Almeida, C.A.C., Mendonça, J., Jesus, M., Gomes, A., 2000. Sistemas aquíferos de Portugal continental. Technical Report. Centro de Geologia da Faculdade de Ciências de Lisboa and Instituto da Água. Lisbon.

Almeida, C.A.C., Lourenço da Silva, M., 1990. Hidrogeologia do Miocénico entre Albufeira e Ribeira de Quarteira. Geolis IV, 16.

Andersen, T.R., Poulsen, S.E., Christensen, S., Jørgensen, F., 2012. A synthetic study of geophysics-based modelling of groundwater flow in catchments with a buried valley. Hydrogeology Journal 20.

Anderson, M.P., Woessner, W.W., 1992. Applied groundwater modeling: simulation of flow and advective transport. Academic Press, San Diego.

Annan, A.P., 1991. Water table detection with ground penetrating radar. 61st Ann. Internat. Mtg., Soc. Expl. Geophys., Expanded Abstracts .

Annan, A.P., 2002. GPR-History, trends, and future developments. Subsurface Sensing Technologies and Applications 3, 253-270.

Archie, G., 1942. Electrical resistivity log as an aid in determining some reservoir characteristics. Petroleum Transactions of AIME 146, 54-61.

Attanayake, A.N.B., 1999. Analysis of fractures in a granitic terrain and their tectonic and hydrogeological implications : a study from Sardón catchment area, Salamanca province, Spain. M.Sc. thesis. ITC-University of Twente. 
Auken, E., Kirkegaard, C., Ribeiro, J., Foged, N., Kok, A., Auken, E., Kirkegaard, C., Ribeiro, J., Foged, N., Kok, A., 2010. The use of airborne electromagnetic for efficient mapping of salt water intrusion and outflow to the sea, in: 21st Salt Water Intrusion Meeting, Azores, Portugal. pp. 53-56.

Aunay, B., Dörfliger, N., Duvail, C., Grelot, F., Le Strat, P., Montginoul, M., Rinaudo, J.D., 2006. Hydro-socio-economic implications for water management strategies: the case of Roussillon coastal aquifer, in: Colloque international sur la gestion des grands aquifères, 150eme anniversaire de la loi de Darcy, 50eme anniversaire de l'AIH (Association Internationale des Hydrogéologues), Bureau de Recherches Géologiques et Minières-BRGM , Gestion de l'Eau, Acteurs et Usages-UMR G-EAU.

Aunay, B., Dörfliger, N., Duvail, C., Grelot, F., Le Strat, P., Montginoul, M., Rinaudo, J.D., 2007. A multidisciplinary approach for assessing the risk of seawater intrusion in coastal aquifers: The case of the Roussillon basin (France), in: Aquifer Systems Management: Darcy's Legacy in a World of Impending Water Shortage: Selected Papers on Hydrogeology 10, p. 459.

Başokur, A.T., Akça, I., Siyam, N.W., 2007. Hybrid genetic algorithms in view of the evolution theories with application for the electrical sounding method. Geophysical Prospecting 55, 393-406.

Baden Ghijben, W., 1888-1889. Nota in verband met de voorgenomen put boring nabij amsterdam. Koninkhijk Institut van Ingenieurs 8.

Baird, K.J., Maddock III, T., 2005. Simulating riparian evapotranspiration: a new methodology and application for groundwater models. Journal of Hydrology 312, 176-190.

Bakker, M., Schaars, F., 2005. The Sea Water Intrusion (SWI) package manual Part I: Theory user manual and example, version 1.2. Technical Report. University of Georgia and Artesia Water Research.

Baltassat, J.M., Legchenko, A., Ambroise, B., Mathieu, F., Lachassagne, P., Wyns, R., Mercier, J.L., Schott, J.J., 2005. Magnetic resonance sounding (MRS) and resistivity characterisation of a mountain hard rock aquifer: the Ringelbach catchment, Vosges Massif, France. Near Surface Geophysics 3, 267-274.

Balugani, E., Lubczynski, M.W., Metselaar, K., 2014. A framework for sourcing of evaporation between saturated and unsaturated zone in bare soil condition. Hydrological Sciences Journal .

Balugani, E., Reyes-Acosta, J.L., van der Tol, C., Lubczynski, M.W., Metselaar, K., 2015. Groundwater and unsaturated zone evaporation and transpiration in a semiarid open woodland. Water Resource Research Submitted.

Bano, M., 2006. Effects of the transition zone above a water table on the reflection of GPR waves. Geophysical Research Letters 33, 5. 
Banta, E., 2000. MODFLOW-2000, the U.S. Geological Survey modular ground-water model - Documentation of packages for simulating evapotranspiration with a segmented function (ETS1) and drains with return flow (DRT1). Technical Report 00-466. U.S. Geological Survey.

Barazzuoli, P., Nocchi, M., Rigati, R., Salleolini, M., 2008. A conceptual and numerical model for groundwater management: a case study on a coastal aquifer in southern Tuscany, Italy. Hydrogeology Journal 16, $1557-1576$.

Baroncini-Turricchia, G., Francés, A.P., Lubczynski, M.W., MartínezFernández, J., Roy, J., 2014. Integrating MRS data with hydrologic model-Carrizal catchment (Spain). Near Surface Geophysics 12.

Batelaan, O., De Smedt, F., 2004. SEEPAGE, a new MODFLOW DRAIN package. Ground Water 42, 576-588.

Batelaan, O., De Smedt, F., Triest, L., 2003. Regional groundwater discharge: phreatophyte mapping, groundwater modelling and impact analysis of land-use change. Journal of Hydrology 275, 86-108.

Batelaan, O., de Smedt, F., 2007. GIS-based recharge estimation by coupling surface-subsurface water balances. Journal of Hydrology 337, 337-355.

Bauer-Gottwein, P., Gondwe, B.N., Christiansen, L., Herckenrath, D., Kgotlhang, L., Zimmermann, S., 2010. Hydrogeophysical exploration of three-dimensional salinity anomalies with the time-domain electromagnetic method (TDEM). Journal of Hydrology 380, 318-329.

Bear, J., Verruijt, A., 1987. Modeling Groundwater Flow and Pollution. Theory and Applications of Transport in Porous Media, Springer Netherlands.

Bentley, L.R., Trenholm, N.M., 2002. The accuracy of water table elevation estimates determined from ground penetrating radar data. Journal of Environmental and Engineering Geophysics 7, 37-53.

Benz, U.C., Hofmann, P., Willhauck, G., Lingenfelder, I., Heynen, M., 2004. Multi-resolution, object-oriented fuzzy analysis of remote sensing data for GIS-ready information. ISPRS Journal of Photogrammetry and Remote Sensing 58, 239-258.

Bernard, J., 2007. Instruments and field work to measure a magnetic resonance sounding. Boletín Geológico y Minero 118 (3), 459-472.

Beven, K., Freer, J., 2001. A dynamic TOPMODEL. Hydrological Processes 15, 1993-2011.

Binley, A., Hubbard, S.S., Huisman, J.A., Revil, A., Robinson, D.A., Singha, K., Slater, L.D., 2015. The emergence of hydrogeophysics for improved understanding of subsurface processes over multiple scales. Water Resources Research 51.

Bishop, T.F.A., McBratney, A.B., 2001. A comparison of prediction methods for the creation of field-extent soil property maps. Geoderma 103, 149-160. 
Blonquist, J.M., Jones, S.B., Robinson, D.A., 2005. Standardizing characterization of electromagnetic water content sensors: Part 2. evaluation of seven sensing systems. Vadose Zone Journal 4, 1059-1069.

Boucher, M., Costabel, S., Yaramanci, U., 2011. The detectability of water by NMR considering the instrumental dead time - a laboratory analysis of unconsolidated materials. Near Surface Geophysics 9, 145-153.

Boucher, M., Favreau, G., Descloitres, M., Vouillamoz, J.M., Massuel, S., Nazoumou, Y., Cappelaere, B., Legchenko, A., 2009a. Contribution of geophysical surveys to groundwater modelling of a porous aquifer in semiarid Niger: An overview. Comptes Rendus-Géoscience 341, 800-809.

Boucher, M., Favreau, G., Nazoumou, Y., Cappelaere, B., Massuel, S., Legchenko, A., 2012. Constraining groundwater modeling with magnetic resonance soundings. Ground Water 50, 775-784.

Boucher, M., Favreau, G., Vouillamoz, J.M., Nazoumou, Y., Legchenko, A., 2009b. Estimating specific yield and transmissivity with magnetic resonance sounding in an unconfined sandstone aquifer (Niger). Hydrogeology Journal 17, 1805-1815.

Bourennane, H., King, D., 2003. Using multiple external drifts to estimate a soil variable. Geoderma 114, 1-18.

Bourennane, H., King, D., Couturier, A., 2000. Comparison of kriging with external drift and simple linear regression for predicting soil horizon thickness with different sample densities. Geoderma 97, 255-271.

Braz Teixeira, S.a., Macedo, F., 2001. Prospecção de manchas de empréstimo ao largo de Albufeira (Algarve). Technical Report. Direção Regional do Ambiente e do Ordenamento do Território do Algarve.

Bronzini, S., 2011. Etude hydrogéologique de la zone d'Albufeira (Algarve, Portugal) et analyse des mécanismes de salinisation des eaux souterraines. Master's thesis. Université de Neuchâtel. CHYN, Switzerland.

Brunner, P., Simmons, C.T., 2012. Hydrogeosphere: A fully integrated, physically based hydrological model. Ground Water 50, 170-176.

Brunner, P., Simmons, C.T., Cook, P.G., Therrien, R., 2010. Modeling surface water-groundwater interaction with MODFLOW: Some considerations. Ground Water 48, 174-180.

Brus, D.J., Knotters, M., van Dooremolen, W.A., van Kernebeek, P., van Seeters, R.J.M., 1992. The use of electromagnetic measurements of apparent soil electrical conductivity to predict the boulder clay depth. Geoderma 55, 79-93.

Burschil, T., Scheer, W., Kirsch, R., Wiederhold, H., 2012. Compiling geophysical and geological information into a 3-D model of the glaciallyaffected island of Föhr. Hydrology and Earth System Sciences 16, 3485-3498.

Butler, J.J., Healey, J.M., 1998. Relationship between pumping-test and slug-test parameters: Scale effect or artifact? Ground Water 36, 305312. 
Cardoso, J.C., 1965. Os solos de Portugal I-A Sul do Rio Tejo.

Carvalho, J., Ramalho, E., Dias, R., Pinto, C., Ressurreição, R., 2012. A geophysical study of the Carcavai fault zone, Portugal. Pure and Applied Geophysics 169, 183-200.

Carvalho, J., Torres, L., Rocha, R., Dias, R., Mendes-Victor, L., 2006. A geophysical study of the S. Marcos-Quarteira fault, Portugal. Journal of Applied Geophysics 60, 153-164.

Ceballos, A., Martínez-Fernández, J., Santos, F., Alonso, P., 2002. Soilwater behaviour of sandy soils under semi-arid conditions in the Duero Basin (Spain). Journal of Arid Environments 51, 501-519.

Chandra, S., Ahmed, S., Ram, A., Dewandel, B., 2008. Estimation of hard rock aquifers hydraulic conductivity from geoelectrical measurements: A theoretical development with field application. Journal of Hydrology 357, 218-227.

Chaudhuri, A., Sekhar, M., Descloitres, M., Godderis, Y., Ruiz, L., Braun, J., 2013. Constraining complex aquifer geometry with geophysics (2-D ERT and MRS measurements) for stochastic modelling of groundwater flow. Journal of Applied Geophysics 98, 288-297.

Chevalier, A., Legchenko, A., Girard, J., Descloitres, M., 2014. Monte Carlo inversion of 3D magnetic resonance measurements. Geophysical Journal International 198, 216-228.

Christiansen, A., Auken, E., Søorensen, K., 2009. The transient electromagnetic method, in: Kirsch, R. (Ed.), Groundwater Geophysics: A Tool For Hydrogeology. Springer Berlin Heidelberg. book section 6, pp. 179-226.

Chung, I.M., Kim, N.W., Lee, J., Sophocleous, M., 2010. Assessing distributed groundwater recharge rate using integrated surface watergroundwater modelling: application to Mihocheon watershed, South Korea. Hydrogeology Journal 18, 1253-1264.

Cook, P.G., 2003. A guide to regional groundwater flow in fractured aquifers. CSIRO.

Cornillon, P.A., Guyader, A., Husson, F., Jégou, N., Josse, J., Kloareg, M., Matzner-Løber, E., Rouviére, L., 2008. Statistique avec R. Presses Universitaires de Rennes.

Cortez, R., 2004. Recharge assessment and groundwater modelling of the Pisões aquifer (Beja-Portugal). M.sc. thesis. ITC.

Corwin, D.L., Lesch, S.M., 2003. Application of soil electrical conductivity to precision agriculture: Theory, principles, and guidelines. Agron J 95, 455-471.

Corwin, D.L., Lesch, S.M., 2005a. Apparent soil electrical conductivity measurements in agriculture. Computers and Electronics in Agriculture 46, 11-43.

Corwin, D.L., Lesch, S.M., 2005b. Characterizing soil spatial variability with apparent soil electrical conductivity: I. survey protocols. Computers and Electronics in Agriculture 46, 103-133. 
Costabel, S., Yaramanci, U., 2011. Relative hydraulic conductivity and effective saturation from Earth's field nuclear magnetic resonance : a method for assessing the vadose zone. Near Surface Geophysics 9, 12.

Costabel, S., Yaramanci, U., 2013. Estimation of water retention parameters from nuclear magnetic resonance relaxation time distributions. Water Resources Research 49, 2068-2079.

Creel, L., 2003. Ripple effects: population and coastal regions. Making the link.

Custodio, E., 2010. Coastal aquifers of Europe: an overview. Hydrogeology Journal 18, 269-280.

Dam, D., Christensen, S., 2003. Including geophysical data in groundwater model inverse calibration. Ground Water 41, 178-189.

Dams, J., Salvadore, E., van Daele, T., Ntegeka, V., Willems, P., Batelaan, O., 2012. Spatio-temporal impact of climate change on the groundwater system. Hydrology and Earth System Sciences 16, 1517-1531.

Danielsen, J., Dahlin, T., Owen, R., Mangeya, P., Auken, E., 2007. Geophysical and hydrogeologic investigation of groundwater in the Karoo stratigraphic sequence at Sawmills in northern Matabeleland, Zimbabwe: a case history. Hydrogeology Journal 15, 945-960.

Danielsen, J.E., Auken, E., Jørgensen, F., Søndergaard, V., Sørensen, K.I., 2003. The application of the transient electromagnetic method in hydrogeophysical surveys. Journal of Applied Geophysics 53, 181-198.

David, T., Ferreira, M., Cohen, S., Pereira, J., David, J., 2004. Constraints on transpiration from an evergreen oak tree in southern Portugal. Agricultural and Forest Meteorology 122, 193-205.

Davies, G., Huang, J., Monteiro Santos, F.A., Triantafilis, J., 2014. Modeling coastal salinity in quasi 2D and 3D using a dualem-421 and inversion software. Groundwater 53, 424-431.

DeMeo, G.A., Laczniak, R.J., Boyd, R.A., Smith, J.L., Nylund, W.E., 2003. Estimated ground-water discharge by evapotranspiration from Death Valley, California, 1997-2001. Technical Report. U.S. Geological Survey.

Descloitres, M., Ruiz, L., Sekhar, M., Legchenko, A., Braun, J.J., Kumar, M.S.M., Subramanian, S., 2008. Characterization of seasonal local recharge using electrical resistivity tomography and magnetic resonance sounding. Hydrological Processes 22, 384-394.

Dewandel, B., Lachassagne, P., Wyns, R., Maréchal, J.C., Krishnamurthy, N.S., 2006. A generalized 3-D geological and hydrogeological conceptual model of granite aquifers controlled by single or multiphase weathering. Journal of Hydrology 330, 260-284.

Dewandel, B., Lachassagne, P., Zaidi, F.K., Chandra, S., 2011. A conceptual hydrodynamic model of a geological discontinuity in hard rock aquifers: Example of a quartz reef in granitic terrain in south India. Journal of Hydrology 405, 474-487. 
Dewandel, B., Maréchal, J., Bour, O., Ladouche, B., Ahmed, S., Chandra, S., Pauwels, H., 2012. Upscaling and regionalizing hydraulic conductivity and effective porosity at watershed scale in deeply weathered crystalline aquifers. Journal of Hydrology 416-417, 83-97.

Dias, J.M.A., Boski, T., Rodrigues, A., Magalhães, F., 2000. Coast line evolution in Portugal since the Last Glacial Maximum until present-a synthesis. Marine Geology 170, 177-186.

Dingman, S.L., 2002. Physical hydrology. Prentice Hall, Upper Saddle River. Second edition.

Doherty, J., 2005. PEST, Model-Independent Parameter Estimation. User Manual: 5th Edition. Watermark Numerical Computing, Brisbane, Australia.

Doherty, J., 2015. Calibration and Uncertainty Analysis for Complex Environmental Models. PEST: complete theory and what it means for modelling the real world. Watermark Numerical Computing.

Domenico, P.A., Schwartz, F., 1998. Physical and chemical hydrogeology. Wiley.

Doolittle, J.A., Jenkinson, B., Hopkins, D., Ulmer, M., Tuttle, W., 2006. Hydropedological investigations with ground-penetrating radar (gpr): Estimating water-table depths and local ground-water flow pattern in areas of coarse-textured soils. Geoderma 131, 317-329.

Doolittle, J.A., Minzenmayer, F.E., Waltman, S.W., Benham, E.C., Tuttle, J.W., Peaslee, S.D., 2007. Ground-penetrating radar soil suitability map of the conterminous united states. Geoderma 141, 416-421.

Doolittle, J.A., Sudduth, K.A., Kitchen, N.R., Indorante, S.J., 1994. Estimating depths to claypans using electromagnetic induction methods. Journal of Soil and Water Conservation 49, 572-575.

Dörfliger, N., 2013. Entre terre et mer, les eaux souterraines du littoral. Géosciences (BRGM) 17, 74-81.

Douglas-Mankin, K., Srinivasan, R., Arnold, J., 2010. Soil and Water Assessment Tool (SWAT) model: Current developments and applications. Transactions of the ASABE 53, 8.

Dutta, S., Krishnamurthy, N.S., Arora, T., Rao, V.A., Ahmed, S., Baltassat, J.M., 2006. Localization of water bearing fractured zones in a hard rock area using integrated geophysical techniques in Andhra Pradesh, India. Hydrogeology Journal 14, 760-766.

Elsendoorn, B., Hoogeveen, H., Vuyck, P., 1982. Geo-electrisch onderzoek van de Miocene aquifer tussen Olhos de Agua en Quarteira, Algarve (Portugal). Technical Report. VU University, Faculty of Earth and Life Sciences. Amsterdam.

Encarnação, J.a., Leitão, F., Range, P., Piló, D., Chícharo, M.A., Chícharo, L., 2013. The influence of submarine groundwater discharges on subtidal meiofauna assemblages in south Portugal (Algarve). Estuarine, Coastal and Shelf Science 130, 202-208. 
Ernstson, K., Kirsch, R., Janik, M., Krummel, H., 2009. Geoelectrical methods, in: Kirsch, R. (Ed.), Groundwater Geophysics: A Tool For Hydrogeology. Springer Berlin Heidelberg. chapter 3, pp. 85-117.

Faneca Sanchez, M., Gunnink, J.L., van Baaren, E.S., Oude Essink, G., Siemon, B., Auken, E., Elderhorst, W., de Louw, P., 2012. Modelling climate change effects on a dutch coastal groundwater system using airborne electromagnetic measurements. Hydrology and Earth System Sciences 16, 4499-4516.

Faraway, J., 2002. Practical Regression and Anova using R. http://cran.rproject.org.

Faraway, J., 2009. faraway: Functions and datasets for books by Julian Faraway. R package version 1.0.4.

Fetter, C., 2001. Applied Hydrogeology. Prentice Hall.

Fienen, M.N., Hunt, R.J., 2015. High-throughput computing versus highperformance computing for groundwater applications. Groundwater $53,180-184$.

Finch, J.W., 1998. Estimating direct groundwater recharge using a simple water balance model-sensitivity to land surface parameters. Journal of Hydrology 211, 112-125.

Finch, J.W., 2001. Estimating change in direct groundwater recharge using a spatially distributed soil water balance model. Quarterly Journal of Engineering Geology and Hydrogeology 34, 71-83.

Fleury, P., Bakalowicz, M., de Marsily, G., 2007. Submarine springs and coastal karst aquifers: A review. Journal of Hydrology 339, 79-92.

Food and Agriculture Organization, 2006. Guidelines for soil description. Technical Report. Food and Agriculture Organization of the United Nations. Rome.

Food and Agriculture Organization, 2009. CROPWAT, a computer program for irrigation planning and management.

Fox, J., 2002. R and S-Plus companion to applied regression. Sage, Thousand Oaks.

Fox, J., Weisberg, S., 2011. An R Companion to Applied Regression. Sage, Thousand Oaks CA. Second edition.

Francés, A.P., 2008. Spatio-temporal groundwater recharge assessment: a data-integration and modelling approach. M.Sc. thesis. ITC-University of Twente.

Francés, A.P., Lubczynski, M.W., 2011. Topsoil thickness prediction at the catchment scale by integration of invasive sampling, surface geophysics, remote sensing and statistical modeling. Journal of Hydrology 405, 31-47.

Francés, A.P., Lubczynski, M.W., 2015. Partitioning and sourcing of evapotranspiration at the catchment scale using coupled MARMITESMODFLOW model. Water Resource Research Submitted. 
Francés, A.P., Lubczynski, M.W., Roy, J., Monteiro Santos, F.A., Mahmoudzadeh, M.R., 2014. Hydrogeophysics and remote sensing for the design of hydrogeological conceptual models in hard rocks-Sardón catchment (Spain). Journal of Applied Geophysics 110, 63-81.

Francés, A.P., Ramalho, E., Fernandes, J., Groen, M., Hugman, R., Khalil, M.A., De Plaen, J., Monteiro Santos, F.A., 2015. Contributions of hydrogeophysics to the hydrogeological conceptual model of the AlbufeiraRibeira de Quarteira coastal aquifer in Algarve, Portugal. Hydrogeology Journal Accepted (April 2015).

Francese, R., Mazzarini, F., Bistacchi, A., Morelli, G., Pasquarè, G., Praticelli, N., Robain, H., Wardell, N., Zaja, A., 2009. A structural and geophysical approach to the study of fractured aquifers in the Scansano-Magliano in Toscana Ridge, southern Tuscany, Italy. Hydrogeology Journal 17, 1233-1246.

Friedman, S.P., 2005. Soil properties influencing apparent electrical conductivity: a review. Computers and Electronics in Agriculture 46, $45-70$

Fukushima, E., Roeder, S., 1981. Experimental Pulse NMR: A Nuts and Bolts Approach. Addison-Wesley.

Furman, A., 2008. Modeling coupled surfacesubsurface flow processes: A review. Vadose Zone Journal 7, 741-756.

Gash, J.H.C., 1979. An analytical model of rainfall interception by forests. Quarterly Journal of the Royal Meteorological Society 105, 43-55.

Gash, J.H.C., Lloyd, C.R., Lachaud, G., 1995. Estimating sparse forest rainfall interception with an analytical model. Journal of Hydrology 170, 79-86.

Gassman, P.W., Reyes, M.R., Green, C.H., Arnold, J.G., 2007. The Soil and Water Assessment Tool: Historical development, applications, and future research directions. Transactions of the ASABE 50, 39.

Gehrels, J., 2000. Groundwater level fluctuations. Ph.D. thesis. Free University of Amsterdam.

Gehrels, J.C., Gieske, A.S.M., 2003. Aquifer dynamics, in: Simmers, I. (Ed.), Understanding water in a Dry Environment-Hydrological processes in arid and semi-arid zones. Balkema, Rotterdam. volume 23 of International Contributions to Hydrogeology, pp. 211-250.

Geirnaert, W., van Beeres, P., de Vries, J., Hoogeveen, H., 1982. Hydrogeologic studies in the East Algarve, Portugal. Part I: Geo-electric survey of the miocene aquifer between Quarteira and Olhao, Algarve, Portugal, in: III Semana de Hidrogeologia, 10-14 May, Lisbon, Portugal. pp. 2-22.

Geotomo software, 2010. RES2DINV ver. 3.59-Rapid 2-D resistivity and IP inversion using the least-squares method.

Giannopoulos, A., 2005. Modelling ground penetrating radar by GPRMax. Construction and Building Materials 19, 755-762. 
Gieske, A., 2003. Operational solutions of actual evapotranspiration, in: Simmers, I. (Ed.), Understanding water in a dry environment : hydrological processes in arid and semi arid zones. Balkema, Rotterdam. volume 23, pp. 65-114.

Glover, R.E., 1959. The pattern of fresh-water flow in a coastal aquifer. Journal of Geophysical Research 64, 457-459.

Goldman, M., Gilad, D., Ronen, A., Mellow, A., 1991. Mapping of seawater intrusion into the coastal aquifer of Israel by time domain electromagnetic method. Geoexploration 28, 153-174.

van de Griend, A.A., Owe, M., 1994. Bare soil surface resistance to evaporation by vapor diffusion under semiarid conditions. Water Resources Research 30, 181-188.

Guan, H., Wilson, J.L., 2009. A hybrid dual-source model for potential evaporation and transpiration partitioning. Journal of Hydrology 377, 405-416.

Habtemariam, T.B., 2000. Subsurface characterization of granitic basement from structural and resistivity data : a case study from Sardón catchment area, Salamanca, Spain. M.Sc. thesis. ITC.

Harari, Z., 1996. Ground-penetrating radar (GPR) for imaging stratigraphic features and groundwater in sand dunes. Journal of Applied Geophysics 36, 43-52.

Harbaugh, A., 2005. MODFLOW-2005, the U.S. Geological Survey modular ground-water model - the Ground-Water Flow Process. Technical Report 6-A16. U.S. Geological Survey.

Harbaugh, A., Banta, E., Hill, M., Mc Donald, M., 2000. MODFLOW-2000, the U.S. Geological Survey modular ground-water model - User guide to modularization concepts and the Ground-Water Flow Process. Technical Report 00-92. U.S. Geological Survey.

Hassan, S.T., Lubczynski, M.W., Niswonger, R.G., Su, Z., 2014. Surfacegroundwater interactions in hard-rocks in Sárdon catchment of western Spain: an integrated modeling approach. Journal of Hydrology 517, 390-410.

Henderson, R.D., Day-Lewis, F.D., Abarca, E., Harvey, C.F., Karam, H.N., Liu, L., Lane, John W., J., 2010. Marine electrical resistivity imaging of submarine groundwater discharge: sensitivity analysis and application in Waquoit Bay, Massachusetts, USA. Hydrogeology Journal 18, 173185.

Hendricks, J.M.H., Phillips, F.M., Harrison, J.B., 2003. Water flow processes in arid and semi-arid vadose zones, in: Simmers, I.e. (Ed.), Understanding water in a Dry Environment - Hydrological processes in arid and semi-arid zones. Balkema. volume 23 of International Contributions to Hydrogeology. chapter 5, pp. 151-210.

Hengl, T., 2009. A Practical Guide to Geostatistical Mapping. University of Amsterdam, www.lulu.com. Second edition. 
Hengl, T., Gruber, S., Shrestha, D.P., 2003a. Digital terrain analysis in ILWIS : lecture note. Technical Report. ITC.

Hengl, T., Rossiter, D.G., Stein, A., 2003b. Soil sampling strategies for spatial prediction by correlation with auxiliary maps. Australian Journal of Soil Research 41, 1403-1422.

Herckenrath, D., 2012. Informing groundwater models with near-surface geophysical data. Ph.D. thesis. Department of Environmental Engineering, Technical University of Denmark.

Hertrich, M., 2008. Imaging of groundwater with nuclear magnetic resonance. Progress in Nuclear Magnetic Resonance Spectroscopy 53, 227-248.

Herzberg, B., 1901. Die wasserversorgung einiger nordssbader. J. Gasbeleuch. Wasservers , 815-819 and 842-844.

Hill, M., Tiedeman, C., 2006. Effective Groundwater Model Calibration: With Analysis of Data, Sensitivities, Predictions, and Uncertainty. Wiley.

Hiscock, K., Bense, V., 2014. Hydrogeology: Principles and Practice. Wiley.

Holländer, H.M., Wang, Z., Assefa, K.A., Woodbury, A.D., 2015. Improved recharge estimation from portable, low-cost weather stations. Groundwater .

Houser, P.R., Shuttleworth, W.J., Famiglietti, J.S., Gupta, H.V., Syed, K.H., Goodrich, D.C., 1998. Integration of soil moisture remote sensing and hydrologic modeling using data assimilation. Water Resources Research 34, 3405-3420.

Hugman, R., Stigter, T.Y., Monteiro, J.P., 2014a. Developing a 3-D variable density numerical model for a heavily exploited coastal aquifer with submarine spring discharge - South Portugal, in: IAH (Ed.), 41st IAH International Congress "Groundwater : Challenges and Strategies", Marrakech.

Hugman, R., Stigter, T.Y., Monteiro, J.P., Costa, L., Nunes, L.M., 2014b. Modeling the spatial and temporal distribution of coastal groundwater discharge for different water use scenarios under epistemic uncertainty: case study in south portugal. Environmental Earth Sciences 73, 2657-2669.

Hunt, R.J., Luchette, J., Schreuder, W.A., Rumbaugh, J.O., Doherty, J., Tonkin, M.J., Rumbaugh, D.B., 2010. Using a cloud to replenish parched groundwater modeling efforts. Ground Water 48, 360-365.

Illman, W.A., 2006. Strong field evidence of directional permeability scale effect in fractured rock. Journal of Hydrology 319, 227-236.

Instituto Geológico y Minero de España, 1978. Mapa geológico de España a escala 1:50 000. Hoja 426 (Fuentesauco).

Instituto Geológico y Minero de España, 1991a. Mapa geológico de España a escala 1:50 000. Hoja 450 (Vitigudino).

Instituto Geológico y Minero de España, 1991b. Mapa geológico de España a escala 1:50 000. Hoja 451 (Ledesma). 
Instituto Geológico y Minero de España, 2000. Mapa geológico de España a escala 1:50 000. Hoja 425 (Villamor de los Escuderos).

Jackson, T.J., Schmugge, J., Engman, E.T., 1996. Remote sensing applications to hydrology: soil moisture. Hydrological Sciences 41, 517-530.

Jenness, J., 2006. Topographic Position Index (tpi_jen.avx) extension for ArcView 3.x.

Johnson, E., Yáñez, J., Ortiz, C., Muñoz, J., 2010. Evaporation from shallow groundwater in closed basins in the chilean altiplano. Hydrological Sciences Journal 55, 624-635.

Jyrkama, M., Sykes, J., Normani, S., 2002. Recharge estimation for transient groundwater modeling. Ground Water 40, 638-648.

Keller, G.V., Frischknecht, F.C., 1966. Electrical methods in geophysical prospecting. Pergamon Press, Inc.

Kim, N.W., Chung, I.M., Won, Y.S., Arnold, J.G., 2008. Development and application of the integrated SWAT-MODFLOW model. Journal of Hydrology 356, 1-16.

Kinzelbach, W., Aeschbach, W., Alberich, C., Goni, I., Beyerle, U., Brunner, P., Chiang, W., Rueedi, J., Zollmann, K., 2002. A survey of methods for groundwater recharge in arid and semi-arid regions. Early Warning and Assessment Report Series UNEP/DEWA/RS.02-2, Nairobi, Kenya.

Kirsch, R. (Ed.), 2009. Groundwater Geophysics: A Tool For Hydrogeology. Springer, Berlin. 2nd edition.

Kirsch, R., Yaramanci, U., 2009. Geophysical characterisation of aquifers, in: Kirsch, R. (Ed.), Groundwater Geophysics: A Tool For Hydrogeology. Springer Berlin Heidelberg. book section 17, pp. 491-509.

Kite, G., 2000. Using a basin-scale hydrological model to estimate crop transpiration and soil evaporation. Journal of hydrology 229, 59-69.

Knotters, M., Brus, D.J., Oude Voshaar, J.H., 1995. A comparison of kriging, co-kriging and kriging combined with regression for spatial interpolation of horizon depth with censored observations. Geoderma $67,227-246$.

Kok, A., Auken, E., Groen, M., Riberio, J., Shaars, F., 2010. Using ground based geophysics and airborne transient electromagnetic measurements (SkyTEM) to map salinity distribution and calibrate a groundwater model for the island of Terschelling-The Netherlands, in: 21st Salt Water Intrusion Meeting, Azores, Portugal.

Kollet, S.J., Maxwell, R.M., 2006. Integrated surface-groundwater flow modeling: A free-surface overland flow boundary condition in a parallel groundwater flow model. Advances in Water Resources 29, 945-958.

Kollet, S.J., Maxwell, R.M., 2008. Capturing the influence of groundwater dynamics on land surface processes using an integrated, distributed watershed model. Water Resources Research 44. 
Kravchenko, A., Bullock, D., 1999. A comparative study of interpolation methods for mapping soil properties. Journal of Agronomy 91, 393400.

Krishnamurthy, N.S., Chandra, S., Kumar, D., 2008. Geophysical characterization of hard rock aquifers, in: Groundwater Dynamics in Hard Rock Aquifers, pp. 64-86.

Kroes, J.G., van Dam, J.C., 2003. Reference manual SWAP version 3.0.3. Technical Report Alterra-rapport 773. Alterra, Green World Research.

Kruseman, G., de Ridder, N., 1991. Analysis and evaluation of pumping test data. Number 47 in ILRI Publication, International Institute for Land Reclamation and Improvement (ILRI), Wageningen.

Kuniansky, E., Lowery, M., Campbell, B., 2009. How processing digital elevation models can affect simulated water budgets. Ground Water $47,97-107$.

Kuriakose, S.L., Devkota, S., Rossiter, D.G., Jetten, V.G., 2009. Prediction of soil depth using environmental variables in an anthropogenic landscape, a case study in the western Ghats of Kerala, India. Catena 79, 27-38.

van der Kwaak, J.E., 1999. Numerical simulation of flow and chemical transport in integrated surface-subsurface hydrologic systems. Ph.D. dissertation. University of Waterloo. Waterloo, Ontario.

van der Kwaak, J.E., Loague, K., 2001. Hydrologic-response simulations for the r-5 catchment with a comprehensive physics-based model. Water Resources Research 37, 999-1013.

Lachassagne, P., Wyns, R., Bérard, P., Bruel, T., Chéry, L., Coutand, T., Desprats, J.F., Strat, P., 2001. Exploitation of high-yields in hard-rock aquifers: Downscaling methodology combining GIS and multicriteria analysis to delineate field prospecting zones. Ground Water 39, 568581.

Lachassagne, P., Wyns, R., Dewandel, B., 2011. The fracture permeability of hard rock aquifers is due neither to tectonics, nor to unloading, but to weathering processes. Terra Nova 23, 145-161.

Lambot, S., Binley, A., Slob, E., Hubbard, S., 2008. Ground penetrating radar in hydrogeophysics. Vadose Zone Journal 7, 137-139.

Lambot, S., Hupet, F., Javaux, M., Vanclooster, M., 2004. Laboratory evaluation of a hydrodynamic inverse modeling method based on water content data. Water Resources Research 40.

Langevin, C., Thorne, D.T., J., Dausman, A., Sukop, M., Guo, W., 2007. SEAWAT Version 4: A Computer Program for Simulation of MultiSpecies Solute and Heat Transport. Techniques and Methods TM6 A-22. U.S. Geological Survey.

Leavesley, G., Lichty, R., Troutman, B., Saindon, L., 1983. PrecipitationRunoff Modeling System user's manual. Water-Resources Investigations Report 83-4238. U.S. Geological Survey. 
van der Lee, J., Gehrels, J., 1997. Modeling of groundwater recharge for a fractured dolomite aquifer under semi-arid conditions, in: Simmers, I., Hendrickx, J.M.H., Kruseman, G., Rushton, K.R. (Eds.), Recharge of Phreatic Aquifers in (Semi-) Arid Areas. Balkema, Rotterdam. volume 19 of International Contributions to Hydrogeology, pp. 129-144.

Legchenko, A., 2001. Caractérisation hydrodynamique du bassin versant de Kerbernez (Bretagne) avec la méthode de Résonance Magnétique Protonique. Technical Report RP-51330-FR. BRGM.

Legchenko, A., 2011. Samovar software 11.3 user's guide.

Legchenko, A., 2013. Magnetic Resonance Imaging for Groundwater. FOCUS Series, John Wiley \& Sons.

Legchenko, A., Baltassat, J.M., Bobachev, A., Martin, C., Robain, H., Vouillamoz, J.M., 2004. Magnetic resonance sounding applied to aquifer characterization. Ground Water 42, 363-373.

Legchenko, A., Descloitres, M., Bost, A., Ruiz, L., Reddy, M., Girard, J.F., Sekhar, M., Kumar, M.S.M., Braun, J.J., 2006. Resolution of MRS applied to the characterization of hard-rock aquifers. Ground Water 44, 547554.

Legchenko, A., Descloitres, M., Vincent, C., Guyard, H., Garambois, S., Chalikakis, K., Ezersky, M., 2011. Three-dimensional magnetic resonance imaging for groundwater. New Journal of Physics 13, 025022.

Legchenko, A., Ezersky, M., Camerlynck, C., Al-Zoubi, A., Chalikakis, K., 2009. Joint use of TEM and MRS methods in a complex geological setting. Comptes Rendus Géosciences 341, 908-917.

Lesch, S.M., Corwin, D.L., 2008. Prediction of spatial soil property information from ancillary sensor data using ordinary linear regression: Model derivations, residual assumptions and model validation tests. Geoderma 148, 130-140.

Livari, T.A., Doolittle, J.A., 1994. Computer simulations of depths to water table using ground-penetrating radar in topographically diverse terrains, in: Groundwater quality management. Proceedings Tallinn, Estonia, 6 to 9 September, 1993., pp. 11-20.

Llamas, M., Martínez-Santos, P., 2005. Intensive groundwater use: Silent revolution and potential source of social conflicts. Editorial. Journal of Water Resources Planning and Management 131, 337-341.

Lloyd, J., 1999. Water resources of hard rock aquifers in arid and semiarid zones. Studies and reports in hydrology, UNESCO, Paris.

Loheide, S.P., Butler, J.J., Gorelick, S.M., 2005. Estimation of groundwater consumption by phreatophytes using diurnal water table fluctuations: A saturated-unsaturated flow assessment. Water Resources Research 41.

Lopes, F.C., Cunha, P.P., Le Gall, B., 2006. Cenozoic seismic stratigraphy and tectonic evolution of the Algarve margin (offshore Portugal, southwestern Iberian Peninsula). Marine Geology 231, 1-36. 
López, L.A., 2004. Análisis de la fracturación en un área granítica intraplaca : el Domo de Tormes. Ph.D. thesis. Universidade Complutense de Madrid.

Lubczynski, M., 2000. Groundwater evapotranspiration, underestimated component of the groundwater balance in a semi-arid environment, Serowe case, Botswana, in: Sililo, O. (Ed.), Groundwater : past achievements and future challenges, Balkema Rotterdam. pp. 199-204.

Lubczynski, M., 2009. The hydrogeological role of trees in water-limited environments. Hydrogeology Journal 17, 247-259.

Lubczynski, M., 2011. Groundwater evapotranspiration-underestimated role of tree transpiration and bare soil evaporation in groundwater balances of dry lands, in: Baba, A., Tayfur, G., Gunduz, O., Howard, K.W., Friedel, M.J., Chambel, A. (Eds.), Climate Change and its Effects on Water Resources. Springer. chapter 21, pp. 183-190.

Lubczynski, M., Gurwin, J., 2005a. Integration of various data sources for transient groundwater modeling with spatio-temporally variable fluxes : Sardón study case, Spain. Journal of Hydrology 306.

Lubczynski, M., Roy, J., 2003. Hydrogeological interpretation and potential of the new magnetic resonance sounding (MRS) method. Journal of Hydrology 283, 19-40.

Lubczynski, M., Roy, J., 2004. Magnetic resonance sounding: New method for ground water assessment. Ground Water 42, 291-309.

Lubczynski, M., Roy, J., 2005. MRS contribution to hydrogeological system parameterization. Near surface geophysics 3, 131-139.

Lubczynski, M.W., Gurwin, J., 2005b. Integration of various data sources for transient groundwater modeling with spatio-temporally variable fluxes-sardon study case, spain. Journal of Hydrology 306, 71-96.

Lubczynski, M.W., Roy, J., 2007. Use of MRS for hydrogeological system parameterization and modeling. Boletín Geológico y Minero 118, 509530.

Maathuis, B.H.P., Wang, L., 2006. Digital elevation model based hydroprocessing. Geocarto International 21, 21-26.

Mahmoudzadeh, M., Francés, A., Lubczynski, M., Lambot, S., 2012. Using ground penetrating radar to investigate the water table depth in weathered granites-Sardón case study, Spain. Journal of Applied Geophysics 79, 17-26.

Manfreda, S., Fiorentino, M., Iacobellis, V., 2005. DREAM: a distributed model for runoff, evapotranspiration, and antecedent soil moisture simulation. Advanced Geosciences 2, 31-39.

Manuppella, G., 1992. Carta Geológica da Região do Algarve (1:100 000).

Manuppella, G., Ramalho, M., Telles Antunes, M., Pais, J., 2007. Sheet 53-A (Faro), Carta Geológica de Portugal (1:50 000). 
Maréchal, J.C., Dewandel, B., Subrahmanyam, K., 2004. Use of hydraulic tests at different scales to characterize fracture network properties in the weathered-fractured layer of a hard rock aquifer. Water Resources Research 40, 17.

Markstrom, S., Niswonger, R., Regan, R., Prudic, D., Barlow, P., 2008. GSFLOW-Coupled ground-water and surface-water flow model based on the integration of the Precipitation-Runoff Modeling System (PRMS) and the Modular Ground-Water Flow Model (MODFLOW-2005). U.S. Geological Survey Techniques and Methods 6-D1. U.S. Geological Survey.

de Marsily, G., 1986. Quantitative hydrogeology: groundwater hydrology for engineers. Academic Press.

de Marsily, G., Delay, F., Gonçalvès, J., Renard, P., Teles, V., Violette, S., 2005. Dealing with spatial heterogeneity. Hydrogeology Journal 13, 161-183.

Martínez-Fernández, J., Ceballos, A., 2005. Mean soil moisture estimation using temporal stability analysis. Journal of Hydrology 312, 28-38.

Maxwell, R.M., Putti, M., Meyerhoff, S., Delfs, J.O., Ferguson, I.M., Ivanov, V., Kim, J., Kolditz, O., Kollet, S.J., Kumar, M., Lopez, S., Niu, J., Paniconi, C., Park, Y.J., Phanikumar, M.S., Shen, C., Sudicky, E.A., Sulis, M., 2014. Surface-subsurface model intercomparison: A first set of benchmark results to diagnose integrated hydrology and feedbacks. Water Resources Research 50, 1531-1549.

McNeill, J., 1980. Electromagnetic terrain conductivity measurement at low induction numbers. Technical Report TN-6. Geonics.

Meijerink, A., Bannert, D., Batelaan, O., Lubczynski, M., Pointet, T., 2007. Remote sensing applications to groundwater. volume 16 of IHP-VI series on groundwater. United Nations Educational Scientific and Cultural Organization (UNESCO), Paris.

Miller, G.R., Chen, X., Rubin, Y., Ma, S., Baldocchi, D.D., 2010. Groundwater uptake by woody vegetation in a semiarid oak savanna. Water Resources Research 46.

Mitri, G., Gitas, I., 2002. The development of an object-oriented classification model for operational burned area mapping on the Mediterranean island of Thasos using LANDSAT TM images, in: Viegas, D.X. (Ed.), IV International Conference on Forest Fire Research.

Mohnke, O., Yaramanci, U., 2008. Pore size distributions and hydraulic conductivities of rocks derived from magnetic resonance sounding relaxation data using multi-exponential decay time inversion. Journal of Applied Geophysics 66, 73-81.

Mongelli, G., Monni, S., Oggiano, G., Paternoster, M., Sinisi, R., 2013. Tracing groundwater salinization processes in coastal aquifers: a hydrogeochemical and isotopic approach in the $\mathrm{Na}-\mathrm{Cl}$ brackish waters of northwestern Sardinia, Italy. Hydrol. Earth Syst. Sci. 17, 2917-2928. 
Monteiro, J.P., Matos Silva, J., Guerreiro, P., Martins, J., Reis, E., 2007a. Modelação de relações entre águas superficiais e subterrâneas nos aquíferos do Algarve Central, in: ao Portuguesa dos Recursos Hídricos, A. (Ed.), SeminÃąrio sobre Águas Subterrâneas, Laboratório Nacional de Engenharia Civil (LNEC). p. 8 p.

Monteiro, J.P., Oliveira, M., Costa, J.P., 2007b. Impact of the replacement of groundwater by dam waters in the Albufeira-Ribeira de Quarteira and Quarteira coastal aquifers, in: XXXV AIH Congress - Groundwater and Ecosystems, p. 10 p.

Monteiro Santos, F.A., 2004. 1-D laterally constrained inversion of EM34 profiling data. Journal of Applied Geophysics 56, 123-134.

de Montety, V., Radakovitch, O., Vallet-Coulomb, C., Blavoux, B., Hermitte, D., Valles, V., 2008. Origin of groundwater salinity and hydrogeochemical processes in a confined coastal aquifer: Case of the Rhône delta (Southern France). Applied Geochemistry 23, 2337-2349.

Moore, C., Doherty, J., 2006. The cost of uniqueness in groundwater model calibration. Advances in Water Resources 29, 605-623.

Moriasi, D., Arnold, J., van Liew, M., Bingner, R., Harmel, R., Veith, L.V., 2007. Model evaluation guidelines for systematic quantification of accuracy in watershed simulations. Transactions of the ASABE 50, 15.

Muffels, C.T., Schreüder, W.A., Doherty, J.E., Karanovic, M., Tonkin, M.J., Hunt, R.J., Welter, D.E., 2012. Approaches in highly parameterized inversion: GENIE, a general model-independent TCP/IP run manager. Techniques and Methods TM7-C6. U.S. Geological Survey.

Nakashima, Y., Zhou, H., Sato, M., 2001. Estimation of groundwater level by GPR in an area with multiple ambiguous reflections. Journal of Applied Geophysics 47, 241-249.

Naumburg, E., Mata-gonzalez, R., Hunter, R., Mclendon, T., Martin, D., 2005. Phreatophytic vegetation and groundwater fluctuations: A review of current research and application of ecosystem response modeling with an emphasis on great basin vegetation. Environmental Management 35, 726-740.

Neuman, S.P., Federico, V., 2003. Multifaceted nature of hydrogeologic scaling and its interpretation. Reviews of Geophysics 41, 1-31.

Newman, B.D., Breshears, D.D., Gard, M.O., 2010. Evapotranspiration partitioning in a semiarid woodland: Ecohydrologic heterogeneity and connectivity of vegetation patches. Vadose Zone Journal 9, 561-572.

Newman, S.M., Smith, J.A., Glew, M.D., Rogers, S.M., Taylor, J.P., 2005. Temperature and salinity dependence of sea surface emissivity in the thermal infrared. Quarterly Journal of the Royal Meteorological Society $131,2539-2557$.

Nguyen, F., Kemna, A., Antonsson, A., Engesgaard, P., Kuras, O., Ogilvy, R., Gisbert, J., Jorreto, S., Pulido-Bosch, A., 2009. Characterization of seawater intrusion using 2D electrical imaging. Near Surface Geophysics 7, 377-390. 
Nichols, W.D., 1994. Groundwater discharge by phreatophyte shrubs in the Great Basin as related to depth to groundwater. Water Resources Research 30, 3265-3274.

Niswonger, R., Panday, S., Ibaraki, M., 2011. MODFLOW-NWT, a Newton formulation for MODFLOW-2005. U.S. Geological Survey Techniques and Methods 6-A37. U.S. Geological Survey.

Niswonger, R., Prudic, D., Regan, R., 2006. Documentation of the Unsaturated-Zone Flow (UZF1) package for modeling unsaturated flow between the land surface and the water table with MODFLOW-2005. U.S. Geological Survey Techniques and Methods 6-A19. U.S. Geological Survey.

Odeh, I.O.A., McBratney, A.B., Chittleborough, D.J., 1995. Further results on prediction of soil properties from terrain attributes: heterotopic cokriging and regression-kriging. Geoderma 67, 215-226.

Oliveira, J., 1992. Notícia explicativa da carta geológica de portugalá escala 1:200 000 - folha 8.

Orellana, F., Verma, P., Loheide, S.P., Daly, E., 2012. Monitoring and modeling water-vegetation interactions in groundwater-dependent ecosystems. Reviews of Geophysics 50.

Oude Essink, G., van Baaren, E., de Louw, P., 2010. Effects of climate change on coastal groundwater systems: A modeling study in the Netherlands. Water Resource Research 46.

Oude Essink, G.H., 2001. Density Dependent Groundwater Flow-Salt water Intrusion and Heat Transport - Lecture notes. Utrecht University.

Paço, T.A., David, T.S., Henriques, M.O., Pereira, J.S., Valente, F., Banza, J., Pereira, F.L., Pinto, C., David, J.S., 2009. Evapotranspiration from a mediterranean evergreen oak savannah: The role of trees and pasture. Journal of Hydrology 369, 98-106.

Pais, J., Legoinha, P., Elderfield, H., Sousa, L., Estevens, M., 2000. The Neogene of Algarve (Portugal), in: 1 Congresso sobre o Cenozóico de Portugal, Ciências da Terra (UNL), 14. pp. 277-288.

Paradis, E., Claude, J., Strimmer, K., 2004. Ape: Analyses of phylogenetics and evolution in R language. Bioinformatics 20, 289-290.

Paralta, E., 2009. Utilização de modelos de recarga e técnicas isotópicas na avaliação do impacte da agricultura na qualidade da água subterrânea de zonas agrícolas-Caso de estudo no Aquífero dos Gabros de Beja. Ph.D. in engineering science. Instituto Superior Técnico- Universidade Técnica de Lisboa.

Parasnis, D.S., 1966. Electromagnetic prospecting-C. W. techniques. Geoexploration 4, 177-208.

Parsons, A., Abrahams, A., 2009. Geomorphology of desert environments, in: Parsons, A., Abrahams, A. (Eds.), Geomorphology of Desert Environments. Springer. Earth and Environmental Science, pp. 3-7. 
Pebesma, E.J., 2004. Multivariable geostatistics in S: the gstat package. Computers \& Geosciences 30, 683-691.

Pebesma, E.J., de Kwaadsteniet, J.W., 1997. Mapping groundwater quality in the Netherlands. Journal of Hydrology 200, 364-386.

Plata, J., Rubio, F., 2007. Basic theory of the magnetic resonance sounding method. Boletín Geológico y Minero 118, 441-458.

Plata, J., Rubio, F., 2008. The use of MRS in the determination of hydraulic transmissivity: The case of alluvial aquifers. Journal of Applied Geophysics 66, 128-139.

Plata, J., Uriarte, C., Martínez-Fernandez, J., 2009. Uso de los SRM para la obtención de parámetros hidráulicos y su implementación en la modelización de aguas subterrâneas: aplicación en el acuífero superficial de Los Arenales. Centro de Documentación del IGME 63790. Instituto Geológico y Minero de España.

Post, V., 2008. Wrapping Python around MODFLOW/MT3DMS based groundwater models. AGU Fall Meeting Abstracts , G952+.

Post, V., Abarca, E., 2010. Preface: Saltwater and freshwater interactions in coastal aquifers. Hydrogeology Journal 18, 1-4.

Post, V.E.A., 2005. Fresh and saline groundwater interaction in coastal aquifers: Is our technology ready for the problems ahead? Hydrogeology Journal 13, 120-123.

Post, V.E.A., Groen, J., Kooi, H., Person, M., Ge, S., Edmunds, W.M., 2013. Offshore fresh groundwater reserves as a global phenomenon. Nature 504, 71-78.

Poulsen, S., Rasmussen, K., Christensen, N., Christensen, S., 2010. Evaluating the salinity distribution of a shallow coastal aquifer by vertical multielectrode profiling (Denmark). Hydrogeology Journal 18, 161-171.

Presidência do Conselho de Ministros, 2009. Resolução do conselho de ministros 82/2009 de 8 de setembro de 2009.

Quinn, G., Keough, M., 2002. Experimental Design and Data Analysis for Biologists. Cambridge University Press.

R Development Core Team, 2009. R: A language and environment for statistical computing.

Ramalho, E., Carvalho, J., Gonçalves, R., Monteiro Santos, F., 2012. Understanding the 3D structure of a thermal water fissured granite aquifer by use of geophysical studies. Pure and Applied Geophysics , 1-16.

Reimann, C., Filzmoser, P., Garrett, R.G., Dutter, R., 2008. Statistical data analysis explained : applied environmental statistics with R. Wiley \& Sons, Chichester.

Reis, E., Gago, C., Borges, G., Matos, M., Cláudio, A., Mendes, E., Silva, A., Serafim, J., Rodrigues, A., Correia, S., 2007. Contribuição para o Cálculo do Balanço Hídrico dos Principais Sistemas Aquíferos do Algarve [in Portuguese] (Contribution for the Calculation of Water Balance of 
the Main Aquifer systems in Algarve). Technical Report. Ministério do Ambiente, do Ordenamento do Território e do Desenvolvimento Regional, Comissão de Coordenação e Desenvolvimento Regional do Algarve. Faro.

Rey, J., 2006. Les formations crétacées de l'algarve occidental et central. Comunicações Geológicas 93, 41.

Reyes-Acosta, J., 2015. Tree-water interactions at varying spatio-temporal scales in water limited environments. Ph.d. thesis. ITC-University of Twente.

Reyes-Acosta, J., Lubczynski, M.W., 2013. Mapping dry-season tree transpiration of an oak woodland at the catchment scale, using objectattributes derived from satellite imagery and sap flow measurements. Forest and Agricultural Management 174-175, 184-201.

Robinson, D.A., Binley, A., Crook, N., Day-Lewis, F.D., Ferré, T.P.A., Grauch, V.J.S., Knight, R., Knoll, M., Lakshmi, V., Miller, R., Nyquist, J., Pellerin, L., Singha, K., Slater, L., 2008. Advancing process-based watershed hydrological research using near-surface geophysics: a vision for, and review of, electrical and magnetic geophysical methods. Hydrological Processes 22, 3604-3635.

Robinson, T., Metternicht, G., 2006. Testing the performance of spatial interpolation techniques for mapping soil properties. Computers and Electronics in Agriculture 50, 97-108.

Roque, A.C.F.P., 2007. Tectonostratigrafia do cenozóico das margens continentais sul e sudoeste portuguesas: um modelo de correlação sismostratigráfica. Ph.D. thesis. Universidade de Lisboa.

Roy, J., Lubczynski, M., 2003. The magnetic resonance sounding technique and its use for groundwater investigations. Hydrogeology Journal $11,455-465$.

Roy, J., Lubczynski, M., 2005. MRS multi-exponential decay analysis: aquifer pore-size distribution and vadose zone characterization. Near Surface Geophysics 3, 287-298.

Roy, J., Lubczynski, M.W., 2014. Exploiting the MRS-phase information to enhance detection of masked deep aquifers: examples from the Netherlands. Near Surface Geophysics 12, 309-324.

Rubin, Y., Hubbard, S. (Eds.), 2005. Hydrogeophysics. Water Science and Technology Library, Springer.

Rushton, K., 2004. Groundwater Hydrology: Conceptual and Computational Models. Wiley.

Rushton, K.R., Eilers, V.H.M., Carter, R.C., 2006. Improved soil moisture balance methodology for recharge estimation. Journal of Hydrology 318, 379-399.

Samper, J., Huguet, L., Ares, J., García-Vera, M.A., 2005. Manual del usuario del programa VISUAL BALAN V. 2.0: Código interactivo para la realizacíon de balances hidrológicos y la estimación de la recarga [User 
Guide of VISUAL BALAN V.2.0: Interactive code for conducting water balance and recharge estimation]. Report. Enresa, Civil Engineering School.

Sánchez-Vila, X., Carrera, J., Girardi, J.P., 1996. Scale effects in transmissivity. Journal of Hydrology 183, 1-22.

Sanderson, J.S., Cooper, D.J., 2008. Ground water discharge by evapotranspiration in wetlands of an arid intermountain basin. Journal of Hydrology 351, 344-359.

Scanlon, B.R., Keese, K.E., Flint, A.L., Flint, L.E., Gaye, C.B., Edmunds, W.M., Simmers, I., 2006. Global synthesis of groundwater recharge in semiarid and arid regions. Hydrological Processes 20, 3335-3370.

Scott, R., Cable, W., Huxman, T., Nagler, P., Hernandez, M., Goodrich, D., 2008. Multiyear riparian evapotranspiration and groundwater use for a semiarid watershed. Journal of Arid Environments 72, 1232-1246.

Seo, H., Šimůnek, J., Poeter, E., 2007. Documentation of the HYDRUS package for MODFLOW-2000, the U.S. Geological Survey Modular GroundWater Model. Technical Report. IGWMC-International Ground Water Modeling Center.

Seyfried, M.S., Grant, L.E., 2007. Temperature effects on soil dielectric properties measured at $50 \mathrm{MHz}$. Vadose Zone J 6, 759-765.

Seyfried, M.S., Grant, L.E., Du, E., Humes, K., 2005. Dielectric loss and calibration of the Hydra probe soil water sensor. Vadose Zone Journal 4, 1070-1079.

Seyfried, M.S., Murdock, M.D., 2004. Measurement of soil water content with a 50-MHz soil dielectric sensor. Soil Sci Soc Am J 68, 394-403.

Shah, N., Nachabe, M., Ross, M., 2007. Extinction depth and evapotranspiration from ground water under selected land covers. Ground Water 45, 329-338.

Sheikh, V., Visser, S., Stroosnijder, L., 2009. A simple model to predict soil moisture: Bridging Event And Continuous Hydrological (BEACH) modelling. Environmental Modelling \& Software 24, 542-556.

Šimůnek, J., van Genuchten, M.T., Šejna, M., 2011. The HYDRUS Software Package for Simulating Two- and Three-Dimensional Movement of Water, Heat, and Multiple Solutes in Variably-Saturated Media, Version 2.0. Technical Report. PC Progress. Prague, Czech Republic.

Šimůnek, J., Sejna, M., van Genuchten, M.T., 1998. The HYDRUS-1D software package for simulating the one-dimensional movement of water, heat and multiple solutes in variably-saturated media, Version 2.0. US Salinity Laboratory, ARS/USDA, Riverside, California.

Šimůnek, J., Šejna, M., Saito, H., Sakai, M., van Genuchten, M.T., 2008. The HYDRUS-1D Software Package for Simulating the Movement of Water, Heat, and Multiple Solutes in Variably Saturated Media, Version 4.0, HYDRUS Software Series 3. Technical Report. Department of Environmental Sciences, University of California Riverside. Riverside, California, USA. 
Singh, V., 1997. Kinematic Wave Modeling in Water Resources, Environmental Hydrology. Kinematic Wave Modeling in Water Resources, John Wiley \& Sons.

Singhal, B.B.S., Gupta, R.P., 2010. Applied hydrogeology of fractured aquifers. Springer.

Sivapalan, M., Blöschl, G., Zhang, L., Vertessy, R., 2003a. Downward approach to hydrological prediction. Hydrological Processes 17, 21012111.

Sivapalan, M., Zhang, L., Vertessy, R., Blöschl, G., 2003b. Downward approach to hydrological prediction. Hydrological Processes 17, 20992099.

Slob, E., Sato, M., Olhoeft, G., 2010. Surface and borehole groundpenetrating-radar developments. Geophysics 75, A103-A120.

Sophocleous, M., 2005. Groundwater recharge and sustainability in the High Plains aquifer in Kansas, USA. Hydrogeology Journal 13, 351-365.

Sophocleous, M., Perkins, S.P., 2000. Methodology and application of combined watershed and ground-water models in Kansas. Journal of Hydrology 236, 185-201.

Sousa, F., Carrara, G., Fernandes, J., Boutov, D., Loureiro, M., Leitão, F., Range, P., Machado, A., 2014. Descargas de águas subterrâneas na região dos Olhos de Água, Algarve-alguns resultados das campanhas CTD, in: 8 Assembleia Luso Espanhola de Geodesia e Geofísica, Évora (Portugal).

Soylu, M.E., Istanbulluoglu, E., Lenters, J.D., Wang, T., 2011. Quantifying the impact of groundwater depth on evapotranspiration in a semi-arid grassland region. Hydrology and Earth System Sciences Discussions 7, 6887-6923.

Srinivasa, R., Rao, Y.S., Reddy, Reddy, T., Nayudu, Nayudu, P., 2000. Groundwater targeting in a hard-rock terrain using fracture-pattern modeling, Niva river basin, Andhra Pradesh, India. Hydrogeology Journal 8, 494-502.

Stanton, J.S., Ryter, D.W., Peterson, S.M., 2013. Effects of linking a soilwater-balance model with a groundwater-flow model. Ground Water $51,613-22$.

Steduto, P., Faurès, J.M., Hoogeveen, J., Winpenny, J.T., Burke, J.J., 2012. Coping with water scarcity : an action framework for agriculture and food security. FAO Water report 38. Food and Agriculture Organization of the United Nations. Rome.

Stingaciu, L.R., Weihermüller, L., Haber-Pohlmeier, S., Stapf, S., Vereecken, H., Pohlmeier, A., 2010. Determination of pore size distribution and hydraulic properties using nuclear magnetic resonance relaxometry: A comparative study of laboratory methods. Water Resources Research 46. 
Su, Z., 2002. The surface energy balance system SEBS for estimation of turbulent heat fluxes. Hydrology and Earth System Sciences 6, 85-99.

Sudduth, K.A., Kitchen, N.R., Bollero, G.A., Bullock, D.G., Wiebold, W.J., 2003. Comparison of electromagnetic induction and direct sensing of soil electrical conductivity. Agronnomy Journal 95, 472-482.

Terrinha, P., Rocha, R.B., Rey, J., Cachão, M., Moura, D., Roque, C., Martins, J., Valadares, V., Cabral, J.A., Azevedo, M.d.R., Barbero, L., González Clavijo, E.J., Dias, R.P., Matias, H., Madeira, J., Silva, C.M., Munhá, J., Rebêlo, L.P., Ribeiro, C., Vicente, J., Gonçalves, J.A.N., Youbi, N., Bensalah, M.K.A., 2013. Bacia do algarve : estratigrafia, paleogeografia e tectónica, in: Dias, R., AraÃžjo, A.A., Terrinha, P., Kullberg, J.C. (Eds.), Geologia de Portugal. Escolar Editora.

Terrinha, P.A.G., Noiva, J., Carrara, G., Fernandes, J., Roque, C., Pinheiro, L., 2014. Neogene and quaternary seismostratigraphy and tectonics offshore albufeira and quarteira: implications on the paleogeography and submarine freshwater discharges, in: IX Congresso Nacional de Geologia (IX CNG), Porto, (Portugal).

Therrien, R., Sudicky, E.A., Park, Y.J., McLaren, R.G., 2012. HydroGeoSphere: A Three-Dimensional Numerical Modelling Describing FullyIntegrated Subsurface and Surface Flow and Transport, User Guide. Aquanty Inc.. Waterloo, Ontario, Canada.

Thoms, R.B., Johnson, R.L., Healy, R.W., 2006. User's guide to the Variably Saturated Flow (VSF) process for MODFLOW. Technical Report 6-A18. U.S. Geological Survey.

van der Tol, C., 2012. Validation of remote sensing of bare soil ground heat flux. Remote Sensing of Environment 121, 275-286.

Tonder, G.v., Bardenhagen, i., Riemann, K., Bosch, J.v., Dzanga, P., Xu, Y., 2002. Manual on pumping test analysis in fracture-rock aquifers. Technical Report 1116/1/02. Water Research Commission. Pretoria.

Topp, G.C., Davis, J.L., Annan, A.P., 1980. Electromagnetic determination of soil-water content-measurements in coaxial transmission-lines. Water Resources Research 16, 574-582.

Trabelsi, R., Abid, K., Zouari, K., Yahyaoui, H., 2012. Groundwater salinization processes in shallow coastal aquifer of Djeffara plain of Medenine, southeastern Tunisia. Environmental Earth Sciences 66, 641-653.

Triantafilis, J., Huckel, A.I., Odeh, I.O.A., 2001a. Comparison of statistical prediction methods for estimating field-scale clay content using different combinations of ancillary variables. Soil Science 166, 415-427.

Triantafilis, J., Lesch, S.M., 2005. Mapping clay content variation using electromagnetic induction techniques. Computers and Electronics in Agriculture 46, 203-237.

Triantafilis, J., Monteiro Santos, F., 2010. Resolving the spatial distribution of the true electrical conductivity with depth using EM38 and 
EM31 signal data and a laterally constrained inversion model. Soil Research 48, 434-446.

Triantafilis, J., Odeh, I., McBratney, A., 2001b. Five geostatistical models to predict soil salinity from electromagnetic induction data across irrigated cotton. Soil Sci Soc Am J 65, 869-878.

Trushkin, D.V., Shushakov, O.A., Legchenko, A.V., 1994. The potential of a noise-reducing antenna for surface NMR groundwater surveys in the Earth's magnetic field. Geophysical Prospecting 42, 855-862.

Twarakavi, N.K.C., Šimůnek, J., Seo, S., 2008. Evaluating interactions between groundwater and vadose zone using the HYDRUS-Based Flow package for MODFLOW. Vadose Zone Journal 7, 757-768.

UNEP, 2008. Vital Water Graphics - An Overview of the State of the World's Fresh and Marine Waters. Technical Report. UNEP. Nairobi, Kenya.

Unit Geo Software Development, 2001. ILWIS 3.0 academic user's guide.

Uriarte Blanco, C., Plata, J., Díaz-Curiel, J., Martínez-Fernández, J., 2011. The use of magnetic resonance sounding in shallow aquifers in the Duero River Basin (in Spanish). Aplicación de sondeos de resonancia magnética en acuíferos superficiales de la Cuenca del Duero. Boletín Geológico y Minero 122, 345-362.

U.S. Geological Survey, 2008. Documentation of computer program INFIL3.0-A distributed-parameter watershed model to estimate net infiltration below the root zone. USGS Scientific Investigations Report 2008-5006. U.S. Geological Survey.

Vengosh, A., Spivack, A., Artzi, Y., Ayalon, A., 1999. Boron, strontium and oxygen isotopic and geochemical constraints for the origin of the salinity in ground water from the Mediterranean coast of Israel. Water Resource Research 35, 1877-1894.

Vieira e Silva, J., 1991. Alteração de uma rocha gabróica do Baixo Alentejo. Technical Report. Universidade de Coimbra.

Villar Alonso, P., Portero Urroz, G., González Cuadra, P., García Crespo, J., Nieto García, A.B., Rubio, F., Gómez Fernández, F., Jiménez Benayas, S., 2011. Mapa geológico digital continuo escala 1:50 000, Zona Centroibérica-Domino Ollo de Sapo (Zona-1300).

Voss, C.I., 2011. Editor's message: Groundwater modeling fantasies-part 1, adrift in the details. Hydrogeology Journal 19, 1281-1284.

Vouillamoz, J., Baltassat, J., Girard, J., Plata, J., Legchenko, A., 2007. Hydrogeological experience in the use of MRS. Boletín Geológico y Minero 118, 531-550.

Vouillamoz, J., Sophoeun, P., Bruyere, O., Arnout, L., 2014a. Estimating storage properties of aquifer with magnetic resonance sounding: a field verification in northern Cambodia of the gravitational water apparent cutoff time concept. Near Surface Geophysics 12, 211-216. 
Vouillamoz, J.M., 2003. La caractérisation des aquifères par une méthode non invasive: les sondages par Résonance Magnétique Protonique. Ph.D. thesis. Paris XI.

Vouillamoz, J.M., Descloitres, M., Toe, G., Legchenko, A., 2005. Characterization of crystalline basement aquifers with MRS: comparison with boreholes and pumping tests data in Burkina Faso. Near Surface Geophysics 3, 205-213.

Vouillamoz, J.M., Hoareau, J., Grammare, M., Caron, D., Nandagiri, L., Legchenko, A., 2012a. Quantifying aquifer properties and freshwater resource in coastal barriers: A hydrogeophysical approach applied at Sasihithlu (Karnataka state, India). Hydrology and Earth System Sciences 16, 4387-4400.

Vouillamoz, J.M., Lawson, F.M.A., Yalo, N., Descloitres, M., 2014b. The use of magnetic resonance sounding for quantifying specific yield and transmissivity in hard rock aquifers: The example of Benin. Journal of Applied Geophysics 107, 16-24.

Vouillamoz, J.M., Sokheng, S., Bruyere, O., Caron, D., Arnout, L., 2012b. Towards a better estimate of storage properties of aquifer with magnetic resonance sounding. Journal of Hydrology 458-459, 51-58.

Walsh, D.O., Grunewald, E., Turner, P., Hinnell, A., Ferre, P., 2014. Surface NMR instrumentation and methods for detecting and characterizing water in the vadose zone. Near Surface Geophysics 12, 13.

Wang, Z., Batelaan, O., De Smedt, F., 1996. A distributed model for water and energy transfer between soil, plants and atmosphere (WetSpa). Phys. Chem. Earth 21, 189-193.

Webster, R., Oliver, M.A., 2008. Geostatistics for environmental scientists. John Wiley \& Sons. Second edition.

Weiss, A., 2001. Topographic position and landforms analysis. Poster presentation, in: ESRI User Conference.

Weller, U., Zipprich, M., Sommer, M., Castell, W.Z., Wehrhan, M., 2007. Mapping clay content across boundaries at the landscape scale with electromagnetic induction. Soil Sci Soc Am J 71, 1740-1747.

Welter, D.E., Doherty, J.E., Hunt, R.J., Muffels, C.T., Tonkin, M.J., Schreüder, W.A., 2012. Approaches in highly parameterized inversion: PEST++, a Parameter ESTimation code optimized for large environmental models. Technical Report. U.S. Geological Survey.

Werner, A.D., Bakker, M., Post, V.E.A., Vandenbohede, A., Lu, C., AtaieAshtiani, B., Simmons, C.T., Barry, D.A., 2013. Seawater intrusion processes, investigation and management: Recent advances and future challenges. Advances in Water Resources 51, 3-26.

Wilson, S.R., Ingham, M., McConchie, J.A., 2006. The applicability of earth resistivity methods for saline interface definition. Journal of Hydrology 316, 301-312. 
Winsauer, W.O., Shearin, H.M.J., Masson, P.H., Williams, H., 1952. Resistivity of brine saturated sands in relation to pore geometry. Bull. AAPG 36, 253-277.

Wyns, R., Baltassat, J.M., Lachassagne, P., Legchenko, A., Vairon, J., Mathieu, F., 2004. Application of proton magnetic resonance soundings to groundwater reserve mapping in weathered basement rocks (Brittany, France). Bulletin de la Société Géologique de France 175, 21-34.

$\mathrm{Xu}$, Y.e., Beekman, H.E.e., 2003. Groundwater recharge estimation in southern Africa. Number 64 in IHP Series, United Nations Educational Scientific and Cultural Organization (UNESCO), Paris.

Yang, Y., 2015. Evapotranspiration Over Heterogeneous Vegetated Surfaces-Models and Applications. Springer-Verlag Berlin Heidelberg.

Yao, L., Guo, Y., 2014. Hybrid algorithm for parameter estimation of the groundwater flow model with an improved genetic algorithm and Gauss-Newton method. Journal of Hydrologic Engineering 19, 482-494.

Yaramanci, U., Hertrich, M., 2009. Magnetic resonance sounding, in: Kirsch, R. (Ed.), Groundwater Geophysics: A Tool For Hydrogeology. Springer Berlin Heidelberg. book section 8, pp. 253-273.

Yates, D.N., 1996. Watbal: an integrated water balance model for climate impact assessment of river basin runoff. Water Resources Development $12,121-139$.

Yechieli, Y., Kafri, U., Goldman, M., Voss, C., 2001. Factors controlling the configuration of the fresh-saline water interface in the Dead Sea coastal aquifers: synthesis of TDEM surveys and numerical groundwater modeling. Hydrology Journal 9, 367-377. 


\section{Summary}

Coupled hydrological models require reliable and sufficiently dense data to parametrize surface and subsurface zones. As direct, invasive field data acquisition techniques are reliable but not efficient, they can be complemented by hydrogeophysics and remote sensing to obtain a better data coverage. Therefore, the first main objective of this study was dedicated to the use of various non-invasive, hydrogeophysical methods in combination with remote sensing and direct field data acquisition techniques. In addition to the geoelectrical and electromagnetical methods, the magnetic resonance sounding (MRS) method was applied. The MRS is a unique method that is directly sensitive to the presence of hydrogen nuclei in subsurface, allowing to detect water content with depth and also to retrieve quantitative information regarding aquifer flow and storage parameters. The combination of hydrogeophysics, remote sensing and direct field data acquisition methods allowed to obtain spatially distributed parametric maps and to design hydrological conceptual models that were subsequently used for the parameterization of distributed numerical models in various hydrogeological conditions (Chapters 2-4).

Next to system parameterization, coupled hydrological models of surface, unsaturated and saturated zones require spatio-temporal distribution of driving forces. Despite of numerical advancement of the currently available coupled models, they do not handle properly subsurface evapotranspiration. Therefore, as the second main objective of this study, the new MARMITES distributed model was developed and coupled with standard MODFLOW-NWT. The coupled MARMITESMODFLOW model includes a novel option of partitioning and sourcing of subsurface evapotranspiration. It also introduces a new function to compute the groundwater transpiration that is water table depth independent but driven by climatic conditions. The MARMITES-MODFLOW model is presented in Chapter 5 using study case of small La Mata catchment $\left(\sim 4.8 \mathrm{~km}^{2}\right)$ in Spain. The model was calibrated and validated against field data and a detailed spatio-temporal water balance at the catchment scale is presented. In the final Chapter 6 , the integration of MRS data with the MARMITES-MODFLOW model is implemented in the Carrizal Catchment $\sim 7 \mathrm{~km}^{2}$ ) in Spain. The originality of that application is in the optimization of the MRS estimates of aquifer hydraulic parameters that is not done by pumping tests but throughout the MARMITES-MODFLOW 
model calibration.

Chapter 2 - Topsoil thickness prediction at the catchment scale by integration of invasive sampling, surface geophysics, remote sensing and statistical modeling

Topsoil thickness is a critical input in hydrological modeling because it controls, in conjunction with soil hydraulic properties, the partitioning of water fluxes between the atmosphere and the subsurface. To parameterize a distributed hydrological model that computes groundwater recharge, a data-integration method was developed to predict the clayey topsoil thickness (CTT) and was applied in a small catchment in Portugal $\left(\sim 19 \mathrm{~km}^{2}\right)$. The prediction method is based on the integration of: (i) invasive sampling used as a CTT reference dataset (61 invasive measurements); (ii) surface geophysics applied to complement the timeconsuming invasive sampling; (iii) remote sensing (RS) image processing (high resolution QuickBird image, aerial photographs and ASTER Global Digital Elevation Map) used to derive soils classes and terrain parameters; (iv) geostatistical mixed linear model (MLM) applied to integrate the CTT variability at the catchment scale using geophysical and RS derived auxiliary variables. The selection of the appropriate statistical model derived from the MLM was based on the verification of model assumptions using diagnostic tools.

The 436 Geonics ${ }^{\mathrm{TM}}$ EM-31 field measurements of soil apparent electrical conductivity $\left(E C_{a}\right)$ were first converted into CTT. This was achieved by building MLM based calibration models that integrated 25 invasive CTT measurements paired with corresponding $E C_{a}$ measurements and RS-derived auxiliary variables. Next, the CTT at the catchment scale was predicted by applying the MLM approach and integrating the RS-derived auxiliary variables with: (i) the 436 CTT values derived from surface geophysical dataset; (ii) the 61 CTT values from the reference invasive dataset. The two maps had similar CTT patterns which depicted the spatial variability of the CTT over the geomorphologic catchment features. The prediction map derived from the geophysical dataset resulted in slightly lower CTT values than the reference map (median of $0.87 \mathrm{~m}$ against $1.11 \mathrm{~m}$ ) and a comparable accuracy (RMSE of $0.76 \mathrm{~m}$ against $0.88 \mathrm{~m}$ ). As these differences will be minimized during the calibration process of the hydrological model, the presented methodology is considered suitable for hydrological and environmental studies, in which catchments often need to be investigated over large areas.

Chapter 3 - Contributions of hydrogeophysics to the hydrogeological conceptual model of the Albufeira-Ribeira de Quarteira coastal aquifer in Algarve, Portugal

Geoelectrical and electromagnetic (time and frequency domains) hydrogeophysical methods were applied and jointly interpreted together with auxiliary information such as regional piezometric map and borehole lithological logs, as well as offshore data. The objective was to retrieve 
the structure and geometry of the Albufeira-Ribeira de Quarteira coastal aquifer system (Algarve, Portugal) and to upgrade the current hydrogeological conceptual model.

The results allowed detecting the freshwater-saltwater interface along the coast line, identifying the water-bearing layers and aquitards and their hydraulic relationships, as well as explaining the location of the inter- and subtidal fresh groundwater discharge. A new modeling unit is proposed for groundwater flow modeling. Limitations of the used hydrogeophysical methods are indicated and recommendations are made for follow-up studies.

Chapter 4 - Hydrogeophysics and remote sensing for the design of hydrogeological conceptual models in hard rocks - Sardón catchment (Spain)

Hard rock aquifers are highly heterogeneous and hydrogeologically complex. To contribute to the design of hydrogeological conceptual models of hard rock aquifers, it is proposed in this study a multi-techniques methodology based on a downward approach that combines remote sensing (RS), non-invasive hydrogeophysics and hydrogeological field data acquisition. The proposed methodology is particularly suitable for data scarce areas. It was applied in the pilot research area of Sardón catchment $\left(80 \mathrm{~km}^{2}\right)$ located west of Salamanca (Spain). The area was selected because of hard-rock hydrogeology, semi-arid climate and scarcity of groundwater resources.

The proposed methodology consisted of three main steps. First, the main hydrogeological features at the catchment scale were detected by processing: (i) a high resolution digital terrain model to map lineaments and to outline fault zones; and (ii) high-resolution, multispectral satellite QuickBird andWorldView-2 images to map the outcropping granite. Second, the hydrogeological features identified at step one were characterized at the local scale with: i) ground penetrating radar (GPR) to assess groundwater table depth complementing the available monitoring network data; ii) 2D electric resistivity tomography (ERT) and frequency domain electromagnetic (FDEM) to retrieve the hydrostratigraphy along selected survey transects; iii) magnetic resonance soundings (MRS) to retrieve the hydrostratigraphy and aquifer parameters at the selected survey sites. In the third step, 5 boreholes ( 25 to $48 \mathrm{~m}$ deep) were drilled and slug tests were performed to verify the hydrogeophysical interpretation and to calibrate the MRS parameters. Finally, all acquired data were compiled and integrated to define the geometry and parameters of the Sardón aquifer at the catchment scale.

In line with a general conceptual model of hard rock aquifers, two main hydrostratigraphic layers were identified: a saprolite layer and a fissured layer. Both layers were intersected and drained by fault zones that control the hydrogeology of the catchment. The spatial discontinuities of the saprolite layer were well defined by RS techniques while subsur- 
face geometry and aquifer parameters by hydrogeophysics. The GPR method was able to detect shallow water table at depth between 1 and $3 \mathrm{~m}$ b.g.s. The hydrostratigraphy and parameterization of the fissured layer remained uncertain because ERT and FDEM geophysical methods were quantitatively not conclusive while MRS detectability was restricted by low volumetric water content. The proposed multi-technique methodology integrating cost efficient RS, hydrogeophysics and hydrogeological field investigations allowed us to characterize geometrically and parametrically the Sardón hard rock aquifer system, facilitating the design of hydrogeological conceptual model of the area.

\section{Chapter 5 - Partitioning and sourcing of evapotranspiration at the catchment scale using coupled MARMITES-MODFLOW model}

A coupled model composed of land surface and soil zone MARMITES model and groundwater MODFLOW-NWT model is presented to demonstrate model-based partitioning and sourcing of evapotranspiration (ET) as part of spatio-temporal water balancing at the catchment scale. The partitioning of ET involves its separation into evaporation and transpiration while the sourcing of evaporation and transpiration involves separation of each of the two into soil and saturated zone components.

The MARMITES-MODFLOW coupled model was applied to the La Mata catchment (Salamanca, Spain) to demonstrate its capability to simulate complex hydrological systems. The catchment was characterized by a semi-arid climate with rainfall $\sim 500 \mathrm{~mm} . \mathrm{y}^{-1}$, granitic bedrock, shallow groundwater and sparse oak woodland. The model was calibrated in transient using daily data of two hydrological years. The water balance results of the partitioning and sourcing of $E T$ involved (in \% of rainfall): soil evaporation (34.7\%), soil transpiration (8.0\%), groundwater evaporation (8.5\%) and groundwater transpiration (2.0\%). Accordingly, the gross recharge was $28.5 \%$ and groundwater exfiltration $17.3 \%$, implying low net recharge $0.7 \%$.

The presented MARMITES-MODFLOW model constitutes a powerful tool to analyze catchment water dynamics and water balances in detail, accounting separately for impacts of evaporation and transpiration on groundwater resources. The model generates spatio-temporally variable maps of soil and groundwater fluxes well-depicting recharge and discharge zones, that can be particularly helpful in analyzing impacts of climate and land cover changes on groundwater resources and for mapping groundwater dependent ecosystems.

\section{Chapter 6 - Integrating MRS data with hydrologic model - Carrizal Catchment (Spain)}

Magnetic resonance sounding (MRS) provides quantitative hydrogeological information on hydrostratigraphy and hydraulic parameters of subsurface (e.g. flow and storage property of aquifers) that can be integrated in distributed hydrologic models. The hydraulic parameters 
are typically obtained by pumping tests. In this study, it is proposed an MRS integration method based on optimizing MRS estimates of aquifer hydraulic parameters through hydrologic model calibration.

The proposed MRS integration method was applied in the $73 \mathrm{~km}^{2}$ Carrizal Catchment in Spain, characterized by a shallow unconfined aquifer with an unknown aquifer bottom. 12 MRS survey results were inverted with Samovar 11.3, schematized and integrated in the transient, distributed, coupled, hydrologic, MARMITES-MODFLOW model. As the aquifer bottom was unknown, the aquifer was schematized into one unconfined layer of uniform thickness. For that layer, MRS estimators of specific yield and transmissivity/hydraulic conductivity were calculated as weighted averages of the inverted MRS layers. The MRS integration with hydrologic model was carried out by introducing multipliers of specific yield and transmissivity/hydraulic conductivity that were optimized during transient model calibration using 11 time-series piezometric observation points. The optimized multipliers were 1.0 for specific yield and $3.5 \times 10^{-9}$ for hydraulic conductivity. These multipliers were used, and can be used in future MRS investigations in the Carrizal Catchment (and/or adjacent area with similar hydrogeological conditions), to convert MRS survey results into aquifer hydraulic parameters.

The proposed method of MRS data integration in the hydrologic model of Carrizal Catchment not only allowed us to calibrate the model but also to confirm the functional capability of MRS in quantitative groundwater assessment. Most importantly however, it demonstrated that if pumping tests are not available, the use of MRS integrated in distributed coupled hydrological models, or even in standalone groundwater models, provides a valuable aquifer parameterization alternative. 



\section{Samenvatting}

De toepassing van gekoppelde hydrologische modellen vereist data met een behoorlijke ruimtelijke dichtheid. Die moet voldoende zijn om kenmerken van het aardoppervlak en de onverzadigd en verzadigde ondergrondse lagen om te zetten in ruimtelijke patronen van parameters. Directe invasieve metingen in het veld zijn weliswaar betrouwbaar, maar niet erg efficiãńnt. Met aanvullende geofysische metingen en aardobservatie kan een betere ruimtelijke bedekking worden verkregen. Het eerste doel van dit onderzoek was het combineren van diverse niet-invasieve hydro-geologische methodes, aardobservatie en directe veldmetingen. Naast de geo-elektrische en de elektromagnetische methode is de magnetic resonance sounding (MRS) methode gebruikt. MRS is een unieke methode die waterstofkernen onder de grond detecteert. Dat maakt het mogelijk om het watergehalte op op verschillende dieptes te meten, en om kwantitatieve informatie te verkrijgen over de stoom in het watervoerende pakket, alsmede parameters voor wateropslag. De combinatie van hydro-geofysica, aardobservatie en directe veldmetingen zijn gebruikt om ruimtelijk verdeelde kaarten van parameters te maken, en om conceptuele hydrologische modellen te ontwerpen die vervolgens gebruikt zijn voor het parametriseren van gedistribueerde numerieke modellen voor verschillende geologische omstandigheden (Hoofdstukken 2-4).

Behalve parameterschatting van het systeem vereisen gekoppelde hydrologische modellen ook stuurvariabelen die zowel in tijd als ruimte variÃńren. Hoewel de beschikbare gekoppelde modellen erg geavanceerd zijn, hebben ze geen van allen een goed algoritme om ondergrondse verdamping te schatten. Het tweede doel van dit onderzoek was om hier een model voor te ontwikkelen. Het nieuwe model MARMITES is een gedistribueerd model dat is gekoppeld met een standaard grondwater model: MODFLOW-NWT. Het gekoppelde MARMITES-MODFLOW model is in staat om de bijdragen van verschillende processen aan de ondergrondse verdamping apart te berekenen. Het model biedt ook de mogelijkheid om de opname van grondwater door vegetatie dat vervolgens via het blad transpireert, te berekenen. Deze opname hangt af van de weersomstandigheden, maar niet van de diepte van het grondwater. In hoofdstuk 5 wordt het MAMITES-MODFLOW model gepresenteerd aan de hand van een gebiedsstudie voor het kleine stroomgebied van La Mata (ca. $4.8 \mathrm{~km}^{2}$ ) in Spanje . Het model is gekalibreerd en gevalideerd tegen veld- 
metingen. Er wordt een gedetailleerde waterbalans in ruimte en tijd voor het hele stroomgebied gepresenteerd. In het laatste hoofdstuk zijn MRS data geÃíntegreerd in MARMITES-MODFLOW voor het Spaanse stroomgebied van de Carrizal (ca. $73 \mathrm{~km}^{2}$ ). De originaliteit van deze toepassing is dat de hydraulische parameters van de watervoerende pakketten niet zijn verkregen door pompproeven, maar in plaats daarvan zijn bepaald door MARMITES-MODFLOW te kalibreren tegen MRS metingen. 


\section{ITC dissertations}

A complete list of ITC dissertations is online on the ITC website: www.itc.nl/research/phd/phd_graduates.aspx.

This dissertation has number 275 . 